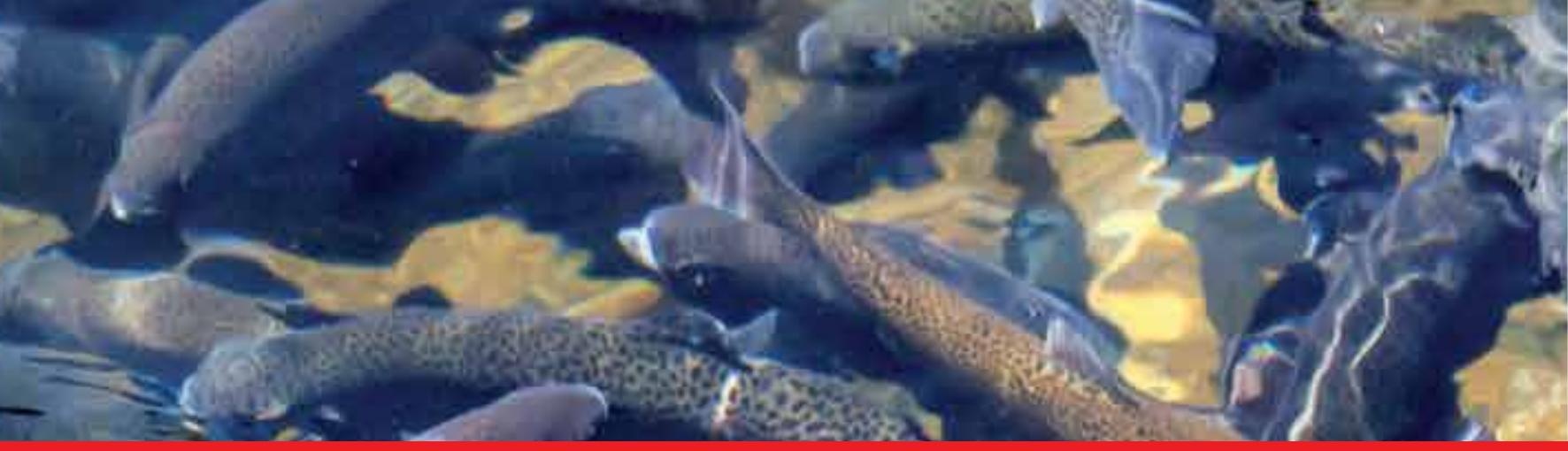

\title{
IntechOpen
}

\section{Fisheries and Aquaculture in the Modern World}

Edited by Heimo Mikkola
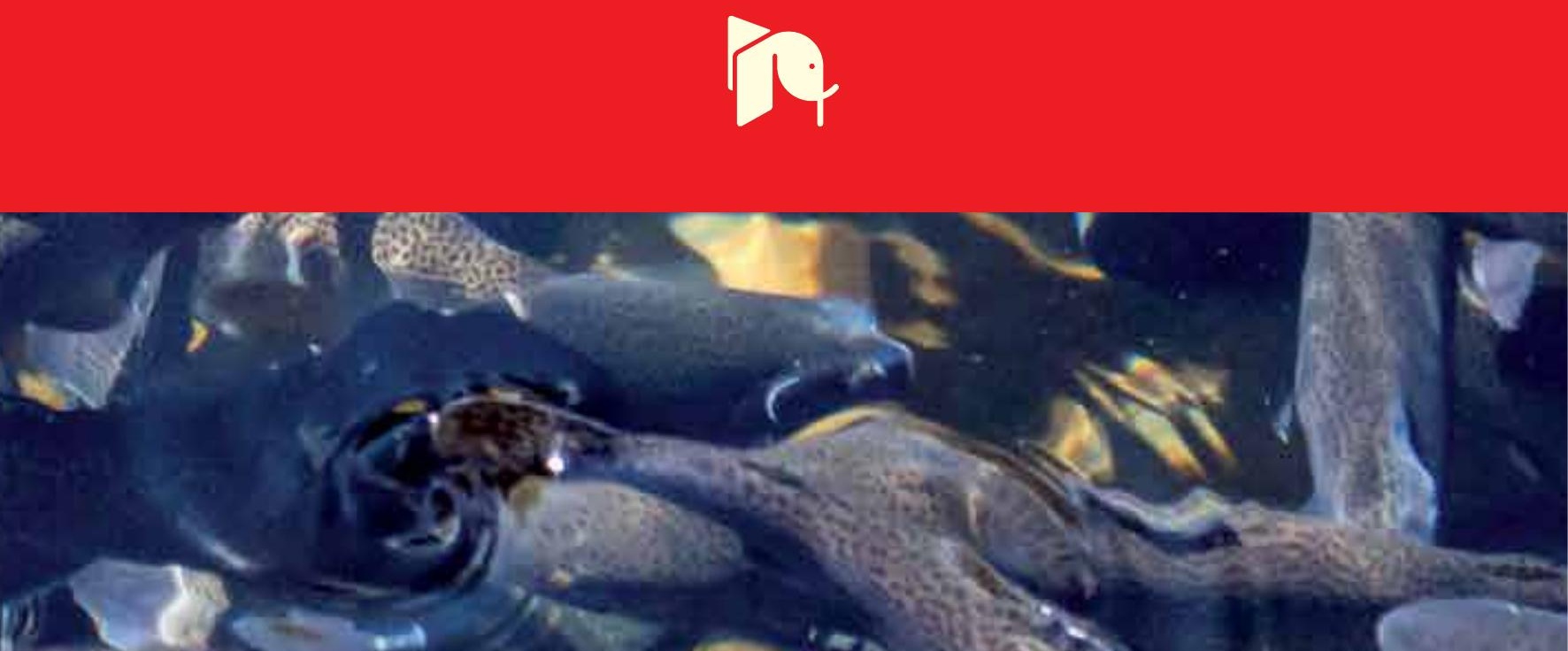



\section{FISHERIES AND \\ AQUACULTURE IN THE MODERN WORLD}

Edited by Heimo Mikkola 


\section{Fisheries and Aquaculture in the Modern World}

http://dx.doi.org/10.5772/61558

Edited by Heimo Mikkola

\section{Contributors}

Hawis Madduppa, Zairion Zairion, Siti Nuraini, Bambang Arif Nugraha, Kuncoro Catur Nugroho, Tsuyoshi Sasaki, M. Dolores Garza-Gil, Juan C. Surís-Regueiro, Manuel M. Varela-Lafuente, Julio Vásquez, James Howard Cowan, Jr., Ross F. Tallman, Eduardo Grimaldo, Manu Sistiaga, Bent Herrmann, Roger B. Larsen, Sher Khan Panhwar, Nazia Qamar, Ghazala Siddiqui, Verma Rajroop Sanyogita, Shanta Satyanarayan

\section{(c) The Editor(s) and the Author(s) 2016}

The moral rights of the and the author(s) have been asserted.

All rights to the book as a whole are reserved by INTECH. The book as a whole (compilation) cannot be reproduced, distributed or used for commercial or non-commercial purposes without INTECH's written permission.

Enquiries concerning the use of the book should be directed to INTECH rights and permissions department (permissions@intechopen.com).

Violations are liable to prosecution under the governing Copyright Law.

\section{(cc) BY}

Individual chapters of this publication are distributed under the terms of the Creative Commons Attribution 3.0 Unported License which permits commercial use, distribution and reproduction of the individual chapters, provided the original author(s) and source publication are appropriately acknowledged. If so indicated, certain images may not be included under the Creative Commons license. In such cases users will need to obtain permission from the license holder to reproduce the material. More details and guidelines concerning content reuse and adaptation can be foundat http://www.intechopen.com/copyright-policy.html.

\section{Notice}

Statements and opinions expressed in the chapters are these of the individual contributors and not necessarily those of the editors or publisher. No responsibility is accepted for the accuracy of information contained in the published chapters. The publisher assumes no responsibility for any damage or injury to persons or property arising out of the use of any materials, instructions, methods or ideas contained in the book.

First published in Croatia, 2016 by INTECH d.o.o.

eBook (PDF) Published by IN TECH d.o.o.

Place and year of publication of eBook (PDF): Rijeka, 2019.

IntechOpen is the global imprint of IN TECH d.o.o.

Printed in Croatia

Legal deposit, Croatia: National and University Library in Zagreb

Additional hard and PDF copies can be obtained from orders@intechopen.com

Fisheries and Aquaculture in the Modern World

Edited by Heimo Mikkola

p. cm.

Print ISBN 978-953-51-2686-7

Online ISBN 978-953-51-2687-4

eBook (PDF) ISBN 978-953-51-5453-2 


\section{We are IntechOpen, the first native scientific \\ publisher of Open Access books}

$3,450+$

Open access books available
$110,000+$

International authors and editors

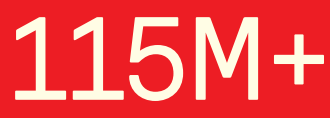

Downloads

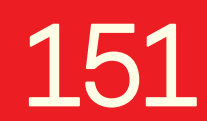

Countries delivered to

Our authors are among the

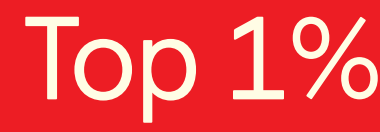

most cited scientists

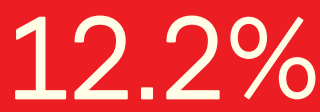

Contributors from top 500 universities

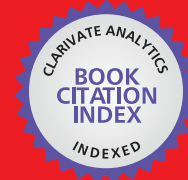

WEB OF SCIENCE ${ }^{\mathrm{TM}}$

Selection of our books indexed in the Book Citation Index in Web of Science ${ }^{\mathrm{TM}}$ Core Collection (BKCI)

Interested in publishing with us?

Contact book.department@intechopen.com

Numbers displayed above are based on latest data collected.

For more information visit www.intechopen.com

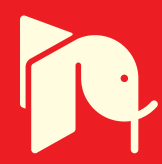





\section{Meet the editor}

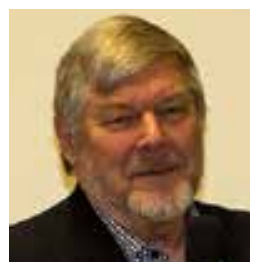

Heimo Mikkola is a PhD in Applied Zoology and Limnology from the University of Kuopio, Finland. He is now retired after 22 years of service in the UN/ FAO as the Resident Representative in Africa and South America. He is still a part-time adjunct professor in the Eastern Finland University and a visiting professor in the Kazakh National Agrarian University in Almaty where he is teaching aquaculture and fisheries to undergraduate and master-level students. He has lifelong experience in all aspects of aquaculture and fisheries development, including project identification, design and management, fish production, processing and marketing, and selection of species for aquaculture. Last five years, he has concentrated in biodiversity-friendly fisheries management, which takes account of the livelihood of local communities as well as promotion of climate sustainability. Till date he has workwise visited 130 countries and published some 250 fisheries and aquaculture-related papers from all continents of the world. With Dr. Ahmed Khan, he has published a book on Sustainable Ocean Development in 2002. 



\section{Contents}

\section{Preface XI}

Chapter 1 Effect of Special Fish Feed Prepared Using Food Industrial Waste on Labeo rohita 1

Sanyogita R. Verma and Shanta Satyanarayan

Chapter 2 Using Taxes to Manage a Multigear Fishery: An Application to a Spanish Fishery 11

M. Dolores Garza-Gil, Manuel Varela-Lafuente and Juan C. SurísRegueiro

Chapter 3 Pan-Arctic Fisheries and their Assessment 25

Ross Tallman, Muhammed Y. Janjua, Daniel Howell, Burton Ayles, Theresa Carmicheal, Matthias Bernreuther, Steve Ferguson and Margaret Treble

Chapter 4 Trawl Selectivity in the Barents Sea Demersal Fishery 69 Eduardo Grimaldo, Manu Sistiaga, Bent Herrmann and Roger B. Larsen

Chapter 5 Oil and Gas Platforms in the Gulf of Mexico: Their Relationship to Fish and Fisheries 95

James H. Cowan and Kenneth A. Rose

Chapter 6 The Brown Seaweeds Fishery in Chile 123 Julio A. Vásquez

Chapter 7 Setting Up Traceability Tools for the Indonesian Blue Swimming Crab Fishery: A Case Study in Southeast Sulawesi 143

Hawis Madduppa, Zairion, Siti Nuraini, Kuncoro Nugroho and Bambang Arif Nugraha 
X Contents

Chapter 8 Direction of Fisheries (SUISAN) Education from a Historical Perspective in Japan 159

Tsuyoshi Sasaki

Chapter 9 Fishery Status and Taxonomy of the Carangids (Pisces) in the Northern Arabian Sea Coast of Pakistan 169

Nazia Qamar, Sher Khan Panhwar and Ghazala Siddiqui 


\section{Preface}

Motto: "Where there is water, there is fish" as an African proverb says.

Global marine fish catch (including estimated unreported catch and discards) is exceeding 100 million metric tons. In addition the freshwater fisheries and aquaculture contributed the fish supply statistics some 35 million metric tons, but this value could be grossly underestimated and inland water contribution, therefore, significantly higher. When marine fish production has largely remained stagnant, inland fisheries and aquaculture have sustained annual growth of about $2 \%$ worldwide, and the potential for further increases is high in many freshwater systems.

The estimated average human trophic level (TL) is 2.2, indicating that we are mainly terrestrial vegetarians (about $80 \%$ ), this being only slightly higher than that of zooplankton in the aquatic fisheries food chains. In contrast, nearly half of the global primary production is aquatic, but only about $2 \%$ of the global human food is derived from fisheries and aquaculture. This discrepancy could indicate at least theoretical potential for aquatic food increase, but remembering the difference between water- and land-based food chain, it is only viable if we start targeting lower trophic levels, that is, catching smaller-size fish. By primarily targeting large adult fish, we feed about two TLs higher in water than on land. In terms of energy, this is a very inefficient utilization of available food as about $99 \%$ of the corresponding energy is lost in the transfer of two trophic levels.

Therefore many people dislike the practice that we catch a lot of small but edible fish species and feed them to salmon and other fish species in the cages and aquaculture ponds. This book serves as one possible way to decrease the need of fish meal in the aquaculture by using fish feed prepared from orange and potato peels (Chapter 1). Feed made out of potato peels proved to be very nutritive and facilitated qualitative and quantitative growth of fish.

Scientists have uncovered that people who eat lots of fatty fish and other seafood run lower risks of a host of ailments, including cancer and cardiovascular diseases. Fatty fish and cod liver oil contain polyunsaturated fatty acids, but how do these work as an agent against diseases? Many of the diseases occur because misfolded proteins accumulate in and around the cells of our body organs. Omega-3 fatty acids activate the human cell's waste treatment system and transport our trash away for recirculation. Well-functioning waste management inside our cells is a key element of disease prevention. Both the genes and the environment contribute to the diseases we contract and timing when we get them. As of today, we cannot do too much with our genes. But the food we eat is very significant among the environmental factors which will either increase or decrease the risk of disease. When people eat fatty 
fish and other seafood, they get the needed omega-3 fatty acids which will help human cells remove many harmful proteins.

But how can people eat more fish when around the world, many commercial fisheries have collapsed and several others, particularly bottom fish and large pelagic, are experiencing the impacts of overexploitation? In the past three decades, human populations have increased tremendously, leading to greater demands for marine fisheries products. Introduction of cash economy has also triggered the need for more efficient methods of fish capture to supply the new higher demand. In many fisheries the fishing gears are known to alter the composition of fish populations or modify the recruitment rate. In Spain taxes have been used as management tool in multi-gear hake fishery (Chapter 2). In particular, the tax level on the trawling effort is greater than that applied to the artisanal fleet, as trawling is more productive and affects the hake population more negatively.

Overfishing in the oceans is obviously a fact, but there is still hope that deep-sea waters in the mesopelagic zone have a huge potential of seafood, but we must take care not to overfish. Same goes with the arctic waters which could give us new areas to be harvested especially when the climate change will free these waters from the permanent ice cover. In this book, we have a chapter on "Pan-Arctic Fisheries" (Chapter 3) and "Barents Sea Demersal Trawl Fishery" (Chapter 4). Oil and gas exploitation is often seen only as a disaster for the fish and fisheries. In this book, however, oil rigs have been given a new positive role as the de facto artificial reef program in the world (Chapter 5).

Climate change may help fisheries in arctic waters but has negative effects elsewhere in the world. The warming of the ocean surface and decreasing nutrient concentrations, both associated with "El Niño," cause high mortalities in brown seaweed populations in Chile (Chapter 6).

In addition, this book describes blue swimming crab fishery management in Indonesia, and Chapter 7 concludes that the self-recorded logbooks by the fishermen and processing plant owners could serve as long-term solution in the fisheries management.

Don't give a man a fish but rather teach him to catch a fish and you do him a good turn. This old Chinese axiom lifts up the importance of all-level teaching of fisheries. Japanese eat more fish per capita $(92 \mathrm{~kg})$ than people of any other nation, so no wonder that they have also developed a specific education system in the fisheries. Historical details of this "Suisan" education system involving universities, research institutions, and aquaria are given in this book (Chapter 8). Suisan covers fishing, aquaculture, and food processing. Modern Japan aims to develop participatory fisheries education actively in every region of the country by using the US Sea Grant College system as a model. Same type of education development should be adopted all around the world.

Fish biodiversity is a very important subject when dealing with the conservation or climate change issues. But no biodiversity studies are possible without proper knowledge of fish species. This is giving a new reason for fish taxonomy research. In this book, we have an interesting presentation from Pakistan with excellent photos on taxonomy of northern Arabian Sea coast species of Carangidae family (Chapter 9).

Jacques Yves Cousteau (late scientist, marine conservationist, and deep-sea diver) said that "We must plant the sea and heard its animals using the sea as farmers instead of hunters. That is what civilization is all about - farming replacing hunting." Due to the rising demand 
for fish and shellfish, aquaculture is predicted to have an increasingly important role in providing a protein source for future generations.

This book has nine chapters on Aquaculture Wetland Ecosystem Services Approach and Climate Change Adaptation which explain how different aquaculture systems could maximize the benefits that society receives from both aquaculture production and the ecosystem services provided by wetland ecosystems. Sustainable development of aquaculture must take into account the societal value of ecosystem services for an efficient and environmentally sound production of food.

Although some issues regarding the potential benefits and implementation of sustainable aquaculture remain, the consideration of food security and minimizing ecosystem impacts suggest that the time has come to take action. If we can efficiently farm the land, why can't we farm more the sea and inland waters?

Heimo Mikkola

University of Eastern Finland

Finland 



\title{
Chapter 1
}

\section{Effect of Special Fish Feed Prepared Using Food Industrial Waste on Labeo rohita}

\author{
Sanyogita R. Verma and Shanta Satyanarayan
}

Additional information is available at the end of the chapter

http://dx.doi.org/10.5772/62736

\begin{abstract}
All food processing industries generate wastes of varying nature in significant quantities. Managing these wastes so as to minimize the impact on the environment is the prime concern. The concept of waste has undergone much change in recent times, with the focus being on utilizing the waste materials as inputs for generation of new or reusable products. Vegetable and fruit wastes are generated in significant quantities and are easily available at minimal charge. The comparative utilization of these wastes as a dietary ingredient was assessed employing the Labeo rohita fingerlings as the test species. The study was conducted over a period of 60 days. Orange peels and potato peels are characterized, and then, formulation of orange peel feed (OPF) and potato peel feed (PPF) was carried out. Market common fish feed (CFF) was taken as a control. The three test diets were designated as CFF, OPF and PPF. Feeding was done once daily. The water quality parameters such as dissolved oxygen, water temperature $\mathrm{pH}$, total alkalinity, total hardness; calcium hardness and magnesium hardness as well as growth response were monitored at fortnightly intervals. The quality of water was maintained by periodic partial replenishment over the period of study. On termination of the trial, higher growth response was recorded in the PPF treatment. The initial and final weight and length of fishes was recorded. The results shows significant growth in PPF and OPF showed brighter body scales than other two feed. Fishes were very healthy and normal throughout the study period indicating no adverse effect on their health. No infection whatsoever was noted during 60 days of experimental period.
\end{abstract}

Keywords: Fish feed, Labeo rohita, Potato peel waste, Orange peel waste, Nutritional value, Aquaculture 


\section{Introduction}

The global consumption of fish and derived fish products has greatly increased during recent decades [1]. Change in consumer trend could be based on a number of distinct factors; foremost among these is the growing knowledge that fish constitute an important and healthy part of the human diet, mainly owing to the presence of $\infty-3$ polyunsaturated fatty acids (PUFA), which play an essential role in human health [2], but also to the presence of vitamins, minerals and proteins with a high biological value. Consequently, it is a well-known fact that fish represent a high-quality nutritional source [3]. Fish demand is also increasing as a result of the increasing world population, higher living standards and the good overall image of fish among consumers [4]. Fish as a whole has a lot of food potential and can therefore be expected to provide relief from malnutrition, especially in developing countries [2]. It provides superior quality protein to that of meat, milk and eggs and well-balanced essential amino acid profile, necessary minerals and fatty acids [5-7]. In addition to the fact that fish flesh is tasty and highly digestible; it also minimizes the risk of heart diseases and increases life expectancy [7].

Aquaculture is one of the fastest developing growth sectors in the world, and Asia presently contributes about $90 \%$ to the global production [8]. Due to proteinous rich dietary and as a source of income, specially for economically weak peoples. However, continued increase in price of fishmeal and disease outbreaks are constraint to aquaculture production and thereby affects both economic development of the country and socio-economic status of the local people in many countries of Asia [9]. However, use of probiotics is one of such methods that are gaining importance in controlling potential pathogens [10].

Fruit processing wastes and vegetable wastes are the potential source of energy in urban areas, which should be exploited to use as ingredients in fish feed. In India, over 35 million tones of fruits and vegetables are processed annually and this resulted in about 10 million tones of wastes [11]. This waste from fruit processing operation constitutes a large untapped source of energy and proteins. Most of these wastes are merely dumped in the fields, which causes pollution. Possible uses of these wastes in animal feed preparation have been suggested by some workers [12]. Utilization of these huge wastes generally escapes the attention of animal nutritionist, especially in case of fish feed. Fish consumption is associated with health benefits because of rich content in proteins of high nutritional value, minerals, vitamins and distinctive lipids.

Very little emphasis has been given to the use of vegetables and fruit processing wastes, which is very cheap, easily available and high in fibre content. In view of above, this study was carried out on the fingerlings of Labeo rohita. This study was aimed at formulating fish feeds comprising of by-products and nutritious food industry waste-based materials using quality evaluation by probiotics and assessing the effects on fish treated with this new variety of feed. 


\section{Fish feed formulation and preparation}

Wastes were collected from several food processing industries. About two kg of orange and potato peels wastes were collected and dried for 1 week continuously. After 1 week, it was oven-dried and then pulverized to make into powder form to size $250 \mu$. The powder was used as media to grow the probiotics. The pure culture of probiotics was inoculated into the filtrate used as media in sterile condition and incubated at $37^{\circ} \mathrm{C}$ for $24 \mathrm{hrs}$. After $24 \mathrm{hrs}$, growth was observed. Calcium carbonate was used to immobilize the probiotics spores grown in media. Experimental diet contained $4 \%$ potato peel powder or $4 \%$ orange peel powder, $4 \%$ calcium carbonate blended with probiotic and $2 \%$ starch as binder. The ingredients were same for both feed, except orange peel used orange peel feed (OPF) and potato peel used in potato peel feed (PPF). Market common fish feed (CPF) was considered as control.

\section{Experimental setup}

The experiment was conducted over a period of 60 days. The fingerlings of Labeo carps (Ham.) were obtained from Futala Lake, Nagpur, Maharashtra. Labeo rohita fingerlings are selected because of its high nutritional value and easy availability. The experiment was set up in three distinct experimental groups, each group having three replicates, in 09 uniform size glass aquariums (20 L capacity each). Each of the aquariums was stocked with 10 fingerlings. Initial length and weight was recorded before loading of fingerlings in experimental aquarium. Round the clock aeration was provided to all the tubs, with a $2 \mathrm{HP}$ air blower. Prior to feeding of experimental diets, the fish were acclimatized and starved overnight to empty their gut and increase their appetite and reception for new diets. The fish were fed ( $5 \%$ body weight) twice daily at 10.00 and $20.00 \mathrm{~h}$. As the water becomes turbid, water was changed every second day to maintained good water quality/dissolved oxygen content.

Experimental tubs were cleaned manually by siphoning all the water along with faecal matter and left over feed daily. The siphoned water was replaced by an equal volume of fresh chlorinefree tap water.

Water quality was monitored using standard method [13] for temperature, $\mathrm{pH}$, alkalinity, dissolved oxygen, total hardness, calcium hardness and magnesium hardness.

After 60 days of experiment, fish were removed from the aquarium and final length and weight was noted. Then, they were dissected to remove muscle tissue and liver, which are nutritious and edible. Tissues like muscle and liver are separated from the bones and cleaned by dabbing it in filter paper to remove excess water. Thus obtained, tissues were weighed and processed for protein content.

Nutritional indices: The growth response of fish fed with different diets was monitored by noting average gain in weight and length

Average gain in weight: It gives the increase in weight of the animals during the experimental period. It was calculated using the formula. 
Average gain in wt. $(\mathrm{g})=$ Average Final wt. $(\mathrm{g})$ - Average Initial wt. $(\mathrm{g})$

Average gain in length: This gives the increase in standard length during the experimental period. It was calculated using following formula.

Average gain in length $(\mathrm{cm})=$ Average Final length $(\mathrm{cm})$ - Average Initial length $(\mathrm{cm})$

\section{Estimation of protein}

Protein Estimation using Lowry's Method. This assay was introduced by Lowry et al. [14]. It is highly sensitive and can detect protein levels as low as $5 \mu \mathrm{g} / \mathrm{ml}$. This is the most widely used method for protein estimations.

\section{Statistical analysis}

The experiment was designed in a completely randomized block design with three replications for each treatment. On termination of the experiment, all surviving fishes were collected and length and weight recorded individually. All statistical analysis was performed using IBM SPSS Statistics version 20.

\section{Results and discussion}

Peel characterization was carried out before preparing the feed (Table 1).

\begin{tabular}{llll}
\hline Sr. no. & Parameters & Potato peel & Orange peel \\
\hline 1 & Protein & $4.12 \mathrm{~g}$ & $1.5 \mathrm{~g}$ \\
2 & Carbohydrate & $14.2 \mathrm{~g}$ & $1.5 \mathrm{~g}$ \\
3 & Fat & $0.79 \mathrm{~g}$ & $0.02 \mathrm{~g}$ \\
4 & Total dietary fibre & $2.9 \mathrm{~g}$ & $10.6 \mathrm{~g}$ \\
5 & Calcium & $31 \mathrm{mg}$ & $97 \mathrm{mg}$ \\
6 & Iron & $3.3 \mathrm{mg}$ & $0.8 \mathrm{mg}$ \\
7 & Potassium & $417 \mathrm{mg}$ & $212 \mathrm{mg}$ \\
8 & Sodium & $8.7 \mathrm{mg}$ & $0.2 \mathrm{mg}$ \\
\hline
\end{tabular}

Table 1. Peel characterization.

Before initiating the experiment, the peel of potato and orange are characterized (Table 1). The results show high content of carbohydrate $(14.2 \mathrm{~g})$ and proteins $(4.12 \mathrm{~g})$ followed by minerals, 
that is potassium $(417 \mathrm{mg}$ ) in potato peels. Whereas in orange peel, it shows high calcium and fibre content.

After peel characterization, it was processed for preparing PPF and OPF. The proximate nutritional values of experimental feed were depicted in Table 2. The percentage of moisture is slightly variable, that is 10.3 and $9.5 \%$ in PPF and OPF, respectively, whereas the ash content is higher in PPF $(32.75 \%)$ than in OPF (12.4\%). In PPF, protein content $(63.98 \%)$ is highly followed by carbohydrate $(14.2 \%)$, fat $(8.2 \%)$, total dietary fibres $(3.65 \%)$ and total nitrogen. While in OPF, total dietary fibres posses high content, that is $(38.12 \%)$ followed by protein $(12.6 \%)$, carbohydrate $(12.6 \%)$, fat $(2.8 \%)$ and total nitrogen $(0.41 \%)$

\begin{tabular}{llll}
\hline Sr. no. & Parameters & PPF (\%) & OPF (\%) \\
\hline 1 & Ash & $32.75 \pm 0.4$ & $12.4 \pm 0.5$ \\
2 & Moisture content & $10.3 \pm 0.7$ & $9.5 \pm 0.6$ \\
3 & Total nitrogen & $0.52 \pm 0.4$ & $0.41 \pm 0.6$ \\
4 & Fat & $8.2 \pm 0.1$ & $2.8 \pm 0.4$ \\
5 & Carbohydrate & $14.2 \pm 0.2$ & $12.6 \pm 0.3$ \\
6 & Total dietary fibres & $3.65 \pm 0.8$ & $38.12 \pm 0.5$ \\
7 & Protein & $63.98 \pm 0.2$ & $21.01 \pm 0.3$ \\
\hline
\end{tabular}

Each value is mean \pm SD of triplicate observations

Table 2. Proximate nutritional values of experimental feed.

The water quality during the study period remained in following range: $\mathrm{pH} 7.4-8.4$, alkalinity 140-170 mg/l, dissolved oxygen 6.8-8.0 mg/l, total hardness 120-160 mg/l, calcium hardness 32-53 mg/l and magnesium hardness $6.5-9.4 \mathrm{mg} / \mathrm{l}$. Since fish are poikilotherm, water temperature plays an important role in energy partitioning, protein assimilation and growth [15]. Water temperature was varied from 28 to $30^{\circ} \mathrm{C}$. All the water quality parameters were within the permissible limit. However, the recommended values are: $\mathrm{pH}$ : 6.7-9.5; alkalinity: 50-300 $\mathrm{mg} / \mathrm{l}$; dissolved oxygen: 5-10 mg/l and total hardness: 30-180 mg/l.

During experimental period, morphological and behavioural characteristics of fish were observed. Fishes were swimming actively throughout the entire tank, not just hanging out or laying at the bottom. They consume the fish feed regularly and swim to the surface quickly during feeding time. Fish do not show any white spots or blemishes on their body; fins were not torn, curved or ragged, and eyes were not bulged. Gill movements were very normal and controlled. Fish showed no stomach bulging or fin curving indicating that they were healthy and the feed was not toxic and can be used in aquaculture.

Results of growth performance in 60 days of CFF, PPF and OPF to the Labeo rohita fish are depicted in Table 3. 


\begin{tabular}{llll}
\hline Treatments & \multicolumn{2}{l}{ Experimental groups } & \\
\cline { 2 - 3 } & CFF & PPF & OPF \\
\hline Initial length $(\mathrm{cm})$ & $7.4 \pm 0.65$ & $8.1 \pm 0.07$ & $7.5 \pm 0.38$ \\
Final length $(\mathrm{cm})$ & $14.6 \pm 0.36$ & $16.0 \pm 0.13$ & $14.7 \pm 0.51$ \\
Length gain $(\mathrm{cm})$ & $7.2 \pm 0.62$ & $7.9 \pm 0.05$ & $7.2 \pm 0.14$ \\
Initial weight $(\mathrm{g})$ & $6.7 \pm 0.20$ & $7.1 \pm 0.08$ & $6.2 \pm 0.24$ \\
Final weight $(\mathrm{g})$ & $23.9 \pm 0.39$ & $26.3 \pm 0.12$ & $23.0 \pm 0.06$ \\
Weight gain $(\mathrm{g})$ & $16.2 \pm 0.56$ & $19.2 \pm 0.07$ & $16.8 \pm 0.29$ \\
\hline
\end{tabular}

Each value is mean $\pm \mathrm{SD}$ of triplicate observations.

Table 3. Growth performance of Labeo rohita fed different test diet treatments.

The mean weight gain of Labeo rohita in the three treatments CFF, PPF and OPF was found to be 16.2, 19.2 and $16.8 \mathrm{~g}$, respectively. The highest average live weight gain was found to be obtained in treatment PPF. The average gain in length of Labeo rohita in the three treatments CFF, PPF and OPF was found to be $7.2,7.9$, and $7.2 \mathrm{~cm}$, respectively. The highest average gain in length was obtained in treatment PPF.

Sunitha and Rao [16] had reported better weight gain in Tilipia mossambica when fed with blue green algae (Chlorella, Anabaena, Oscillatoria, Nostoc) grown with the support of mango waste. Hung et al. [17] had also reported that Pangas catfish (Pangasius pangasius) has been demonstrated to having a capacity for utilizing plant feedstuff carbohydrates for energy. Therefore, it can be concluded that vegetable wastes have considerable potential for partial replacement with fish meal as supplementary feed ingredients in sustainable aquaculture of Labeo carps.

Feed is the single largest item of expenditure to the farmers, accounting for 79-92\% of the total production cost in striped catfish (Platydoras armatulus) farming [18-20]. In general, two types of feeds are used for striped catfish, wet farm made feeds and pelleted feeds, and these differ in formulation and quality [18-20]. According to Hung et al. [21], the traditional feeding of small scale catfish farming is largely based on trash fish (marine origin) constituting approximately $50-70 \%$ of feed formulations. Pangas catfish has been demonstrated to have a capacity for utilizing plant feedstuff carbohydrates for energy, but little research has been performed on these fish species with regard to alternative dietary protein source selection [17]. Using plant-based proteins in aquaculture feeds requires that the ingredients possess certain nutritional characteristics, such as low levels of fibre, starch and antinutritional compounds. They must also have a relatively high protein content, favourable amino acid profile, high nutrient digestibility and reasonable palatability [22]. A number of previous studies discuss the suitability of plant protein feeds and/or local agricultural by-products as an alternative protein source in fish feeds [23-28].

Figure 1 shows the total percentage of protein in 60 days exposure. The results shows significant percentage of protein in muscles and liver of Labeo rohita fed with PPF followed by $\mathrm{OPF}$ and CFF. However, the Labeo rohita fed with OPF showed very active behaviour, lustrous 
body scales and high feeding rate. Feeding rate was calculated on the basis of fish feed left over or settled at the bottom of aquarium. The higher mineral and fibres content in OPF show high quantitative value.

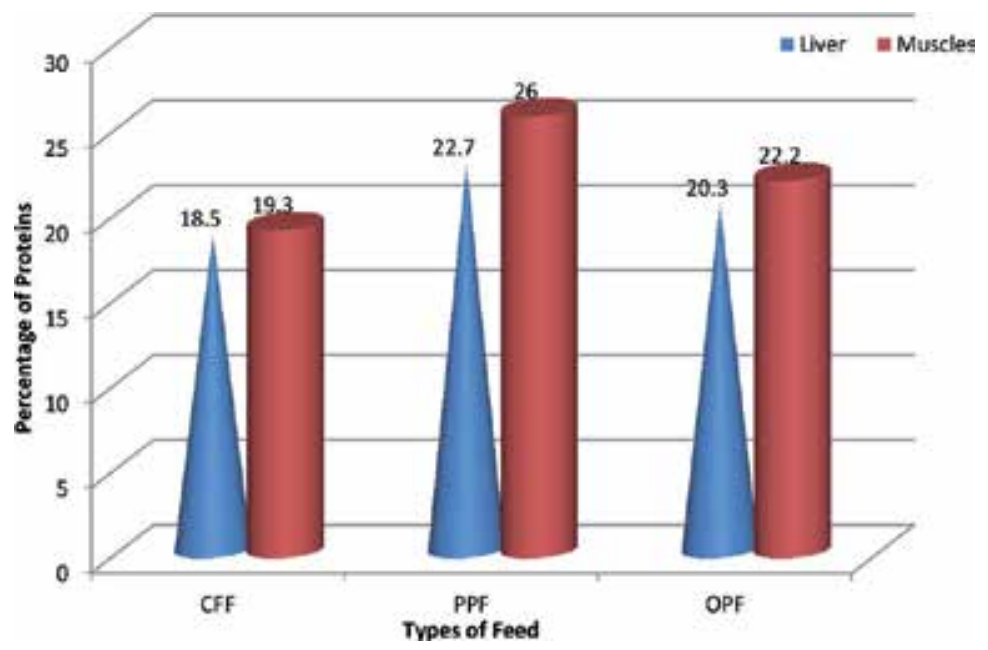

Figure 1. Percentage of protein content in liver and muscles.

\section{Conclusion}

It is clear from the study that feed prepared for fishes are non-toxic and have good nutritive value of orange and potato peel waste. There appeared no adverse changes morphologically. Comparative studies between CFF, PPF and OPF showed that PPF is very nutritive and helps in the qualitative and quantitative growth of fish. While in OPF and CFF, growth is slow. But Labeo rohita fed with OPF showed brighter body scales than other two feed. Fishes were very healthy and normal throughout the study period indicating no adverse effect on their health. No infection whatsoever was noted during 60 days of experimental period.

\section{Author details}

Sanyogita R. Verma ${ }^{1^{*}}$ and Shanta Satyanarayan ${ }^{2}$

*Address all correspondence to: sanyogitaverma1@rediffmail.com

1 Department of Zoology, Anand Niketan College, Anandwan, Warora, Chandrapur, (M.S), India

2 Waste Water Treatment, NEERI, Nagpur, (M.S), India 


\section{References}

[1] Wim, V., Isabelle, S., Karen, B., Stefaan, DH and John, VC (2007) Consumer perception versus scientific evidence of farmed and wild fish: exploratory insights from Belgium. Aquac Int 15:121-136.

[2] Ruxton, CH, Reed, SC, Simpson, MJ and Millington, KJ (2004) The health benefits of omega-3 polyunsaturated fatty acids: a review of the evidence. J Hum Nutr Diet 17:449 459.

[3] Sidhu, KS (2003) Health benefits and potential risks related to consumption of fish or fish oil. Regul Toxicol Pharmacol 38:336-344.

[4] Cahu, C., Salen, PD and Lorgeril, M. (2004) Farmed and wild fish in the prevention of 11 cardiovascular diseases: assessing possible differences in lipid nutritional values. Nutrition, Metabolism E Cardiovascular Diseases (NMCD) 14 (1):34-41

[5] Astawan, M. 2004. "Ikan yang Sedap dan Bergizi”. Tiga Serangkai. Solo : 1-7

[6] Hossain, MA (1996) Proximate and amino acid composition of some potential Bangladeshi fish feed ingredients. Bangladesh J Zool 24:163-168.

[7] Ashraf, MA, Zafar, A., Rauf, S., Mehboob, S. and Qureshi, NA (2011) Nutritional values of wild and cultivated silver carp (Hypophthalmichthys molitrix) and grass carp (Ctenopharyngodon idella). Int J Agric Biol 13:210-214.

[8] Jauncey, K. and Ross, S. (1982) A Guide to Labeo rohita Feed and Feeding. University of Sterling, Scotland.

[9] Balcazar, JL (2003) Evaluation of probiotic bacterial strains in Litopenaeus Vannamei. Final Report. National Center for Marine and Aquaculture Research, Guayaquil, Ecuador.

[10] Maheswari, RC, Bohra, CP and Srivastava, PK (1984) Energy demand and biomass energy potential. Chang Villages 6(5):337-341.

[11] Patel, BM, Patel, CA and Talpada, PM (1972) Evaluation of mango seed kernels and tomato waste in the ration of bullocks. Indian J Nutr Diet 9(6):347-350.

[12] Course manual. ((2003). ) Biochemical Technology in Fisheries, Central Institute of Fisheries Education (CIFE), Mumbai.

[13] Lowry, OH, Rosenbrough, NJ, Farr, AL and Randall, RJ (1951) Protein measurement with folin phenol reagent. J Biol Chem 193:265-267.

[14] Choudhary, BBP, Das, DR, Ibrahim, M. and Chakraborty, SC (2002) Relationship between feeding frequency and growth of one Indian major carp Labeo rohita (ham.) fingerlings fed on different formulated diets. Pak J Biol Sci 5(10):1120-1122. 
[15] Sunitha, M. and Rao, DG (2003) Bioconversion of mango processing waste to fish feed by microalgae isolated from fruit processing industrial effluents. J. Sci Ind Res 62:344347.

[16] Hung, LT, Suhenda, N., Slembrouck, J., Lazard, J. and Moreau, Y. (2003) Comparison of starch utilization in fingerlings of two Asian catfishes from 68 the Mekong River (Pangasius bocourti Sauvage, 1880, Pangasiushypophthalmus Sauvage, 1878). Aquac Nutr 9:215-222.

[17] Belton, B., Little, DC and Sinh, LX (2011) The social relations of catfish production in Vietnam. Geoforum 42(5):567-577.

[18] Da C.T., Hung L.T., Berg H., Lindberg J.E. and Lundh T. (2011). Evaluation of potential feed sources, and technical and economic considerations of small scale commercial striped catfish (Pangasius hypothalamus) pond farming systems in the Mekong Delta of Vietnam. Aquaculture Research (doi:10.1111/j.1365-2109.2011.03048.x), 1-13.

[19] Phan, TL, Tam, BM, Thuy, NTT, Geoff, GJ, Brett, IA, Hao, NV, Phuong, NT and Silva, SSD (2009) Current status of farming practices of striped catfish, Pangasianodon hypophthalmus in the Mekong Delta, Vietnam. Aquaculture 296:227-236.

[20] Hung, LT, Suhenda, N., Slembrouck, J., Lazard, J. and Moreau, Y. (2004) Comparison of dietary protein and energy utilization in three Asian catfishes (Pangasius bocourti, $P$. hypophthalmus and P. djambal). Aquac Nutr 10:317-326.

[21] NRC. (2011) Nutrient requirements of fish and shrimp, National Research Council of the National Academies Washington, D.C (US), 363.

[22] Burr, GS, Wolters, WR, Barrows, FT and Hardy, RW (2012) Replacing fishmeal with blends of alternative proteins on growth performance of 63 rainbow trout (Oncorhynchusmykiss), and early or late stage juvenile Atlantic salmon (Salmosalar). Aquaculture 334-337: 110-116.

[23] Bonaldo, A., Parma, L., Mandrioli, L., Sirri, R., Fontanillas, R., Badiani, A. and Gatta, PP (2011) Increasing dietary plant proteins affects growth performance and ammonia excretion but not digestibility and gut histology in turbot (Psetta maxima) juveniles. Aquaculture 318(1-2): 101-108.

[24] Brinker, A. and Reiter, R. (2011) Fish meal replacement by plant protein substitution and guar gum addition in trout feed, Part I: effects on feed utilization and fish quality. Aquaculture 310(3-4):350-360.

[25] Cabral, EM, Bacelar, M., Batista, S., Castro-Cunha, M., Ozstro-, ROA and Valente, LMP (2011) Replacement of fishmeal by increasing levels of plant protein blends in diets for Senegalese sole (Soleasenegalensis) juveniles. Aquaculture 322-323: 74-81.

[26] Nyina-Wamwiza, L., Wathelet, B., Richir, J., Rollin, X. and Kestemont, P. (2010) Partial or total replacement of fish meal by local agricultural by-products in diets of juvenile 
African catfish (Clarias gariepinus): growth performance, feed efficiency and digestibility. Aquac Nutr 16(3):237-247.

[27] Cabral E.M., Bacelar M., Batista S., Castro-Cunha M., Oz'orio R.O.A. and Valente L.M.P. (2011). Replacement of fishmeal by increasing levels of plant protein blends in diets for Senegalese sole (Soleasenegalensis) juveniles. Aquaculture 322-323, 74-81.

[28] Nyina-Wamwiza L., Wathelet B., Richir J., Rollin X. and Kestemont P. (2010). Partial or total replacement of fish meal by local agricultural by-products in diets of juvenile African catfish (Clarias gariepinus): growth performance, feed efficiency and digestibility. Aquaculture Nutrition, 16(3), 237-247 
Chapter 2

\title{
Using Taxes to Manage a Multigear Fishery: An Application to a Spanish Fishery
}

\author{
M. Dolores Garza-Gil , Manuel Varela-Lafuente and \\ Juan C. Surís-Regueiro
}

Additional information is available at the end of the chapter

http://dx.doi.org/10.5772/62285

\begin{abstract}
When fishing gears alter the composition of fish populations or modify the recruitment rate, it is advisable to include the degree of their fishing selectivity in the analysis. Fishing selectivity can cause two different management problems: interspecies selectivity or by-catch of fish stocks for which no quota has been set by the regulator. The case study is the Spanish fishery of hake (Merlucius merlucius), where the fleet operates using two main gears; most of the vessels are trawlers but a few boats use longlines and other fixed gears. Fishery management by means of effort taxes and how the degree of intraspecies selectivity may affect the resource and tax levels are analyzed. The results show that the tax level will depend on the social value of the marine stock, the marginal productivity of each fleet's effort, and the effect that the fishing activity of each one has on the growth of the hake biomass.
\end{abstract}

Keywords: European hake, fisheries management, multigear fishery, tax, Spanish fishery, fishing selectivity

\section{Introduction}

From an economic point of view, fishery resources are assets that provide flows of income over time but show certain characteristics. These are linked with the renewable character of fish stocks, the institutional structure under which the activity takes place, and the existence of externalities in the use of a resource. Bioecological rules are essential to determine the functions of production and meet the necessary biological restrictions in an objective function optimization. However, the institutional conditions in the fish stock exploitation establish who is 
entitled to capture that resource and under what circumstances, and this is essential to understand and predict the behavior of the economic agents involved in the economic activity (the fishermen) and properly drive any regulatory intervention.

Concern for the implications associated with the extraction of marine resources is relatively recent; scarcity problems were largely associated with nonrenewable natural resources until the mid-twentieth century. From then on, the fishing economy has developed quickly. This can be explained by the increasing concerns for the conservation of resources to the perception of degradation of nature and the environment. The effects of the decisions taken at the Third Conference of UN on Law of the Sea in the mid-1970s also have influenced this development, as it recognized the extension of fishery jurisdiction to 200 miles from coastal line and transforming the status of fishery resources from free access to the exclusive property of coastal states.

Marine resource exploitation is one of the typical examples of the tragedy of the commons in which the logic of individual maximization of benefits leads to a continual increase in pressure on the resources and their consequent overexploitation. As the population has expanded, the problem of a lack of resources has become more evident. Society has increasingly valued natural and environmental resources. Key institutional figures have become more necessary for establishing more efficient and sustainable management of natural resources to prevent a tragedy of the commons. Thus, the study of the commons is relevant when analyzing common ownership or open access systems, but its conceptual significance goes far beyond these concrete systems because it represents the starting point in the search to understand the rise and formation of institutions.

These characteristics pose specific management problems for those who need to build theoretical formalization different from those used for the rest of economic assets and those who must be focused on the determination of optimal trajectories for the exploitation of the renewable natural resources sustainably over time. The marine resources must be managed in a rational way, especially if the welfare of future generations is taken into account in the decision-making process.

In a fishery where two or more fleets are using several fishing technologies or gears, it is useful to assume that fishing activity influences the net natural dynamics of the marine resources through the catches, whereas the natural growth function depends on the fish biomass and environmental conditions, and these are taken as stable and constants over time in the specialized literature [1-4]. However, in some fisheries (as the Spanish hake fishery), several fishing technologies could alter the composition of fish populations or modify the recruitment rate [5]. In this case, it is advisable to include the degree of their fishing selectivity in the study. The selectivity could cause two different management problems: interspecies selectivity or bycatch of fish stocks for which no quota has been set by the regulator [6-9].

The case study is the Spanish fishery of European hake (Merlucius merlucius) in Ibero-Atlantic grounds. The Spanish fleet involved in this fishery operates uses two main gears; most of vessels are trawlers, but a few boats use longlines and other fixed gears (majority gillnets). Trawlers harvest mainly young individuals of hake of a lower size than that corresponding to 
sexual maturity (although it too catches mature fish). The other fishing technology (artisanal fleet) catches only mature fish. Based on this, we focus on the intraselectivity problem. We introduce in the analysis of the management of the fishery by means of effort taxes [10-16].

On the contrary, and given that the International Council for the Exploration of the Sea (ICES; this institution analyzes the stock situation and proposes management measures to the European regulator) and the European Commission (EC) recommend that one of the two technologies involved in the hake fishery (in particular, trawling fleet) improves the level of fishing selectivity and aim to individuals of a larger size, we pose several scenarios and study how the levels of hake stock and the tax applied to each group of vessels would be affected. The results obtained show that the optimum tax level depends not only on the social value of the marine resource and the marginal productivity of each fleet's effort but also on the effect that the fishing activity of each one has on the growth of the hake biomass. Furthermore, and as the fleet that is less conservationist with the stock (trawlers) improves the degree of selectivity of its technology, the equilibrium fishing effort level for this fleet increases and the optimum tax falls, to the detriment of the stationary values corresponding to the other fleet.

The particular issue with which this chapter is concerned is how the degree of intraspecies selectivity may affect the hake stock and tax levels. The chapter is structured as follows: the Spanish fishery is described in Section 2. A simple management model applied to the fishery is analyzed in Section 3. The primary results are summarized in Section 4. Lastly, the chapter concludes with the discussion presented in Section 5.

\section{Description of the fishery}

The M. merlucius species is listed within the group of demersal beings and therefore a fish stock of long life. Although it is distributed in the area located between the coast north of Morocco and the North Sea, the ICES valued it separately since 1979, distinguishing two biological units: Northern stock (corresponding to zones IV, VI, and VII and divisions VIIIa and VIIIb; see Figure 1) and Southern stock (divisions VIIIc and IXa). Thus, these two stocks are considered by European regulators as two different management units. This is due to the existence of two well-differentiated recruitment areas: one on the west coast of France (Northern stock) and the other on the coast northwest of the Iberian Peninsula (Southern stock).

The fishery we are studying is European hake in ICES divisions VIIIc and IXa, better known as the Southern stock of European hake. The juvenile individuals of European hake mainly feed on zooplankton and decapod prawns (Nephrops norvegicus). Larger hake feed predominantly on fish, with blue whiting (Micromesistius poutassou) being the most important prey in waters deeper than $100 \mathrm{~m}$. Horse mackerel (Trauchurus trauchurus) and mackerel (Scomber scombrus) are the most important prey species in shallower waters. Hake are known to be cannibalistic species located at the top of the food chain. European hake recruitment processes lead to patches of juveniles found in the localized areas of the Iberian continental shelf. European hake concentrations could vary in density according to the strength of the year class; however, they remain generally stable in size and spatial location. The ICES estimates that the 
spatial patterns could be related to environmental conditions. On the eastern shelf of the Cantabrian Sea, years of large inflow of the shelf-edge current have produced low recruitment rates due to larvae and pre-recruits being transported away from spawning areas. The recent high recruitment has not yet been linked to an environmental process.

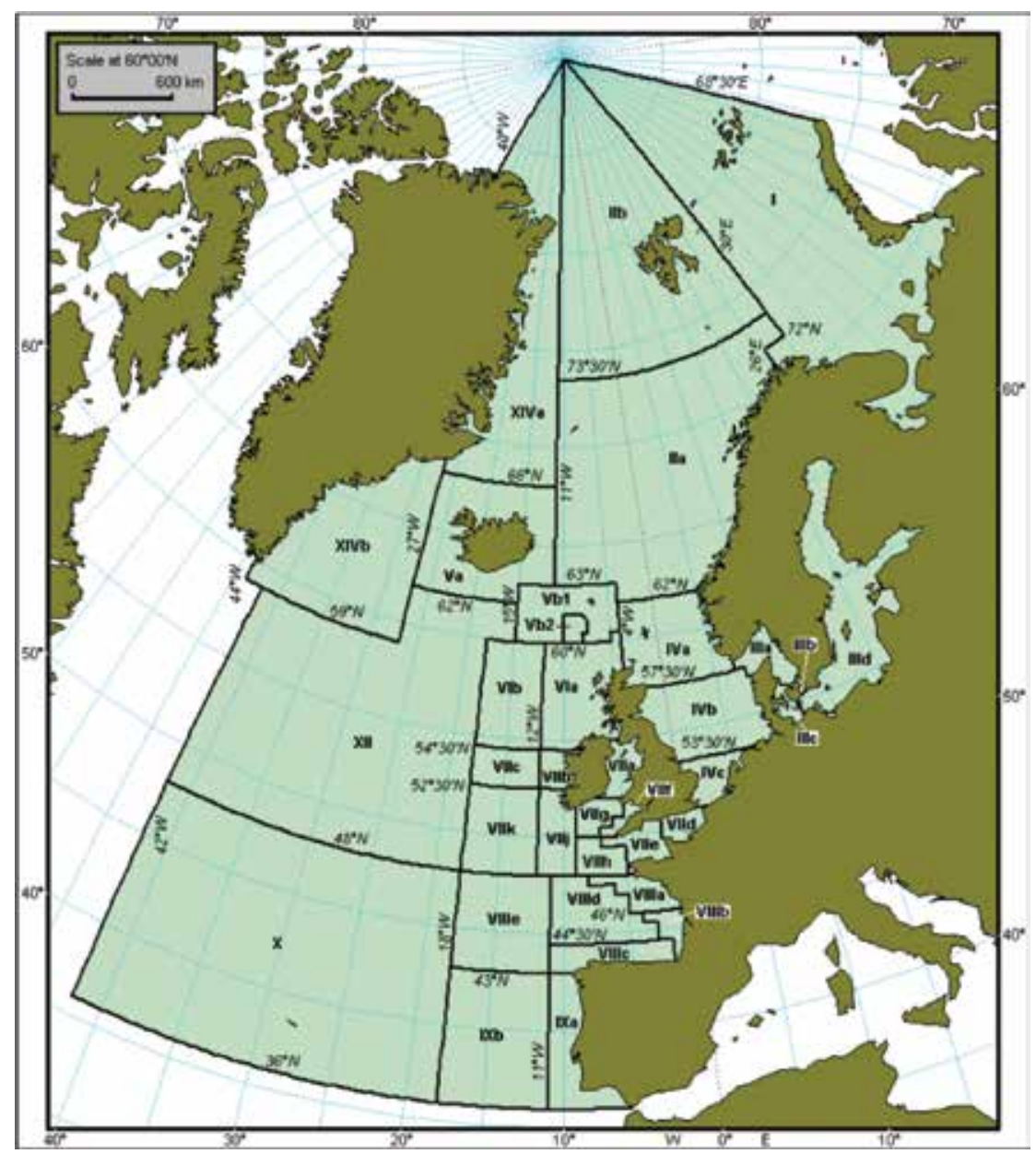

Figure 1. ICES zones. Source: Spanish Oceanographic Institute.

European hake in ICES divisions VIIIc and IXa is caught in a mixed fishery by trawlers and artisanal vessels. The trawling fleet is homogeneous and uses mainly two gears: pair trawl and bottom trawl. The artisanal fleet is quite heterogeneous and uses a wide variety of fixed gears, mainly large and small fixed gillnets and longlines. The amount of hake in the landings of Spanish trawlers is low in relative terms. However, trawling vessels provide by $55 \%$ of the total Spanish hake landings for last years. These fishing gears affect the hake biomass in different ways. Trawling, although it catches individuals of all ages, has a negative impact on 
young individuals preventing them from reaching adulthood. The more traditional method, however, affects mainly mature fish and is less damaging to the hake stock.

Trawl fleet is one of the most important fleets among those operating on the Spanish Atlantic continental shelf in terms of landings value. The standard vessel has approximately 145 GRT of fishing capacity and $330 \mathrm{~kW}$ of engine power, is close to $28 \mathrm{~m}$ long, has 9 crew members, and has an average age of 20 years. The main target species are hake, megrim, anglerfish, lobster, and horse mackerel. The longline and gillnet fleet is less important than the trawler fleet and the standard vessel has approximately $35 \mathrm{GRT}$ and $150 \mathrm{~kW}$, is close to $20 \mathrm{~m}$ long, has 5 crew members, and has an average age of 18 years.

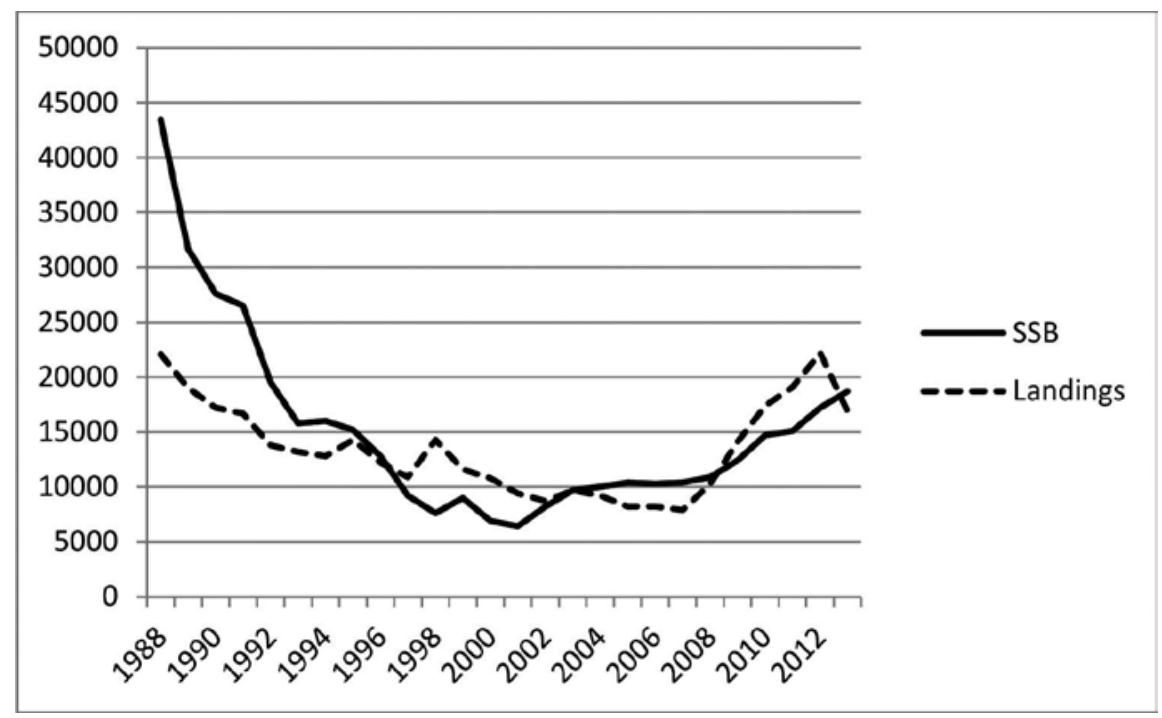

Figure 2. Spawning stock biomass (SSB) and landings. Data in tons. 1988-2013. Source: Own compilation from ICES.

The European Union (EU), within the framework of the Common Fisheries Policy (CFP), manages European hake fishery with total allowable catch (TAC), mainly set based on biological criteria. In addition to TACs, EU implements minimum sizes of catches for hake since 1987 and closed areas. The Spanish Government sets a closed list of vessels of each fishing fleet for the last decades. Furthermore, and in the face of the poor biological situation of the stock (see Figure 2), since 2006, a recovery plan has been implemented, aimed at recovering the spawning biomass above precautionary biomass and reducing fishing mortality to 0.27 [17]. To do so, the EC, while continuing with the establishment of downward TAC, proposes to reduce the effort exercised in the fishery and includes the improvement in the selectivity of some of the fishing methods.

Regarding the Southern stock of European hake, we have obtained information from the ICES on the spawning biomass for the period 1985 to 2014. Figure 2 shows how the hake biomass has decreased to such an extent in the late 1990s, as it reached only $25 \%$ of that which existed 
in the early 1980s, falling well outside the biological safety limits in spite of the recovery experienced in the last 3 years [18]. This hake biomass evolution indicates that the resource is being exploited to excess. With respect to the total catches, we can see that it has shown a decreasing trend in the said period and in keeping with the deterioration of the fish biomass (see Figure 2).

The trends in both variables show that the measures adopted by the EU were not sufficient to avoid the overexploitation of hake stock and the resource is still being overfished in the last years. Therefore, it is necessary to introduce a regulatory mechanism to manage the hake fishery in a sustainable way to avoid the overexploitation of resource and depletion of the fish stock.

\section{Method}

If the regulator of fishery establishes a tax on effort $\left(\tau_{i}\right)$, both fleets will assume an increase in the unit cost of the effort and will be faced with the following problem:

$$
\operatorname{Max}_{e_{i}} \int_{0}^{\infty}\left\{p_{i} h_{i}\left(e_{i}(t), X(t)\right)-\left(w_{i}+\tau_{i}\right) e_{i}(t)\right\} e^{-\delta t} \partial t \quad i=1,2
$$

where $p, w, h, e$, and $X$ denote the unit price of hake, unit cost of effort, total landings, fishing effort, and fish stock, respectively. The parameter $\delta$ represents the discount rate.

The usual natural growth function of the marine resource $(F)$ is modified by a new parameter $\theta$, which catches the selectivity of both fleets. The fish stock dynamic is shown as follows:

$$
G\left(X_{t}, \theta_{t}\right)=\theta_{t} \mathrm{~F}\left(X_{t}\right)
$$

where $F(\cdot)$ is the natural growth function of the resource. The effects that the different technologies have on it are defined as follows [19]:

$$
\theta_{t}=1-\sum_{i} \gamma_{i} \frac{h_{i}\left(X_{t}, e_{i t}\right)}{h\left(X_{t}, e_{t}\right)} \quad \text { con } 0<\theta \leq 1 ; \quad \mathrm{i}=1,2
$$

where the parameter $\gamma_{i}\left(0 \leq \gamma_{i}<1, i=1,2\right)$ shows the level of fishing selectivity of each technology or fleet. If the $i$-fleet technology has no effects on the fish stock dynamics, the fleet shows a high selectivity level and this fleet can be considered as conservationist with the marine resource. In this case, the parameter $\gamma_{i}$ takes on a zero value. In contrast, if technology has effects on the marine stock dynamics in a negative way, the fleet shows a nonselective level and it can be considered as a less conservationist fleet with the fish stock. Therefore, the fishing selectivity parameter will approach the unit value. 
From one of the first-order conditions to resolve the problem (1) [20], the following equation is obtained:

$$
p_{i} \frac{\partial \mathrm{h}_{\mathrm{i}}(.)}{\partial \mathrm{e}_{\mathrm{i}}}=\mathrm{w}_{\mathrm{i}}+\tau_{\mathrm{i}} \quad i=1,2
$$

In the absence of regulation (i.e., no tax would be implemented), we would obtain the following expression [19]:

$$
\left(p_{i}-\mu\right) \frac{\partial \mathrm{h}_{\mathrm{i}}(.)}{\partial \mathrm{e}_{\mathrm{i}}}+\mu \frac{\partial \mathrm{G}(.)}{\partial \mathrm{e}_{\mathrm{i}}}=\mathrm{w}_{\mathrm{i}}
$$

and if both expressions (4) and (5) are compared, the optimum tax value can be obtained (i=1,2):

$$
\tau_{\mathrm{i}}=\mu\left[\frac{\partial \mathrm{h}_{\mathrm{i}}(.)}{\partial \mathrm{e}_{\mathrm{i}}}-\frac{\partial \mathrm{G}(.)}{\partial \mathrm{e}_{\mathrm{i}}}\right]=\mu \frac{\partial \mathrm{h}_{\mathrm{i}}(.)}{\partial \mathrm{e}_{\mathrm{i}}}\left[1-\frac{\left(\gamma_{\mathrm{j}}-\gamma_{i}\right) h_{j}(.) F(X)}{\left(h_{i}+h_{j}\right)^{2}}\right]
$$

This expression indicates that the tax level depends not only on the social value of the marine resource $(\mu)$ and the marginal productivity of the effort $\left(\partial h_{i} / \partial e_{i}\right)$ but also on the effect on the natural growth of the resource $\left(\partial G(\cdot) / \partial e_{i}\right)$. On the contrary, the lower (higher) the marginal productivity of the fleet $i$, the lower (higher) the tax level that will have to be paid to fish in the fishery.

On the contrary, and for $\gamma_{i} \neq \gamma_{j}$, if fleet $i$ shows a high (low) selectivity level and with $\gamma_{i}<\gamma_{j}\left(\gamma_{i}\right.$ $\left.>\gamma_{j}\right)$, then $\gamma_{i} \rightarrow 0\left(\gamma_{i} \rightarrow 1\right)$ and the effect of the activity of $i$ on the natural growth function will be lower (higher), allowing a greater (smaller) growth of the fish population, that is, $\left(\gamma_{j}-\gamma_{i}\right)>0$ $\left(\left(\gamma_{j}-\gamma_{i}\right)<0\right)$ and $\partial G(\cdot) / \partial e_{i}>0\left(\partial G(\cdot) / \partial e_{i}<0\right)$. Consequently, given that $\partial h_{i}(\cdot)>0$, the tax level for this fleet will be higher (lower) than that which corresponds to the other fleet.

\section{Estimations}

Because fishing effort (fishing days) data are not available separately for the trawling and artisanal fleets for the last 10 years, we will use the parameter values estimated by Garza-Gil and Varela-Lafuente [19] for this fishery, who made an econometric estimation through the Ordinary Least Squares (OLS) method with annual observations for 20 years and for different options of the natural resource dynamic and the production functions. These values are summarized in Table 1. Substituting those values of the parameters in the above expression (6), the stationary solutions for the tax levels can be estimated.

However, previously, and because the selectivity parameters are unknown, we must assume some value for them. Regarding trawling, this fleet catches mainly smaller-sized individuals, 
as mentioned in the previous sections, and therefore has a negative impact on the Southern stock hake population by preventing a greater number of young fish from reaching maturity and being able to spawn for next years. On that basis, we will assume a selectivity parameter value for this fleet initially closer to unit value than to zero, in particular $\gamma_{1}=0.7$.

Regarding the artisanal fleet, although it captures mostly mature individuals, it also captures a small amount of young individuals. This figure does not reach $10 \%$ of the landings [19]. Therefore, we will assume a selectivity value for artisanal fleet closer to zero (0.1).

\begin{tabular}{lcc}
\hline & Expression/value & Unit \\
\hline Hake dynamic & $\begin{array}{l}G(X, \theta)=\theta F(X)=\tilde{a} X^{0.82310}=8.9263 \theta X^{0.82310} \\
\text { with } \tilde{a}<a\end{array}$ & \\
Trawl technology & $h_{1 t}=20.82804 e_{1 t}^{0.37744} X_{t}^{0.17164}$ & \\
Artisanal technology & $h_{2 t}=e_{2 t}^{0.12609} X_{t}^{0.74163}$ & Euros per tonne \\
Price of trawl landings & 4,565 & Euros per tonne \\
Price of artisanal landings & 7,482 & Euros per fishing day \\
Cost of trawl effort & 373 & Euros per fishing day \\
Cost of artisanal effort & 419 & Percentage \\
Discount rate & 5 &
\end{tabular}

"1" indicates trawling and " 2 " artisanal.

Source: Own compilation from Refs. [19, 21].

Table 1. Parameter values for estimations.

On the contrary, the trawling may improve the selectivity of this gear, as the EC [17] and the ICES [18] proposed in its management recommendations with a view to improving the pattern of hake production for this fishery. Accordingly, some options may increase, for example, the size of the mesh and expand the cod-end of the fishing nets (the "cod-end" is the rearmost part of a trawl net, of net of the same mesh size, having either a cylindrical or a tapering shape). If this technology improves its fishing selectivity level, the negative effects of its activity on hake dynamic will decrease. In this case, other possible and lowest values for $\gamma_{1}$ can be posed. The results obtained for different values of parameter $\gamma_{1}$ are shown in Table 2 .

It can be seen that the tax level on trawling (in euros per fishing day) is higher than that applied to the artisanal fleet in the scenarios contemplated for selectivity parameter due fundamentally to the fact that it shows a greater marginal productivity in the effort and a negative effect on hake biomass. Consequently, it should pay more to fish in the fishery. Furthermore, as the trawling selectivity improves $\left(\gamma_{1} \rightarrow 0\right)$ and therefore the negative effect of the activity of this 
fleet on the hake population diminishes, the tax per unit of effort applied to this fleet also decreases, whereas, for the artisanal fleet, it increases and its effort level decreases.

\begin{tabular}{llll}
\hline$\gamma_{1}$ & $\mathbf{X}$ & $\tau_{1}$ & $\tau_{2}$ \\
\hline 0.7 & 31,416 & 2,389 & 38 \\
0.6 & 34,143 & 2,183 & 53 \\
0.5 & 37,116 & 1,627 & 83 \\
0.4 & 37,262 & 1,075 & 109 \\
0.3 & 42,499 & 1,062 & 242 \\
0.2 & 43,014 & 994 & 262 \\
\hline
\end{tabular}

"1" indicates trawling and "2" artisanal.

Table 2. Hake biomass (metric tons) and tax levels (euros/day) for different $\gamma_{1}$ and $\gamma_{2}=0.1$.

\section{Discussion and conclusions}

The intensive exploitation of the fishery resources around the world for the last decades has shown the natural limitations of the productivity of fish stocks. In this environment with a depletion of marine resources, economists have been worried about searching for management tools oriented to change the behavior of fishermen to save the resource and also to maintain a positive economic return. From an economic point of view, fish populations are treated as capital assets that can provide flows of income over time. The aim is therefore to determine the path of exploitation of marine resources in a sustainable way and to incorporate the biological conditions of the marine resource and institutional conditions of fishing into the analysis. In this way, the fishing economy has advanced since the first works by Gordon [22] and Scott [23], which includes biological and institutional conditions of basic form, to the development raised by Clark [11] and Clark and Munro [24], who introduced the theory of capital to manage a fishing resource in a dynamic context.

In general, the regulatory mechanisms can be classified into two groups [11]: (1) those that are directed toward the direct control on the fish stocks as well as to maintain high production levels and (2) a group of mechanisms that, in addition to indirectly control the size of the stock, points to sustain activity in economically efficient levels. The methods that have been traditionally implemented, such as production quotas, closed seasons, closed zones, and restrictions on the equipment, correspond to the first group and it has been shown that they have failed to prevent the overexploitation of fish stocks [25-27]. The allocation of property rights and the system of taxes (on production or on the inputs) are in the second group. Among the latter, individual property rights require the creation of markets; the regulator may establish certain rules with respect to fishery exploitation (distribution of the surplus of the marine resource among fishermen involved in the fishery) and allow a rights transaction market to emerge to 
ensure that fishermen comply with its conduct selling or buying part of that right. Taxes can be defined as mechanisms based on the regulation via prices; the essence of these instruments involves the introduction of a price (cost) linked to the behavior that the regulator wants to promote or discourage.

In this chapter, we have studied the European hake fishery (Southern stock), where two fishing fleets are operating using different technologies. We have shown the way in which effort taxes exercised in this multigear fishery make it possible to reach a socially optimum solution for this marine resource, introducing a variable into the analysis, which includes the effects of fishing activity on the natural growth function of the hake population. The efficient stationary solutions for the hake stock levels, its social value and the effort exercised by the two fleets involved in the fishery (trawling and artisanal), propose different scenarios with regard to the selectivity parameter for the fleet that has a more intensive impact on young individuals and then on marine resource dynamics. If trawling selectivity improves, then the optimum level of the natural resource and its shadow price increases, whereas the global level of effort diminishes, increasing that of the trawling fleet and reducing that of the longline fleet [19].

If the present situation is compared to the optimal estimations obtained in this study, it can be seen that the Southern stock of European hake is being fished in an inefficient way, both from an economic point of view and the conservation of the natural resource point of view. In particular, the amount of hake biomass existing at the end of the period studied is significantly lower than that derived from a socially stationary solution. Even in a few years, landings have exceeded the spawning hake biomass in Iberian-Atlantic waters.

To reach socially stationary solutions, we have incorporated an intervention mechanism based on taxes, particularly a tax based on effort exercised by each fleet. The tax equilibrium level is directly related to the social value of the fishing resource, with the marginal productivity of the effort exercised and with the effect that fishing activity has on the natural growth of the resource. In particular, the tax level on the trawling effort is greater than that applied to the artisanal fleet, as it is more productive and affects the hake population more negatively. Therefore, it will pay more to exercise its effort in the fishery. On the contrary, the equilibrium level obtained for the tax on the effort of the artisanal fleet is lower, as it is less productive and much more selective. However, when the trawling fleet improves its selectivity, its effort equilibrium level increases and the optimum tax decreases, to the detriment of the stationary values that correspond to the artisanal fleet.

In this framework, the proposed regulation involving declines in the level of fishing (reducing the pressure on the stock of fish) is not usually well received by the fishing industry. However, an efficient regulation allows maintaining the marine resources in a sustainable way and it will generate economic income for fishermen. An inefficient situation to an efficient change must be associated with a policy of income distribution suitable based on the criteria of equity. The regulation mechanism based on taxes could offer a solution to the externalities associated with the absence of efficient allocations. Although the analysis shown in this chapter is simple, the results can orient the regulator to achieve a more rational exploitation of the Southern stock of hake. 


\section{Acknowledgements}

The authors acknowledge the financial support from FEDER and Xunta de Galicia (GRC2014/022) and the Ministry of Economy and Competitiveness (ECO2014-52412-R and ECO2013-44436-R).

\section{Author details}

M. Dolores Garza-Gil*, Manuel Varela-Lafuente and Juan C. Surís-Regueiro

*Address all correspondence to: dgarza@uvigo.es

Department of Applied Economics, University of Vigo, Vigo, Spain

\section{References}

[1] Armstrong C, Clark D. 1997. Just fishing? Equity and efficiency in fisheries management regimes. Marine Resource Economics 12: 203-220.

[2] Garza-Gil MD. 1998. ITQ systems in multifleet fisheries. An application for Iberoatlantic hake. Environmental and Resource Economics 15: 93-106.

[3] Costa Duarte C, Brasao A, Pintasilgo P. 2000. Management of the Northern Atlantic bluefin tuna: an application of C-Games. Marine Resources Economics 14: 21-36.

[4] Bjorndal T, Lindroos M. 2003. International Management of North Sea Herring. Paper presented at the 12th Annual Conference of European Association of Environmental and Resources Economists 2003.

[5] Lleonart J, Recasens L. 1996. Fisheries and Environment in the Mediterranean Sea. Resources and Environmental Issues Relevant to Mediterranean Fisheries Management. Studies and Reviews General Fisheries Council for the Mediterranean, No. 66. Rome: FAO.

[6] Boyce J. 1996. An economic analysis of the fisheries bycatch problem. Journal of Environmental Economics and Management 31: 314-336.

[7] Prellezo R, Gallastegui C. 2003. Gear selectivity based regulation in a mixed fishery. Paper presented at the 12th Annual Conference of European Association of Environmental and Resource Economists 2003.

[8] Turner MA. 1997. Quota induced discarding in heterogeneous fisheries. Journal of Environmental Economics and Management 33: 186-195. 
[9] Espasa M, Prellezo R. 2003. Fishing technology and optimal distribution of harvest rates. Environmental and Resource Economics 25: 377-394.

[10] Clark CW. 1980. Towards a predictive model for the economic regulation of commercial fisheries. Canadian Journal of Fisheries and Aquatic Sciences 37: 1111-1129.

[11] Clark CW. 1990. Mathematical Bioeconomics. The Optimal Management of Renewable Resources. 2th ed. New York: Wiley-Interscience Publication, 386 pp.

[12] Arnason R. 1989. Minimum information management with help of catch quotas. In: Neher P, Arnason R, Mollet N, editors. Right Based Fishing. Netherlands: Kluwer Academic Publishers, pp. 215-240.

[13] Surís-Regueiro JC. 1993. Regulation of the Iberoatlantic sardine fishery. Environmental and Resources Economics 3: 457-470.

[14] Weitzman M. 2002. Landing fee vs. harvest quotas with uncertain fish stocks. Journal of Environmental Economics and Management 43: 325-338.

[15] Jensen F, Vestergaard N. 2002. Moral hazard problems in fisheries regulation: the case of illegal landings and discards. Resource and Energy Economics 24: 281-299.

[16] Garza-Gil MD, Varela-Lafuente M, Surís-Regueiro JC. 2003. European hake fishery bioeconomic management (Southern stock) applying an effort tax. Fisheries Research 60: 199-206.

[17] European Commission. 2003. Proposal for Recovery Measures for Southern Hake. Brussels: COM 818, Brussels.

[18] ICES. 2015. Hake-Southern Stock Report. http://www.ices.dk.

[19] Garza-Gil MD, Varela-Lafuente M. 2007. Bioeconomic management and fishing selectivity: an application to the European hake fishery. American Journal of Agricultural and Biological Sciences 2: 69-74.

[20] Kamien M, Schwartz N. 1991. Dynamic Optimization. The Calculus of Variations and Optimal Control in Economics and Management. New York: North-Holland Ed., 377 pp.

[21] European Union. 2014. Economic Assessment of EU Fisheries Economic Performance of Selected European Fishing Fleets. Annual Reports. https://stecf.jcr.ec.europa.eu.home.

[22] Gordon HS. 1954. The economic theory of a common property resource: the fishery. Journal of Political Economy 62: 124-142.

[23] Scott A. 1986. Progress in Natural Resource Economics. Clarendon Press.

[24] Clark CW, Munro GR. 1975. The economics of fishing and modern capital theory: a simplified approach. Journal of Environmental Economics and Management 2: 92-106. 
[25] Neher P, Arnason R, Mollet N. 1989. Right Based Fishing. Netherlands: Kluwer Academic Publishers.

[26] Townsend R.E. 1990. Entry restrictions in the fishery: a survey of the evidence. Land Economics 66: 359-378.

[27] Wilen J. 1988. Limited entry licensing: a retrospective assessment. Marine Research Economics 5: 313-324. 

Chapter 3

\title{
Pan-Arctic Fisheries and their Assessment
}

\author{
Ross Tallman, Muhammed Y. Janjua, \\ Daniel Howell , Burton Ayles, Theresa Carmicheal, \\ Matthias Bernreuther, Steve Ferguson and \\ Margaret Treble
}

Additional information is available at the end of the chapter

http://dx.doi.org/10.5772/62347

\begin{abstract}
Pan-Arctic fisheries are highly diverse in their purpose, species biology, productivity, economic and strategic importance as well as in how they are prosecuted. They range from full industrial fisheries to community-based artisanal, sport and subsistence fisheries. The nature of Arctic ecosystems in the region varies from extremely productive to relatively barren in terms of fisheries production. Gear types vary, but offshore trawl fisheries and inshore and freshwater gillnet fisheries are the most common. Rights-based fisheries (e.g., for indigenous inhabitants) are more prominent in the Canadian and American Arctic than in European jurisdictions. The principal harvested species in freshwater environments tend to be from few taxa mainly Salvelinus spp. and from the family Coregonidae, while the marine taxa are more diverse. Compared to north temperate fisheries, Arctic fisheries have impressive variation across longitudes; some jurisdictions support only small-scale subsistence fisheries, whereas others contain some of the largest yields among industrial fisheries. Approaches to scientific assessment are also highly diverse with a range from catch-based indicators to sophisticated fully age-structured population models.
\end{abstract}

Keywords: arctic, fisheries, models

\section{Introduction}

This chapter describes some of the major Pan-Arctic fisheries, the stock assessment methods applied to assess them and how the fisheries might change with climate warming and further 
development of the northern regions. The chapter is a broad overview to introduce the reader to this topic which has not been included in most fisheries text books.

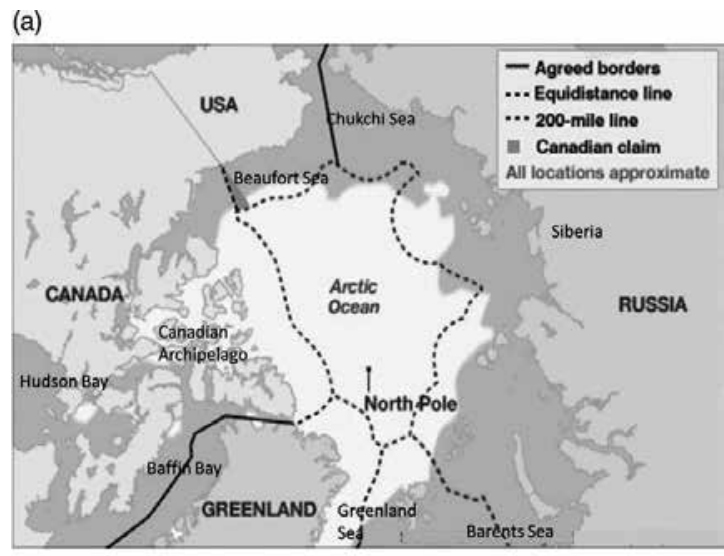

(b)

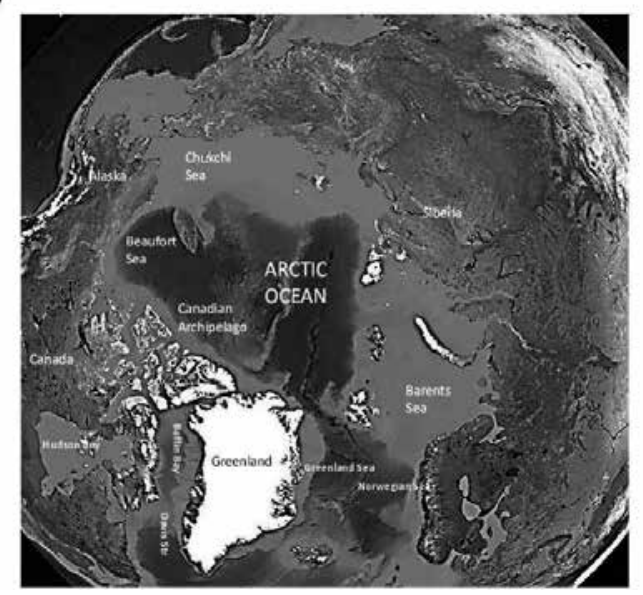

Figure 1. (a) Arctic Ocean and surrounding land masses showing approximate jurisdictional boundaries and (b) fishing areas discussed in the text.

Pan-Arctic fisheries are highly diverse in their purpose, species biology, productivity, economic and strategic importance as well as in how they are conducted. They range from full industrial fisheries to community-based artisanal, sport and subsistence fisheries. Rights-based fisheries (e.g., for indigenous inhabitants) are more prominent in the Canadian and American Arctic than in European jurisdictions. The patchy nature of Arctic environments has a strong influence on species life cycles such that geographically extensive migrations between critical habitats for rearing and growth, spawning or calving and over-wintering are undertaken by many taxa. Species tend to be long-lived. The principal harvested species in freshwater environments tend to be from few taxa mainly Salvelinus spp. and from the family Coregonidae. While the marine taxa are more diverse, the dominance of marine mammals at the apex 
of the food chain and as a source of food for humans is important in driving fisheries policy for a large portion of the Arctic zone. Compared to north temperate fisheries, Arctic fisheries have impressive variation across longitudes; some jurisdictions support only small-scale subsistence fisheries, whereas others contain some of the largest yields among industrial fisheries.

The chapter is organized by geographic regions: Barents Sea, Arctic Atlantic-Norwegian Sea, Arctic Atlantic-Greenland Sea, Greenland-continental, Baffin Bay-Davis Strait, Hudson Bay, Canadian Archipelago, Canadian Arctic mainland, Alaska, Beaufort Sea, Siberia and Chukchi Sea (Figure 1).

\section{Barents Sea}

The Barents Sea (Figure 2) is on the continental shelf surrounding the Arctic Ocean. It connects with the Norwegian Sea to the west and the Arctic Ocean to the north and the Kara Sea to the east. Its contours are delineated by the continental slope between Norway and Spitsbergen to the west, the top of the continental slope towards the Arctic Ocean to the north, Novaya Zemlya archipelago to the east and the coasts of both Norway and Russia to the south. It covers an area of approximately 1.4 million $\mathrm{km}^{2}$, has an average depth of approximately $230 \mathrm{~m}$ has and a maximum depth of about $500 \mathrm{~m}$ at the western end of Bear Island Trough. Its topography is characterized by troughs and basins (300-500 m deep), separated by shallow bank areas, with depths ranging from 100 to $200 \mathrm{~m}$. The three largest banks are Central Bank, Great Bank and Spitsbergen Bank. Several troughs over $300 \mathrm{~m}$ deep run from central Barents Sea to the northern

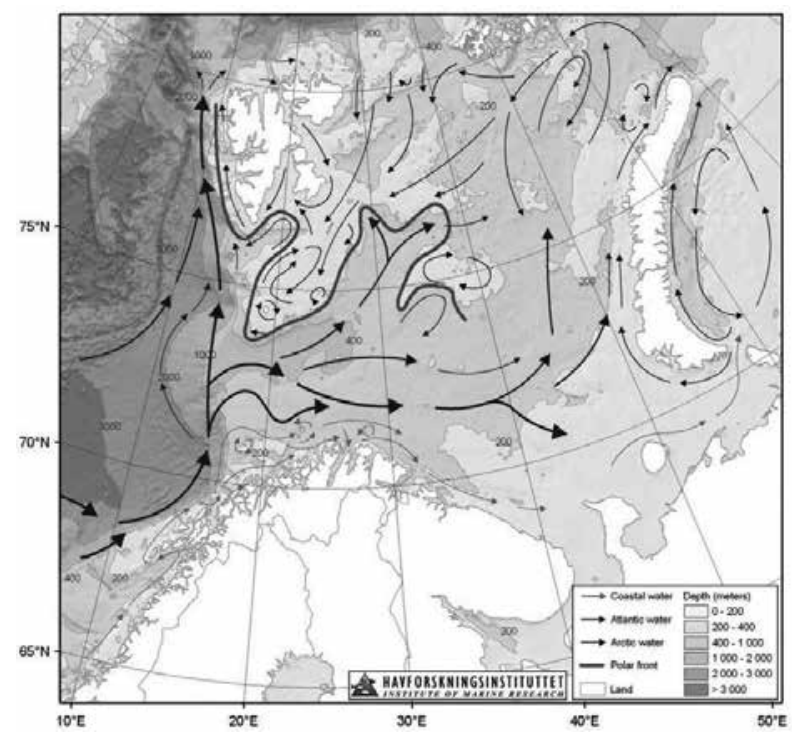

Figure 2. The main features of the circulation and bathymetry of the Barents Sea [2]. 
(e.g., Franz Victoria Trough) and western (e.g., Bear Island Trough) continental shelf break. These western troughs allow the influx of Atlantic waters to the central Barents Sea. The Barents Sea is shared between Russia and Norway, and there is long history of relatively successful cooperation in fisheries management, even during periods that were otherwise marked by political tensions [1].

The Barents Sea is home to the most productive commercial fisheries in the Pan-Arctic Region (Figure 2).

\section{Fisheries}

\subsection{Benthos and shellfish}

The sea floor is inhabited by a wide range of organisms. Some are buried in the sediments, others are attached to a substrate, some are slow and sluggish, and others are roving and rapid. More than 3050 species of benthic invertebrates inhabit the Barents Sea [3]. The benthic ecosystems in the Barents Sea have considerable value, both in direct economic terms and in their ecosystem functions. Scallop, shrimp and king crab are harvested in the region. Snow crab may be regarded as a potential commercial species in the Barents Sea. Many species of benthos, such as sea cucumber, snails and bivalves, are also of interest for bio-prospecting or as a potential food resource. Important fish species such as haddock, cod, catfish and most flatfishes primarily feed on benthos. Many benthic animals, primarily bivalves, filter particles from the ocean and effectively remove particulate matter from the water column. Others scavenge on dead organisms, returning valuable nutrients to the water column. Detritus feeders and other active diggers regularly move the bottom sediments around and therefore increase sediment oxygen content and overall productivity-much like earthworms on land.

The decline in the total biomass of benthos, from 1924-1935 to 1968-1970 [4], occurred throughout most of the Barents Sea and has been attributed to climate change by many investigators. The mechanism behind this biomass reduction is not clear, however.

The northern shrimp (Pandalus borealis) is distributed in most deep areas of the Barents Sea and Spitsbergen waters. The densest concentrations are found in depths between 200 and 350 meters. This species mainly feeds on detritus but will also scavenge for food. It is also important as a food item for many fish species and seals.

Red king crab (Paralithodes camtschatica) was introduced to the Barents Sea in the 1960s. Presently, it is an important commercial species. Adult red king crabs are opportunistic omnivores.

The snow crab (Chionoecetes opilio) is an invasive species deliberately introduced to this region. The first recordings of this species in the Barents Sea were in 1996. Since 2003, snow crab have been found in the stomachs of cod, haddock, wolffish and thorny skates, indicating that the crab abundance and settlement density have substantially increased. 
The Iceland scallop (Chlamys islandica) is a slow-growing species common in all shallow areas $(<150 \mathrm{~m})$. It is usually associated with hard bottom substrate and most commonly in areas with strong currents [5]. The scallop is a filter feeder and is therefore highly dependent on seasonal phytoplankton production, which also has impacts on its growth [6]. The lifespan is 30 years and above.

There are eight species of squid inhabiting the Barents Sea [7]. The flying squid Todarodes sagittatus was a significant fishing resource in Norwegian waters during several periods up to1988 [8]. However, since then it has been almost absent from the waters and only sporadic catches have been recorded. Gonatus fabricii is another abundant squid species in the off shore waters of the Barents and the Norwegian Sea [9]. This species is important food for several bird and cetacean species, but could probably also be seen as a potential fishing resource.

\subsection{Fish}

More than 200 fish species are registered in trawl catches during surveys of the Barents Sea, of which nearly 100 occur regularly. The different water masses, together with bottom type and depth, are important factors determining the distribution of fish species. For pelagic species, the distribution and abundance of zooplankton are additionally important factors. The most important demersal fish species include Northeast Arctic cod (Gadus morhua), Northeast Arctic haddock (Melanogrammus aeglefinus), saithe (Pollachius virens), redfish (Sebastes mentella and S. norvegicus), Greenland halibut (Reinhardtius hippoglossoides), long rough dab (Hippoglossoides platessoides), wolffish (Anarhichas lupus, A. minor and A. denticulatus) and European plaice (Pleuronectes platessa), while the important pelagic species are Barents Sea capelin (Mallotus villosus), polar cod (Boreogadus saida) and immature Norwegian spring-spawning herring (Clupea harengus). In some warm years, increased numbers of young blue whiting (Micromesistius poutassou) have migrated into the Barents Sea. There have been large variations in abundance of most of these species. These variations are due to a combination of fishing pressure and environmental variability.

The recruitment of the Barents Sea fish species has shown a large year-to-year variability [2]. This variability in recruitment causes large variations in the biomass of pelagic forage fish, which are all either short-lived (capelin and polar cod) or spend only a short part of their lifespan in the Barents Sea (herring). The most important reasons for the recruitment variability are variations in the spawning biomass, hydrographic conditions, changes in circulation pattern, food availability and predator abundance and distribution. Recent work on larval drift has shown that even small changes in spawning locations can have a large impact on the drift pattern of fish larvae. Vikebø et al. [10] and Opdal et al. [11] investigated the drift of cod and herring eggs and larvae spawned at different locations along the Norwegian coast. Results showed that spawning further offshore and more to the south gave a much higher possibility for the larvae to end up west of Svalbard. By contrast, more northern spawning resulted in a higher proportion of larvae entering the Barents Sea. Also, retention of the larvae was affected by spawning site, and hence, the development stage for larvae when they reach the entrance to the Barents Sea. A report on the knowledge base in the Lofoten area showed that about $70 \%$ of the egg, larvae and juvenile stages of the total commercial stocks (measured in catch biomass) 
in the Norwegian and Barents Sea pass by the Lofoten--Vesterålen area. About $12 \%$ of the total stocks (measured in catch biomass) spawn in the Barents Sea. The Lofoten-Vesterålen area is therefore a vulnerable key area for the recruitment to the commercial stocks in the Norwegian and Barents Sea [2].

Cod is the most important predator among fish species in the Barents Sea. It feeds on a wide range of prey, including larger zooplankton, most available fish species, including their own juveniles, as well as shrimp [2]. Cod prefer capelin as prey, and fluctuations of the capelin stock may have a strong effect on growth, maturation and fecundity of cod, as well as on cod cannibalism and hence recruitment to the stock. The role of euphausiids in the cod diet increases in the years when capelin stock is at a low level [12]. Also, according to Ponomarenko [13], inter-annual changes in euphausiid abundance are important for the survival of cod during the first year of life.

Capelin is an important consumer of zooplankton biomass produced near the ice edge. Farther south, capelin is the most important prey species in the Barents Sea as it transports biomass from northern to southern regions [14]. The Barents Sea capelin stock underwent drastic changes in stock size during the last three decades. Three stock collapses occurred in 19851989, 1993-1997 and 2003-2006, and data from 2015 suggest that the capelin may be headed towards a fourth collapse. The collapses had effects both downwards and upwards in the food web [15]. The release in predation pressure from the capelin stock led to increased amounts of zooplankton during the two first collapse periods. When capelin biomass was drastically reduced, its predators were affected in various ways. Cod experienced increased cannibalism, growth was reduced, and maturation delayed during the first capelin collapse. Sea birds experienced increased rates of mortality and total recruitment failures, and breeding colonies were abandoned for several years. Harp seals experienced food shortage and increased mortality because they invaded the coastal areas and were caught in fishing gears and because of recruitment failures. There is evidence for differences in how the three capelin collapses affected the predators. The effects were most serious during the 1985-1989 collapse, but much less during the second and third collapse. This was probably related to increased availability of alternative food sources during the two last periods of collapse.

Herring is also a major predator on zooplankton. The herring spawns along the Norwegian western coast, and the larvae drift into the Barents Sea as well as into fjords along the coast. The juveniles of the Norwegian spring-spawning herring stock are distributed in the southern parts of the Barents Sea. They stay in this area for about three years before they migrate west and southwards along the Norwegian coast and mix with the adult part of the stock. The presence of young herring in this area has been described to have a profound effect on the survival of capelin larvae and therefore on the recruitment to the capelin stock. The three collapses during the last three decades were all caused by recruitment failures, and all three were associated with rich herring year classes inhabiting the Barents Sea. However, while the presence of herring is seemingly a necessary factor for total recruitment failures of the capelin stock, it is not the only factor, since in some years the capelin recruitment has been relatively good in spite of moderate to high amounts of young herring in the Barents Sea. 
Haddock is also a common species and migrates partly out of the Barents Sea. The stock has large natural variations in stock size. Water temperature at the first years of the life cycle may be used as an indicator of year class strength. Food composition of haddock consists mainly of benthic organisms.

Saithe is found mainly along the Norwegian coast, but also occurs in the Norwegian Sea and in the southern Barents Sea. The 0-group saithe drifts from the spawning grounds to inshore waters. The smaller individuals feed on crustaceans, while larger saithe depend more on fish as prey [16]. The main fish preys are young herring, Norway pout, haddock, blue whiting and capelin, while the dominating crustacean prey is krill.

Polar cod is a cold-water species found particularly in the eastern Barents Sea and in the north. It seems to be an important forage fish for several marine mammals, but to some extent also for cod. There is little fishing of this stock, and relatively little fisheries data. However, it is clear that the stock abundance is in decline.

Deep-sea redfish and golden redfish are important elements in the fish fauna in the Barents Sea, but due to heavy over-fishing, these stocks declined strongly during the 1980s and have since then stayed at a low level. Young redfish are plankton eaters, but larger individuals take larger prey, including fish.

Greenland halibut is a large fish predator with the continental slope between the Barents Sea and the Norwegian Sea as its most important area. It is also found in the deeper parts of the Barents Sea and the continental shelf. Investigations in the period 1980-1990 showed that cephalopods (squids, octopuses) dominated in the Greenland halibut stomachs, as well as fish (mainly capelin and herring). Ontogenetic shift in prey preference was clear with decreasing proportion of small prey (shrimp and small capelin) and increasing proportion of larger fish with increasing predator length. The largest Greenland halibut (length more than $65-70 \mathrm{~cm}$ ) had a rather large portion of cod and haddock in the diet. The stock was over-fished leading to low (though uncertain) stock abundance in the 1980s, but a partial moratorium in the early 1990s led to stock recovery, and the stock is now assessed as above limit reference points.

The blue whiting has its main distribution area in the Norwegian Sea and Northeast Atlantic, and the marginal northern distribution is at the entrance to the Barents Sea. Usually, the blue whiting population in the Barents Sea is small. In some years, the blue whiting may enter the Barents Sea in large numbers and can be a dominant species in the western areas. This situation occurred from 2001 and during 2003-2007. Since then, the abundance has decreased strongly, but showed an increase in 2012. These fluctuations are probably due to a combination of variation in stock size and environmental conditions. In the diet of blue whiting, zooplankton (copepods, hyperiids and euphausiids) is dominant in the younger age groups, while fish is increasingly important as the blue whiting gets older [17].

\subsection{Marine mammals}

Marine mammals, as top predators and keystone species, are significant components of the Barents Sea ecosystem. Twenty-five species of marine mammals regularly occur in the Barents Sea, including: seven pinnipeds (seals and walruses); 12 large cetaceans (large whales); five 
small cetaceans (porpoises and dolphins); and the polar bear (Ursus maritimus). Some of these species are not full-time residents in the Barents Sea and use temperate areas for mating, calving and feeding (e.g., minke whale Balaenoptera acutorostrata). Others reside in the Barents Sea all year round (e.g., white-beaked dolphin Lagenorhynchus albirostris and harbor porpoise Phocoena phocoena). Some marine mammals are naturally rare, such as the beluga whale Delphinapterus leucas. Others are rare due to historic high exploitation, such as bowhead whale Balaena mysticetus and blue whale Balaenoptera musculus.

Marine mammals are important predators on the commercial fish species in the Barents Sea. However, their consumption estimations are associated with high level of uncertainty. According to Folkow et al., [18] and Nilssen et al., [19], marine mammals may consume up to equally much or even more fish than those caught in fisheries. Minke whales and harp seals have the largest consumptions and may together consume around 5 million tons annually of crustaceans, capelin, herring, polar cod and other gadoid fish (cod, haddock, saithe) [2]. Functional relationships between marine mammals and their prey seem closely related to fluctuations in marine ecosystems. Both minke whales and harp seals are thought to switch between krill, capelin and herring depending on the availability of the different prey species $[20,21,19]$.

The only marine mammal species commercially harvested in the Barents Sea are harp seals and minke whale. Harp seal pup production estimates are based on data collected during the traditional Russian multispectral aerial survey. Since 2004, the abundance of harp seal pup production in the White Sea has been sharply reduced, according to these surveys. One of the key factors which caused the reduction in the harp seal pup abundance in the last years is the diminished ice extent due to warming. The changed ice conditions were responsible for the redistribution of animals in the pup period. Abnormal ice conditions in the White Sea possibly also led to higher natural mortality of pups.

\section{Fisheries assessment}

The benchmark assessment for North East Atlantic (NEA) cod was done in 2015 [22]. The assessment advised continuation of use of the Extended Survivors Analysis (XSA) model as a main tool for NEA cod assessment. Some changes in model configuration were recommended.

The main model used for assessment of key stocks is the Extended Survivors Analysis (XSA) $[23,24]$. The model is generally fitted to the catch at age and natural mortality data and works similarly to most typical Virtual Population Analysis (VPA) back-calculating models. The backcalculations in these implementations work the same way, but they differ in the statistical methods used for "tuning" to indices of population size.

For North East Atlantic cod, saithe, the XSA was used as the main assessment method. For Norwegian Coastal cod, the "separable VPA" (SVPA) model proposed by [25] was used. This model assumes that fishing mortality can be separated into an annual component common to all ages of a same year and into a component at age common to many years. According to this 
model, fishing mortality in year $i$ and age $j$ or $f(i, j)$ is defined as follows: $f(i, j)=F(i) \times S(j)$ where $\mathrm{F}(\mathrm{i})$ represents fishing mortality for year $\mathrm{i}$ and $\mathrm{S}(\mathrm{j})$ the exploitation pattern or selectivity at age j.

Haddock and beaked redfish (Sebastes mentella) are both assessed using statistical catch-at-age (SCAA) models. In contrast to the VPA methods, SCAA is a forward calculation method and is becoming more widely used throughout ICES fisheries with the introduction of the SAM (REF) model, which is used for haddock in the Barents Sea.

Where age data are uncertain or absent, an alternative model, the age- and length-structured Globally Applicable Area Disaggregated General Ecosystem Toolbox model or GADGET, is used for assessment. The model is currently used for the golden redfish, Sebastes norvegicus, and Greenland halibut.

\section{Arctic Atlantic-Norwegian Sea, Iceland and Greenland Sea}

\subsection{Fisheries}

\subsubsection{Norwegian Sea}

The Norwegian Sea is a deep open ocean system, covering around 1.1 million $\mathrm{km}^{2}$ extending from the Norwegian coast and the continental slope west of the Barents Sea out into the open Atlantic, as far west as the Iceland Sea and Jan Mayen, and bounded to the south by the North Sea. The area covers two separate deep water basins, the Norwegian and Lofoten basins, with water depths of 3000-4000 m, while the shallower water is dominated by the Norwegian Atlantic current branch of the Gulf Stream [26]. As a result of this steady influx of warm water, the area, although mostly in the Arctic, is largely free of sea ice, and the zooplankton is dominated by Calanus finmarchicus, which in turn supports large pelagic stocks. In contrast with many of the other systems described here, there exists a sizable area outside national territorial waters, the so-called "banana hole," in the gap between the 200-nm zones extending east from Jan Mayen and west from the Norwegian coast. Fisheries in the Norwegian Sea are primarily targeted at three large wide-ranging pelagic stocks: Norwegian spring-spawning herring (Clupea harengus), mackerel (Scomber scombrus) and blue whiting (Micromesistius poutassou), with a limited amount of horse mackerel (Trachurus trachurus) in the south. The region also has a high biomass of squid. There are several abundant pelagic stocks that span both the Norwegian and Barents Seas, notably the Norwegian spring-spawning herring which use the Barents Sea as a nursery area before moving to the Norwegian Sea at about age 3 or 4 , and the beaked redfish which is caught in both the Norwegian and Barents Seas. The mackerel and blue whiting in the Norwegian Sea represent the northern extreme of stocks ranging down to the Iberian peninsula. There are thus significant connections between the Norwegian Sea and adjacent ecosystems, and consequently, much of the stock assessments are conducted on a wider scale than the Norwegian Sea alone. The seabed of the main basins is dominated by deep water benthos, while along the continental shelf closer to the Norwegian coast are a 
number of cold-water coral reefs. These corals are slow growing and support a high biodiversity and receive protection in the form of exclusion areas for bottom trawlers. The minke whale population described in the Barents Sea section passes through the Norwegian Sea on its migration route, and a fraction of the stock remains in the Norwegian Sea to feed in the summer, while the remainder continues to the Barents Sea, possibly based on the biomass of herring encountered en route [27]. Other main marine mammal predators in the region are larger whales, including humpbacks, blue whales and fin whales, as well as several species of dolphins, notably white-beaked (Lagenorhynchus albirostris) and white-sided (Lagenorhynchus acutus) dolphins, as well as harp and hooded seals. In addition to the top-down forcing imposed by the marine mammal predators, there is considerable bottom-up forcing arising from multiple large pelagic stocks feeding largely on the same plankton resource (Skjoldal et al. 2004). The recent large biomasses of mackerel and blue whiting are associated with a decline in the biomass of zooplankton.

The main fisheries target wide-ranging pelagic, and the assessment and management of these species are therefore conducted through an international ICES WG on widely dispersed species, WGWIDE [28], extending beyond the Norwegian Sea. In 2014, 13 countries reported catches of over 9000 tonnes of mackerel (with the Faroes, Greenland, Iceland, Ireland, Norway, Russia and the UK all reporting catches of over 75,000 tonnes) out of a catch of 1.4 million tonnes, 7 countries reported over 9000 tonnes of NSS herring (with the catch dominated by Norway and Russia) out of a total of 460,000 tonnes, and 11 countries reported over 9000 tonnes of blue whiting (dominated by the Faroes, Iceland, Norway and Russia) out of a catch of 1.15 million tonnes. Although discards are believed to exist, they are highly variable with either 0 or $100 \%$ discards when the entire haul is discarded. As a result, estimates of discards are difficult to compile and considered inadequate by the WG (although believed to be low for blue whiting).

Both mackerel and blue whiting are assessed with the SAM catch-at-age model [29]. Norwegian spring-spawning herring has been assessed with a VPA model, although at the time of writing, an ongoing benchmark process is reviewing the choice of assessment model.

The mackerel stock ranges from the Iberian coast to the northern Norwegian Sea and supports a highly valuable fishery. Although line fisheries exist in the south, the Norwegian Sea fishery is based on freezer trawlers, pelagic trawlers and purse seine vessels. The assessment is based on catch-at-age data, a recruitment index from the IBTS surveys in the North Sea, the Norwegian Sea ecosystem survey (IESSNS) and an SSB index derived from an egg survey, as well as tag recapture data. There is considerable uncertainty in the assessment of the stock, with the perception of the stock changing between assessments. In the absence of an agreed management plan, ICES gives advice on a MSY basis. Following the expansion of the mackerel stock into Icelandic and Faroese waters, no general agreement has existed between the main states catching the mackerel on distribution of the quota since 2009, and consequently, the sum of the declared quotas in 2015 was 1.24 million tonnes, which was 330 thousand tonnes above scientific advice.

The blue whiting stock also ranges widely in the East Atlantic, with the Norwegian Sea believed to be the key nursery area. The assessment showed a significant downward revision in 2015 
in accordance with a reduction in the survey index. The assessment is considered to have high, but non-quantifiable uncertainties. The stock is managed with an ICES-approved precautionary HCR agreed between the EU, Norway, the Faroes and Iceland, and catch in 2014 was slightly below the advised quotas. The bulk of the catch comes from large pelagic trawlers (although demersal trawlers also target blue whiting in the Norwegian Sea), with $92 \%$ of the catch being taken in the first half of the year. The Norwegian Sea forms the main nursery area for the stock; however, most of the catches occur further south.

In contrast to the other main pelagic stocks, the NSS herring is largely confined to Norwegian Sea and adjacent Icelandic and Faroese waters, except for the nursery area in the Barents Sea (which is not subject to a commercial fishery). The management of the fishery is thus controlled by Norway and Russia, and a long-term management plan has been in place since 1999. The plan has been evaluated by ICES and found to be precautionary. Following a collapse to $0.1 \%$ of its previous SSB in the late 1960s, the Norwegian spring-spawning herring retreated to the Norwegian coast. However, an exceptionally large year class in 1983 led to the stock recovering and resuming a widely distributed habit, with spawning grounds near the Norwegian coast and feeding throughout the northern Norwegian Sea. A series of poor year classes led to a decline in the stock, to the extent that the 2015 assessment estimated the stock to be below the Bpa of 5 million tonnes, although predicted to stabilize above Blim. The fishery follows the annual migration of the stock. A fishery begins in January on the spawning aggregation near the Norwegian coast, no spring fishery, a summer fishery in Icelandic and Faroese waters and around Jan Mayen and Svalbard, and finally a fourth quarter fishery (taking the largest fraction of the catch) in the eastern Norwegian Sea. The Norwegian fleet is dominated by purse seiners $(92 \%)$ and pelagic trawlers (8\%), while the Russian fleet is a variety of trawl vessels. Within the Norwegian-administered Norwegian Sea, a minimum catch size of $25 \mathrm{~cm}$ restricts the fishery to largely targeting mature individuals.

In addition to the fisheries described above, a small developmental catch exists for Calanus finmarchicus. The Calanus is pressed to extract the oil, which is marketed as an omega-3 supplement, highlighting that as a species with low trophic level, the oil is unlikely to have accumulated pollutants. The remaining mass is sold as fishmeal. Although the fishery is profitable at the current small scale, and a harvest of $1 \%$ of the stock could produce in excess of 2 million tonnes of marine oils and protein [30], it is unclear whether the fishery could be commercially viable if it expanded beyond the relatively small market for omega- 3 supplements.

\subsubsection{Icelandic Waters}

Although Iceland sits just below the Arctic Circle, the EEZ covers $758,000 \mathrm{~km}^{2}$ and extends into the Arctic and adjoins Greenlandic waters to the west and the Norwegian Sea and Faroese waters to the north and east. Fisheries are of critical importance to the Icelandic economy. The country was one of the first to claim a 200-nm economic zone, and total landings in 2014 were 1017 tonnes - for a population of 323,000. Seafood exports represent $41 \%$ of total export value, and the fisheries and related industries comprise 25\% of GDP in 2014. By far, the most economically important component of the fishery is on the cod stock, representing over a one- 
third of the value of the exported seafood, and the 2015-2016 quota of 239,000 tonnes equates to almost $3 / 4$ of a ton of cod per Icelander.

The extensive EEZ ensures that many stocks are largely or wholly within Icelandic waters. The major exception is a mixed pelagic fishery in the east, catching NSS herring, mackerel and blue whiting from the margins of the stocks in the Norwegian Sea (see above), as well as an Icelandic herring stock. The ocean redfish (principally S. mentella and S. norvegicus) extends into international waters and is regulated by NEAF. This is divided into several stocks as well as two species, although there is a dispute as to the number of biological stocks, and ICES advice is to avoid "disproportional exploitation rate of any one component." The other major fisheries are on cod, haddock and capelin, with Greenland halibut, ocean wolfish, plaice, shrimp and lobster also caught.

In addition to large vessels, the fishing sector is managed to encourage small boats $(<15 \mathrm{~m})$ to participate in the commercial fishery by allocating a fraction of the total quota to this sector, reflecting the importance of fishing as a source of employment. The main gears used for demersal fishing are bottom trawls, longlines, gillnets and Danish seines, while mid-water trawls and purse seines are the main pelagic gears.

A wide variety of stock assessment methods are used, depending on the stock biology and data availability, ranging from detailed analytic modeling to qualitative measures for some redfish stocks. For most stocks, a TAC is set based on either a MSY approach or an explicit HCR. For capelin, an escapement strategy is used. In addition to the stocks described in the Norwegian Sea section, the following assessment models are used for the major Icelandic stocks.

ADAPT-type models are used for the Icelandic herring stock and the haddock. Cod is assessed with a statistical catch-at-age model (implemented in AD model builder). Capelin uses a shortterm forecast model to project from survey estimates to SSB, taking into account predation from cod, haddock and saithe, in order to set an escapement strategy TAC such that the final SSB in 95\% likely to be above Blim. Greenland halibut uses a Baysean surplus production model. The GADGET age and length-structured model is used to provide assessment for golden redfish (S. norvegicus), tusk (Brosme brosme) and ling (Molva molva), where the ability to use length data directly is considered valuable. Other redfish (multiple S. mentella stocks) are assessed using qualitative or survey-based methods in the absence of more reliable data.

\subsubsection{Greenland Sea}

The Greenland Sea is bounded by Greenland, the Arctic Ocean, Svalbard, the Norwegian Sea, Iceland, and the Denmark Strait to the south (Figure 3). The cold and deep (>2000 m) Greenland Sea is separated from the deep and warmer southern Irminger Sea by a relatively shallow (maximum depth of $630 \mathrm{~m}$ ), east-to-west-oriented submarine sill in the Denmark Strait. Along with the Norwegian Sea, it forms the Arctic Ocean's main outlet to the Atlantic. On the shelf area north of this sill, the hydrographical conditions are dominated by the cold southwardflowing East Greenland Current (EGC) which, to a large extend, is composed of Norwegian Deep Water with temperatures often below $0^{\circ} \mathrm{C}$ [31]. The EGC is formed in the Arctic by the 
cooling of warmer northerly flowing North Atlantic Water (NAW) that is taken into the Arctic by the Norwegian Atlantic Current. Warmer water enters the Greenland Sea Gyre where it undergoes cooling through contact with the Arctic Ocean and associated sea ice. Most part of the Greenland Sea falls under ICES area of North East Atlantic Fisheries Commission (NEAFC) $\mathrm{XIVa}$ and IIb2. The ICES provides scientific advice for fisheries in the area through its advisory committee which is used by the relevant management authorities, e.g., NEAFC.

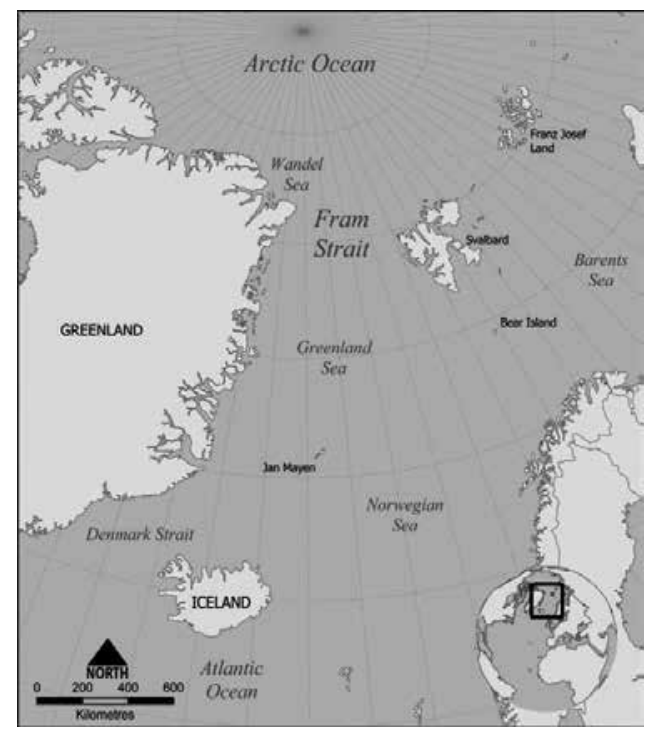

Figure 3. Arctic Atlantic: The Greenland Sea, Iceland and Norwegian Sea.

Arctic zooplankton produced in Greenland Sea migrates with the sea currents into the Iceland and Norwegian Seas and contributes to the feeding for the large stocks of pelagic fish [40]. In the past decades, the Greenland Sea has experienced warmer temperatures due to increased influx of North Atlantic water [32] which may have a significant influence on the anticipated yields of commercial species in this area. Cheung [33] has projected $15-45 \%$ increases in maximum catch potential in Greenland Sea between 2005 and 2050. Greenland halibut (Reinhardtius hippoglossoides), red fish (Sebastes spp.), Arctic cod (Boreogadus saida), herring (Clupea harengus), blue whiting (Micromesistius poutassou), tusk (Brosme brosme) and capelin (Mallotus villosus) are important commercial fish species in Greenland Sea and adjacent areas. Capelin was historically the largest fish stock in the adjacent Iceland Sea area. However, since the mid-2000s, there is a decline in its recruitment and stock size probably due to an increase in the inflow of Atlantic water [34].

\subsection{Fish and fisheries}

The total number of fish species known from the Greenland exclusive economic zone (EEZ) is 269 , whereas the lowest numbers of fish species with 47 are observed in the northeast of Greenland in the Greenland Sea [35]. 
Fisheries targeting marine resources off Greenland can be divided into inshore and offshore fleets. The majority of the Greenland fleet is comprised of approx 450 larger vessels and a big fleet of small boats. It is estimated that around 1700 small boats are dissipating in some sort of artisanal fishery mainly for private use or in the pound net fishery [36]. In East Greenland, fishing and other anthropogenic activities take place mainly in the southern parts.

The inshore fleet is constituted by a variety of different platforms from dog sledges used for ice fishing to small multipurpose boats engaged in whaling or deploying passive gears such as gillnets, pound nets, traps, dredges and longlines. The main targeted species are shrimp (Pandalus borealis), Atlantic cod (Gadus morhua), lumpfish (Cyclopterus lumpus), snow crabs (Chionoecetes opilio) and salmon (Salmo salar). The coastal fleets fishing for Atlantic cod, snow crab, scallops and shrimp are regulated by licenses, TAC and closed areas. Fishery for salmon and lumpfish is unregulated [36].

Apart from the Greenland fleet, the marine resources in Greenland waters are exploited by several nations, mainly EU, Iceland and Norway using bottom and pelagic trawls as well as longlines. The demersal offshore fishery is comprised of vessels primarily fishing Greenland halibut (Reinhardtius hippoglossoides), shrimp, redfish (Sebastes mentella and S. norvegicus) and Atlantic cod. Greenland halibut and redfish have been targeted since 1985 using demersal otter board trawls [36]. Longliners are operating on both the east and west coast with Greenland halibut and Atlantic cod as targeted species. Bycatches include roundnose grenadier (Coryphaenoides rupestris), roughhead grenadier (Macrourus berglax), tusk (Brosme brosme), Atlantic halibut (Hippoglossus hippoglossus) and Greenland shark (Somniosus microcephalus) (Gordon et al. 2003). The pelagic fishery in Greenland waters is conducted in East Greenland and currently targeted species are Atlantic mackerel (Scomber scombrus) and pelagic redfish (Sebastes mentella). A relatively small fishery for herring (Clupea harengus) is carried out in the border area between Greenland, Iceland and Jan Mayen. Additionally, Arctic cod (Boreogadus, saida), blue whiting (Micromesistius poutassou) and capelin (Mallotus villosus) are caught by the commercial fishery in the Greenland Sea and adjacent areas.

The main area of the Greenland Sea is part of divisions XIVa and IIb of the International Council for the Exploration of the Sea (ICES) and part of the convention area of the North East Atlantic Fisheries Commission (NEAFC). ICES provides scientific advice for fisheries in the area through its advisory committee which is used by the relevant management authorities, e.g., NEAFC. The demersal and pelagic offshore fishing together with longlines is managed by TAC, minimum landing sizes, gear specifications and irregularly closed areas.

Many species of cetaceans and pinnipeds feed in the Greenland Sea during the open water including walrus (Odobenus rosmarus), ringed seal (Pusa hispida), bearded seal (Erignathus barbatus), harp seal (Phoca groenlandica), hooded seal (Cystophora cristata) and bowhead whale (Balaena mysticetus). The Greenland Sea is an important whelping ground for harp seals and hooded seals. Hooded seal stocks in the area were quite large [37] and have been subject to commercial exploitation for centuries. However, giving an estimated total population of 84,020 hooded seals in 2013, this stock is below the conservation reference point in the precautionary harvest strategy developed by ICES and since 2007, the stock is protected from commercial 
hunt [38]. In contrast, harp seal are in abundance. The 2013 total abundance was estimated to be 627,410 with harvest level of only around 6000 per year [2].

Minke whales in the Norwegian Sea belong to the same stock as those feeding in the Barents Sea. The minke whales pass through on their way to summer feeding grounds in the Barents Sea, and a fraction remains in the Norwegian Sea.

There are few fisheries in the northern part of this area. In East Greenland, fishing and other anthropogenic activities take place in southern parts of east Greenland. Only small-scale subsistence hunting and fisheries take place near Ittoqqortoormiit. There are about seven marine fish species stocks which are harvested by commercial fisheries in Greenland Sea [39], mostly near Iceland. Arctic zooplankton produced in Greenland Sea migrates with the sea currents into the Iceland and Norwegian Seas and contributes to the feeding for the large stocks of pelagic fish [40]. The east Greenland drift ice forms a unique marine habitat under climate change that is not studied yet [41]. In the past decades, the Greenland Sea has experienced warmer temperatures due to increased influx of North Atlantic water [32]. Cheung [33] has projected $15-45 \%$ increases in maximum catch potential in the Greenland Sea from 2005 to 2050.

\subsection{Fisheries assessment}

\subsubsection{Greenland halibut}

The assessment model for Greenland halibut is a stochastic version of the logistic surplus production model using a new combined survey index and an Icelandic cpue index. Reference points as derived from this model are 30\% BMSY as Blim, $1.7 \times$ FMSY as Flim and an MSYBtrigger defined as 50\% BMSY. BMSY and FMSY are inherited references in the model approach. An exploratory assessment on Greenland halibut using GADGET (Globally Applicable Area Disaggregated General Ecosystem Toolbox model) was presented in 2015.

\subsubsection{Capelin}

The assessment method is a stochastic projection of the stock starting from scientific acoustic measurements and finding the total allowable catch (TAC) that leads to the probability of the spawning stock biomass (SSB) $<$ Blim being $<5 \%$. The initial quota is expected to be revised, based on in-season acoustic survey information in the autumn. The final TAC is expected to be set on the basis of survey information in the following winter.

\subsubsection{Offshore Atlantic cod}

No stock assessment can be undertaken for this stock, due to the lack of significant rebuilding since the stock collapsed in the late 1960s. Two scientific surveys targeting cod are considered reliable indicators of the stock status. However, they are associated with large uncertainty due to single large hauls. 


\subsubsection{Golden and Beaked redfish}

GADGET is used for the assessment of golden redfish (Sebastes norvegicus) using commercial catch data and survey data from an Icelandic and a German survey. The demersal beaked redfish (Sebastes mentella) on east of Greenland and on the Icelandic slope is being assessed, based on trends in survey biomass indices from the Icelandic Autumn Survey in terms of the ICES "trends-based assessment" approach. Supplementary data used include relevant information from the fishery and length distributions from the commercial catch and the Autumn Survey.

\subsubsection{Northeast Atlantic mackerel}

The model for Northeast Atlantic mackerel is SAM, the state-space assessment model. In SAM, the "states" (fishing mortalities and abundances at age) are constrained by the survival equation and follow a random walk process. The variances of the random-walk processes on abundances and fishing mortalities are parameters estimated by the model. SAM is a fully statistical model in which all data sources (including catches) are treated as observations, assuming a lognormal observation model. The corresponding variances, the so-called observation variances, are also parameters estimated by the model. Observational variances can be used to describe how well each data source is fitted in the model and effectively corresponds to the internal weight given by the model to the difference data sources. The other parameters estimated are the catchabilities of the surveys. Uncertainties (standard errors) are estimated for all parameters and for all states (fishing mortalities and abundances at age).

\section{GREENLAND-CONTINENTAL}

\subsection{Fisheries}

The fisheries of the Greenland continent (Figure 4) are mainly subsistence and rights based on species such as Arctic char and various marine mammals such as harp seal, hooded seal and ringed seal as well as walrus, narwhal, beluga whale and bowhead whale. Rivers with Arctic char are throughout the Greenland coast, and fishing is typically by gillnets set close to shore. The Arctic char is known to spawn in winter in river outlets in South East Greenland and utilizes the coastal areas, but no comprehensive reviews have been published [42]. Little information is available regarding the total harvest and management of Arctic char in Greenland. They are an important fish in Greenland providing a food resource for Greenlanders. They are also important in terms of socio-economic value as they are of interest to tourism with anglers and fly fishing enthusiasts traveling to Greenland.

\subsection{Fisheries assessment}

As the Arctic char fisheries are prosecuted by local Greenlanders, there do not seem to be any published stock assessments. It is likely that assessments, if any, are carried out using catchbased methods. 


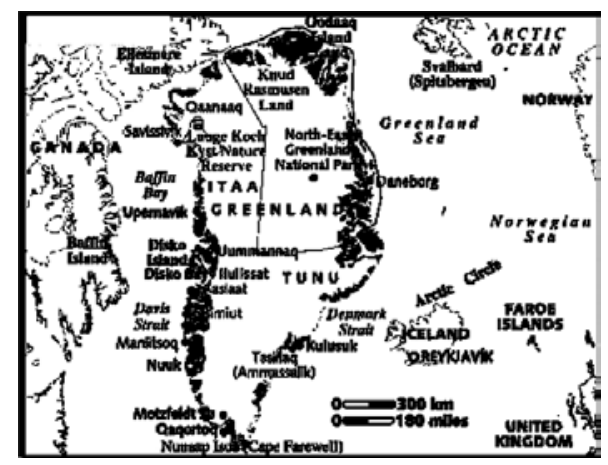

Figure 4. Iceland, Greenland, the Norwegian and Greenland Seas.

\section{Baffin Bay-Davis Strait}

Baffin Bay and Davis Strait are two large basins between Baffin Island and Greenland (Figure 5). According to Hamilton and $\mathrm{Wu}[43]$, Baffin Bay is a semi-enclosed ocean basin between Baffin Island and Greenland that connects the Arctic Ocean and the Northwest Atlantic, providing an important pathway for exchange of heat, salt and other properties between these

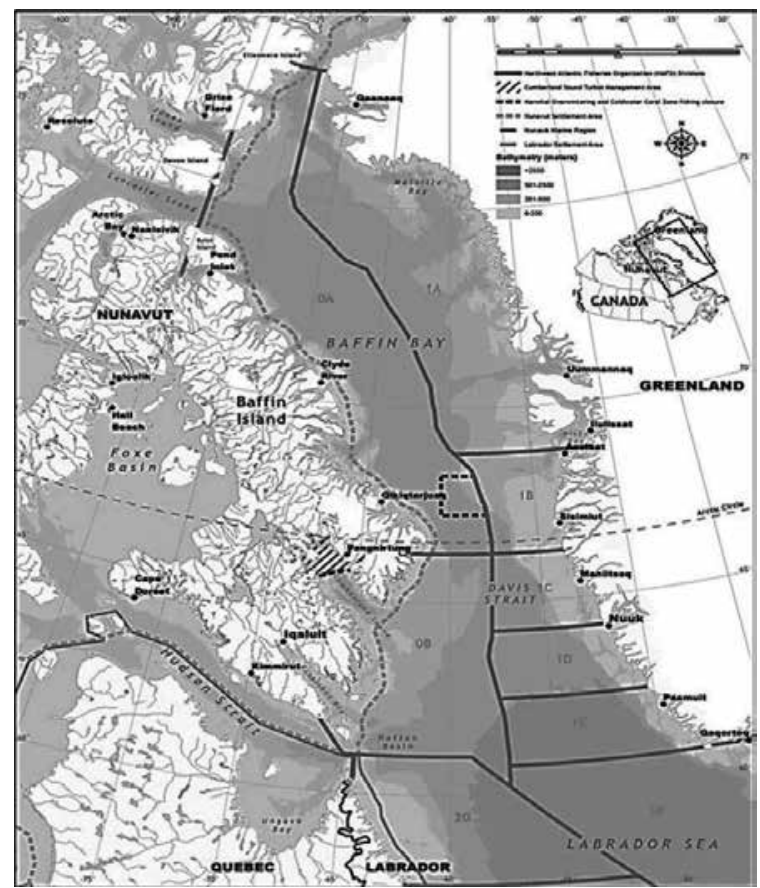

Figure 5. Map of Baffin Bay and Davis Strait. 
2 oceans. To the south, the connection with the Atlantic is through Davis Strait, which is about $300 \mathrm{~km}$ wide and $1000 \mathrm{~m}$ deep. Baffin Bay's direct connection to the Arctic Ocean is far more restricted, being just 3 relatively small passages through the islands of the Canadian Arctic Archipelago (CAA). Arctic water also enters Baffin Bay-Davis Strait via the West Greenland Current which flows northwards along the western coast of Greenland. Melting ice sheets, changing sea ice conditions and changing weather also influence oceanographic conditions in Baffin Bay and Davis Strait. Trends and variability in the freshwater and heat input into the western North Atlantic via Baffin Bay-Davis Strait is of special interest because of the potential impact this input may have on global ocean circulation. Higher volumes of lighter, fresher water entering the Labrador Sea would increase stratification, with potential impact on the thermohaline circulation. The sinking of atmospherically cooled surface water in the Labrador Sea (the northwest arm of the North Atlantic) provides one of the driving forces for the "global ocean conveyor belt" which is vital in transporting heat and salt to northern latitudes. However, freshwater entering Baffin Bay is somewhat confined to the ocean's margins as part of a cyclonic circulation pattern, a principal component being the Baffin Island Current (BIC) that flows southwards along Canada's shelf and slope. Therefore, there is a potential for changes in this freshwater flux to impact the western North Atlantic ecosystem and fisheries by altering the physical properties of productive east coast banks and slope areas.

\subsection{Fisheries}

A total of 183 species of marine fish have been recorded in Baffin Bay-Davis Strait near shore and offshore areas and Lancaster Sound region [44]. Jørgensen et al. [45] found seven assemblages of fishes in Davis Strait and the southern Baffin Bay by a standard type of cluster analysis. They found four of the assemblages in Baffin Bay, two in Davis Strait and one mainly in Davis Strait but scattered into Baffin Bay. The most important fish in the region is the Greenland halibut (Reinhardtius hippoglossoides). The area has many other species as noted by Jørgensen et al. [46] who collected 45 fish species from northern Baffin Bay between $72^{\circ} 02^{\prime}-76^{\circ} 55^{\prime} \mathrm{N}$ at depth 150-1418 m. Their surveys found two species Greenland halibut and the sea snail very common and represented in large numbers in almost all trawl hauls. Greenland halibut from Greenland, Newfoundland and Labrador spawn in the deep waters of Baffin Bay. Arctic cod (Boreogadus saida) is important species and a dominant trophic link between zooplankton and higher predators such as seals and sea birds. The capelin and herring are important forge fishes in Davis Strait. Greenland halibut and shrimp are the main commercially important fish species in the region.

\subsubsection{Greenland halibut fisheries}

Greenland halibut is the only large-scale commercial fishery in Canada's Arctic. This fishery was begun in 1996 as a small exploratory fishery but has been expanding [47]. It takes place throughout the year. Greenland halibut is caught in both inshore and offshore areas. In fjords, fish are caught by longlines either from small vessels or from the winter ice. The offshore fishery for Greenland halibut takes place in summer and autumn on the shelf slopes. On the Canadian side, NAFO Area 0 is divided into Area 0A (North, Baffin Bay) and Area 0B (South, Davis 
Strait) (Figure 6). On the Greenland side, Area 1 is divided into 1A (offshore) and 1B (Baffin Bay), and 1C, 1D and $1 \mathrm{E}$ (Davis Strait). Canada retains management authority for stocks in Subarea 0, while Greenland retains management authority in Subarea 1. NAFO Scientific Council conducts the stock assessment for the Subarea 0 and 1 for Canada and Greenland and recommends total allowable catch (TACs). Biomass, abundance, length frequency distribution and CPUE are the key metrics used in stock assessments and subsequent recommendations. The Greenland halibut fishery in western Baffin Bay is addressed by DFO's Integrated Fisheries Management Plan (IFMP) for NAFO Subarea 0 [47]. The Division 0A fishery quota is reserved exclusively for Nunavut, while the Division 0B quota is shared between Nunavut, Nunavik, Labrador, Newfoundland and Nova Scotia. Both mobile and fixed gears are used. In Area 0A, there is also a 100-t exploratory inshore quota. In 2015, the TAC is 16,000 tons in Div. 0A+ Div. $1 \mathrm{AB}, \mathrm{TAC}$ for Div. 0B+ Div. $1 \mathrm{CF}$ is 14,000 tons, and the total TAC for the area (excluding inshore areas in Div. 1A) is 30,000 tons. In 2014, total catches were 31,083 tons [48]. In both areas of 0 Division, Greenland halibut catches are around 15,000 $t$ in 2014, generating a landed value of more than $\$ 50$ million/year. Inshore Cumberland Sound fishery is also an important winter fishery near Baffin Island. This fishery began in 1986 and has been operated during the winter months using longlines through holes in the ice. In 2005, a turbot management zone was established in Cumberland Sound with a TAC of $500 \mathrm{t}$. This quota is separate from NAFO Division 0B. In 1992, these catches peaked at $430 \mathrm{t}$. However, they were declined to levels below $100 \mathrm{t}$ through the late 1990s. They peaked again to $245 \mathrm{t}$ in 2003 . However, harvest again declined significantly during the last decade because of poor ice conditions and reduced fishing effort (DFO 2008). Greenland halibut catches have averaged around 120 tonnes/year. Recently, there has been interest in a fishery in the open water season as well as exploring deeper areas (500-1000 m) in the center of Cumberland Sound, outside the winter fishing grounds and

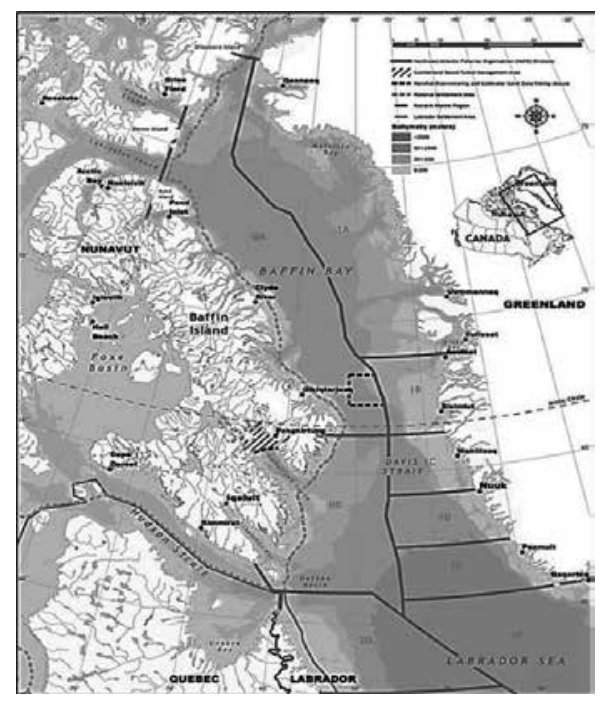

Figure 6. Northwest Atlantic Fisheries Organization Subareas and Divisions relevant to the Greenland Halibut fishery. 
expanding turbot management areas up to the mouth of Cumberland sound. Greenland sharks are common bycatch. However, estimates of shark biomass, productivity and fishing mortality are unknown. Therefore, the ability to predict impact of Greenland halibut fisheries on the Greenland shark population is limited. In the eastern Baffin Bay, Greenland halibut can be found in all waters around Greenland both offshore and inshore, but the highest concentration is in NAFO division 1A inshore [49]. An inshore fishery for Greenland halibut developed in the beginning of the twentieth century, with the introduction of the longline in 1910. The majority of inshore fishing is concentrated near cities and settlements and in areas of iceberg producing glaciers having better fish catches. At present, this inshore fishery catches are around 20,000 tons [49]. The catches in Subarea 1 (offshore 1A + Div. 1B-1F) were 16,146 tons in 2014. Catches in these areas are taken by vessels from Greenland, Norway, EU-Germany Faeroe Islands and Russia mostly by trawl netting.

\subsubsection{Northern shrimp fishery}

In Baffin Bay, the Northern shrimp (Pandalus borealis) occurs on the continental shelf off West Greenland in NAFO Divisions 0A (Canada) and 1A-1F (Greenland) in depths between 150 and $600 \mathrm{~m}$. For assessment and management purposes, the widely distributed northern shrimp population in East Canada, West Greenland and international waters in NAFO Sub-areas 0 and 1 is considered to be a single stock. Northern shrimp may represent a single metapopulation within the Northwest Atlantic, but treating fishery management and ecological relationships at a smaller spatial scale appears consistent with precautionary fishery management [50]. Shrimp Fishing Area 1 (NAFO Division 0A) is a joint Canada-Greenland stock, and its management is bilateral, and annual assessments of this stock are done by NAFO Scientific Council. During 2005-2006, shrimp catches were recorded highest up to 157,000 tons. In 2012, a joint TAC of 105,000 tons was set by the Greenland Government for Subarea 1 (Greenland) and Div. 0 A (Canada) [51]. Canada has set a separate shrimp quota east of $60^{\circ} 30^{\prime} \mathrm{W}$. Canada has set a TAC of 16,921 for its fishery in SFA1 for 2012. Canadian shrimp catches have decreased in recent years, from about 7000 tons in 2003-2005 to 1300 tons in 2011. Northern shrimp fishery management is guided by the precautionary approach and ecosystem-based management approach [52]. The shrimp fishery in Greenland is regulated by individual quotas. In in western Greenland, the fishery for northern shrimp has declined during the last decade. However, as a response to climatic changes with higher temperatures in southwest Greenland, the stock is moving further north and it is possible that the area could regain its importance for commercial shrimp fisheries [51]. Bycatch of ground fish species by the small meshed shrimp trawls is a concern for these fisheries. Two species of wolffish, Anarhichus denticulatus and Anarhichus minor listed as threatened under SARA, are a bycatch in the northern shrimp fishery. To reduce it, an exclusion device known as the Nordmore grate was introduced into the Canadian shrimp fishery. This device sorts out the larger fish, allows them to escape while retaining the smaller shrimp, and has decreased groundfish mortality remarkably. There are gear restrictions in Greenland that include a cod-end mesh size of at least 40-mm stretched, sorting grids with 22$\mathrm{mm}$ bar spacing to reduce finfish bycatch, the use of rolling rockhopper ground gear and toggle chains to keep trawl netting off the bottom [51]. 


\subsubsection{Arctic char fisheries}

Arctic char is a diverse and abundant resource in Nunavut. Its anadromous (searun) form is common in many river systems, primarily targeted by exploitation in small-scale fisheries. Several rivers flow into the Baffin Bay, Davis Strait and Cumberland Sound which support anadromous char. They spawn and over-winter in freshwater habitats, and adults normally spend the summers feeding in the marine waters of Cumberland Sound in the vicinity of their natal stream [53]. They feed in near-shore areas along the coast during the summer and migrate into fresh water during the fall. Arctic char is an important fishery in Nunavut coastal areas both for subsistence and commercial purposes. Subsistence fisheries are managed by hunters and trappers organizations, whereas Fisheries and Oceans Canada (DFO) is responsible for the management of the commercial harvest. Commercial harvest of char has been ongoing in several communities since the 1960s [54]. Combined commercial harvests in Nunavut between 2001 and 2008 have ranged between 74,124 and 95,558 kg [54]. Commercial harvest quotas are usually assigned to different rivers separately. To minimize the chances of over-exploitation, a system of exploratory licenses was set in place where a conservative quota is assigned to a river, which is then fished for five consecutive years gathering biological information on the harvested catch. These data are then used to assess the sustainability of the current harvest level. In the absence of abundance estimates, quotas are set at a conservation level using DFO precautionary approach model on the basis of best available information. Some mark recapture, weir enumeration and modeling estimates of abundance have been done in certain locations. However, their complicated migratory behavior violates many assumptions of these methods [54], and high uncertainty is associated with these results. The Cumberland Sound Arctic char commercial fisheries are operated on 17 stocks in the region [54]. All these fisheries take place in the fall during the upstream migration and utilize gillnets with 140-mm mesh size. Commercial quotas are set for each river, with none being greater than 5,000 kg [54]. Most watersheds sustaining Arctic char fisheries are fairly small, and these rivers probably support smaller populations However, no abundance estimates for these stocks have been done so far, and most of the fishery in the area is still at an exploratory phase. Although the distance between fish-bearing freshwater systems is comparatively larger, genetic data indicate that stock mixing does occur [55]. The community of Qikiqtarjuaq on western Baffin Bay traditionally harvests char from lake and river systems around Qikiqtarjuaq. Paddle Fiord, Nudluit and Confederation Fiord are important fishing areas. The quotas are usually for the areas, not for the water bodies. As compared to other Arctic char fisheries in Nunavut, very few studies have been conducted on Qikiqtarjuaq fisheries areas. Arctic char are fished from many waters close to Clyde River. There is no significant bycatch in Arctic char fisheries, and ecosystem impact of these fisheries is also negligible.

\subsubsection{Other fisheries}

The commercial fishery for snow crab (Chionoecetes opilio) was also once an important fishery in western Greenland, but its stocks are decreasing, and landings have dropped from 15,000 tons in 2002-2000 tons in 2007, and it is unlikely that a fishery for snow crab will develop in the near future in this area [56]. Snow crab are fished for using traps, but tangle nets may also 
be deployed. There are other small subsistence fisheries in near shore and fjords mostly in spring and summer.

Atlantic cod (Gadus morhua) were targeted using gillnets and trawls in West Greenland. The fishery was started in the 1920s and reached up to 400,000 tonnes per annum in the 1960s. However, due to over-fishing, the stock size declined and the fishery collapsed completely in the early 1990s. A recent survey in 2014 in West Greenland estimated at 110 million individuals with a biomass at 84,900 tons showing an increase. In 2014, the catches were $116 \mathrm{t}$. This fishery occurred in spring from March to May [36].

\subsection{Fisheries assessment}

A variety of methods are used to assess the major stocks in the Region. An Otter Trawl survey index (biomass) is the primary approach for assessment of Greenland halibut. Additionally, gillnet and longline surveys are conducted for the inshore stock of Greenland halibut in Cumberland Sound. For northern shrimp, the Northwest Atlantic Fisheries Organization uses a Bayesian model which incorporates cod predation on shrimp. For northern shrimp within Canadian waters, a survey biomass is used.

Arctic char fisheries have been assessed using trend analysis of age structure and mortality [57]. A number of modeling approaches for the assessment of Arctic char have been used including basic catch-based models such as depletion-corrected average catch, status quo models, Bayesian and life history invariant-based surplus production models [58, 59], agestructured models and zero-inflated generalized linear models (Xinhua Zhu, pers. comm.).

\section{Hudson Bay}

\subsection{Fisheries}

Cree and Inuit harvest fish during the open water season from James Bay and Hudson Bay estuarine or coastal waters (Figure 7). They do not have a tradition of offshore marine fishing. Fishing is a traditional social and cultural activity. Anadromous Arctic char are most sought after by Inuit in Nunavut and north of Kuujjuarapik in Nunavik. The reasons for its preference are predictable times and locations, growth and large size, and they are free of parasites. Further south, they harvest anadromous cisco, whitefish, longnose sucker and brook trout. Most fish are caught using gillnets set near the communities, either along the coasts or at river mouths. However, subsistence fisheries are not restricted in terms of the fishing area, season, or harvest. Capelins are also harvested when they spawn on the beaches. Subsistence harvests of cod and sculpin are much greater on the eastern side of Hudson Bay [60]. Commercially, marine fish species have not been found in sufficient quantity to support a marine fishery in Hudson Bay or James Bay. Small near-shore commercial fisheries for anadromous Arctic char have developed along the Kivalliq coasts and at Puvirnituq. There is an international standard meat-processing plant that processes fresh and frozen Arctic char for sale to domestic and international markets. This fish-processing operation has not received enough fish to consis- 
tently meet operating expenses. Transportation is a particular problem for these fisheries. Fishermen generally participate in the commercial fishery to subsidize subsistence harvests [60]. Commercial harvesting of coastal and estuarine fish especially Arctic char is also conducted by many communities along the Quebec coast during summer. Commercial harvest quotas at these locations are opened on request of the Hunters and Trappers Organizations. Commercial fisheries are closely regulated; however, over-harvesting can occur in areas with large subsistence fisheries. There is no marine trophy fishery in Hudson Bay or James Bay, and most sport angling is by local residents mostly for Arctic char.

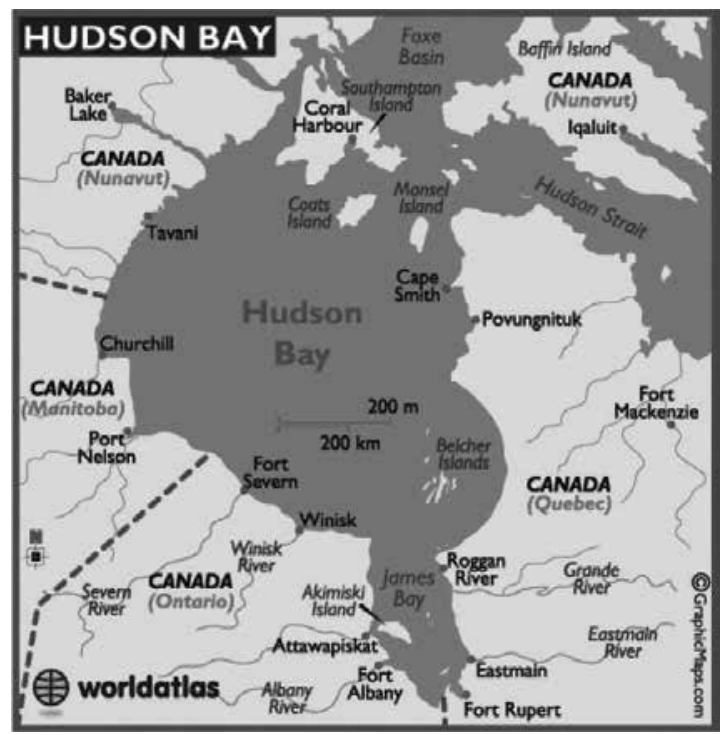

Figure 7. Hudson Bay, James Bay and surrounding territories.

\subsection{Fisheries assessment}

Fisheries assessment has mainly been using trend analysis in age structure with the exception of a virtual population analysis approach used for the last formal assessment of the Diana River stock [61] on the Kivalliq coast, but recently data-limited models have been applied to historic data [57].

\section{Canadian Archipelago and Arctic mainland}

\subsection{Canadian Arctic Archipelago}

Arctic char are distributed across the Canadian Arctic Ocean including around the islands of the Arctic Archipelago (Figure 8). While this species may also be found in many rivers and lakes located in Canada's far north, the sea-run Arctic char are the most sought after for food 
and commercial uses. Arctic char are an important cultural, subsistence and economic resource in the Arctic. A number of commercial fisheries take place in the ocean tidal waters and river waters, as well as many subsistence fisheries for Canada's Inuit. Arctic char are a highly priced delicacy, marketed mainly fresh and frozen as whole-dressed fish and steaks. A small quantity is also processed into value-added products including smoked char and jerky.

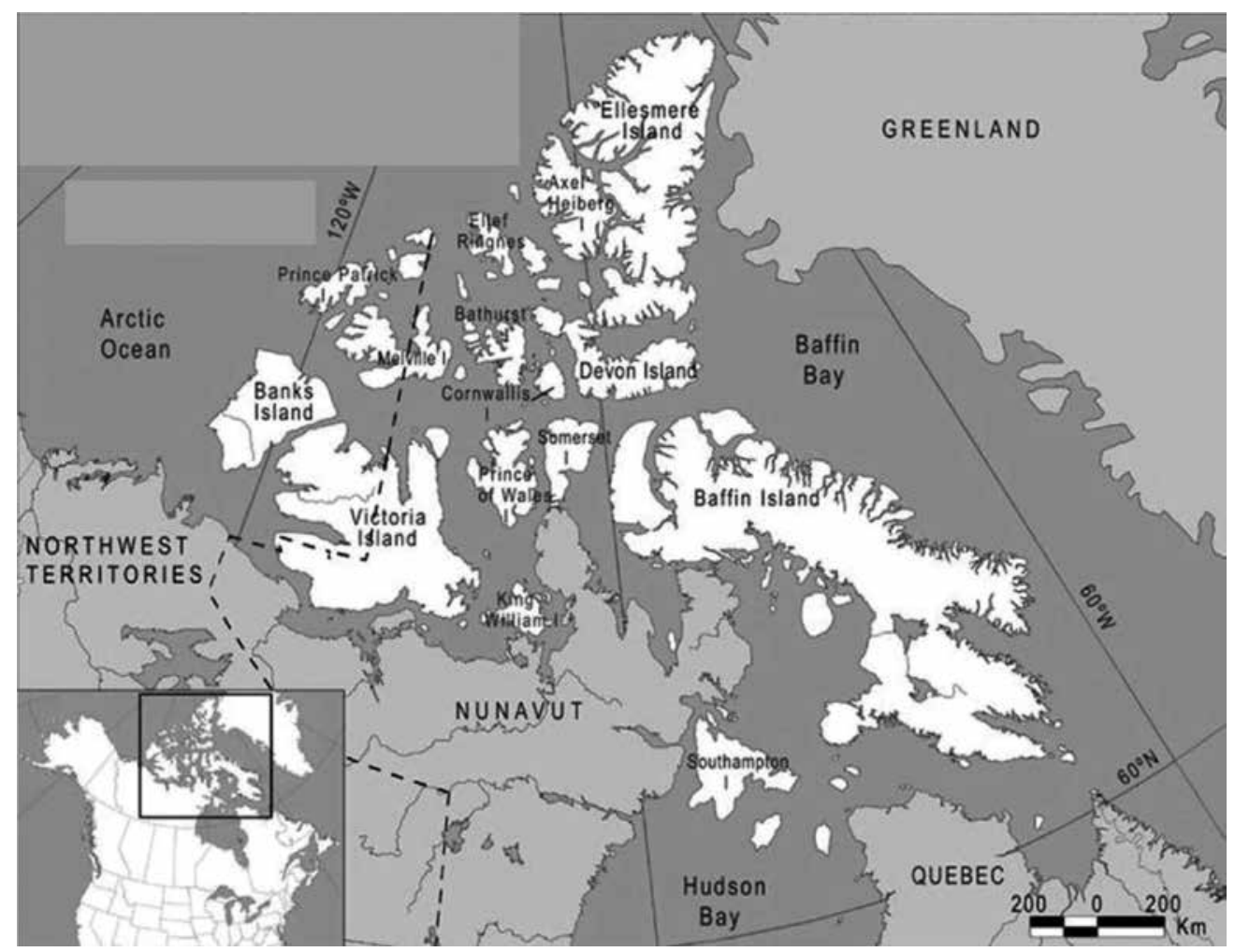

Figure 8. The Canadian Arctic Archipelago, Mainland and Hudson Bay.

Arctic char have the most northerly distribution of any freshwater fish. This species has a body shape typical of most salmonids and exhibits great variability in form and coloration. In the Cambridge Bay area, for example, spawning fish have an orange back, sides and belly, and the intensity of color is most pronounced in males. Arctic char may be anadromous, moving downstream to the sea in spring and returning in the fall or may remain permanently in freshwater.

\subsection{Fisheries}

Arctic char fisheries are important for the Inuit and in the subsistence economy of many circumpolar people. These fisheries are concentrated near communities and are predominately conducted using gillnets. In 2004, it was estimated that the subsistence harvest in the Cam- 
bridge Bay area was about $50 \%$ the size of the commercial harvest. The very first commercial fishing effort of Arctic char began in Cambridge Bay.

Fisheries are prosecuted in tow fashions using weirs (mainly at Cambridge Bay) and gillnets. Weirs may be traditional stone weirs or made using conduit pipe to form a fence guiding the char into a trap. Gillnets are typically set close to shore in the marine and estuarine areas and within lakes during the winter.

A number of commercial fisheries take place in various river systems throughout the Canadian Arctic, with the majority occurring in Nunavut such as Cumberland Sound and Cambridge Bay areas. There are also exploratory fisheries to examine potential for future commercial char fishing areas.

Commercial landings were 57 tonnes in 2012, 52 tonnes in 2011, 29.4 tonnes in 2010 and 31.8 in 2009.Value:Landed value was $\$ 186,000$ in 2012, $\$ 175,550$ in 2011, $\$ 118,000$ in 2010 and $\$ 133,367$ in 2009.

Abundance status and trends data are limited given the geographic distribution and nature of the fisheries. However, there are indications that the commercial stocks are stable.

Conservation measures: Arctic char fisheries in the Canadian Arctic are managed in cooperation with respective co-management partners. Conservation measures for commercial fisheries include minimum gillnet mesh size and total harvest levels.

The Arctic char fisheries in the Nunavut settlement area are co-managed by the DFO, the Nunavut Wildlife Management Board, Regional Wildlife Organizations, and Hunter and Trapper Organizations, in accordance with the Nunavut Land Claims Agreement, the Fisheries Act and its Regulations, and in some communities by local Hunter and Trapper Organization bylaws. This ensures that the best available information guides Arctic char fishery management decisions. Integrated Fishery Management Plans are also in development for the main Arctic char commercial fisheries.

\subsection{Fisheries assessment}

DFO scientists, external experts and fish harvesters regularly review Arctic char stock assessments, and the results are published on the Canadian Science Advisory Secretariat Web site. Although these are data-poor stocks, the biological data collected from the fishery indicate a wide range of size and ages are present, with no loss of older age classes. This suggests that current levels of exploitation are likely sustainable.

Information about the condition and status of the oceans is also collected to better understand the effect of environmental conditions on char populations. For example, research activities have assessed: char biodiversity and trophic (feeding) variation in the Canadian North and its role in ecosystem structuring and function; the thermal ecology (temperature histories) of chars and how climate change might affect these; the link between climate change and the bioaccumulation of mercury; and changes in char populations as directly observed through community-based monitoring. 
A number of approaches for the stock assessment of Arctic char have been used including basic catch-based models such as depletion-corrected average catch, status quo models), Bayesian and life history invariant-based surplus production models, age-structured models and zeroinflated generalized linear models $[58,59]$.

Commercial Arctic char fisheries in Nunavut are subject to a range of management measures designed to promote the sustainability and conservation of the char resource. Conservation measures include, but are not limited to minimum gillnet mesh size, total harvest levels and community-based monitoring. The management of these fisheries is complicated by the lack of harvesting data, the widespread distribution and biological complexity of Arctic char. New approaches using life history parameters as well as harvest and habitat information are being developed.

\section{Canadian Arctic Mainland}

\subsection{Fisheries}

Subsistence, commercial and sport fishing are important activities on Canadian Arctic Mainland, both culturally and economically. Most of commercial fisheries are confined to the lakes under some specific quota system, while subsistence fisheries are confined to rivers and stream in the vicinity of the communities. There are two distinct fishing seasons, summer and winter. In Mackenzie River Basin, fish production rate is low because of late maturity and slow growth rate [62]; however, standing stocks of large size fish are high. The remote locations of commercial fisheries in Mackenzie River Basin are a limiting factor, and most of the commercial fisheries are not viable. Because of low species diversity and low productivity, Mackenzie River Basin is less resilient to anthropogenic impacts. Commercial fisheries in Mackenzie River Basin are dominated by whitefish, and other low-value fish, e.g., burbot, suckers, are usually discarded. Lake whitefish has the ability to respond to the exploitation and is the basis of its success (Healey 1980). Reliable data on the actual fish yield from Mackenzie River Basin is lacking. Fish stocks in the Mackenzie Great Bear sub-basin have been assessed but not on a regular basis. Harvesting of different fish species by recreational and commercial fishers is regularly monitored by DFO. Great Bear Lake is world renowned for its trophy lake trout. There was a decrease in the harvest of lake trout during the 1970s up to 1980s. However, conservation measures have been adopted including catch release practice and the use of barbless hooks. The current harvest of lake trout in Great Bear Lake is below the maximum sustainable yield $[63,64]$.

Subsistence fisheries occur in the Inuvialuit, Gwich'in, Sahtu and Deh Cho areas of lower Mackenzie River Basin [65]. Broad whitefish and lake whitefish are important species in subsistence catches along with inconnu and lake cisco. The subsistence fishing has declined in recent years, due to less dependency on dogs. Because of its high productivity, the lower Mackenzie River broad whitefish is able to withstand commercial and subsistence exploitation. Broad whitefish is one of the most important species to the aboriginal subsistence fisheries in the lower Mackenzie River and Delta [66, 67]. The Fisheries Joint Management Committee 
(FJMC) works jointly with DFO to co-manage all fish, fish habitat and marine mammals within the Inuvialuit Settlement Region and directly advise the Fisheries and Oceans on fisheries issues. The committee is responsible for collecting harvest information and making recommendations on subsistence quotas for fish and harvestable quotas for marine mammals. People from the communities of Tuktoyaktuk, Aklavik, Inuvik, Ft. McPherson, Tsiigehtchic and Ft. Good Hope harvest broad whitefish for subsistence and commercial purposes. The Tetlit Gwich'in First Nation of Fort McPherson catches broad whitefish from the Peel River for domestic use [68]. Annual catches are around 10-12 thousand fish per year. Changing lifestyles and a less use of dogs for transportation have decreased the overall fish harvest [68]. The Rat River is associated with a key subsistence fishery for the Gwich'in of the Northwest Territories, the Rat River Dolly Varden char (Salvelinus malma). Rat River Dolly Varden char are a largely anadromous population, migrating from the Arctic Ocean up through the Mackenzie Delta to over-winter in the spring-fed pools of water known as Fish Hole on the headwater tributary Łuk Njik, Fish Creek [69]. Fisheries in Great Slave Lake Basin include subsistence, sport and commercial fishing. However, reliable up-to-date data are available for the water areas under commercial fisheries, for example Great Slave Lake. There are six fish management areas in Great Slave Lake with each area having its own management plan. Its east arm and certain inshore areas are closed to commercial fishing; however, east Arm is managed for a trophy lake trout fishery. Commercial fish catch in Great Slave Lake is the biggest fishery in the Mackenzie River Basin and catch about 1100 t of which $80 \%$ is lake whitefish and $10 \%$ is pike [70]. Exploitation of fish stocks in Great Slave Lake has affected fish populations in some cases, e.g., the lake trout population declined in west basin 40 years ago [71, 72]. There is a reduction in commercial fisheries since 1990 because of reduction in effort results from lifestyle changes. Information on fish stocks and harvest is not complete, and management usually adopt a precautionary approach towards management. There are also reports of reduction in inconnu populations in some of the major tributaries to Great Slave Lake (VanGerwen-Toyne et al. 2013). However, whitefish stocks and the commercial harvest of this species seem to be sustainable [72]. At present, commercial harvest is around 500 tonnes against a quota of 1800 tonnes. Eigty percentage of the catch is composed of lake whitefish with about $10 \%$ cull. Great Slave Lake Advisory Committee (GSLAC) advises DFO on fishery management issues and ensures longterm conservation of fish and fish habitat. All communities living in Great Slave Lake Basin have subsistence fisheries which are poorly monitored. Traditional knowledge surveys and recent evidence suggest that the subsistence harvest was less than $5 \%$ of the total for the commercial harvest [73].

Whitefish make up $68 \%$ of the overall subsistence catch. Kakisa and Tathlina lakes support important walleye fisheries which account for over $70 \%$ of the walleye harvested commercially each year in the N.W.T. [74]. All three important fisheries including commercial, subsistence and sport fishers are using the fish stocks in the Liard sub-basin. Watson, Frances and Simpson lakes are popular for lake trout and northern pike. Lake trout stocks are deteriorated in Watson Lake. White sucker, northern pike, burbot, walleye, lake whitefish, inconnu and Arctic grayling are important part of the subsistence fishery in the Liard sub-basin [75]. The main fishery management issues standing out in the Mackenzie River Basin include the potential for overharvesting of migratory stocks which may also be fished in other areas, the potential for 
damage to harvested fish stocks from winterkill or summer warming, and the potential for adverse impacts from the development of pipeline, transportation, mining and hydroelectric developments.

\subsection{Fisheries assessment}

A variety of assessment models and methods have been used for stock assessment. Survey and commercial catch rate indices have been used in Great Slave Lake and other fisheries. Trends in age structure and catch curve analysis is the most frequent approach, but surplus production models have been applied.

\section{Alaska}

\subsection{Fisheries}

Arctic Alaska consists of the Chukchi and Beaufort Sea coasts (Figure 9). On the Chukchi Coast, the Noatak River produces a large run of chum salmon that maintain a Kotzebue-based commercial fishery. Many thousands of anadromous Dolly Varden over-winter the lower 300 $\mathrm{km}$ of the river and spawn in some of the river's tributary streams. This system is known for the large size of its Dolly Varden, and the current state record $8.9 \mathrm{~kg}$ (19.75 lbs.) was taken in 1991 from the Noatak River. Whitefish, Arctic grayling, burbot and northern pike are resident in the Noatak River. Inconnu use the lower reaches of the river for feeding during the spring of the year, but are not known to spawn there. Both the Selawik and Kobuk rivers support spawning populations of Inconnu in their upper reaches. (http://www.adfg.alaska.gov/ index.cfm?adfg=ByAreaInteriorNorthwest.moreoverview).

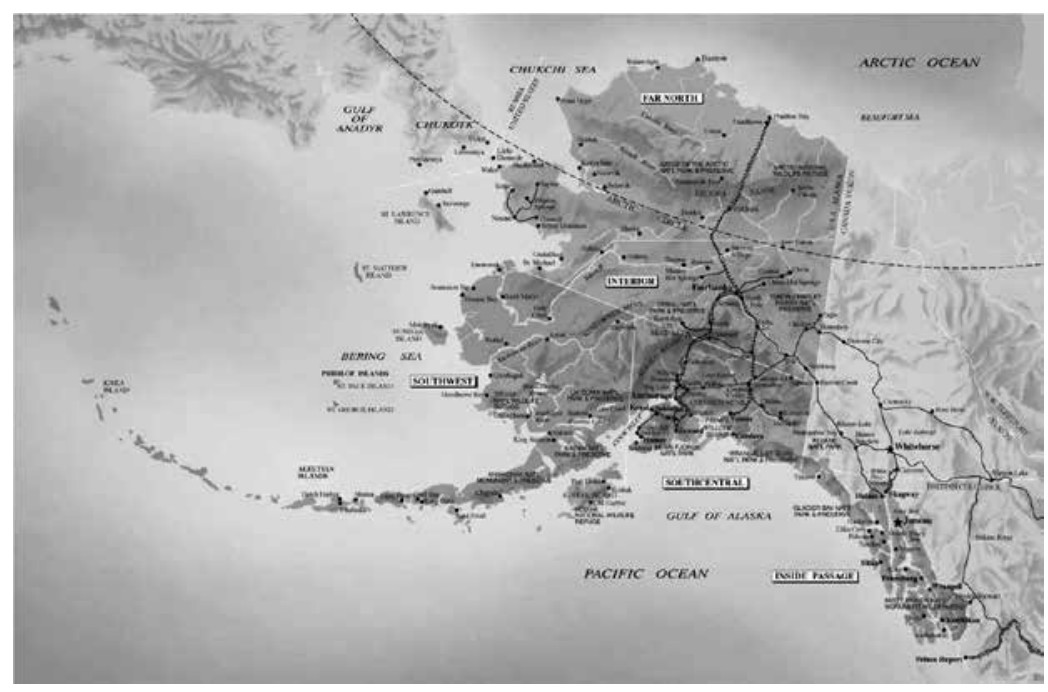

Figure 9. Continental Alaska and coastal seas. 
Rivers on the Beaufort Sea coast have stocks of Arctic char that are harvested for subsistence and sport. The largest river is the Colville River where subsistence harvesting is done using gillnets. Arctic cisco (Coregonus autumnalis) and least cisco (C. sardinella) are harvested in the Colville River Delta near Nuiqsut, Alaska, after ice forms in the fall [76]. Arctic cisco targeted by the fall fishery derive from spawning stocks in the Mackenzie River of Canada. Young-ofthe-year fish are recruited into the Colville region during August or September, aided by westerly coastal currents generated by predominantly easterly winds. In contrast, anadromous least cisco, harvested as the primary bycatch in the fishery, spawn and winter entirely in the Colville delta and lower river. Moulton et al. [76] reported on fishery monitoring for the 20year period 1985-2004. During this period, effort in the subsistence fishery showed an increasing trend. Arctic cisco, the target species, averaged over $65 \%$ of the annual observed catch, and least cisco averaged 22\%. From 1985 to 2002, total harvest of arctic cisco for the combined subsistence and commercial fisheries averaged 38,600 fish $(15,958 \mathrm{~kg})$ per year, ranging from a low of 5859 fish $(2799 \mathrm{~kg})$ in 2001 to 78,254 fish $(31,340 \mathrm{~kg})$ in 1993. During the same period, catches of least cisco averaged 18,600 fish (5819 kg), ranging from a low of 6606 fish (2014 kg) in 2001 to 33,410 fish $(11,319 \mathrm{~kg})$ in 1985 . The subsistence fishery caught $56 \%$ of the total arctic cisco harvest and $42 \%$ of the least cisco harvest (in numbers of fish). In the six years for which estimates of both harvest and population level were available, total estimated annual harvest of arctic cisco within the Colville River Delta averaged $8.9 \%$ of the available fish, with yearly estimates ranging from 5.4 to $12.9 \%$. For least cisco, the average annual removal rate was $6.8 \%$ (range $2.9-13.8 \%$ ).

\subsection{Fisheries assessment}

Assessments have used age-structured and hydro-acoustic models and environmental models in the case of Arctic cisco [77].

\section{Beaufort Sea}

\subsection{Fisheries}

The Beaufort Sea is shared by Alaska and Canada (Figure 10). On both sides, there is no commercial fishing on marine fish. Historically, there was a commercial fishery on the USA side for Arctic Cisco. The fisheries now are for subsistence with moderate harvests by Inuvialuit and Alaskan aboriginal peoples of marine mammals, Dolly Varden char, Salvelinus malma, and Arctic Cisco, Coregonus autumnalis.

History of commercial fisheries in Beaufort Sea is dated back prior to 1960s; however, an economically viable commercial fishery has not been implemented in the region. Most fisheries in the region have focused on harvesting large anadromous broad whitefish, C. nasus. These are caught by gillnets along the coast in summer or when they enter freshwater rivers to spend the winter. Broad whitefish grow to a large size and have higher-quality meat. However, because of limited local markets and high cost of transportation, a commercial fishery was not developed. 


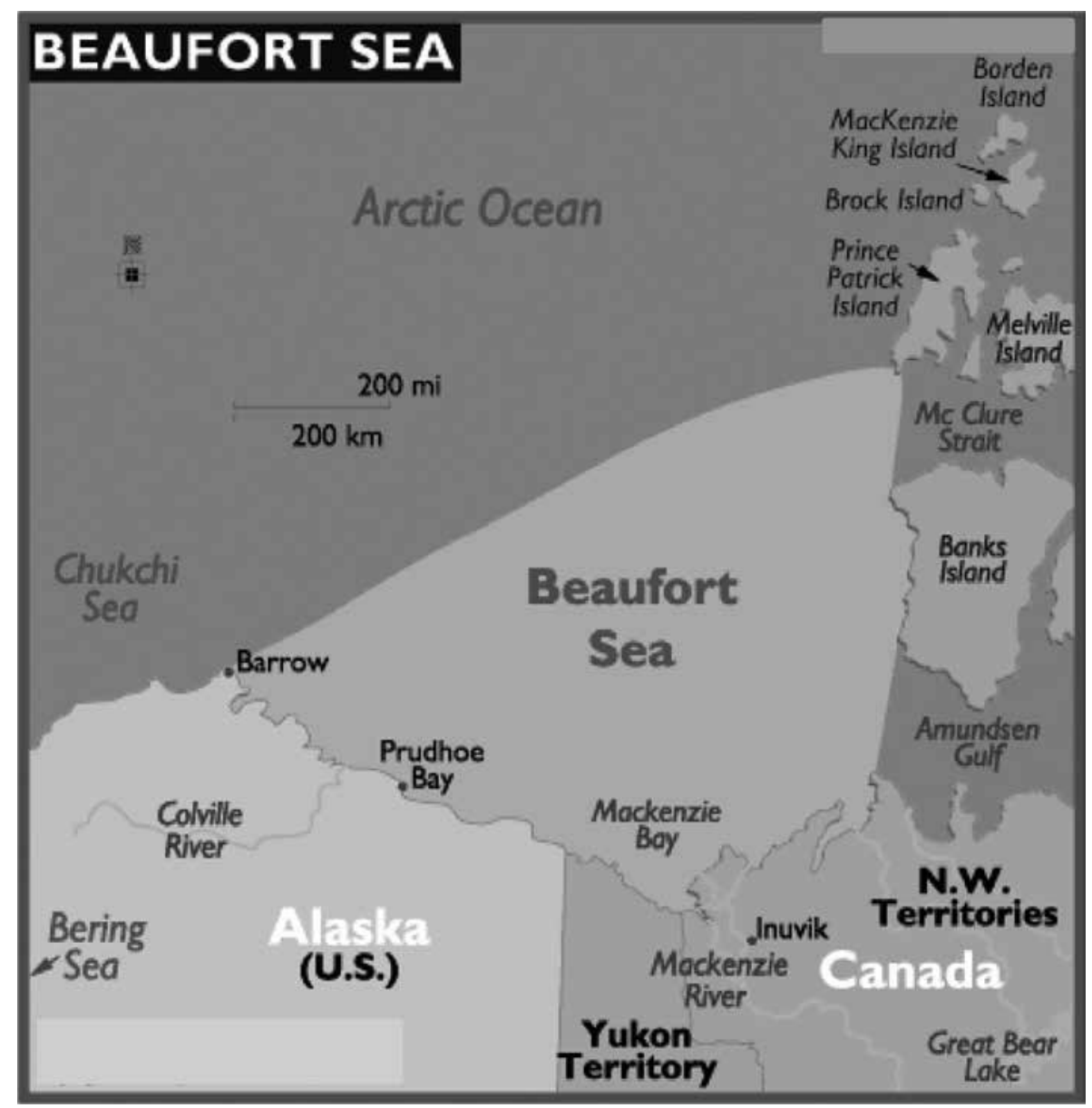

Figure 10. The Beaufort Sea.

Dolly Varden (Salvelinus malma) char west of the Mackenzie River were once thought to represent a distinct form of Arctic char (Salvelinus alpinus). They inhabit the Rat River and its tributaries. They are harvested mostly for subsistence purpose. However, in two areas Big Fish River and Rat Rivers, they were harvested both by subsistence and commercial fisheries. Arctic char typically occur in river systems to the east of the Mackenzie River drainage (e.g., Hornaday River, Kuujjua River).A Fisheries Joint Management Committee (FJMC) works jointly with DFO to co-manage all fish, fish habitat and marine mammals. The FJMC has the power to directly advise the Minister of Fisheries and Oceans on fisheries issues. The committee is responsible for collecting harvest information and making recommendations on subsistence quotas for fish and marine mammals. The FJMC also monitor sports fishing in the area. Community consultations are essential part of fisheries management in the area. The FJMC has a research budget and provides funding to complement traditional knowledge and science to solve resource management issues. Canadian federal government and 
the Inuvialuit people of the western Arctic have signed an agreement in 2011 to maintain fishing limits in the Beaufort Sea as a step towards a comprehensive ocean management plan for the Beaufort Sea. At present, commercial fishing does not exist in the Beaufort Sea, but there were many experimental applications in fishing license since 2000. The melting of sea ice has opened many waterways of the Arctic that led to boats, commercial vessels and fishing boats coming into the region. Integrated management framework for fisheries in the Beaufort Sea requires future commercial fisheries to have the support of the Inuvialuit living in the area.

Mathias [78] notes that main subsistence food for the Canadian Inuvialuit comes from beluga whale, broad whitefish, Arctic char, ringed seal, inconnu, humpback whitefish, and Arctic cisco. Fisheries productivity, or even biomass, on the Canadian Beaufort shelves, is unknown. There have been no systematic surveys of demersal and pelagic fish (other than larval fish) in the Canadian Beaufort Sea, although some locations have been fished with gillnets, beach seines, fyke nets and small mid-water trawls. In fact, Byers [[79], p. 40] stated: “The distribution and ecology of deep-water, off-shelf fish communities of the Canadian Beaufort Sea remain mostly unstudied. This is likely due, in part, to inaccessibility due to ice-cover and (until recently) a historical lack of industrial interest in abyssal regions." Mathias [78] noted that evidence suggests the Canadian shelves may be less productive than the Alaskan Shelf because they are less influenced by inflow from the productive Bering Sea and there may be other productivity differences brought about by the massive depositional environment caused by the Mackenzie River.

The Alaskan Shelf survey of the Beaufort Sea took place from the edge of Barrow Trough to $\sim 109 \mathrm{~km}$ east and fished from 40 to $500 \mathrm{~m}$, crossing the shelf break. A standardized bottom trawl survey quantified the distribution and density of demersal fish. Biomass estimates were produced for two depth strata (40-100 $\mathrm{m}$ and 100-500 m), and the two estimates were summed to provide a total biomass estimate of $18 \mathrm{~kg} / \mathrm{ha}$ for a 6280 -ha area of the shelf. Arctic cod made up $81 \%$ of the catch, while Bering flounder and walleye pollock together made up another $4 \%$. The depths sampled were considered appropriate for a potential commercial fishery on the continental shelf and upper continental slope, but unlikely to occur in very shallow, near-shore areas.

On the same 6280-ha sampling site of the Alaskan Shelf, pelagic mid-water trawls and hydroacoustic gear measured biomass estimates for Arctic cod of $19.2 \mathrm{~kg}$ ha-1 in the $40-$ to $100-\mathrm{m}-$ depth range, and $53.7 \mathrm{~kg} \mathrm{ha}^{-1}$ in the 100 - to 500 -m-depth range [80]. These densities may be compared with the estimate of unfished biomass for demersal Arctic cod from otter trawls, 18 $\mathrm{kg} \mathrm{ha}^{-1}\left(=1.8 \mathrm{mt} \mathrm{km}{ }^{-2}\right)$. The results of this fisheries survey on the Alaskan Shelf suggest that regardless of what species a commercial fishery targets, Arctic cod may constitute a significant bycatch [81]. Demersal fish were only $6 \%$ of the catch by mass; the overwhelming biomass was brittle stars. Arctic cod dominated fish catches, comprising $81 \%$ of fish biomass. Eelpouts made up $11 \%$ of the fish catch, while Greenland halibut were $0.7 \%$, and walleye pollock and Pacific cod together (neither of which is reported from the Canadian Beaufort Sea) made up $2 \%$. 


\subsection{Fisheries assessment}

Assessments of key marine mammal species, such as Bowhead Whale are done by aerial survey and a Potential Biological Removal (PBR) model. Assessment of Dolly Varden has been done using surplus production and age-structured models (X. Zhu, DFO personal communication).

\section{Chukchi Sea}

\subsection{Fisheries}

For most fish stocks within the Chukchi Sea, stock size was insufficient to support commercial activity (Figure 11). Three stocks: snow crab (Chionoecetes opilio); Arctic cod (Boreogadus saida); and saffron cod (Eleginus gracilis) are of sufficient size to support commercial activity [82, 83].

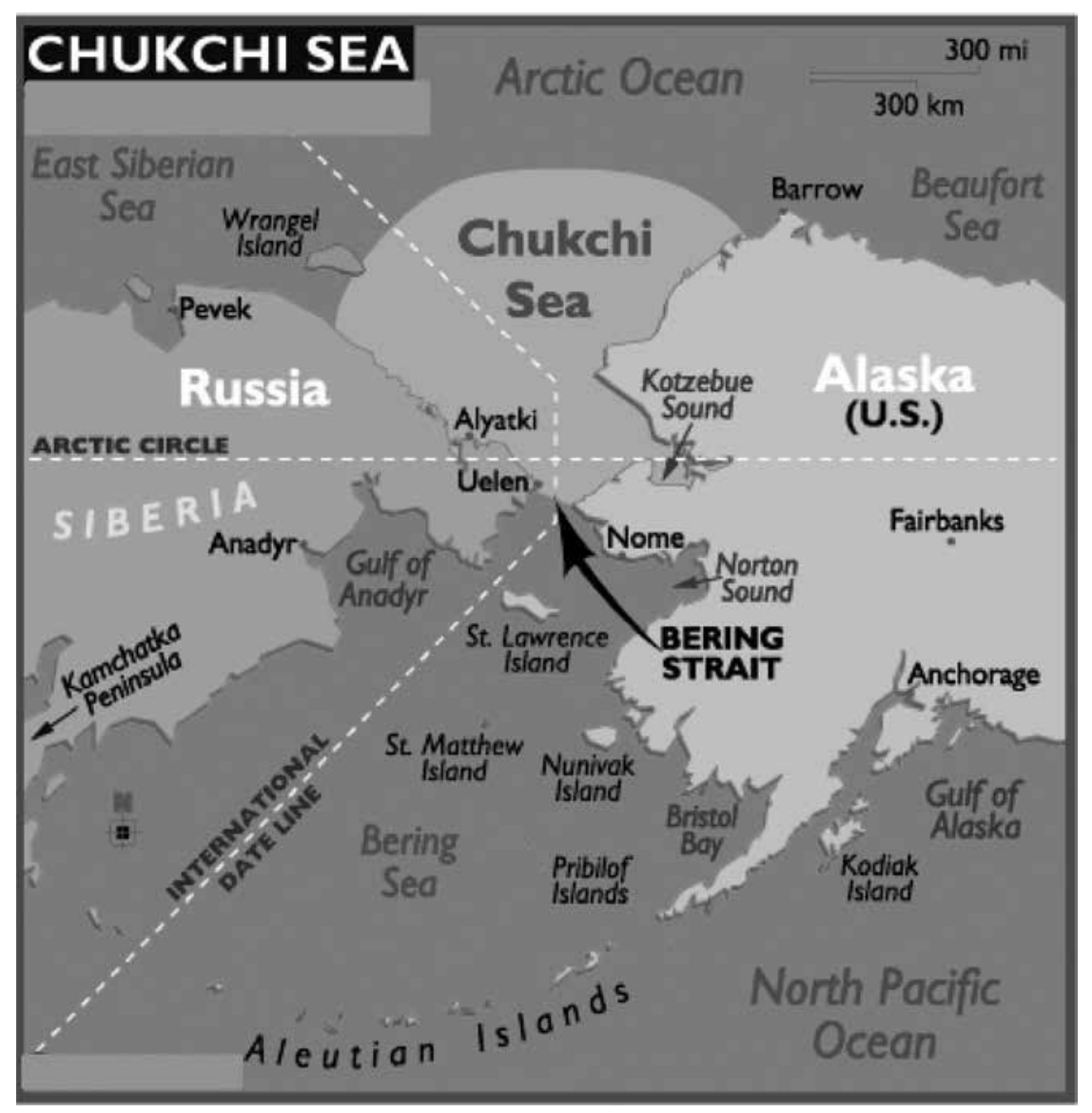

Figure 11. The Chukchi Sea. 


\subsection{Fisheries assessment}

Little formal stock assessment has been done, but density-based estimates have been used for assessment. Stock size has been inferred from catch effort data from surveys.

\section{Siberia}

\subsection{Fisheries}

The nature of Siberian fisheries is relatively unknown because assessments, if any, are published in Russian and not disseminated broadly (Figure 12). It is likely that the fisheries are similar to the Canadian coastal and inland fisheries which are prosecuted using gillnets and are usually interception fisheries capturing various species during their migrations for spawning or over-wintering. Siberia does contain a number of large rivers and Chum Salmon, Orcorhynchus keta, exists as far along the coast as the Lena River. The fisheries are likely on Pacific salmon, broad whitefish, inconnu, Arctic Cisco and Arctic char.

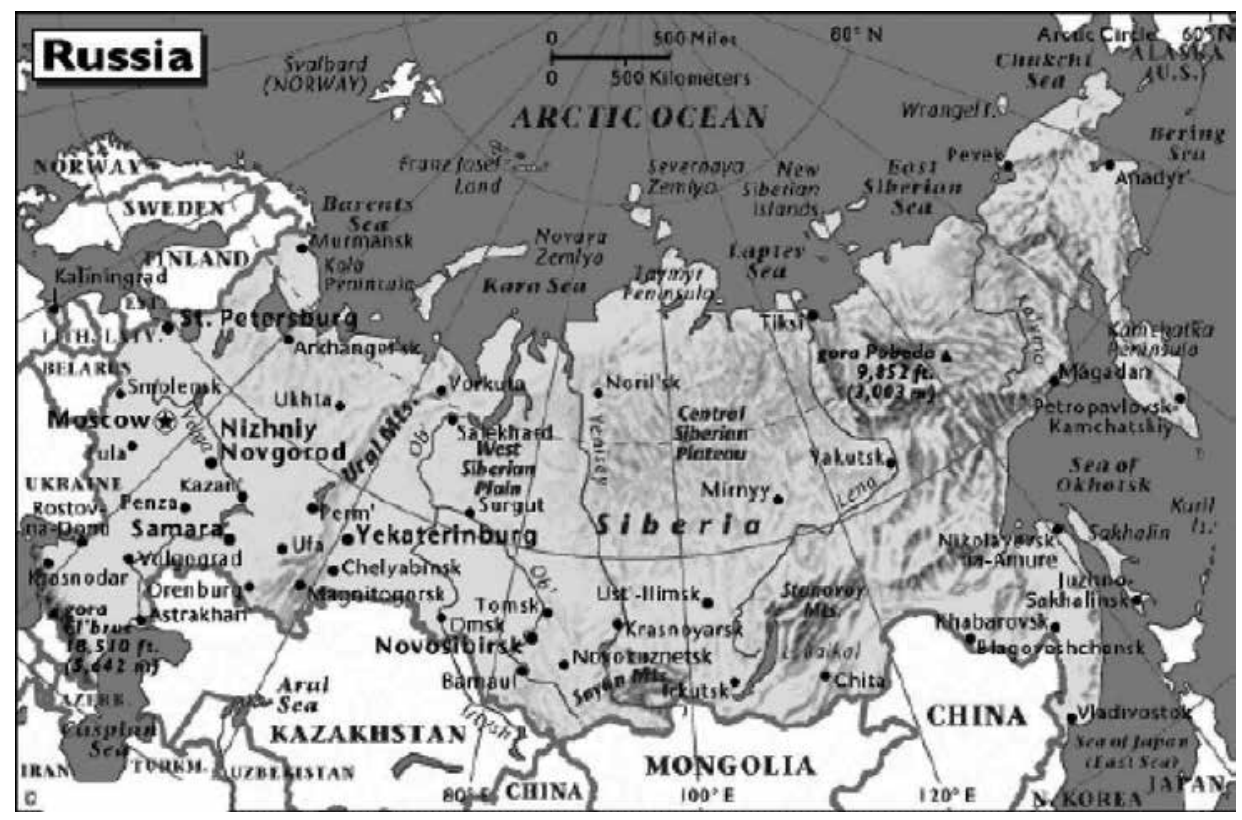

Figure 12. Continental Russia featuring Siberia.

\subsection{Fisheries assessment}

As noted above, published assessments in English are not known, and therefore, stock assessment models are unknown. 


\section{General aspects of assessment}

The Arctic region shows wide variation in the nature of fisheries and the practice of stock assessment. The differences are as great within the marine areas compared to the freshwater fisheries. For example, the Barents Sea has large-scale industrial fisheries with total harvest near to 2 million tonnes, mainly from bottom trawl harvest, whereas an area comparable in size and latitude, the Beaufort Sea, has a tiny fraction of that harvest from subsistence activities with no commercial fisheries. The key species are much different with the Barents Sea being dominated by groundfish, especially Gadiods, while the fisheries in the Beaufort Sea are mainly on marine mammals and anadromous fish such as Dolly Varden char. Stock assessment of the Barents Sea fisheries is highly sophisticated, deploying a variety of analytical population models such as extended survivor analysis. In contrast, with the exception of recent assessments of Dolly Varden char, the Beaufort Sea stocks are not modeled and only indicator values are used in assessment.

There is likely less variation in the nature and assessment of freshwater fisheries. A large proportion of freshwater fisheries are prosecuted as interception fisheries using gillnets. Assessment is mainly regarding demographic trends in size at age although recently, surplus production and age-structured models have been applied in analysis. Data-limited assessment tools hold much promise for freshwater assessments, and the incorporation of fisher and aboriginal traditional knowledge through methods such as the traffic light approach is likely to be important in the future.

\section{Conclusion}

\subsection{Future trends in arctic fisheries}

\subsubsection{Potential and realized effects of climate change}

Climate change will have the most profound effect on the aquatic ecosystems of the Arctic [82, 83]. It has already been noted that the range of demersal species in the Barents Sea has shifted northward in recent years as there is less and less multiyear sea ice. Shift in Barents Sea stocks northwards. Ice-based ecologies of animals such as seals and Arctic cod in the Canadian Archipelago will shift even further northwards, and lower overall population sizes will occur. Access to fishing areas in the central offshore will be increased with unknown results in terms of harvest and management. Some species will increase growth and colonization, and increases in abundance of species more typical of temperate areas will occur.

\subsubsection{Use of data-limited and traffic light approaches}

Traditional assessment methodologies with a full range of fishery-dependent and fisheryindependent metrics may not be possible for many of the small widely spread artisanal fisheries of the Arctic. However, there has been much new research in the area of data-limited 
fisheries assessment $[58,83]$. These methodologies may be well suited to areas where sampling for detailed time series of demographic traits and other metrics is difficult. As well, for community-based fisheries where traditional ecological knowledge may exceed the knowledge based on scientific data collection approaches such as the traffic light approach that uses the sum of series of relatively "soft" indicators may be more effective for stock assessment than traditional methods from industrial fisheries.

\subsubsection{Development and application of advanced population models}

For areas with large-scale industrial fisheries such as the Barents Sea, ongoing development of advanced population models will surely happen in the future. The population models will likely include both fishery and stock statistics but environmental factors as well. Bayesian approaches to stock assessment are likely to grow in importance to be able to take advantage of prior knowledge and provide multiple options to managers.

\subsubsection{Development and application of ecosystem models}

Ecosystem models such as ECOPATH-ECOSYM may gradually mature so that they can be used for the development of annual quotas - taking into account the environmental conditions as well as stock and fishery. The incorporation of ecosystem-based models will be important to predict the effects of climate variation on yield and should be part of the fisheries manager's toolkit.

Ecosystems, fisheries and stock assessment are highly variable around the Arctic region. Understanding of Arctic fisheries is as complex as any other part of the world, if not more so. There will be great advances tailored to the Arctic fisheries assessment as understanding becomes clearer with more integration of scientific and traditional ecological knowledge.

\section{Author details}

Ross Tallman ${ }^{1 *}$, Muhammed Y. Janjua ${ }^{1}$, Daniel Howell ${ }^{2}$, Burton Ayles ${ }^{3}$, Theresa Carmicheal ${ }^{1}$, Matthias Bernreuther ${ }^{4}$, Steve Ferguson ${ }^{1}$ and Margaret Treble ${ }^{1}$

*Address all correspondence to: ross.tallman@dfo-mpo.gc.ca

1 Arctic Stock Assessment and Integrated Ecosystem Research, Central and Arctic Region, Fisheries and Oceans Canada, Winnipeg, Manitoba, Canada

2 Institute of Marine Research, Bergen, Norway

3 Fisheries Joint Management Committee, Inuvik, NT, Canada

4 Thüen Institute of Sea Fisheries, Braunschweig, Germany 


\section{References}

[1] Hønneland, G. (2005) Barents Breaking. Norwegian Foreign Policy in the North after the Cold War. HøyskoleForlaget. ISBN: 82-7634-649-9

[2] Bogstad, B., Kovalev, Y., Lindemann, D., Aanes, S., Aglen, A., Alonso, C., Alpoim, R., Aranda, M., Bernruether, M., Bertelsen, M., Borisov, V., Bulatov, O., Bulgakova, T., Chetyrkin, A., Drevetnyak, K., Filin, A., Fotland, A., Janusz, J., Jakobsen, T., Gjosaeter, H., Howell, D., Nedreaas, K., Planque, B., Prozorkevich, D., Russkikh, A., Santurtin, M., Smirnov, O., Stainsen, J-E., Sunnana, K., Tallman, R., Titov, O., and N. Yaragina. (2014) Report of the Arctic Fisheries Working Group (AFWG), 21-29 April 2014, Lisbon, Portugal. 572 pp.

[3] Sirenko, B.I. ed. (2001) List of species of free-living invertebrates of Eurasian Arctic seas and adjacent deep waters. Russian Academy of Science, Zoological Institute, Moscow.

[4] Antipova, T.V. (1975) Distribution of benthos biomass in the Barents Sea. Trudy PINRO, 35, pp. 121-124.

[5] Wiborg, K.F. (1962) Some observations on the Iceland scallop. Chlamys islandica.

[6] Sundet, J.H. and Vahl, O. (1981) Seasonal changes in dry weight and biochemical composition of the tissues of sexually mature and immature Iceland scallops, Chlamys islandica. Journal of the Marine Biological Association of the United Kingdom, 61(04), pp. 1001-1010.

[7] Golikov, A.V., Sabirov, R.M., Lubin, P.A. and Jørgensen, L.L. (2013) Changes in distribution and range structure of Arctic cephalopods due to climatic changes of the last decades. Biodiversity, 14(1), pp.28-35.

[8] Borges, T.C. (1990) A contribution to the biology of the ommastrephid squid, Todarodes sagittatus, with emphasis on the possible application of morphometric data to population studies. Norwegian college of Fisheries Science at the University of Tromsø. Tromsø, University of Tromsø, Doctor scientiarum.

[9] Bjørke, H. (1995) Norwegian investigations on Gonatus fabricii (Lichtenstein). ICES.

[10] Vikebø, F., Jørgensen, C., Kristiansen, T. and Fiksen, Ø. (2007) Drift, growth, and survival of larval Northeast Arctic cod with simple rules of behavior.

[11] Opdal, A.F., Vikebø, F. and Fiksen, Ø. (2011) Parental migration, climate and thermal exposure of larvae: spawning in southern regions gives Northeast Arctic cod a warm start.

[12] Jorgensen, T. (1992) Long-term changes in growth of North-east Arctic cod (Gadus morhua) and some environmental influences. ICES Journal of Marine Science., 49:263277. 
[13] Ponomarenko, I. (1984) Survival of bottom-dwelling young cod in the Barents Sea and its determining factors. Reproduction and Recruitment of Arctic cod, p. 210.

[14] Von Quillfeldt, C., and Dommasnes, A. (2005). Report of the working group on fish stocks and fisheries (including production and energy flows). The Scientific Basis for Environmental Quality Objectives (EcoQOs) for the Barents Sea Ecosystem. Norway, $0-2$.

[15] Gjøsæter, H., Bogstad, B. and Tjelmeland, S. (2009) Ecosystem effects of the three capelin stock collapses in the Barents Sea. Marine Biology Research, 5(1), pp.40-53.

[16] Mehl, S. (1991) The Northeast Arctic cod stock's place in the Barents Sea ecosystem in the 1980s: an overview. Polar research, 10(2), pp. 525-534.

[17] Dolgov, A., Johannesen, E., Olsen, E. and Heino, M. (2010) Trophic ecology of blue whiting in the Barents Sea. IIASA. Interim Report . IIASA, Laxenburg, Austria, IR-10-035

[18] Folkow, Lars; Haug, Tore; Nilssen, Kjell Tormod; Nordøy, Erling Sverre. Estimated food consumption of minke whales Balaenoptera acutorostrata in northeast Atlantic waters in 1992-1995. (fulltekst) NAMMCO scientific publications (2000); Volum 2. ISSN 1560-2206.s 65 - 80.s doi: 10.7557/3.2972.

[19] Nilssen, K.T., Pedersen, O.-P., Folkow, L., and Haug, T. (2000). Food consumption estimates of Barents Sea harp seals. NAMMCO Scientific Publication Series, 2: 9-28.

[20] Lindstrøm, U., Nilssen, K.T., Pettersen, L.M.S. and Haug, T. (2013). Harp seal foraging behaviour during summer around Svalbard in the northern Barents Sea: diet composition and the selection of prey. Polar biology 36: 305-320.

[21] Haug,T., Nilssen, K.T., Lindblom, L. et al. (2007). Diets of hooded seals (Cystophora cristata) in coastal waters and drift ice waters along the east coast of Greenland. Marine Biology 3: 123-133.

[22] Dingsør, G.E. (2015) Bottom-trawl indices from ecosystem survey for cod and haddock, using a design-based approach. WD17, WKARCT.

[23] Shepherd, J.G. (1991) Extended survivors analysis: an improved method for the analysis of catch-at-age data and abundance indices. ICES Journal of Marine Science, 56(5), pp. 584-591.

[24] Darby, C.D. and Flatman, S. (1994) Virtual population analysis: version 3.1 (Windows/ Dos) user guide .Great Britain, Ministry of Agriculture, Fisheries and Food, Directorate of Fisheries Research. p. 85.

[25] Pope, J.G. and Shepherd, J.G. (1982) A simple method for the consistent interpretation of catch-at-age data. Journal du Conseil, 40(2), pp.176-184. 
[26] Loeng, H., and Drinkwater, K. (2007). An overview of the ecosystems of the Barents and Norwegian Seas and their response to climate variability. Deep Sea Research Part II: Topical Studies in Oceanography, 54(23), 2478-2500.

[27] Lindstrøm, U., Nilssen, K.T., Pettersen, L.M.S. and Haug, T. (2010). Harp seal foraging behaviour in the northern Barents Sea: diet composition and the selection of prey. Polar biology 33: 305-320.

[28] ICES. (2015) Report of the Working Group on Widely Distributed Stocks (WGWIDE), 25 August-31 August 2015, Pasaia, Spain. ICES CM 2015/ACOM:15. 588pp

[29] Nielsen, A. and C.W. Berg. (2014). Estimation of time-varying selectivity in stock assessments using state-space models. Fisheries Research, 158:96-101.

[30] Torrissen, O., Olsen, R.E., Toresen, R., Hemre, G.I., Tacon, A.G.J., Asche, F., Hardy, R.W., Lall, S. (2011) Atlantic Salmon (Salmo salar): the "Super-Chicken" of the Sea? Reviews in Fisheries Science. 19, 257-278.

[31] Buch, E.M. (2000) A monograph on the physical oceanography of the Greenland waters. Danish Metrological Institute. Scientific Report 00-12, 405 pp.

[32] Walczowski, W. and Piechura, J. (2007) Pathways of the Greenland Sea warming. Geophysical Research Letters, 34(10).

[33] Cheung, W.W., Dunne, J., Sarmiento, J.L. and Pauly, D. (2011). Integrating ecophysiology and plankton dynamics into projected maximum fisheries catch potential under climate change in the Northeast Atlantic. ICES Journal of Marine Science: Journal du Conseil, p.fsr012.

[34] Pálsson, Ó.K., Gislason, A., Guðfinnsson, H.G., Gunnarsson, B., Ólafsdóttir, S.R., Petursdottir, H., Sveinbjörnsson, S., Thorisson, K. and Valdimarsson, H. (2012) Ecosystem structure in the Iceland Sea and recent changes to the capelin (Mallotus villosus) population. ICES Journal of Marine Science: Journal du Conseil, 69(7), pp.1242-1254.

[35] Møller, P. R., Nielsen, J. G., Knudsen, S. W., Poulsen, J. Y., Sünksen, K., \& Jørgensen, O. A. (2010). A checklist of the fish fauna of Greenland waters. Zootaxa, (2378), 1-84.

[36] ICES. (2015) Report of the North-Western Working Group (NWWG), 28 April 5 May, ICES HQ, Copenhagen Denmark. ICES CM 2015/ACOM:07. 717 pp.

[37] Folkow, L.P. and Blix, A.S. (1999) Diving behaviour of hooded seals (Cystophora cristata) in the Greenland and Norwegian Seas. Polar Biology, 22(1), pp. 61-74.

[38] ICES (2013) Report of the ICES Working Group on Harp and Hooded Seals (WGHARP), PINRO, Murmansk, Russia, 26-30 August 2013. ICES CM 2013/ ACOM: 20, 55 pp.

[39] Christiansen, J.S., Mecklenburg, C.W. and Karamushko, O.V. (2014) Arctic marine fishes and their fisheries in light of global change. Global change biology, 20(2), pp.352-359. 
[40] ICES (2004) Report of the ICES Advisory Committee on Fishery Management and Advisory Committee on Ecosystems, 2004. ICES Advice, vol. 1, no. 2. 1544 pp.

[41] McKinney, M.A., Iverson, S.J., Fisk, A. et al. (2013) Global change effects on the longterm feeding ecology and contaminant exposures of East Greenland polar bears. Global Change Biology, 19, 2360-2372.

[42] Boertmann, D. and Mosbech, A. (eds.) (2011) The western Greenland Sea, a strategic environmental impact assessment of hydrocarbon activities. Aarhus University, DCE -Danish Centre for Environment and Energy, 268 pp. Scientific Report from DCEDanish Centre for Environment and Energy no. 22.

[43] Hamilton, J.M., and Wu, Y. (2013) Synopsis and trends in the physical environment of Baffin Bay and Davis Strait. Canadian Technical Report of Hydrography and Ocean Sciences. 282: vi +39 p.

[44] Coad, B.W. and Reist, J.D. (2004) Annotated list of the Arctic Marine Fishes of Canada. Canadian Manuscript Report of Fisheries and Aquatic Sciences. 2674: iv + 112 p.

[45] Jørgensen, O.A., Hvingel, C., Møller, P.R. and Treble, M.A. (2005) Identification and mapping of bottom fish assemblages in Davis Strait and southern Baffin Bay. Canadian Journal of Fisheries and Aquatic Sciences, 62(8), pp.1833-1852

[46] Jørgensen, O.A., Hvingel, C., Treble, M.A. (2011) Identification and mapping of bottom fish assemblages in Northern Baffin Bay. Journal of Northwest Atlantic Fishery Science 43:65-78

[47] DFO (2014) Greenland Halibut (Reinhardtius hippoglossoides) Northwest Atlantic Fisheries Organization Subarea 0-Effective 2014. http://www.dfo-mpo.gc.ca/fm-gp/ peches-fisheries/ifmp-gmp/groundfish-poisson-fond/halibut-fletan-eng.htm

[48] Jørgensen, O.A. and Treble, M.A. (2015) Assessment of the Greenland Halibut Stock Component in NAFO Subarea $0+$ Division 1A Offshore + Divisions 1B-1F. Serial No. N6457 NAFO SCR Doc.15/032.

[49] Nygaard, R. (2015) Fisheries and catches of Greenland Halibut Stock Component in NAFO Division 1A Inshore in 2014. Serial No. N6466, NAFO SCR Doc. 15/039.

[50] Aschan, M., Powles, H., Angel, J. (2012) MSC Assessment Report for the Canadian Offshore northern shrimp (Pandalus borealis) trawl fishery - Shrimp Fishing Area 1. Client: Canadian Association of Prawn Producers (CAPP) and the Northern Coalition (NC). Version: Final Report Draft. 176 pp.

[51] Arboe, N.H. and Kingsley, M.C.S. (2013) The Fishery for Northern Shrimp (Pandalus borealis) off West Greenland, 1970-2013. Serial No. N6219 NAFO SCR Doc. 013/058.

[52] DFO (2007) Integrated Fisheries Management Plan Northern Shrimp Northeast Newfoundland, Labrador Coast and Davis Strait. http://www.dfo-mpo.gc.ca/fm-gp/ peches-fisheries/ifmp-gmp/shrimp-crevette/shrimp-crevette-2007-eng.htm. 
[53] Harris, L.N. and Tallman, R.F. (2010) Information to support the assessment of Arctic Char, Salvelinus alpinus, from the Isuituq River system, Nunavut. DFO Canadian Science Advisory Secretariat Research Document. 2010/063. vi + 37 p.

[54] Roux, M.J., Tallman, R.F. and Lewis, C.W. (2011) Small-scale Arctic charr Salvelinus alpinus fisheries in Canada's Nunavut: management challenges and options. Journal of Fish Biology, 79(6), pp.1625-1647

[55] Moore, J.-S., Harris, L.N., and Tallman, R.F. (2014) A review of anadromous Arctic char (Salvelinus alpinus) migratory behavior: implications for genetic population structure and fisheries management. Canadian Manuscript Report of Fisheries and Aquatic Sciences. 2014/3051: vi +27 p.

[56] GINR 2010.

[57] Tallman., R.F, VanGerwen-Toyne, M., Harris, L., Gallagher, C., Carmichael, T., Howland, K. and Zhu, X. (2012) Stock Assessment of anadromous charrs [genus Salvelinus] in the Central and Arctic Region. Canadian Manuscript Report of Fisheries and Aquatic Sciences. 3007: v +26 p.

[58] Tallman, R.F., Xinhua Zhu, Janjua, Y., Toyne, M., Roux, M.J., Harris, L., Howland, K. L., and Gallagher, C. (2013) Data limited assessment of selected North American anadromous charr stocks. Journal of Ichthyology, 53(10):867-874.

[59] Zhu, X., Day, A.C., Carmichael, T.J., Tallman, R.F. (2014) Hierarchical Bayesian modeling for Cambridge Bay Arctic Char, Salvelinus alpinus (L.), incorporated with precautionary reference points. DFO Canadian Science Advisory Secretariat Research Document. 2014/096. v +35 p.

[60] Stewart, D.B. and Lockhart, W.L. (2004) Summary of the Hudson Bay Marine Ecosystem. Overview. Canada Department of Fisheries and Oceans, Central and Arctic Region, Winnipeg, Manitoba.

[61] Tallman, R.F. and Kristofferson A.V. (1995) A virtual population analysis using ADAPT of the population dynamics of the Diana River Arctic Charr, Salvelinus alpinus. IN: Cosens, S.E. (ed) Report of the Arctic Fisheries Stock Assessment Committee for 1995. Department of Fisheries and Oceans.

[62] Bodaly, R. A., Reist, J.D., Rosenberg, D.M., McCart, P.J. and Hecky, R.E. (1989) Fish and fisheries of the Mackenzie and Churchill River basins, northern Canada. In Proceedings of the International Large River Symposium. Canadian Special Publication of Fisheries and Aquatic Sciences, vol. 106, pp. 128-144. 1989.

[63] Muir, A.M., Leonard, D.M. and Krueger, C.C. (2013) Past, present and future of fishery management on one of the world's last remaining pristine great lakes: Great Bear Lake, Northwest Territories, Canada. Reviews in Fish Biology and Fisheries, 23(3), pp. 293315. 
[64] Janjua, M.Y., Tallman R.F. and Howland K.L. (2015) Preliminary analysis of trophic relationships in Great Bear Lake using Ecopath model. Canadian Technical Report of Fisheries and Aquatic Sciences. 3137: vi + 24 p.

[65] Stewart, D.B., and G. Low. (2000). A review of information on fish stocks and harvests in the Deh Cho area, Northwest Territories. Can. Manuscr. Rep. Fish. Aquat. Sci. 2549: iv $+73 \mathrm{p}$.

[66] Tallman, R.F. and Reist, J.D. (1997) The proceedings of the Broad Whitefish workshop: the biology, traditional knowledge and scientific management of Broad Whitefish in the lower Mackenzie River. Canadian Technical Report of Fisheries and Aquatic Sciences. 2193:63-74.

[67] Martin, Z. (2010) Adaptation and habitat selection during the migration of an Arctic anadromous fish, Broad Whitefish (Coregonus nasus (Pallas 1776). M.Sc. Thesis. University of Manitoba, Winnipeg.

[68] VanGerwen-Toyne M. and Tallman R. (2000) The Peel River Fish Study, 1998-1999 with emphasis on broad whitefish (Coregonus nasus). DFO, Winnipeg.

[69] Gwich'in Renewable Resources Board (2010) Gwich'in Traditional Knowledge: Rat River Dolly Varden Char. Gwich'in Renewable Resources Board, Inuvik.

[70] Read C.J. and Taptuna W.E.F. (2003) Data from the commercial fishery for lake whitefish, Coregonus clupeaformis (Mitchill), on Great Slave Lake, Northwest Territories, 1999/00 to 2001/02. Canadian Data Report of Fisheries and Aquatic Science, 1111: 54.

[71] Low, G., Stewart D.B., Day A.C. and Taptuna W.E.F. (1999) Comparison of Fish Harvests From the East Arm of Great Slave Lake, N.W.T., By Itinerant Sport Anglers in 1986 and 1994. Canadian Technical Report Fisheries and Aquatic Sciences 2263.Department of Fisheries and Oceans, Winnipeg.

[72] Tallman R. F. and Friesen M. K. (2007) A review of trends in length and age of lake whitefish (Coregonus clupeaformis) harvested from Great Slave Lake between 1972 and 1995. Canadian Manuscript Report of Fisheries and Aquatic Sciences. 2819: 27 p.

[73] Janjua, M.Y. and Tallman R.F. (2015) A mass-balanced Ecopath model of Great Slave Lake to support an ecosystem approach to fisheries management: preliminary results. Canadian Technical Report of Fisheries and Aquatic Sciences. 3138: vi + 32 p.

[74] Roberge, M.M., Low, G. and Read, C.J. (1988) An assessment of the commercial fishery and population structure of walleye in Tathlina Lake, Northwest Territories. Canadian Technical Report of Fisheries and Aquatic Science 1594: 54 p.

[75] Louie, W.H., Hardisty, E., and MacDonald, D.D. (1995) Acquisition of traditional environmental knowledge in the lower Liard River Basin. Environment and Renewable Resources Directorate, Indian and Northern Affairs Canada, Ottawa. 
[76] Moulton, L.L., SeAvey, B. and Pausanna, J. (2010) History of an under-ice subsistence fishery for arctic cisco and least cisco in the Colville River, Alaska. Arctic, pp. 381-390.

[77] Fechhelm, R.G., Streever, B. and Gallaway, B.J. (2007) The Arctic cisco (Coregonus autumnalis) subsistence and commercial fisheries, Colville River, Alaska: a conceptual model. Arctic, pp. 421-429.

[78] Mathias, J. (2013) Canada/Inuvialuit Fisheries Joint Management Committee Technical Report 2013-01: viii + 111 p.

[79] Byers, M., (2013), International Law and the Arctic, Cambridge Series on International and Comparative Law, 314 pages.

[80] Logerwell, E., K. Rand, S. Parker-Stetter, J. Horne, T. Weingartner, and B. Bluhm. (2010): Beaufort Sea Marine Fish Monitoring 2008: Pilot Survey and Test of Hypotheses. Final Report. Minerals Management Service, U.S. Department of the Interior, BOEMRE 2010048, 263 pp.

[81] NPFMC 2009.

[82] Hollowed, A.B. and Sigler, M.F. (2012) Fish and Fisheries in the Chukchi and Beaufort Seas: Projected Impacts of Climate Change. Alaska Fisheries Science Center, National Marine Fisheries Service, National Oceanic and Atmospheric Administration, 7600 Sand Point Way NE, Seattle, WA 981152 Alaska Fisheries Science Center, National Marine Fisheries Service, National Oceanic and Atmospheric Administration, 17109 Point Lena Loop Road, Juneau, AK 99801.

[83] Hollowed, A.B. and Sundby, S. (2014) Insights.

[84] Øigård, T.A., Haug, T. and Nilssen, K.T. (2014) From pup production to quotas: current status of harp seals in the Greenland Sea. ICES Journal of Marine Science: Journal du Conseil, 71(3), pp. 537-54.

[85] Skjoldal, H. R., Dalpadado, P., and Dommasnes, A. (2004) Food webs and trophic interactions. In The Norwegian Sea Ecosystem, 1st edn, pp. 263-288. Eds. H. R. Skjoldal R. Sætre, A. Fernö, O.A. Misund and I. Røttingen. Tapir Academic Press, Trondheim, Norway. 55.

[86] Tallman, R., Cadigan, N, Cass, A., Duplisea, D., Healey, B., Trzcinski, K. and Wade, E. (2011) Techniques for the Provision of Advice in Information-Poor Situations. DFO Canadian Science Advisory Secretariat Research Document. 2011/106. vi + 42 p.

[87] Gordon, J.D.M., Bergstad, O.A., Figueiredo, I. and G. Menezes. (2003) Deep-water Fisheries of the Northeast Atlantic: I. Description and current Trends. J. Northw. Atl. Fish. Sci. Vol: 31; 37-150.

[88] Bowering, W.R. and Brodie, W.B. (1995) Greenland halibut (Reinhardtius hippoglossoides). A review of the dynamics of its distribution and fisheries off eastern Canada 
and Greenland. Pp. 113-160. In: Hoppr, A.G. (ed.). Deep-water fisheries of the North Atlantic Oceanid slope. - NATO ASI Series.

[89] ICES. (2006) Report of the Working Group on the Biology and Assessment of Deep-Sea Fisheries Resources. ICES CM 2006/ACFM:07.

[90] VanGerwen-Toyne, M., Walker-Larsen, J., and Tallman, R. F. (2008) Monitoring spawning populations of migratory inconnu and coregonids in the Peel River, NWT: the Peel River fish study 1998-2002. Canadian Manuscript Report of Fisheries and Aquatic Sciences 2851, Winnipeg.

[91] VanGerwen-Toyne, M., Day, A.C., Taptuna, F., Leonard, D., Frame, S., and Tallman, R. (2013) Information in support of Assessment of Buffalo River Inconnu, (Stenodus leucichthys), Great Slave Lake, Northwest Territories, 1945-2009. DFO Canadian Science Advisory Secretariat Research Document. 2012/069. vii +81 p. 

Chapter 4

\title{
Trawl Selectivity in the Barents Sea Demersal Fishery
}

\author{
Eduardo Grimaldo, Manu Sistiaga , \\ Bent Herrmann and Roger B. Larsen \\ Additional information is available at the end of the chapter
}

http://dx.doi.org/10.5772/63019

\begin{abstract}
This chapter provides a general overview of the Barents Sea demersal trawl fishery. First, it reviews historical catch levels and current biomass status of four commercially important demersal species (cod, haddock, Greenland halibut, and redfish) and includes an overview of their management plan that has been carried out by the Joint Norwegian-Russian commission. Then, it presents the evolution of the technical regulations for improving size selectivity in this fishery and describes current challenges in gear selectivity. Later, this chapter describes the concept of size selectivity, introduces the selective parameters that define a selection curve, and progressively introduces different parametric models that describe the selection process. The most common experimental methods and gear used to collect selectivity data are described, and their advantages and disadvantages are discussed. Finally, this chapter describes an alternative, or a complementary method, to the conventional estimation of trawl selectivity-the FISHSELECT method. This method is based on morphology measurements and fish penetration models to estimate the selective properties of different mesh shapes and sizes at different mesh openings, which are later used to provide simulation-based prediction of size selectivity. FISHSELECT has already been applied to four important species of the Barents Sea Demersal Fishery, and the results have in all cases showed to be coherent with the results obtained from sea trial results.
\end{abstract}

Keywords: selectivity, trawl, bottom trawl, Barents Sea, demersal fishery, FISHSELECT 


\section{Introduction}

The main target species for the Norwegian bottom trawling fleet north of $62^{\circ} \mathrm{N}$ are the Northeast Arctic cod (Gadus morhua), haddock (Melanugrammus aeglefinus), and saithe (Pollachius virens); all of these species belong to the gadoid family. During the past 20 years, the catches of cod have averaged 625649 tonnes per year, with the largest landing being in 2014 (986 449 tonnes) [1]. During the same period, the catches of haddock and saithe averaged, respectively, 165222 and 162578 tonnes per year, with the largest landing for haddock registered in 2012 (315 627 tonnes) and for saithe in 2006 (212 822 tonnes) [2, 3]. Of these catches, approximately $83 \%$ of cod, $90 \%$ of haddock, and $97 \%$ of saithe were harvested by Norwegian and Russian vessels; the rest was caught by vessels from Iceland, Greenland, and the EU [1-3]. In 2014, nearly 70\% of the total catch of cod, $76 \%$ of haddock, and $49 \%$ of saithe were fished by bottom trawlers. The rest of the quota for these species was fished by gillnetters, longliners, jiggers, and demersal seiners [1-3]. Other commercially important species, mostly caught as bycatch in this fishery, are redfish (Sebastes marinus) and Greenland halibut (Reinhardtius hippoglossoides).

A key strategy of the Norwegian-Russian fishing legislation is to minimize the capture of undersized fish. When more than $15 \%$ of the catch (by numbers) is undersized, the fishery is closed. Moreover, the discard of dead or dying fish from regulated species is forbidden in this (Norway-Russian) fishery. The aim with size selection is to reduce the capture of undersized fish while also reducing the loss of fish above the minimum legal size (MLS). To achieve this goal, the use of sorting grids with a minimum bar spacing of $55 \mathrm{~mm}$ is currently mandatory in all trawls fishing for gadoids in this fishery.

Assessments of the Joint Norwegian-Russian Fisheries Commission show that the Northeast Arctic cod stock is in a fairly good state. The spawning biomass in 2013 was estimated at 2 million tonnes, while the total stock biomass was estimated to be around 3.5 million tonnes [1]. The International Council for the Exploration of the Sea (ICES), which is a global organization that develops science and advice to support the sustainable use of the oceans, advises the Joint Russian-Norwegian Fisheries Commission to set a total allowable catch (TAC) of 805000 tonnes in 2016 [1].

The Northeast Arctic haddock and saithe stocks are considered to be in good condition. ICES advises that when the Joint Russian-Norwegian Fisheries Commission management plan is applied, landings in 2016 should not exceed 223000 tonnes for haddock and 140000 tonnes for saithe $[2,3]$.

\section{Technical regulations for improving size selectivity}

In 1979, the Northeast Atlantic Fisheries Commission (NEAFC) agreed to increase the mesh size of codends made of cotton, polyamide, and polyester from 120 to $125 \mathrm{~mm}$. As of 1 January 1980, the minimum legal size of cod and haddock that could be kept was set at 39 and $35 \mathrm{~cm}$, respectively; in addition, the catches of undersized fish could not exceed 15\% (by weight) of 
the catch [4]. In 1982, the NEAFC increased the commercial sizes of cod and haddock to 42 and $39 \mathrm{~cm}$, respectively, and established that the bycatch of undersized fish should not exceed $15 \%$ (by numbers) of the catch. Norway also unilaterally increased the minimum mesh size of trawl codends to $135 \mathrm{~mm}$ regardless of the trawl material [4]. In 1983, a discard ban was introduced into the fishery [5]; it stated that vessels were obliged to land also the catches of all undersized fish. A surveillance program established during 1983-1984 showed that substantial areas need to be closed to the commercial fishery due to the high proportions of undersized cod and haddock in the catch. Typical catches in these areas could contain $30-50 \%$ of juvenile fish (by numbers). Therefore, the temporary closure of certain fishing areas led to a less efficient fishery because the fleet had to search for other areas to fish on [6].

Between 1985 and 1991, researchers in Norway conducted selectivity experiments that aimed at improving size selectivity of bottom trawl codends. These experiments considered different mesh configurations, round straps, different top and bottom panels, codend twine materials, and sorting grid systems $[7,8]$. The methods found to be most practical were the shortened lastridge ropes (12-15\% reduction) and the escape grids (Sort-X system). The shortened lastridge ropes gave similar size selection estimates as square mesh codends. However, square mesh codends were associated with meshing of fish, and especially redfish, and maneuverability challenges on deck [9].

Even though the Sort- $X$ sorting grid represented a revolutionary method for improving selectivity in trawl codends, in 1990 the Norwegian Directorate of Fisheries, in 1990, increased the minimum size of cod to $47 \mathrm{~cm}$ and of haddock to $44 \mathrm{~cm}$. According to this institution, an alternative mean of resource management had to be enforced in the fishery because the development of technical codend modifications had still not given the expected results [10].

Between 1990 and 1996, experiments with sorting grids that aimed at reducing the catch of young fish were conducted in Norway and Russia [11, 12]. In 1995, the Joint Russian-Norwegian selectivity experiments on cod in the Barents Sea proved that the selectivity of the Russian single-steel grid system "Sort- $V$ " and that of the double steel grid system "Sort- $X$ " were similar [12]. Based on the results of these experiments, as of 1 January 1997 both types of grids with 55-mm interbar space began to be used in cod and haddock fisheries in some limited areas of the Barents and Norwegian Seas (Figure 1). Later, the Institute of Marine Research of Norway satisfactorily adapted the Sort-V system to Norwegian trawlers [13, 14]. The new system, which is known as the Single grid and only includes some slight changes from the Sort-V system, was legalized by the Norwegian Directorate of Fisheries in 2000.

Since their introduction, the Sort- $\mathrm{X}$, Sort- $\mathrm{V}$, and Single grid have been associated with crew safety problems, especially when handling the grid sections in bad weather. During the late 1990s, experiments with grids made of other materials, such as plastics, fibreglass, nylon, and rubber, were promoted. The intention behind these experiments was to offer the industry grids that could be more easily handled, were more user-friendly, and were cheaper to purchase [15]. The systems studied were the plastic Sort- $X$, the Eurogrid, and the Flexigrid. The plastic Sort$X$ was made of high-density polyethylene (HDPE) materials and weighed considerably less than the steel version. The Eurogrid was made of massive nylon and was developed primarily for the trawl fishery in the North Sea [16]. Although these grids were designed to be more user- 
friendly alternatives to other grids on the market because of their low weight, flexibility, and the possibility of storing them in net drums, none of them was successfully introduced into the fishery. During three years of experimental work, the Flexigrid (made of Polyamide (PA) bars and rubber frames) (Figure 1) proved to have a selection capacity similar to that of the Sort- $X$ [17-20]. This new grid system was lighter, smaller, more flexible, and therefore easier to handle on deck. Thus, the Flexigrid system was legalized in the beginning of 2002.

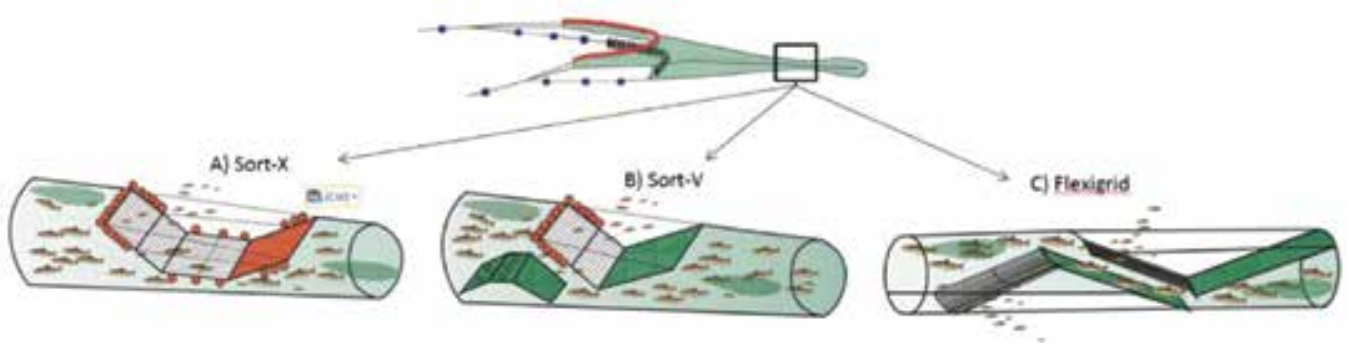

Figure 1. Mandatory sorting grids in the Barents Sea Demersal Fishery: (A) Sort-X, (B) Sort-V, and (C) Flexigrid.

Between 2004 and 2008, further experiments with escape panels were performed in the Barents Sea [21]. Despite the results showing similar selective performance to mandatory sorting grids [22, 23], escape panels were not considered as an alternative selection device for the Barents Sea Demersal Fishery.

Today, all four sorting grids described above are legal with a minimum grid bar spacing of 55 $\mathrm{mm}$ : the Sort- $X$, Sort-V, Single grid, and Flexigrid. The Sort-V and the Single grid system are still used by some vessels, but the system employed by the majority of vessels today is the Flexigrid. The two main reasons for fishermen to prefer the flexigrid system are that (a) it is a safer grid to use on deck, especially in bad weather, and (b) the retention of fish above the minimum size for cod and haddock is higher for the flexigrid than for the Sort-V/Single grid [24]. This second argument became especially important when in 2011 the minimum legal size was reduced from 47 to $44 \mathrm{~cm}$ for cod and from 44 to $40 \mathrm{~cm}$ for haddock. This reduction in minimum size resulted from the Russian-Norwegian joint meetings and the aim of standardizing the regulations for the Barents Sea. This reduction in minimum sizes was also accompanied by a reduction in the minimum codend mesh size. Thus, in addition to the grid, trawlers can today use codends with a minimum diamond mesh size of $130 \mathrm{~mm}$.

The rapid increase in the biomass of Atlantic cod in the period 2008-2014 has brought some unusual challenges for the Barents Sea trawlers, which have often met really high concentrations of cod in the fishing grounds. From the beginning, these high concentrations at sea were quickly reflected in reduced sorting capacity of sorting grids. The high catch rates encountered by the grid sections have led not only to reduced selection performance of the grids but also to more serious problems like breakage of grids and grid sections. Underwater recordings have 
shown that fish accumulates both in front and behind the grid [25] and does not fall back in the codend. Because the catch sensors are placed in the codend, the skipper does not receive any information on the ongoing catch accumulation in the gear. The consequence of this process is unwanted big catches that exceed the vessel's processing capacity and lead to reduced quality of the catch [25].

The main reason for the accumulation of fish in front and behind the grid is related to the reduction in water flow created by the presence of the grid section and especially the sorting $\operatorname{grid}(\mathrm{s})$ [26]. In the past years, there have been efforts to increase the water flow in the grid sections to try to mitigate the fish accumulation problem. If the water flow is too high, grids lose their selective properties and fish can flow through the section without having a chance to contact the grid. Sorting grid sections have traditionally been constructed as two-panel constructions, but in an attempt to improve the flow conditions in the section new four-panel constructions have been tested in the past years. Gjøsund et al. [26] showed that a four-panel Single grid section allows higher water flow through the section than an equivalent two-panel grid section. Because the tests carried out at sea also indicate that at high catch rates four-panel sorting grid sections with larger cross-section areas perform better than two-panel grid sections (Sort- $X$, Sort-V, and Flexigrid) (own data, unpublished), the use of these types of sections was legalized in 2014 and 2015.

\section{Description of size selectivity}

Selective fishing refers to the ability of a fishing method to target and capture fish by size and/ or species. Size selective fishing in the Barents Sea demersal trawl fishery aims at avoiding catching fish below the minimum landing sizes that enters the fishing gear while simultaneously having high probability of retaining fish above the minimum size. In the Barents Sea demersal trawl fishery, the selective devices in the fishing gear consist of a sorting grid followed by a size selective codend. The grid enables releasing fish up to a certain size through the grid, provided that they are able to find their way out between the bars. Fish that do not manage to escape through the grid fall back into the codend where they have an additional chance to escape through the meshes, provided that they are not too big to be able to pass through them. It is obvious that based on this system only fish below a certain size will have a chance to escape through the grid or codend meshes. The smaller the fish the easier they will fit through between the grid bars and through the codend meshes. Therefore, it is to be expected that the retention probability for a fish entering the gear will increase with the size of the fish. For the description of the size selection in a fishing gear, it is convenient to use a parametric mathematical model that is able to describe the retention probability $r$ of the fish as a function of its length $l$. Traditionally, as for many other fisheries and trawl constructions the combined size selection of the grid and codend for the species in the Barents Sea demersal trawl fishery has been described by the logit size selection model: 


$$
r(l, L 50, S R)=\frac{\exp \left(\frac{\ln (9)}{S R} \times(l-L 50)\right)}{1.0+\exp \left(\frac{\ln (9)}{S R} \times(l-L 50)\right)}
$$

In a logit size selection model, the retention probability will increase monotonously with the length of the fish. The size selection for this model is fully defined based on the value of the two parameters $L 50$ and SR. $L 50$ can be interpreted as the length at which a fish will have $50 \%$ probability of being retained by the fishing gear conditioned that it enters the gear. $S R$ can be interpreted as the difference length between fish with, respectively, $75 \%$ and $25 \%$ of being retained in the fishing gear conditioned they enter it. Figure 2 illustrates the logit size selection model and the meaning of the selection parameters L50 and SR.

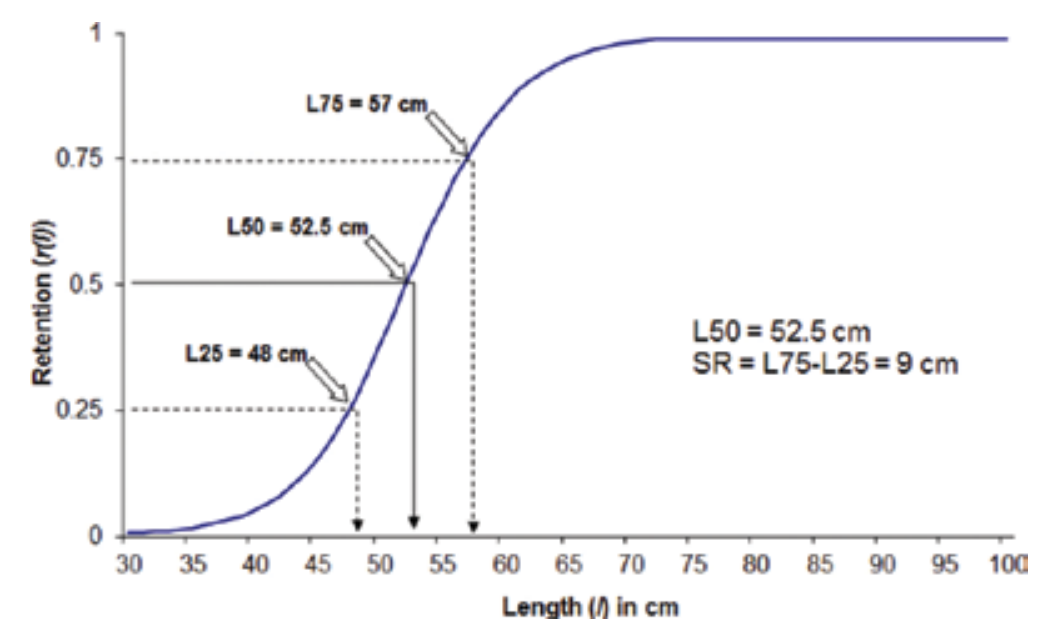

Figure 2. A selection curve that describes the logit size selection model.

Based on the values of $L 50$ and $S R$ for a logit size selection model, the length $L i$ of a fish with $i$ $\%$ of being retained can be calculated by:

$$
L i=L 50+\frac{S R}{\ln (9)} \times \ln \left(\frac{0.01 \times i}{1.0-0.01 \times i}\right)
$$

Several studies have aimed at quantifying size selection for cod and haddock in the selective systems deployed in the Barents Sea demersal trawl fishery in terms of the values for L50 and SR using the logit size selection model [11, 13, 14, 16, 21, 22].

However, the logit size selection model presents some limitations which are important when considering the size selection systems used in the Barents Sea demersal trawl fishery. First, it 
does not explicitly reflect the dual nature of the size selection of a system consisting of a size selective grid preceded by a size selective codend. This can lead to a poor description of the size-dependent retention probability in the fishing gear in cases where the size selective properties of the grid and the codend differ considerably. Second, the logit model does not enable quantifying the individual contributions of the grid and the codend to the combined size selection in the gear. This is an important limitation when trying to improve size selection based on implementing gear modifications. Third, the logit model is not able to account for that not necessary all fish are able to make contact with the grid during their drift towards the codend. Besides potentially leading to a poor overall description of the size selection in the gear, this limitation also disables the quantification effect on the sorting efficiency of the grid by, for example, changing grid area size or making modifications to the lifting panel ahead of a Sort-V/Single grid section.

Based on the above-mentioned limitations, recent studies on the size selection in the Barents Sea demersal trawl fishery [30] have applied a more complex dual size selection model $r_{\text {dual }}$ that accounts for all of these limitations:

$$
\begin{aligned}
& r_{\text {dual }}\left(l, C_{\text {grid }}, L 50_{\text {grid }}, S R_{\text {grid }}, L 50_{\text {codend }}, S R_{\text {codend }}\right)=\left(1.0-C_{\text {grid }}+C_{\text {grid }} \times \operatorname{logit}\left(l, L 50_{\text {grid }}, S R_{\text {grid }}\right)\right) \\
& \times \operatorname{logit}\left(l, L 50_{\text {codend }}, S R_{\text {codend }}\right)
\end{aligned}
$$

The dual size selection model contains five parameters, $C_{\text {grid }} L 50_{\text {grid, }} S R_{\text {grid }} L 50_{\text {codend }}$ and $S R_{\text {codend }}$. The first three describe the size selection in the grid while the last two describe the size selection in the codend. The parameter $C_{\text {grid }}$ quantifies the proportion of fish entering the grid section that makes contact with the grid and is size selected by it. For the fish that makes contact with the grid, their size selection is described by a logit model with the parameters $L 50_{\text {grid }}$ and $S R_{\text {grid }}$. For the codend, the size selection is described by an additional logit model with the parameters $L 50_{\text {codend }}$ and $\mathrm{SR}_{\text {codend }}$.

The grid contribution to the combined size selection is described by Eq. (3) (the term in the first brackets) and is named as the clogit size selection model [31]:

$$
r_{\text {clogit }}\left(l, C_{\text {grid }}, L 50_{\text {grid }}, S R_{\text {grid }}\right) \equiv 1.0-C_{\text {grid }} \times\left(1.0-r_{\text {logit }}\left(l, L 50_{\text {grid }}, S R_{\text {grid }}\right)\right)
$$

Model (4) quantifies the length-dependent retention probability for that (conditioned it entered that part of the trawl) a fish is still inside the trawl after it has passed through the section of the trawl where the grid is installed. Based on Eq. (4), Eq. (3) can be simplified to:

$$
\begin{aligned}
& r_{\text {dual }}\left(l, C_{\text {grid }}, L 50_{\text {grid }}, S R_{\text {grid }}, L 50_{\text {codend }}, S R_{\text {codend }}\right)= \\
& r_{\text {clogit }}\left(l, C_{\text {grid }}, L 50_{\text {grid }}, S R_{\text {grid }}\right) \times r_{\text {logit }}\left(l, L 50_{\text {codend }}, S R_{\text {codend }}\right)
\end{aligned}
$$




\section{Experimental methods for collecting selectivity data}

The selectivity of fishing gear should be measured under conditions that mimic commercial fishing. Ideally, the sea trials should be undertaken on commercial fishing grounds, at commercial fishing depths, at commercial catch rates and sizes, and during the commercial fishing season. It is well known that variations in the environmental conditions or fish composition in the fishing grounds can influence the selective performance of fishing gear. This is not only because environmental factors affect fish behaviour towards fishing gears but also because selective fishing gears can have limitations with regard to fish densities entering it for example.

Success in selectivity trials at sea rely first on a good experimental design. It is important to determine when and where the experiments will be carried out so that the trials represent ordinary fishing conditions. Also, the choice of a sampling method to be used is crucial because it will determine what kind of additional gear one will have to use during the trials. Finally, the choice of a sampling method should be done considering the analytical and practical advantages/disadvantages of each of the available methods.

Different methods for measuring selectivity in towed fishing gears are described in reference [27]. These authors divided the methods into two categories: the Paired-gear method and Covered-gear method. In the Paired-gear method, two gears of equal overall dimensions are towed alternatively or alongside each other. In one of the gears (the test gear), the selectivity device to be tested is installed, whereas the other gear (the control gear) is built in small unselective meshes (Figure 3). Thus, the selective properties of the tested device are calculated, assuming that the small mesh size gear captures a size and species composition that is equal to the one that has entered the test gear.
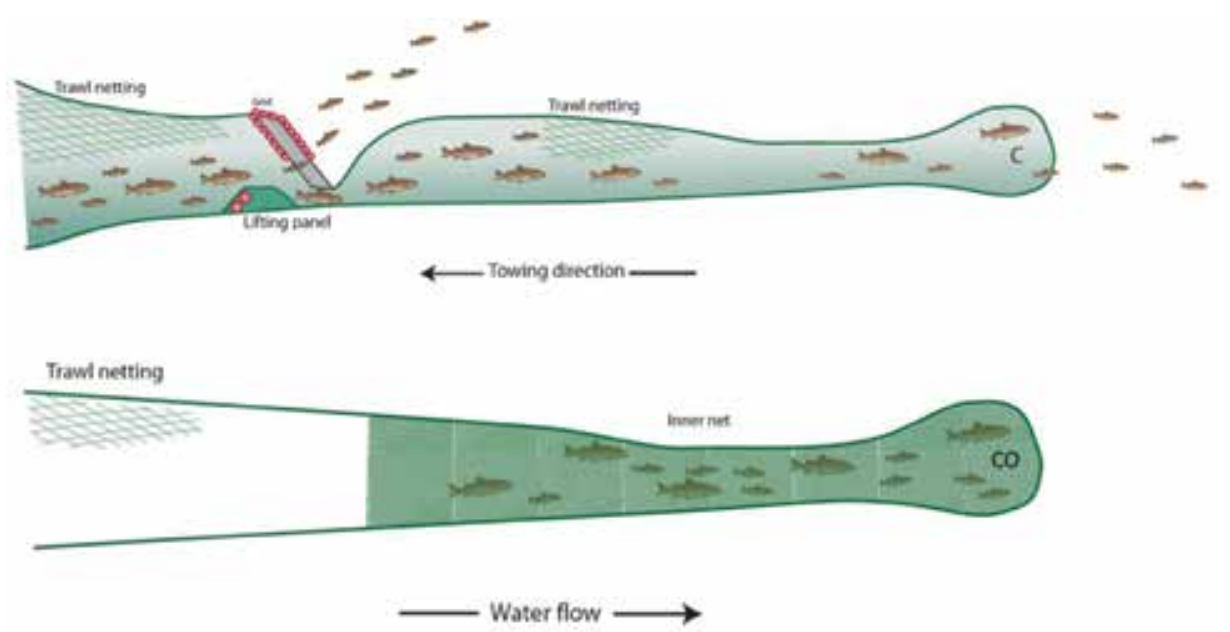

Figure 3. Illustration of the Paired-gear method showing the test (above) and the control (below) gear. 
The trouser trawl, twin trawl, parallel haul, and alternate haul methods are examples of the Paired-gear method [27]:

- Trouser trawl method: In a single trawl, the belly is divided into two extension pieces and codends in a way that one of them acts as the control gear and the other one acts as the test gear.

- Twin trawl method: In this case, the gear is composed of two trawls. In one of the trawls, the gear to be tested is installed while the other one is used as control.

- Parallel haul method: In this case, two vessels tow one single trawl each alongside each other. In one of the trawls, the gear to be tested is installed while the other one is used as control.

- Alternate haul method: Here one vessel alternates the use of the test and the control gear.

The covers used in the Covered-gear method can vary a lot in size and shape, depending on the gear they need to cover [24]. The most important properties to look for when choosing a cover are that it needs to cover the selective device completely, it should keep the desired geometry and not be an obstacle for fish escaping through the tested device (avoid masking effect), and it should not (or minimally) reduce water flow. Square mesh covers are therefore most often used to avoid geometry problems and masking of the selective device. Still, measurements of the water flow show that the flow inside codends can be substantially reduced even when using these types of square mesh covers [28].

In the Barents Sea, the compulsory selectivity devices fishermen are allowed to use are composed of a grid section followed by a 130-mm codend. Thus, the selectivity process in the gear is a dual selection process [30] where a selection process in the grid section is followed by a selection process in the codend. To measure the selectivity of such dual selection devices, one can either install a single cover over both devices (Figure 4) [11] or install an independent cover over each of the selective devices (Figure 5) [29]. The challenge of using independent covers with respect to using a single cover is that there is an additional compartment to be considered and that the practical operations on board with multiple covers can be more challenging.

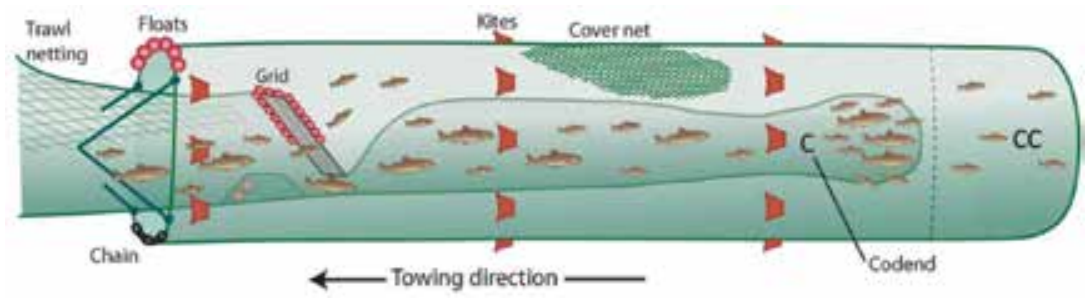

Figure 4. Single covered method that covers the grid section and codend. 


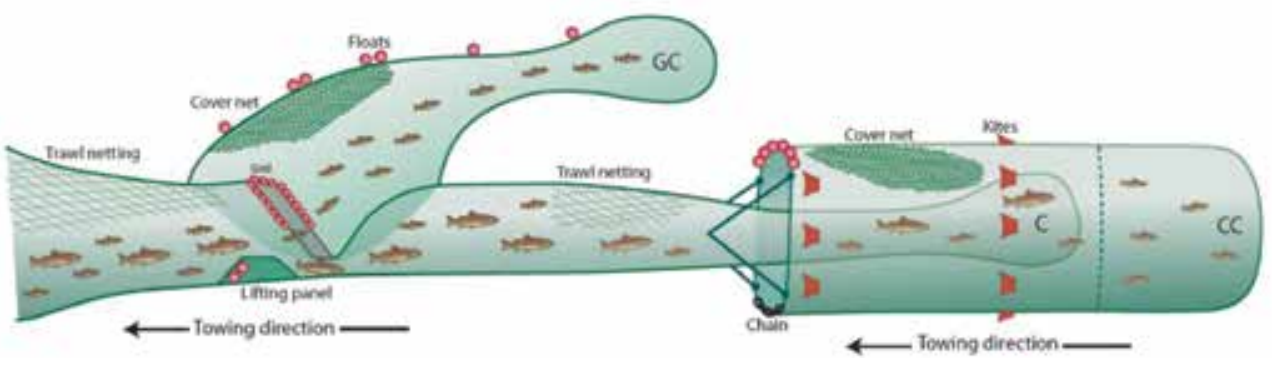

Figure 5. Dual cover method.

If the objective of the experiment is to collect selectivity data in order to assess only the size selection in the grid section, then the covered-grid method can be applied (Figure 6) [25].

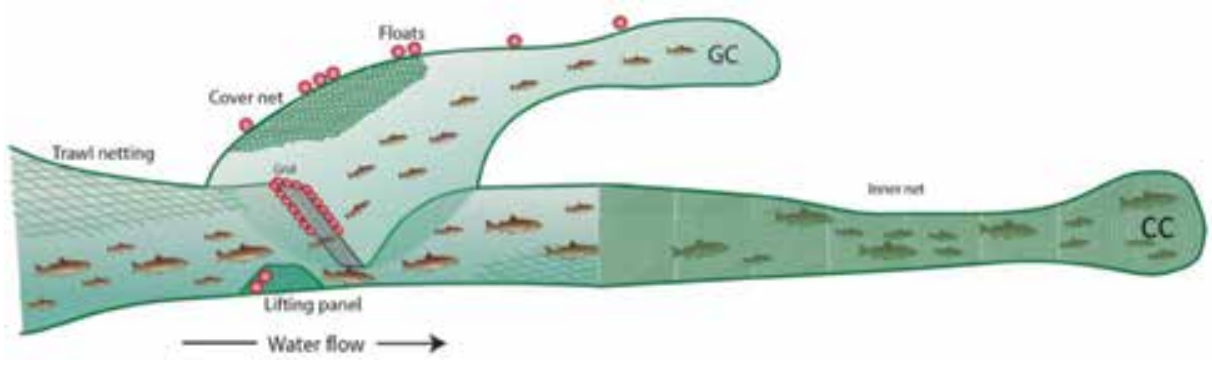

Figure 6. The Covered-grid method.

In some experiments, the use of covers can be challenging, for example, they cannot be installed in a way that can guarantee that all escapees are collected, there is limited space on the vessel, etc. In such circumstances, the Paired-gear method is applied.

When carrying out trawl selectivity experiments, it is important that the trials are carried out within a limited period of time and in an area that holds a fairly similar species and size distribution of fish. Large variations in the availability of fish can create loss of precision in the results, whereas large variations in the size distribution of fish can lead to large between-haul variation in the selectivity parameters L50 and SR. Methods like the Covered-gear method, which provides direct information about the fish escaping from the selective device being tested, are more robust regarding variability in both abundance and size distribution of fish. Other methods, like, for example, the alternate haul method, are more sensible to changes in fishing area as one needs to assume that the size and species distribution entering the gear is the same for the test and control hauls carried out.

Measuring the size selective properties of towed fishing gears requires length measuring the fish collected in the different compartments of the gear (test codend and cover(s) or control codend). The number of fish that needs to be caught and length measured to achieve a certain precision in the selectivity results have for years been an issue among fisheries scientists. 
Especially in the cases where the catches exceed the number of fish that can be measured, it is important to know how many fish one should measure and how an eventual subsample should be taken. An ideal subsample is a random sample that represents well the size distribution of the fish in the catch. Normally this subsample is taken from the catch in random batches to avoid potential accumulations of specific sizes of fish that can occur, for example, in the collection bins of the vessels. For each species, the fish in the fraction of the catch that is not length measured needs to be counted to calculate the sampling ratio in the catch.

Diverse sampling strategies in experimental trawl selectivity gear were studied by Millar [34], who concluded that sampling the same number of fish from the different compartments was the most efficient sampling method. Also, how the precision in selectivity results varied depending on the amount of fish caught and length measured with both the Paired-gear and the Covered-gear methods was investigated in reference [35]. The results of the investigation showed that the uncertainty in the selection parameters L50 and SR decreased with increasing number of fish measured, and that this relationship could be described by a power model. The results also demonstrated that the sampling effort needed to achieve a specific uncertainty level for the selection parameters was always lower for the Covered-gear method compared to the Paired-gear method (in many cases the number of fish that would need to be measured to maintain a specific uncertainty level was around 10 times higher for the Paired-gear method than for the Covered-gear method). The results of these studies illustrate again the importance of carrying out proper experimental design before starting the sea trials. Both the potential limitations of the operations that need to be carried out on board and the advantages and disadvantages of the different sampling methods need to be always considered.

For each haul conducted with one of the experimental collection methods described above (Figures 3-6), the catch in each compartment (codend, cover(s), control) is length measured species by species. These length measurements are sorted into so-called length classes that in the Barents Sea are typically $1 \mathrm{~cm}$ wide. In a dataset, each haul consists of count data that show how many fish of those collected in each of the compartments belong to the same length class. If subsampling is applied only to a proportion of the fish in each compartment, the sampling factor for each compartment is also provided together with the count data. Table 1 shows an example of a data file resulting from one haul. In this case, the data was collected using the single covered method (Figure 4), and $54 \%$ of the fish in codend and $62 \%$ of the fish in the cover were length measured. The rest of the fish in each compartment was counted. Analysis of such data (Table 1) forms the basis for estimating the selectivity of trawl gear by the methods described in the next section.

\begin{tabular}{lll}
\hline Length class $(\mathbf{c m})$ & Number of fish in the codend & Number of fish in the cover \\
\hline 25.5 & 0 & 0 \\
26.5 & 0 & 0 \\
27.5 & 0 & 0 \\
28.5 & 0 & 0
\end{tabular}




\begin{tabular}{|c|c|c|}
\hline Length class $(\mathrm{cm})$ & Number of fish in the codend & Number of fish in the cover \\
\hline 29.5 & 0 & 0 \\
\hline 30.5 & 2 & 43 \\
\hline 31.5 & 2 & 23 \\
\hline 32.5 & 3 & 64 \\
\hline 33.5 & 1 & 118 \\
\hline 34.5 & 7 & 116 \\
\hline 35.5 & 5 & 279 \\
\hline 36.5 & 7 & 137 \\
\hline 37.5 & 5 & 179 \\
\hline 38.5 & 10 & 180 \\
\hline 39.5 & 13 & 106 \\
\hline 40.5 & 12 & 266 \\
\hline 41.5 & 2 & 61 \\
\hline 42.5 & 7 & 50 \\
\hline 43.5 & 9 & 52 \\
\hline 44.5 & 12 & 26 \\
\hline 45.5 & 16 & 21 \\
\hline 46.5 & 12 & 61 \\
\hline 47.5 & 14 & 9 \\
\hline 48.5 & 21 & 18 \\
\hline 49.5 & 16 & 8 \\
\hline 50.5 & 26 & 3 \\
\hline 51.5 & 13 & 11 \\
\hline 52.5 & 21 & 0 \\
\hline 53.5 & 10 & 5 \\
\hline 54.5 & 22 & 0 \\
\hline 55.5 & 16 & 1 \\
\hline 56.5 & 11 & 2 \\
\hline 57.5 & 10 & 0 \\
\hline
\end{tabular}




\begin{tabular}{lll}
\hline Length class $(\mathrm{cm})$ & Number of fish in the codend & Number of fish in the cover \\
\hline 58.5 & 20 & 1 \\
59.5 & 7 & 0 \\
60.5 & 9 & 0 \\
61.5 & 8 & 0 \\
62.5 & 7 & 0 \\
63.5 & 5 & 0 \\
64.5 & 0 & 0 \\
65.5 & 2 & 0 \\
SAMPLING & 0.54 & 0.62 \\
\hline
\end{tabular}

Table 1. Illustration of a dataset (one single haul) collected using the covered codend method.

\section{Methods to estimate size selection parameters}

The accepted scientific method for estimation of trawl size selectivity is based on a Maximum Likelihood Estimation (MLE) [27]. The maximization problem this represents is by convenience converted into a minimization problem simply by adding a minus sign in front of the function that else would have been a maximization. Further, to simplify the formulation, the natural logarithm $(l n)$ is taken to the function prior to minimization as this leads to a simpler formulation that is easier to minimize. This step is in valid since the $\ln$ of a function, and the function itself, has the same minimum for the same model parameter values. The function to minimize depends both on the selection system for which the data has been collected and the level of detail intended, and as described in the previous section on which of the experimental data collection has been applied. Conditioned that the size selection model applied in the estimation is able to describe the size selection processes occurring sufficiently well, the MLE estimation provides the model parameters (see Section 3) that make the collected experimental size selection data most likely. If the intention is to assess the combined size selectivity in a single haul $j$ based on the covered gear method (Figure 4), based on the logit model Eq. (1), the following equation is minimized with respect to $\mathrm{L} \mathrm{O}_{\mathrm{j}}$ and $\mathrm{SR}_{\mathrm{j}}$ :

$$
-\sum_{l}\left\{\begin{array}{l}
n c_{j l} \times \ln \left(\frac{q c_{j} \times r_{\text {logit }}\left(l, L 50_{j}, S R_{j}\right)}{q c_{j} \times r_{\text {logit }}\left(l, L 50_{j}, S R_{j}\right)+q c c_{j} \times\left(1.0-r_{\text {logit }}\left(l, L 50_{j}, S R_{j}\right)\right)}\right)+n c c_{j l} \\
\times \ln \left(\frac{q c c_{j} \times\left(1.0-r_{\text {logit }}\left(l, L 50_{j}, S R_{j}\right)\right)}{q c_{j} \times r_{\text {logit }}\left(l, L 50_{j}, S R_{j}\right)+q c c_{j} \times\left(1.0-r_{\text {logit }}\left(l, L 50_{j}, S R_{j}\right)\right)}\right)
\end{array}\right\}
$$


Where $n c_{j l}$ is the number of fish in length class $l$ that is length measured in the haul $j$ in the codend; and $n c c_{j l}$ is the number of fish in length class $l$ that is length measured in the haul $j$ in the cover. $q c_{j}$ and $q c c_{j}$ are the corresponding sampling rates. The summation in Eq. (6) is over length classes $l$.

In case the Paired-gear method (Figure 3) is applied for the data collection, the function to minimize would be:

$$
-\sum_{l}\left\{\begin{array}{l}
n c_{j l} \times \ln \left(\frac{q c_{j} \times S P_{j} \times r_{\text {logit }}\left(l, L 50_{j}, S R_{j}\right)}{q c_{j} \times S P_{j} \times r_{\text {logit }}\left(l, L 50_{j}, S R_{j}\right)+q c o_{j} \times\left(1.0-S P_{j}\right)}\right)+n c o_{j l} \times \\
\ln \left(\frac{q c o_{j} \times\left(1.0-S P_{j}\right)}{q c_{j} \times S P_{j} \times r_{\text {logit }}\left(l, L 50_{j}, S R_{j}\right)+q c o_{j} \times\left(1.0-S P_{j}\right)}\right)
\end{array}\right\}
$$

Compared to Eq. (6), Eq. (7) includes an additional parameter $S P_{j}$ that needs to be estimated together with $L 50_{j}$ and $S R_{j} . S P_{j}$ is the so-called split parameter that quantifies the proportion of fish entering the test side of the gear. $n c o_{j l}$ is the amount of fish in length class $l$ that is length measured in the control codend and $q c o_{j}$ is the corresponding sampling rate.

Several of the size selection studies carried out in the Barents Sea demersal trawl fishery have applied Eq. (6) or (7) to estimate the combined size selection for individual hauls. In most cases, a mean size selection for the group hauls is subsequently estimated in a second estimation step using the size selection results obtained in the individual hauls and following an estimation procedure described in references [24, 30,32]. This procedure accounts for both the uncertainty in the estimated size selectivity in the individual hauls (often named within-haul variation) and the between-haul variation in the size selection.

However, in most of the recent studies the dual nature of the size selection process in the gears has been explicitly accounted for by basing the analysis on the dual selection model described by Eq. (5). Further, in most of these studies the final aim has been to estimate the size selection averaged over a group of hauls. Therefore, the process involves summing data over hauls in the estimation process.

If the single covered data collection method (Figure 4) is applied, this would lead to minimizing the following equation:

$$
-\sum_{j=1}^{m} \sum_{l}\left\{\begin{array}{l}
\frac{n c_{j l}}{q c_{j}} \times \ln \left(r_{\text {dual }}\left(l, C_{\text {grid }}, L 50_{\text {grid }}, S R_{\text {grid }}, L 50_{\text {codend }}, S R_{\text {codend }}\right)\right)+\frac{n c c_{j l}}{q c c_{j}} \times \\
\ln \left(1-r_{\text {dual }}\left(l, C_{\text {grid }}, L 50_{\text {grid }}, S R_{\text {grid }}, L 50_{\text {codend }}, S R_{\text {codend }}\right)\right)
\end{array}\right\}
$$

In the case of Eq. (8), the minimization is carried out in five dimensions to estimate $C_{\text {grid }} L 50_{\text {gridr }}$ $S R_{\text {grid, }} L 50_{\text {codend }}$ and $S R_{\text {codend }}$. The outer summation is over the $m$ hauls conducted. 
If the Paired-gear data collection method (Figure 3) is applied, then the estimation is conducted in six dimensions because the average split $S P$ also needs to be estimated. In this case, the function to minimize becomes:

$$
-\sum_{j=1}^{m} \sum_{l}\left\{\begin{array}{l}
\frac{n c_{j l}}{q c_{j}} \times \ln \left(\frac{S P \times r_{\text {dual }}\left(l, C_{\text {grid }}, L 50_{\text {grid }}, S R_{\text {grid }}, L 50_{\text {codend }}, S R_{\text {codend }}\right)}{S P \times r_{\text {dual }}\left(l, C_{\text {grid }}, L 50_{\text {grid }}, S R_{\text {grid }}, L 50_{\text {codend }}, S R_{\text {codend }}\right)+1-S P}\right)+\frac{n c o_{j l}}{q c o_{j}} \\
\times \ln \left(\frac{1-S P}{S P \times r_{\text {dual }}\left(l, C_{\text {grid }}, L 50_{\text {grid }}, S R_{\text {grid }}, L 50_{\text {codend }}, S R_{\text {codend }}\right)+1-S P}\right)
\end{array}\right\}
$$

If the dual covered data collection method (Figure 5) is applied, the precision in estimating the size selection of the gear can be improved. In this case, the equation to be minimized becomes:

$$
\sum_{j=1}^{m} \sum_{l}\left\{\begin{array}{l}
\frac{n g_{j l}}{q g_{j}} \times \ln \left(1-r_{\text {clogit }}\left(l, C_{\text {grid }}, L 50_{\text {grid }}, S R_{\text {grid }}\right)\right)+\frac{n c c_{j l}}{q c c_{j}} \times \\
\ln \left(r_{\text {clogit }}\left(l, C_{\text {grid }}, L 50_{\text {grid }}, S R_{\text {grid }}\right) \times\left(1-r_{\text {logit }}\left(l, L 50_{\text {codend }}, S R_{\text {codend }}\right)\right)\right)+\frac{n c_{j l}}{q c_{j}} \times \\
\ln \left(r_{\text {clogit }}\left(l, C_{\text {grid }}, L 50_{\text {grid }}, S R_{\text {grid }}\right) \times r_{\text {logit }}\left(l, L 50_{\text {codend }}, S R_{\text {codend }}\right)\right)
\end{array}\right\}
$$

If the only objective is to assess the average size selection in the grid section, then the Coveredgrid data collection method (Figure 6) can be applied. In this case, the function to minimize will be:

$$
\sum_{j=1}^{m} \sum_{l}\left\{\begin{array}{l}
\frac{n g_{j l}}{q g_{j}} \times \ln \left(1-r_{\text {clogit }}\left(l, C_{\text {grid }}, L 50_{\text {grid }}, S R_{\text {grid }}\right)\right)+\frac{n c c_{j l}}{q c c_{j}} \times \\
\ln \left(r_{\text {clogit }}\left(l, C_{\text {grid }}, L 50_{\text {grid }}, S R_{\text {grid }}\right)\right)
\end{array}\right\}
$$

When estimating the average size selectivity, based on minimizing Eq. (8)-(10) or (11), the uncertainty on the parameters and size selection curve is often estimated using a double bootstrap method as described in references [30, 31, 33].

The ability of a size selection model to describe the experimental size selection data is frequently evaluated based on calculating a $p$-value for model deviance versus the degrees of freedom [31]. This $p$-value quantifies the probability to by coincidence obtain at least as big discrepancy between model and data as observed. Thus, this $p$-value should not be below 0.05 for the model to be able to describe the experimental size selection data well. However, a low $p$-value can also be a result of over-dispersion in the data, which in case of having a low $p$ value should be inspected before rejecting the size selection model. 


\section{The FISHSELECT methodology}

FISHSELECT is a framework of methods, tools, and software developed to determine whether or not a fish is able to penetrate a certain mesh [36]. Through computer simulation, FISHSELECT enables the estimation of the selectivity parameters L50 and SR for a certain species and selection device by comparing the morphological characteristics of the former and the shape and size of the latter. This methodology has been successfully used to estimate mesh selectivity of the most relevant demersal fish species in the Barents Sea: cod (G morhua), haddock ( $M$. aeglefinus), Greenland halibut (R. hippoglossoides), and redfish (Sebastes ssp.) [31, 37-39]. The results obtained with the application of FISHSELECT have proved the reliability of the method as they are coherent with the results registered from earlier sea trials [37-39]. Thus, if we consider the flexibility the method offers compared to the traditional selectivity measuring methods, the value of the method becomes obvious.

By means of the FISHSELECT tools and software, one can predict the selectivity of a specific fishing gear and species. This can also be achieved with the more traditional selectivity study methods; however, FISHSELECT is unique that once the morphology analyses are carried out for a certain species, one can predict the selectivity of this species for endless mesh shapes (including grids), sizes, and opening angles (OAs). Some of the features or advantages of FISHSELECT with respect to the traditional sea trial selectivity studies are that:

I. New estimations do not need additional fieldwork.

II. FISHSELECT provides fast answer on the selectivity parameters that can be expected from an eventual change in the gear. In a similar way, if one wishes to change the selection properties of a gear to achieve certain selectivity for a species or multiple species, FISHSELECT can fast predict the changes necessary in the gear to achieve those selectivity objectives.

III. The method gives an overall estimation of as many species as one wishes. It is interesting to note that most often the gear will be designed as a compromise on the selective properties of several species [37] that different cleaner-fish species with various body sizes and shapes are harvested at the same time.

IV. The results obtained from FISHSELECT can also be used to aid in the interpretation of sea trial selectivity results.

Because FISHSELECT is based on the relationship between fish length and weight, and the shape of the fish's cross-section at different points of its body, factors like the condition of the fish in the different seasons need to be taken into consideration. When collecting the morphological data for a certain species, it is important to cover the whole length spectra for the fish as through its growth not all the body parts grow proportionally. Also, if the fish included in the measurements is captured through different seasons, it would help covering a wider spectra of the different shapes the species can acquire. The wider the spectra of fish covered and the higher the amount of fish included in the measured fish pool, the lower the uncertainty in the predictions. 
The application of FISHSELECT is divided into four steps:

Step 1: morphological data

In the first step, the fish length (in mm), weight (in g), and its morphology at different cross sections (CSs) need to be measured. The number and position of the CSs taken are different for each fish species, and are decided based on earlier experiences considering the positions likely to determine if a fish will be able to escape through meshes or grids of different sizes and shapes. For fish, in general, three cross sections have been measured per fish [38]. For cod and haddock, for example, these three cross sections were located at the end of the opercula (maximum girth of the head), at the foremost point of the first dorsal fin, and maximum girth of the fish [37]. The cross sections are measured by means of a mechanical sensing tool named morphometer. The morphometer consists of an aluminum frame and measuring aluminum sticks ( $2.5 \mathrm{~mm}$ wide) that can be shifted horizontally and fixed at a desirable position (Figure 7). The shape formed in the morphometer is later converted into a digital image using a flatbed scanner. The image resulting from the scanner is finally digitized using the image analysis tools implemented in the FISHSELECT software tool [36].

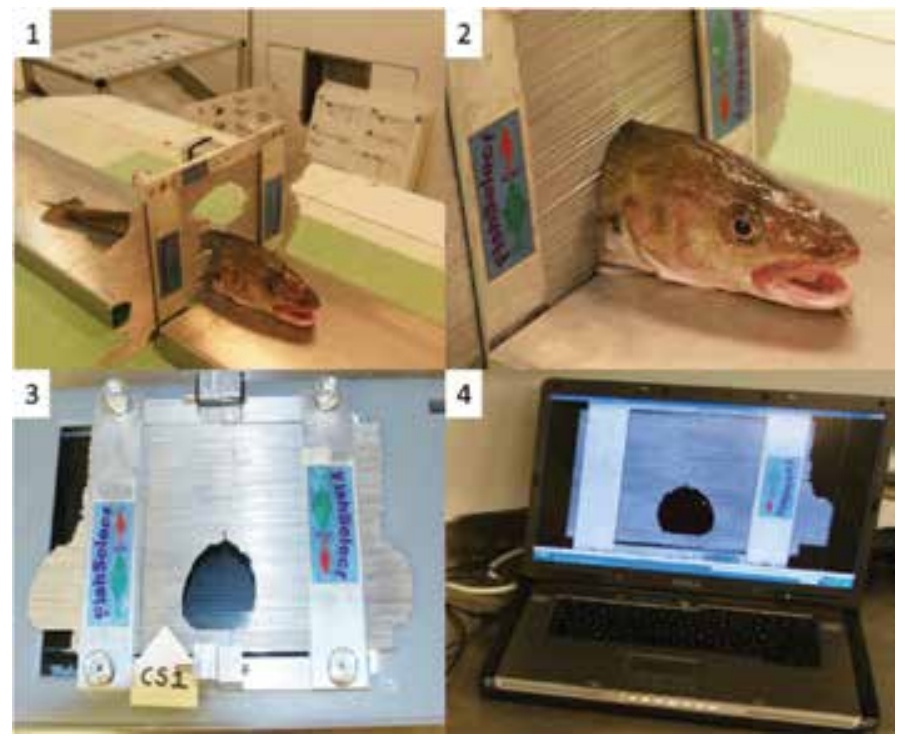

Figure 7. Illustration of the use of a morphometer on cod (Gadus morhua).

\section{Step 2: Fall-through experiments}

Fall-through experiments are carried out to decide if a fish can in principle physically pass through a certain rigid shape (subjected to the force of gravity only) (Figure 8). These shapes are perforated in 5-mm-thick solid nylon plates [39]. The shapes tested normally include diamonds, hexagons, and rectangles; however, there are no restrictions to the shapes one can test and use in FISHSELECT. 


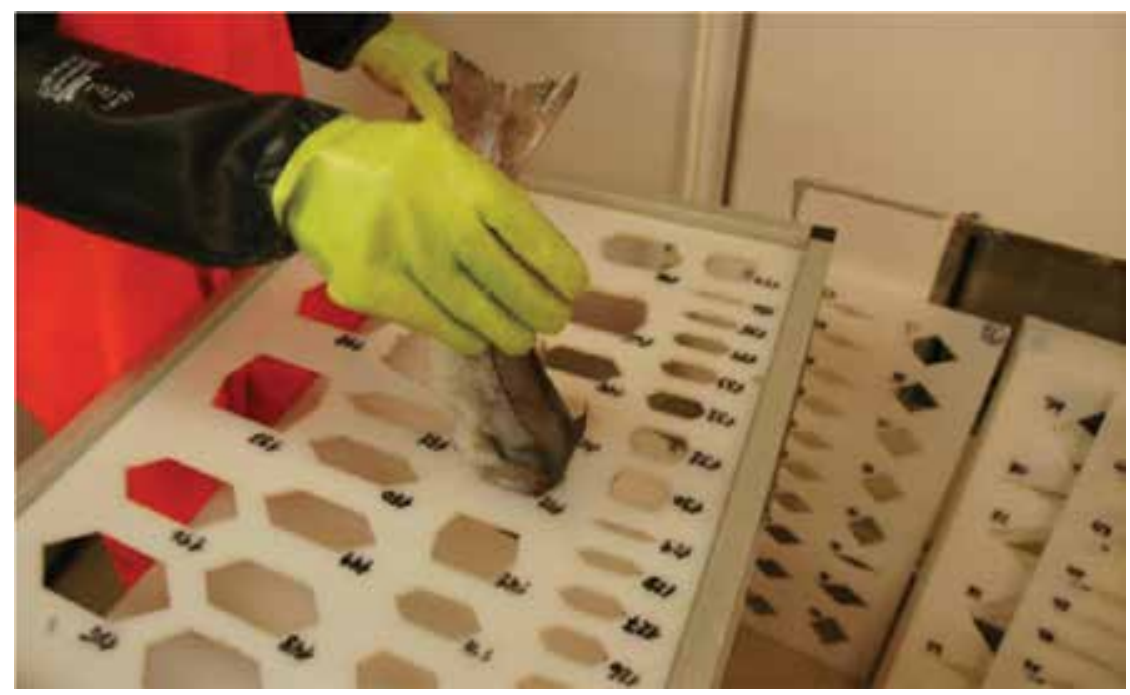

Figure 8. Illustration of the fall-through procedure on haddock (Melanugrammus aeglefinus). Each interchangeable plate contains a number of different mesh shapes where each fish is tested. All fish included in the study need to be tested in all meshes.

\section{Step 3: Cross-section modeling}

The CS shapes registered with the morphometer need to be modeled so that they can be further analyzed in FISHSELECT. The software has more than 100 different models available to model each of the different cross sections of the fish (Figure 9). One needs to first determine which of the available models seems to represent each of the CSs well enough and later fit all these relevant models to each digitized shape. Each of the models is tested on each of the CSs registered for each fish, and the model with the lowest AIC [40] is chosen for further analysis in FISHSELECT. Once the parameters in the model defining each of the cross sections are the length of the fish, one can create virtual populations with defined CSs.

a

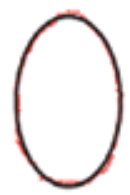

e

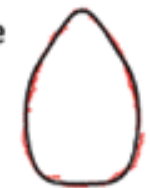

b
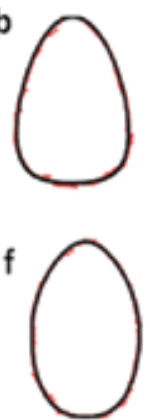

c
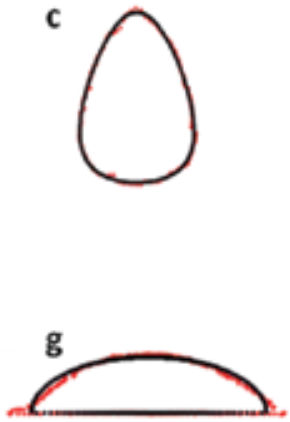
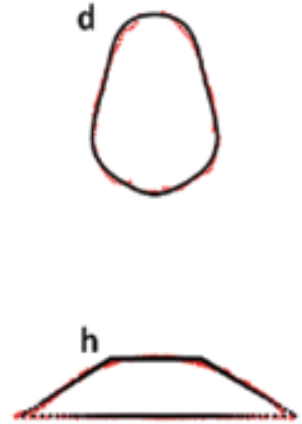

Figure 9. Illustration of some of the parametric shapes available in FISHSELECT: Shapes like (a)-(f) are typically used for roundfish while $(\mathrm{g})-(\mathrm{h})$ are normally used on flatfish species. 


\section{Step 4: search for penetration model}

Fish can be compressed both dorsoventrally and laterally. Thus, different compression models need to be tested for each CS as a first step to establish an optimal penetration model for the species tested (Figure 10). The optimal penetration model is established by comparing the penetration results of each compression model tested with the fall-through results. The degree of agreement (DA) between the simulated and experimental fall-through results is then used to choose an optimal penetration model (see $[36,37]$ for the mathematical expression and further information about DA).

\section{CS1}

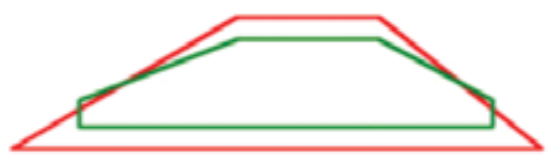

\section{CS2}

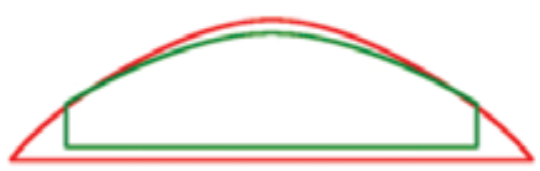

Figure 10. Shape of the optimal penetration model (green) overlapped on the original shape modeled from the morphometer (red) for Greenland Halibut (Reinhardtius hippoglossoides).

Given virtual populations with the desired population structure and defined CSs and a defined penetration model, the size selective properties of a range of mesh shapes and sizes can be predicted in FISHSELECT by simulation. The outcome of the method consists of L50 and SR estimations for all of the included mesh sizes, shapes, and OAs.

\section{FISHSELECT results for Northeast Arctic demersal species}

Cod, haddock, redfish, and Greenland halibut are the four most important commercial species in the Barents Sea demersal trawl fisheries. FISHSELECT has already been applied to all four species, and the results have in all cases showed to be coherent with the results obtained from earlier sea trials [31, 37-39], . Because the compulsory gear in the Barents Sea demersal trawl fishery is composed of a sorting grid followed by a size selective diamond mesh codend, the FISHSELECT studies present results for both different bar spacing grids and different diamond mesh size codends. Figure $\mathbf{1 1}$ shows selectivity results obtained with the different bar spacing grids for both cod and haddock [37]. Figure 12 shows the predicted and observed L50 versus mesh size for Sebastes spp. Figure 13 shows historical selectivity results for Greenland halibut compared to FISHSELECT predictions. Finally, Figure 14 shows the variation in L50 for redfish with varying mesh size and $\mathrm{OA}$ for diamond meshes. 

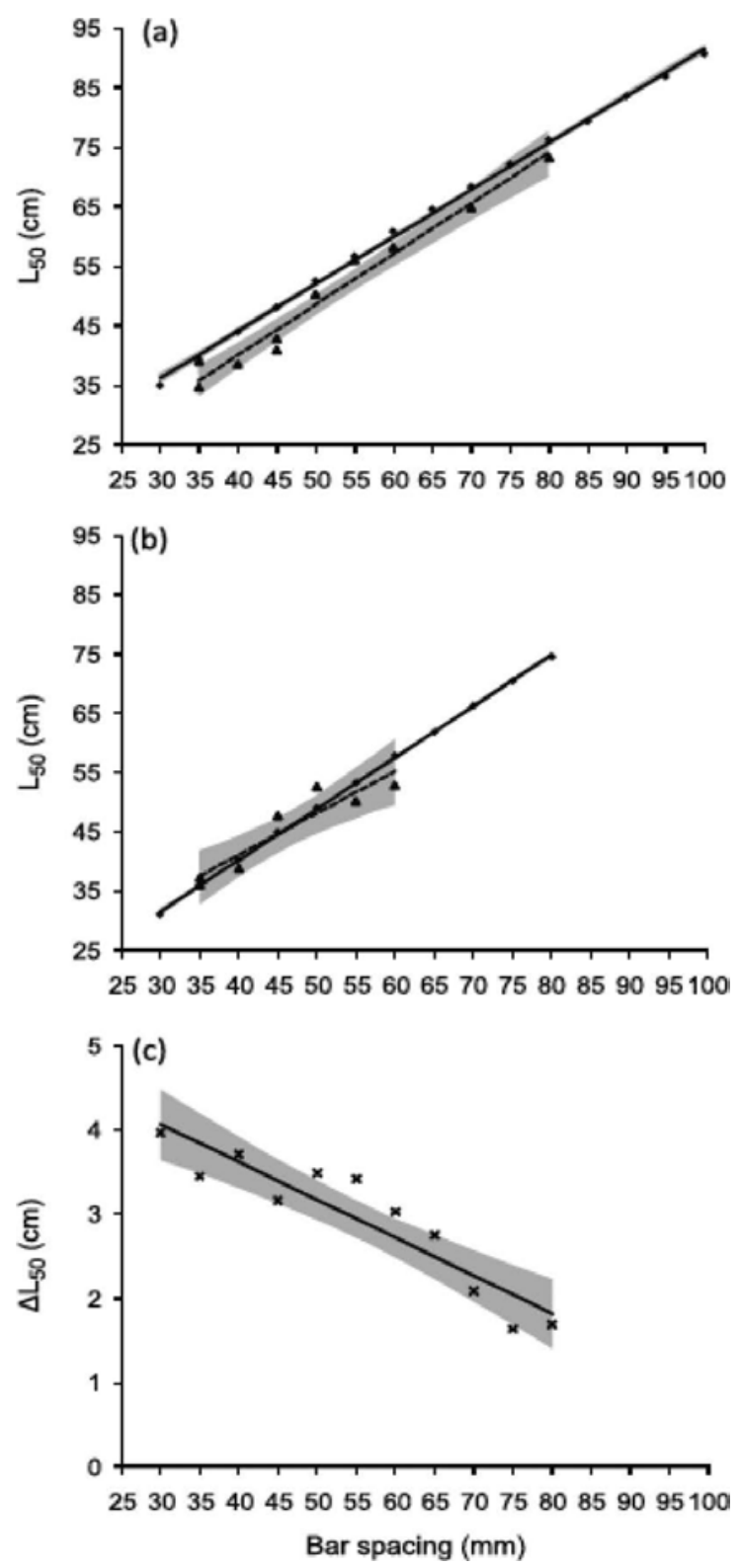

Figure 11. Selectivity results obtained with the different bar spacing grids for both cod (G. morhua) (a) and haddock (M. aeglefinus) (b). The solid line is a trend line fitted to the FISHSELECT results (diamonds), which are presented for up to the maximum fish size included in the data collection process. The broken line is a trend line added to the sea trial selectivity results (triangles) obtained for the different bar spacing grids in [41]. Panel (c) shows the L50 differences and a trend line for these differences between cod and haddock. The gray areas in the three panels represent the $95 \%$ confidence limits for the added trend lines. Source: [37]. 


\section{$\mathrm{L}_{50}$ vs. mesh size (Sebastes spp.)}

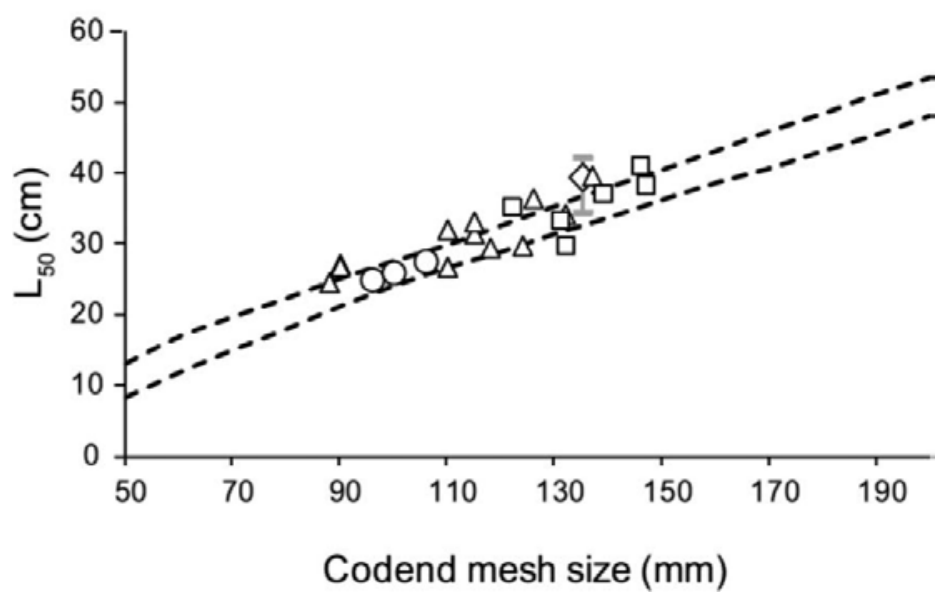

Figure 12. Predicted and observed L50 versus mesh size relationships for redfish (Sebastes spp.): Predicted band for codend L50 for different mesh sizes based on the FISHSELECT analysis of the data collected for Sebastes marinus (stippled curves); new results from sea trials for S. marinus (diamonds); previous results for S. marinus (squares); previous results for Sebastes mentella (triangles) and Sebastes mentellalfaciatus (circles). Source: [38].

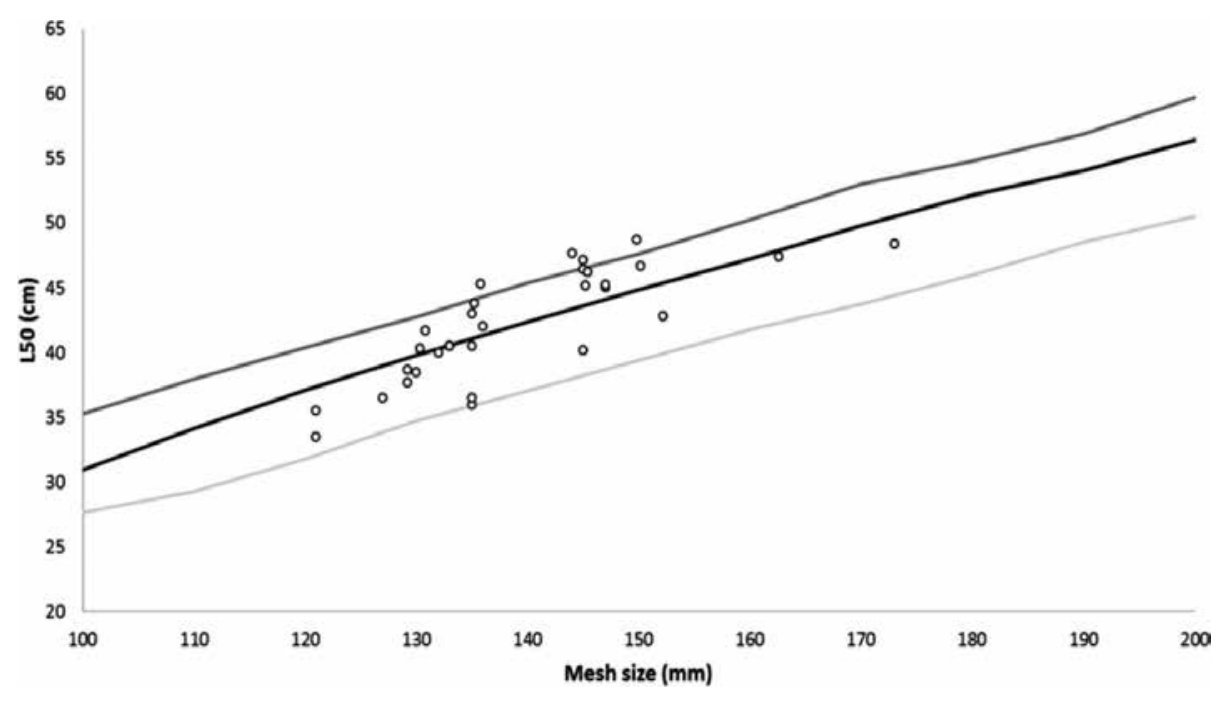

Figure 13. Historical data for Greenland halibut (R. hippoglossoides) codend selectivity (circular marks) plotted together with FISHSELECT estimations (lines). Source: [39] 


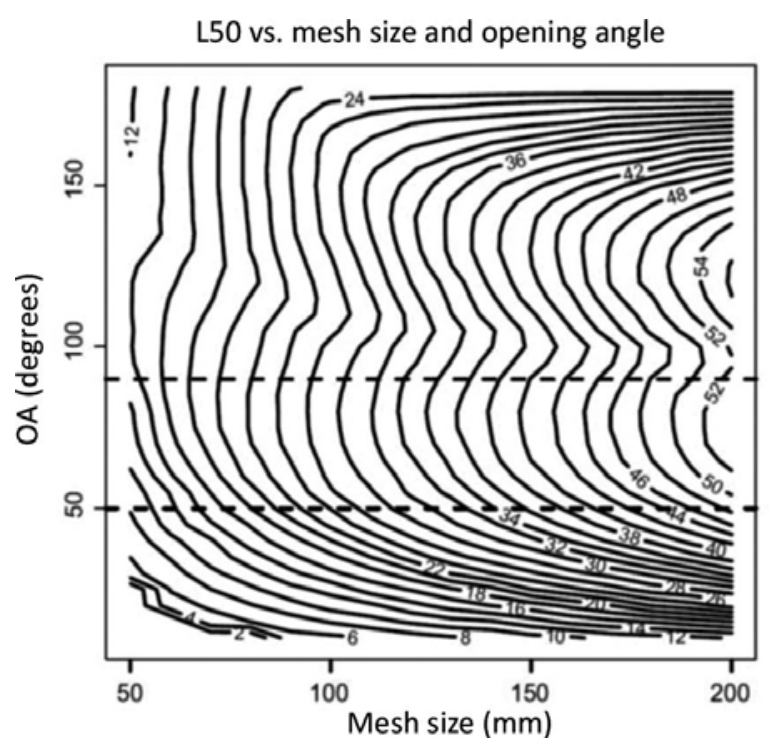

Figure 14. Design guide showing the variation in L50 for redfish (S. marinus) with varying mesh size and OA for diamond meshes. Source: [38].

\section{Acknowledgements}

Most of the information presented in this work has been obtained through diverse research projects that have been carried out in the past years. We gratefully acknowledge the financial support from the Norwegian Research Council, the Norwegian industrial research fund (FHF), and the Norwegian Directorate of Fisheries. The initial development of FISHSELECT was financially supported by a project under the development program for sustainable fisheries financed by the European Union and Danish Ministry of Food, Agriculture, and Fisheries.

\section{Author details}

Eduardo Grimaldo ${ }^{1^{*}}$, Manu Sistiaga ${ }^{1}$, Bent Herrmann ${ }^{2}$ and Roger B. Larsen ${ }^{3}$

*Address all correspondence to: Eduardo.Grimaldo@sintef.no

1 SINTEF Fisheries and Aquaculture, Trondheim, Norway

2 SINTEF Fisheries and Aquaculture, North Sea Science Park, Hirtshals, Denmark

3 Norwegian College of Fisheries and Aquatic Sciences, University of Tromsø, Tromsø, Norway 


\section{References}

[1] ICES [2015]ICES Advice: Cod (Gadus morhua) in Subareas I and II (Northeast Arctic) [http://www.ices.dk/sites/pub/Publication\%20Reports/Advice/2015/2015/codarct.pdf]. 12 June 2015.[Accessed: 26 January 2016]

[2] ICES [2015] ICES Advice: Haddock (Melanogrammus aeglefinus) in Subareas I and II (Northeast Arctic) [http://www.ices.dk/sites/pub/Publication\%20Reports/Advice/ 2015/2015/had-arct.pdf]. 12 June 2015.[Accessed: 26 January 2016]

[3] ICES [2015] ICES Advice: Saithe (Pollachius virens) in Subareas I and II (Northeast Arctic) [http://www.ices.dk/sites/pub/Publication\%20Reports/Advice/2015/2015/saiarct.pdf]. 12 June 2015.[Accessed: 26 January 2016]

[4] Lisovsky, S.F. [2001] Evolution of technical measures regulating fishery on cod and haddock in the Barents Sea and Norwegian Sea. In: Shevelev, M., Lisovsky, S.F. (Eds.) Technical regulations and by-catch criteria in the Barents Sea fisheries. Proceedings of the 9th PINRO-IMR Symposium, Murmansk 1415 August, 2001.

[5] Kvamme, C., Frøysa, K.G. [2008] Assessing the effects on stocks of selectivity changes in a fishery. Fish. Res.; 93: 283-292.

[6] Huse, I., Ånondsen, S., Ellingsen, H., Engås, A., Furevik, N., Graham, N., Isaksen, B., Jørgensen, T., Løkkeborg, S., Nøttestad, L. \& Soldal, A.V. [2002] A desk-study of diverse methods of fishing when considered in perspective of responsible fishing, and the effect on ecosystem caused by fishing activity. Bergen, July 2002. TemaNord 501.

[7] Isaksen B., Valdemarsen, J.W. [1986] Selectivity experiments with square mesh codends in bottom trawls. ICES CM1986; B:28.

[8] Larsen, R.B. [1989] A review on the application and selectivity of square mesh netting in trawls and seines. In: Carr, H.A. (Ed.) Proceedings of the square mesh workshop. World symposium on fishing gear and fishing vessel design. St. John's Canada, November 1989; 13-36.

[9] Isaksen, B. [1991] A brief review of codend selectivity investigations in Norway from 1985-1991. In: Workshop on codend selectivity. June 1991. Marine Laboratory, Aberdeen Scotland.

[10] Løbach, T. [1991] Gear selectivity: Report of the Nordic conference on gear selectivity. Køge, 28-29 May 1991.TemaNord 513: 115-124.

[11] Larsen, R.B., Isaksen, B. [1993] Size selectivity of rigid sorting grid in bottom trawls for Atlantic cod (Gadus morhua) and haddock (Melanogrammus aeglefinus). ICES Mar. Sci. Symp.; 196: 178-182. 
[12] Isaksen, B., Lisovsky, S., Larsen, R.B., Sakhnoe, V., Gamst, K. \& Misund, R.[1996] Joint Russian - Norwegian selectivity experiments on cod (Gadus morhua) in the Barents Sea 1995. Fisken og Havet.; 1996; 16: 55pp.

[13] Isaksen, B., Gamst, K., Kvalsvik, K. \& Axelsen, B. [1998] Comparison of selectivity and handling characteristics between the Sort- $\mathrm{X}$ and the single grid (Sort-V). Experiments performed on board the commercial vessel "Anny Kræmer" in Bear Island, 15-28 August 1997. Norwegian Institute of Marine Research. 1998; 15pp. (In Norwegian).

[14] Isaksen, B., Gamst, K., Kvalsvik, K. \& Kristiansen, A.[1998] Single sorting grid in to panel trawls for cod. Comparison of selectivity and handling characteristics between Sort-X and the single grid (Sort-V). Norwegian Institute of Marine Research. 1998; 19pp. (In Norwegian).

[15] Misund, R. [2001] Development of sorting grids in the Norwegian fishery - A review. In: Shevelev, M. and Lisovsky, S. (Eds.), Technical regulations and by-catch criteria in the Barents Sea fisheries. Proceedings of the 9th PINRO-IMR Symposium, Murmansk, 14-15 August, 2001.

[16] Jørgensen, T., Galbraith, D., Graham, N., Hansen, K., Holst, R., Larsson, P.O., Mortreux, S., Sangster, G.I., Soldal, A.V. \& Tschernij, V.[2002] Design, handling and selectivity properties of the Eurogrid. In: ICES-FAO Working Group on Fishing Technology and Fish Behaviour, ICES CM 2002/B:01. Sáte, France, 6-8 June 2002.

[17] Angell, S., Andersen, M., Lilleng, D. \& Torsvik, O.K. [2001] Comparison of the selectivity and handling characteristics between a $50 \mathrm{~mm}$ Sort- $X$ and $50 \mathrm{~mm}$ Flexigrid in the bottom trawl fishery for saithe. Experiments on board"Bliki", 9-20 March 2001. SINTEF Fisheries and Aquaculture. STF80 A013032. 2001; 23pp. (In Norwegian).

[18] Angell, S., Lilleng, D., Hassel, K. \& Røttingen, Å.[2001] Selectivity experiments with a $55 \mathrm{~mm}$ Flexigrid in the bottom trawl fishery for saithe. Experiments on board "Bliki", 3-12 April 2000. SINTEF Fisheries and Aquaculture. STF80 A00050.2001; 16pp. (In Norwegian)

[19] Angell, S., Lilleng, D., Kolbeinshavn, A., Vollstad, J. \& Larsen, R.B. [2001] Selectivity experiments with a $55 \mathrm{~mm}$ Flexigrid in the bottom trawl fishery for saithe. Experiments on board "Bliki", 21 September - 2 October 2000.SINTEF Fisheries and Aquaculture. STF80 A0113030. 2001; 18pp. (In Norwegian)

[20] Angell, S., Lilleng, D., Vollstad, J. \& Grimaldo, E.[2001] Selectivity experiments with 55 and $60 \mathrm{~mm}$ Flexigrid in the bottom trawl fishery for cod. Experiments on board "Bliki" 11- 23 June 2001. SINTEF Fisheries and Aquaculture. STF80 A013040. 2001; 19pp. (In Norwegian).

[21] Grimaldo, E., Larsen, R.B. \& Holst, R. [2007] Exit Windows as an alternative selective system for the Barents Sea Demersal Fishery for cod and haddock. Fish. Res.; 91: 295305. 
[22] Grimaldo, E., Sistiaga, M. \& Larsen, R.B. [2008] Evaluation of codends with sorting grids exit windows, and diamond meshes: size selection and fish behaviour. Fish. Res.; 91 : 271-280.

[23] Grimaldo, E., Larsen, R.B., Sistiaga, M., Madsen, N. \& Breen, M. [2008] Selectivity and escape percentages during three phases of the towing process comparing codends fitted with different selection systems. Fish. Res.; 95: 198-205.

[24] Sistiaga, M., Herrmann, B. \& Larsen, R.B. [2009] Investigation of the paired-gear method in selectivity studies. Fish. Res.; 97: 196-205.

[25] Grimaldo, E., Sistiaga, M., Herrmann, B., Gjøsund, S.H. \& Jørgensen, T. [2015] Effect of lifting panel on selectivity of a compulsory grid section (Sort-V) used by the demersal trawler fleet in the Barents Sea cod fishery. Fish. Res.; 170: 158-165.

[26] Gjøsund, S.H., Grimaldo, E., Sistiaga, M. \& Hansen, K.[2013] Water flow measurements in two and four-panel grid sections. SINTEF Fisheries and Aquaculture. Report A24698. 2013 (In Norwegian).

[27] Wileman, D., Ferro, R.S.T., Fonteyne, R. \& Millar, R.B.[1996] Manual of methods of measuring the selectivity of towed gears. ICES Coop. Res. Rep. No. 215; 126 pp.

[28] Breen, M., Sangster, G., O'Neill, B., Kynoch, R., Jones, E. \& Soldal, A.[2002] Evidence of sampling induced biases in mortality estimates from experiments investigating mortality in fish escaping from towed fishing gears. ICES CM 2002/V: 25.

[29] Kvamme, C., Isaksen, B. [2004] Total selectivity of a commercial cod trawl with and without a grid mounted: grid and codend selectivity of North-east Arctic cod. Fish. Res.; 68: 305-318.

[30] Sistiaga, M., Herrmann, B., Grimaldo, E. \& Larsen, R.B.[2010] Assessment of dual selection in grid based selectivity systems. Fish. Res.; 105: 187-199.

[31] Herrmann, B., Sistiaga, M., Larsen, R.B. \& Nielsen, K. [2013] Size selectivity of redfish (Sebastes spp.) in the Northeast Atlantic using grid-based selection systems for trawls. Aquat. Living Resourc.; 26: 109-120.

[32] Fryer, R.J. [1991] A model of between-haul variation in selectivity. ICES J. Mar. Sci.; 48 : 281-290.

[33] Sistiaga, M., Herrmann, B., Grimaldo, E. \& Larsen, R.B. [2015] Effect of lifting the sweeps on bottom trawling catch efficiency: a study based on the Northeast arctic cod (Gadus morhua) trawl fishery. Fish. Res.; 167: 164-173

[34] Millar, R.B. [1994] Sampling from trawl gears used in size selectivity experiments. ICES J. Mar. Sci.; 51: 293-298.

[35] Herrmann, B., Sistiaga, M., Santos, J. \& Sala, A. [2015] How many fish need to be measured in trawl selectivity studies? In: ICES. 2015. Second Interim Report of ICES- 
FAO Working Group on Fishing Technology and Fish Behaviour (WGFTFB), 4-7 May 2015, Lisbon, Portugal. ICES CM 2015/SSGIEOM:22. 183pp.

[36] Herrmann, B., Krag, L.A. \& Frandsen, R.P. [2009] Prediction of selectivity from morphological conditions: methodology and a case study on cod (Gadus morhua). Fish. Res.; 97: 59-71.

[37] Sistiaga, M., Herrmann, B., Nielsen, K.N. \& Larsen, R.B. [2011] Understanding limits to cod and haddock separation using size selectivity in a multispecies trawl fishery: an application of FISHSELECT. Canadian J. Fish. Aquat. Sci.; 68: 927-940.

[38] Herrmann, B., Sistiaga, M., Nielsen, K.N. \& Larsen, R.B. [2012] Understanding the size selectivity of redfish (Sebastes spp.) in North Atlantic trawl codends. J. Northw. Atlan. Fish. Sci.; 44: 1-13.

[39] Herrmann, B., Sistiaga, M., Larsen, R.B., Nielsen, K.N. \& Grimaldo, E. [2013] Understanding sorting grid and codend size selectivity of Greenland halibut (Reinhardtius hippoglossoides). Fish. Res.; 146: 59-73.

[40] Akaike, H. [1974] A new look at the statistical model identification. IEEE Trans. Autom. Control.; 19(6): 716-723.

[41] Sistiaga, M., Grimaldo, E., \& Larsen, R.B. [2008] Size selectivity patterns in the northeast Arctic cod and haddock fishery with sorting grids of 55, 60, 70 and $80 \mathrm{~mm}$. Fish. Res.; 93: 195-203. 
Chapter 5

\title{
Oil and Gas Platforms in the Gulf of Mexico:
}

\section{Their Relationship to Fish and Fisheries}

\author{
James H. Cowan, Jr. and Kenneth A. Rose \\ Additional information is available at the end of the chapter
}

http://dx.doi.org/10.5772/63026

\begin{abstract}
There are over 2300 standing oil and gas platforms in the northern Gulf of Mexico (GOM). It has been argued that platforms provide reef-like habitat that increases the growth and survival rates of fishes by increasing prey availability and affording shelter for protection from predators, provide additional spawning substrate, and by acting as a visual attractant for organisms not otherwise dependent upon hard bottom. Platforms differ from most natural habitats, and from traditional artificial reefs, in that their vertical profile extends upward through the water column into the photic zone and the sea surface. Increased habitat quality on, or immediately around, oil and gas platforms are thought to be derived from increased in situ food production associated with encrustation by fouling organisms. In this chapter, we address the issue of how to evaluate the role of artificial reefs by first establishing levels of evaluation for individual fish species found on oil and gas platforms in the GOM. The levels of evaluation relate to the amount and adequacy of the available information, which was populated with an extensive literature and data search. Three levels of assessment are established, analogous to the levels of analysis established National Oceanographic and Atmospheric Administration (NOAA) Fisheries for identification of Essential Fish Habitat. More than 1300 documents, including reports, stock assessments, other gray literature, and papers published in the primary literature, were used to complete this chapter. When available, published literature was the preferred source of information.
\end{abstract}

Keywords: Gulf of Mexico, oil and gas platforms, fish, fisheries, biomass production

\section{Introduction}

In the waters of the northern Gulf of Mexico (GOM) there are over 2300 standing oil and gas platforms that together constitute the largest de facto artificial reef program in the world 
(Figure 1). It has been argued that platforms provide reef-like habitat that increases the growth and survival rates of fishes by increasing prey availability, and affording shelter for protection from predators, provide additional spawning substrate, and by acting as a visual attractant for organisms not otherwise dependent upon hard bottom. Platforms differ from most natural habitats, and from traditional artificial reefs, in that their vertical profile extends upward through the water column into the photic zone and the sea surface. Increased habitat quality on, or immediately around, oil and gas platforms are thought to be derived from increased in situ food production associated with encrustation by fouling organisms.
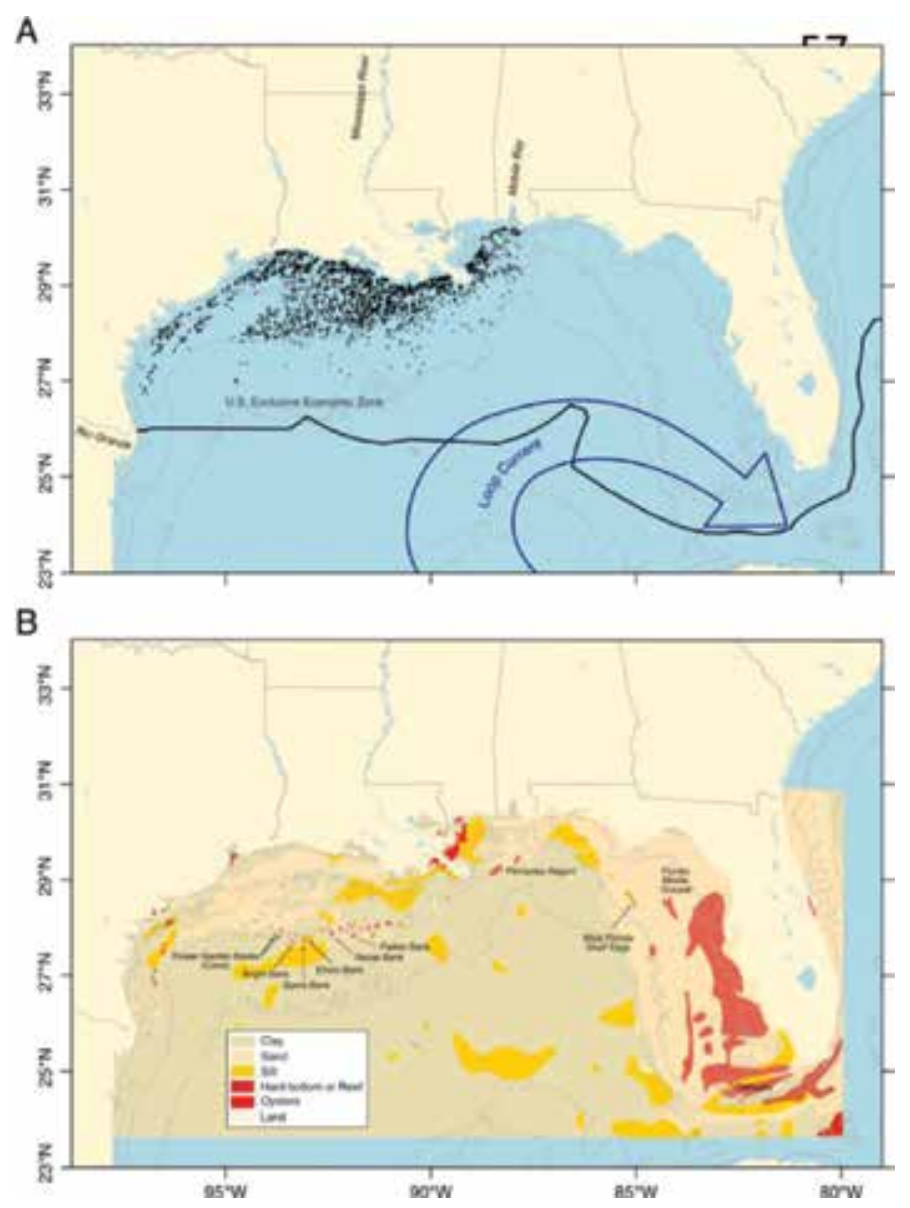

Figure 1. Map of the northern Gulf of Mexico. Panel A depicts oil and gas structures currently in place (black dots), the U.S. exclusive economic zone, and depth contours for 20, 200, and $2000 \mathrm{~m}$. The continental shelf follows the 200-m contour approximately. Panel B (adapted from Gulf of Mexico Fishery Management Council 2005) depicts the primary bottom substrate in the area. Labeled banks were sampled during fishery independent reef fish surveys.

Artificial reefs, such as oil and gas platforms, may be useful tools for fishery managers if they increase reef fish biomass production, but many researchers question whether or not they are a positive influence on fish stock dynamics. If artificial reefs constitute habitat that is otherwise 
limiting for reef-associated fishes, then they may be viable management tools. If they are simply attracting fish, then they may be promoting overfishing. Unfortunately, the extent to which structures have influenced the status of exploited fish stocks, either directly via population production rates or indirectly through changes in fishing mortality rates, is still not well understood. The structures may alter fish populations and communities as a result of altering ecosystem structure and function. The effects on exploited fish stocks could also be detrimental if the high levels of fishing mortality rates do not result in compensatory processes that lead to increases in stock production.

\section{Methods}

In this chapter, we evaluate the role of artificial reefs by first establishing levels of evaluation for individual fish species found on oil and gas platforms in the GOM. The levels of evaluation are dependent upon the amount and adequacy of the available information, which was populated with an extensive literature and data search. Three levels of assessment are established, analogous to the levels of analysis established National Marine Fisheries Service for identification of Essential Fish Habitat (EFH). More than 1300 documents, including reports, stock assessments, other gray literature, and papers published in the primary literature, were used to complete this chapter. When available, published literature was the preferred source of information.

Level 1-For species about which little process information is known, the evaluation is based simply upon whether the species has been observed in association with platforms or artificial reefs.

Level 2-Here we used the conceptual model of Bohnsack [1] (qualitative, Figure 2). This conceptual model centers on the attraction vs. production issue, which encompasses much of the debate about the ecological role of artificial reefs (including oil and gas platforms) in a complex and dynamic coastal geography. The difference between Level 1 and Level 2 assessments is the degree of inference at the process level about the species in question, even if the process information (e.g., fishing mortality, site fidelity) is poorly documented. As such, relative knowledge of where a species falls along the continuum of data availability and confidence for several process-related variables provides significant insight into how that species may be affected by platforms. The evaluation presented here is based upon information reported In FishBase ${ }^{\circledR}$ (http://www.fishbase.org/), combined with expert opinion, and is used to provide relative species-specific assessments of: (1) Site fidelity (High, Moderate, Low); (2) Whether or not a directed fishery exists for this species (Yes or No, includes recreational fishing); (3) Whether diet is derived directly from reef habitat (Reef, Benthic, Pelagic); (4) Whether population size is believed to be limited by recruitment or habitat limitation (Habitat limited, Recruitment limited); (5) Type of behavior of adults (Reef, Demersal, Pelagic, Highly Migratory); and, (6) A summary judgment about whether the species is reef or habitat dependent, and the type of habitat on which some dependent species are most often found (e.g., Sargassum, Sea Grass, Hard Bottom). 


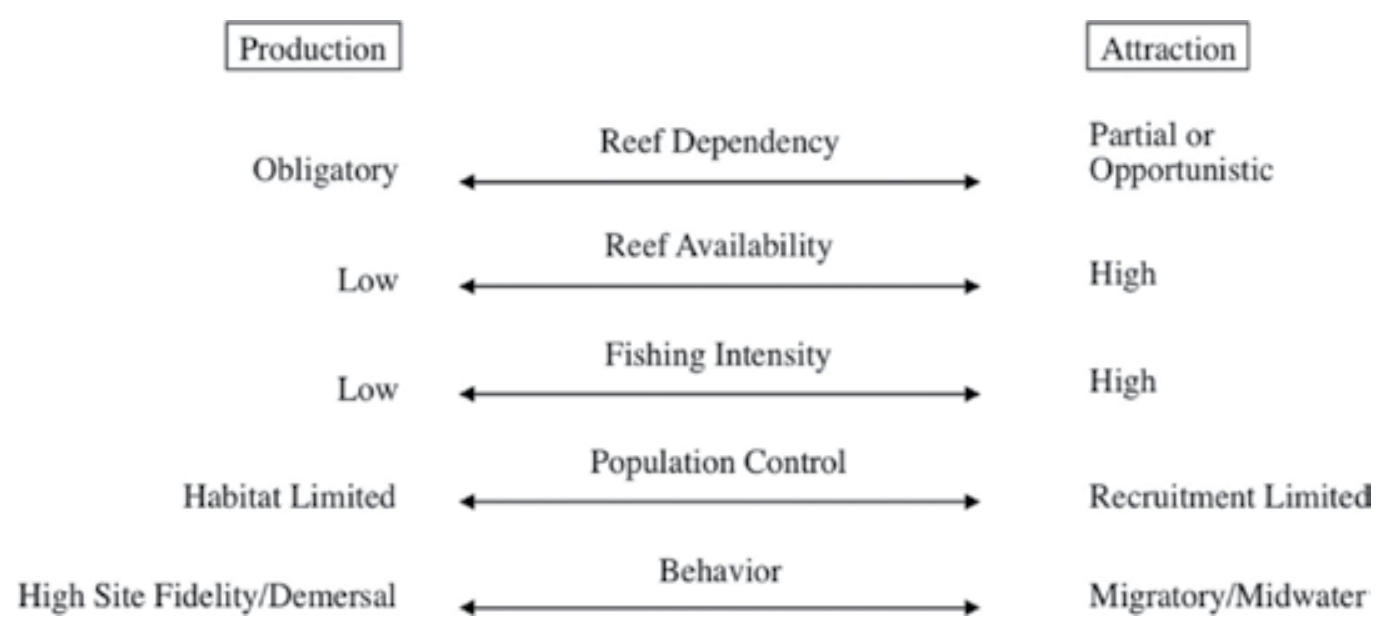

Figure 2. Bohnsack's [1] conceptual model for addressing the role of reefs in fisheries (redrawn from Bull. Mar. Sci. 44: 631-645).

Level 3-Based upon our extensive review of the literature, data for only five species of fishes were deemed sufficient for more complex analysis of estimating production; these are red snapper Lutjanus campechanus, blue runner, Caranx crysos, sheepshead Archosargus probatocephalus, Atlantic spadefish Chaetodipterus faber, and bluefish Pomatomus saltatrix. As might be expected, these species are abundant around standing platforms in the Gulf of Mexico and have been studied in some detail. Here evaluations are based upon various semi-quantitative or quantitative models found in the published literature.

The first model used in Level 3 evaluations is the semi-quantitative model described in Powers and colleagues [2], which uses the species-specific fish biomass production of a population on a reef (here a platform) weighted by the degree to which growth (biomass production) is attributable to prey resources produced on the reef. The production estimate for each species is multiplied by an index of reef exclusivity (IRE) derived from quantitative diet data. Applying the IRE, annual production (P) of a species attributed to a platform (AP; $\mathrm{kg}_{\text { platform }}^{-1} \mathrm{yr}^{-1}$ ) is calculated by:

$$
A P_{i}=I R E_{i}^{*} P_{i}
$$

where AP is a measure of relative species-specific production attributable to a platform. In the original equation, there was a term for the difference between pre-structure and post-structure biomass, but we are unable to provide pre-structure data because almost all of the platforms on the continental shelf were employed more than 25 years ago. We also believe that an estimate of biomass on a seafloor lacking structure, when compared to biomass after a structure has been constructed, may result in an overestimate of new biomass production because of the likelihood that individuals of many species are simply attracted to standing platforms.

The second method of estimating annual production for Level 3 is an empirical model [3]: 


$$
P=0.00051^{*} B^{0.69 *} T^{1.04}
$$

where $\mathrm{P}$ is production $\left(\mathrm{g} \mathrm{dw} \mathrm{d}^{-1}\right), \mathrm{B}$ is biomass $(\mathrm{kg})$, and $\mathrm{T}$ is temperature $\left({ }^{\circ} \mathrm{C}\right)$. We assumed that $\mathrm{gdw}=\mathrm{g}$ wet weight ${ }^{*} 0.20$. The data used to estimate $\mathrm{B}(\mathrm{g})$ is based upon data obtained from published literature on biomass, estimated daily somatic production, and ambient water temperature for 62 species of fishes collected from numerous locations in Australia and elsewhere. Temperature data were summarized from several Gulf of Mexico studies on the continental shelf.

The previous and following methods of estimating production require an estimate of biomass on a platform. To make this estimate, we first calculated the simple arithmetic mean number of fish by species on a platform by summing all of the available estimates of numbers observed, based mostly upon visual surveys using scuba diving. In addition to numbers of individuals, length ranges $(\mathrm{cm})$ are also reported for each species.

The third estimate of production for Level 3 is based upon methods described in by Ricker [4] where annual production is estimated by:

$$
\hat{P}=\bar{B}^{*}(G)
$$

where $\widehat{P}$ is biomass production, $\bar{B}$ is annual mean biomass, and $\mathrm{G}$ is specific growth rate $\mathrm{yr}^{-1}$. Annual mean biomass is estimated by using:

$$
\begin{aligned}
& \bar{B}=\frac{B\left(1-e^{-(Z-G)}\right)}{Z-G} \text { when } G>Z \\
& \bar{B}=\frac{B\left[\left(e^{(G-Z)}-1\right)\right]}{G-Z} \text { when } Z>G
\end{aligned}
$$

Where $\bar{B}$ is annual mean biomass, $\mathrm{B}$ is biomass per platform in $\mathrm{kg}, \mathrm{G}$ is specific growth rate $\mathrm{yr}^{-1}$, and $\mathrm{Z}$ is specific mortality rate $\mathrm{yr}^{-1}$. In actuality, $\mathrm{Z}$ is the sum of $\mathrm{F}$ (annual fishing mortality rate) plus $M$ (annual natural mortality rate). In our Level 3 assessment, we ignore F in calculations, but we discuss the implications of this omission in the discussion. Biomass estimates were calculated based upon age and growth relationships reported in the literature from samples collected in the GOM for all species except Atlantic spadefish. For Atlantic spadefish, we used data collected in South Carolina. To estimate length at age, we used the Von Bertalanffy growth model (Tables 1 and 2):

$$
T L_{t}=L_{\infty}\left(1-e^{-k\left(t-t_{0}\right)}\right)
$$




\begin{tabular}{llcccc}
\hline Species & MN & SR & ML & AR & B (kg) \\
\hline Red snapper & 1884 (range 905-4632) & $25.5-79.1$ & 295.3 & $2-10$ & 886 \\
Bluefish & 1438 (range 282-4000) & $45-50$ & 475 & $1-6$ & 1489 \\
Atlantic spadefish & 4177 (range 10-5323) & $10-50$ & 30.0 & $1-8$ & 2618 \\
Sheepshead & 2250 (range 150-17,000) & $22-50$ & 360 & $2-5$ & 1774 \\
Blue runner & 6260 (range 427-25,188) & $30-36$ & 33.5 & $2-6$ & 4152 \\
\hline
\end{tabular}

Table 1. Literature values for mean number per platform (MN), size range at platform (SR, cm FL), mean length of individuals observed (ML, cm FL), age range (AR yrs), and biomass per platform (B kg wet wt) for five abundant species of fishes collected from Gulf of Mexico oil and gas platforms.

\begin{tabular}{|c|c|c|c|c|c|c|c|c|c|c|}
\hline Species & $T_{\max }$ & G & $\mathbf{M}$ & AD & L. & $\mathbf{K}$ & $\mathbf{t}_{0}$ & $\mathbf{a}$ & b & Source \\
\hline Red snapper & 57 & $\begin{array}{l}0.31 \\
\text { (at } \mathrm{T}_{\max } \mathrm{G}=0.05 \text { ) }\end{array}$ & $\begin{array}{l}0.10 \\
\text { (at } \mathrm{T}_{\max } \mathrm{M}=0.07 \text { ) }\end{array}$ & $2-10$ & 94.1 & 0.18 & -0.55 & 0.0165 & 3.03 & [5-7] \\
\hline Blue runner & 11 & 0.39 & 0.38 & $2-4$ & 41.2 & 0.35 & -1.17 & 0.0524 & 2.690 & [8] \\
\hline Sheepshead & 20 & 0.23 & 0.22 & $2-5$ & $\begin{array}{l}41.9(\mathrm{M}) \\
44.7(\mathrm{~F})\end{array}$ & $\begin{array}{l}0.417 \\
0.367\end{array}$ & $\begin{array}{l}-0.901 \\
\text { to } 1.025\end{array}$ & $\begin{array}{l}0.000448 \\
0.000530\end{array}$ & $\begin{array}{l}2.88 \\
2.85\end{array}$ & [9] \\
\hline $\begin{array}{l}\text { Atlantic } \\
\text { spadefish }\end{array}$ & 8 & 0.41 & 0.58 & $1-8$ & 49.0 & 0.340 & -0.18 & 0.0927 & 2.64 & [10] \\
\hline Bluefish & 8 & 0.41 & 0.58 & $1-6$ & 94.4 & 0.18 & 1.033 & -10.02 & 2.80 & [11] \\
\hline
\end{tabular}

$\mathrm{T}_{\max }=$ maximum age; $\mathrm{M}=$ natural mortality rate; $\mathrm{G}$ = specific growth rate $(\mathrm{yr}) ; \mathrm{L} .(\mathrm{cm} \mathrm{TL})$ is the asymptotic maximum length, $\mathrm{K}$ is a constant (the Brody growth coefficient), and $\mathrm{t}_{0}$ is a constant representing the age (yr) at 0 length. Letters in parentheses following L. indicates sex if males and females were dimorphic. Fish length is converted to wet weight using a length-weight equation with constants $a$ and $b$. Age distributions of fish (AD) were derived from empirical data for size ranges at age of fishes observed at platforms, except for red snapper that are most abundant from ages 2 to 6 (Wilson and Nieland 2001).

Table 2. Literature values for maximum age, estimated growth and mortality rates, and Von Bertalanffy length-at-age parameters used in production calculations.

where $T L_{t}$ is total length (TL) at age $t, L$ is the asymptotic $T L, k$ is the Brody growth coefficient, $t$ is age in years, and $t_{0}$ is a hypothetical age when TL is zero. Using species-specific versions of this equation, we determined the age range of each species observed on platforms that correspond to the observed length ranges. Length-length relationships available for each species allowed for conversion among total length (TL), fork length and standard length as necessary for consistency among units of length. Length at age was converted to wet weight at age using:

$$
T W_{i}=a^{*} T L^{b}
$$


where $T W_{i}$ is wet weight in $g$ of species $\mathrm{i}, T L(\mathrm{~cm})$ and a and $\mathrm{b}$ are constants derived for each species. The values for $a$ and $b$ for each species are reported in Table 3. Growth $(G)$ is estimated using the equation:

$$
G=\left(\ln W_{t=j}-\ln W_{t-i}\right)+\left(t_{j}-t_{i}\right)
$$

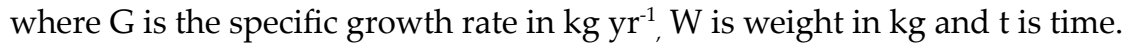

\begin{tabular}{|c|c|c|c|c|c|c|c|c|}
\hline Species & $\begin{array}{l}\text { Trophic } \\
\text { Level (SE) }\end{array}$ & Diet Composition (source) & IRE & $\mathrm{T}^{\circ} \mathrm{C}$ & $\mathbf{P}_{\mathrm{r}}$ & $\mathbf{P}_{\mathrm{e}}$ & $\mathbf{A P}_{\mathbf{r}}$ & $\mathbf{A P}_{\mathrm{e}}$ \\
\hline Red snapper & $4.01 \pm 0.59$ & $\begin{array}{l}\text { Benthic inverts, demersal fishes, } \\
\text { squid, pelagic zooplankton [12-15] }\end{array}$ & 0.05 & 25.9 & 306 & 115 & 15 & 6 \\
\hline Blue runner & $4.40 \pm 0.77$ & $\begin{array}{l}\text { Fish, decapods, hyperid amphipods, } \\
\text { chaetognaths, other [[16], FishBase] }\end{array}$ & 0.10 & 25.9 & 1627 & 333 & 163 & 33 \\
\hline Sheepshead & $3.53 \pm 0.53$ & $\begin{array}{l}\text { Portunid crabs, shrimp, barnacles, } \\
\text { fish, copepods, bryozoans, amphipods, } \\
\text { sargassum [[17], FishBase] }\end{array}$ & 0.90 & 25.9 & 410 & 185 & 369 & 167 \\
\hline $\begin{array}{l}\text { Atlantic } \\
\text { spadefish }\end{array}$ & $3.50 \pm 0.47$ & $\begin{array}{l}\text { Sponges and tunicates, cnidarians, } \\
\text { worms, ascidicans, plants, benthic } \\
\text { inverts, echinoderms, zooplankton } \\
\text { (FishBase) }\end{array}$ & 0.95 & 25.9 & 987 & 243 & 938 & 231 \\
\hline Bluefish & $4.50 \pm 0.55$ & $\begin{array}{l}\text { Pelagic and demersal fish and } \\
\text { macrocrustaceans (from soft bottoms) [18] }\end{array}$ & 0.01 & 25.9 & 561 & 164 & 6 & 2 \\
\hline
\end{tabular}

The index of reef exclusivity (IRE) is an estimate of species utilization of resources associated with platform habitat compared to resources from nearby natural habitat (Powers et al. 2003). The IRE is based upon diet information from the sources provided. Trophic level for each species was obtained from FishBase (http://www.fishbase.org/), $\mathrm{T}^{\circ} \mathrm{C}$ is the annual averaged sea surface temperature in degrees centigrade obtained from the NOAA Data Buoy Center for years 2013-2015 and 2005 at SPLL1 (28.87 N, 90.48 W) and MRSL1 (29.44 N, 92.06 W) on the Louisiana Shelf. $P_{\mathrm{r}}=$ annual biomass production in $\mathrm{kg}$ platform ${ }^{-1} \mathrm{yr}^{-1}$ based upon calculations using Ricker (1975). $\mathrm{P}_{\mathrm{e}}=$ annual biomass production in $\mathrm{kg}$ platform ${ }^{-1} \mathrm{yr}^{-1}$ estimated by using the empirical relationship in Edgar and Shaw (1990). $\mathrm{AP}_{\mathrm{r}}=\operatorname{IRE}^{*} \mathrm{P}_{\mathrm{r}}, \mathrm{AP}_{\mathrm{e}}=\operatorname{IRE}^{*} \mathrm{P}_{\mathrm{e}}$. Numbers proceeded by * refer to literature resources listed on the table.

Table 3. Estimated relative production attributable to oil and gas platforms (AP).

\section{Results}

Levels 1 and 2: In total, 246 species of fishes have been reported from oil and gas platforms in the GOM (Appendix Table 1, hereafter ATable 1). Of these, 33 species are Caribbean expatriates (23 of which are reported to be reef dependent) that occur sporadically in low numbers, and are not believed to contribute to overall stock productivity because their larvae are nearly absent in waters of the northern GOM [17]. One hundred-two species have life 
history strategies that conclusively exclude them from being reef associated or dependent ( $\mathrm{N}$ in ATable 1), even though these species have been reported in collections of fishes from platforms. Thirty-six species are conclusively considered to be reef dependent ( $\mathrm{Y}$ in ATable 1; note that $Y=$ reef dependent, $Y$ plus habitat descriptor $H B, S G, S$ are habitat dependent on a specified habitat), which here indicates that reef habitat is required for these species to complete their life cycles, or that their diet is almost exclusively derived from the reef [18]. Reef dependent species that are not expatriates are: Balistes capricus; Cantherhines pullus; Cephalopholis cruentatus; Chaetodipterus faber; Clepticus parrae; Parablennius marmoreus; and Xyrichthys novacula. Thirteen species have life history strategies that appear to preclude reef dependency, or are documented to occur on structured, non-reef habitats, but are listed in FishBase as reef associated. In ATable 1, these 13 species are denoted with an $\mathrm{N}$ under the Dep category, followed by the habitat type that is reported to be of greatest importance.

The species for which we assigned an $\mathrm{N}$ have life history and behavioral characteristics that are qualitatively similar to the attraction end of the Bohnsack's continuum [1]. These species are directly fished or overfished, exhibit low site fidelity, are less or not dependent upon the reef for food, are not dependent upon the reef for completion of their life cycles, and are pelagic and/or migratory, and thus less likely to habitat limited. In contrast, the species for which we assigned a $\mathrm{Y}$ in ATable 1 have life history and behavioral characteristics that are qualitatively more similar to production end of the continuum [1]. These species have relatively high site fidelity, the need for reef or structured habitat to complete the life cycle, and a significant fraction of their diet is comprised primarily of reef-associated prey.

There are numerous species for which expectations about reef dependence are more difficult to describe, even qualitatively. To provide some interpretation, we use both a qualitative assessment relative to the Bohnsack [1] conceptual model, and insight derived from the Level-3 assessments to make comparisons among the reef-associated species in ATable 1. Where possible, we identify species that are comparable with respect to ecology, life history, and behavioral characteristics to the Level-3 species. It is fortunate that the latter group is comprised of species that appear to differ significantly in their relative ecological dependence on reefs and, by extension, to platforms. We also consulted additional reference materials to make our determinations [18-24].

In all, 46 species are listed as reef associated (RA in ATable 1). Of these, many are known to be pelagic and/or highly migratory. Among this group are several species of jacks (fm. Carangidae, genus Caranx (6 species), genus Seriola (3 species), Elagatis bipinnulata, Selar crumenophthalmus, Oligoplites saurus, and Trachurus lathami), mackerels (fm. Scombribdae, Scomberomorus (2 species)), clupeids (Harengula jaguana, Opisthonema oglinum, and Sardinella aurita), barracudas (genus Sphyraena (3 species)), cobia (Rachycentron canadum), and ocean triggerfish (Canthidermis sufflamen). Although listed as reef associated in FishBase, they exhibit life history and behavioral characteristics that are more typical of fishes at the attraction end of Bohnsacks continuum, and appear to be most comparable in their use of reefs and platforms to bluefish and/or blue runner. As such, these species may not be significantly dependent upon platforms. 
Thirty of the 46 species listed as reef associated (RA) have other habitats listed as primary (fm. Carangidae, mackerels $\mathrm{fm}$. Scombribdae, and clupeiods herrings and anchovies). Many of these species are reported to primarily associate with hard-bottom (HB) habitats $(25$ species including most of the groupers). This makes sense given the nature of most of the natural reef habitat in the GOM. Other species are reported to associate with sea grass (SG) meadows. Where possible, we have included additional detail in ATable $\mathbf{1}$ about primary habitat associations reported for many of the reef-associated species. These primary habitats are consistent with natural habitats reported to occur in the GOM and include reef flats, rocky reefs, coral reefs, oyster reefs, floatsam, shelf-edge banks, offshore rock bottoms, offshore banks, Oculina reefs, and structure of all types. This group clearly is the most difficult to assess. We note that the lack of habitat-specific, process-level data makes the following interpretations speculative.

Most of the grouper species reported in ATable 1 in the genus Epinephelus, with the exception of E. itajara, and in the genus Mycteroperca, with the exception of M. microlepis, are managed as a complex in the GOM referred to as the "deep-water groupers." Relatively little is known about the ecology and behavioral characteristics of these species, although they are believed to be long-lived and exhibit relatively low stock productivity [25]. Assessment of the role that platforms play in their life histories would be speculation on our part, but it is likely that association with platforms does not significantly increase their vulnerability to fishing, especially to recreational anglers, given their preferred depth distribution. It also is unlikely that a significant number of platforms are available as habitat for these groupers for the same reason; these fishes are likely to occur only on those structures near or on the shelf-edge banks shown in Figure 1. In contrast, E. itajara, the goliath grouper, and M. microlepis, the gag grouper, are found inshore on a variety of habitats ranging from platforms to artificial reefs, to bridge pilings, piers, docks, seawalls, and other hard structures [26]. Juvenile goliath groupers are most often found in mangroves, which appear to be its primary nursery ground. Goliath groupers are overfished in the US GOM and currently, harvest is limited [27]. They are confined mostly to Florida Bay and the southern portion of the Florida peninsula and the Bay of Campeche where they are harvested in great numbers as juveniles in the GOM, but have been observed occasionally by scuba divers around platforms. As the stock rebuilds and expands northward in the GOM, however, it is plausible that platforms will contain increasing numbers of goliath groupers. The relative role of platforms as sources of stock productivity and fishing mortality should be closely monitored as the goliath grouper stock increases.

Gag groupers are more widely distributed in the GOM, but also are overfished [28]. They are extremely vulnerable to overexploitation because they are haremic as adults, and aggregate to spawn at just a few locations in the northeastern GOM. Juvenile gag groupers are mostly associated with sea grass meadows as nursery areas. To our knowledge, the ecology of gag grouper on platforms has received little study. However, the work of Lindberg and coworkers on the west Florida shelf has demonstrated that the value of artificial reefs as habitat is affected both by size and spatial arrangement of reef modules. The net effect on stock production of reefs is negative when fishing mortality is considered [29,30]. Despite these results, we caution against drawing inference about the role of platforms as habitat for gag groupers because the 
aforementioned work was done on relatively small, low-relief, reef modules. Two other species reported as reef-associated in ATable 1 (Neoconger mucronatus and Ophidion selenops) also are found in deep waters on or near the shelf edge.

There are several species in ATable 1 that are reported to be reef-associated, but also occur on a wide variety of habitats including inshore waters, bays, estuaries, and sea grass meadows. Qualitatively, these species have life history and behavioral characteristics that are more similar to those found at the production end of Bohnsack's continuum [1]. These include Chilomycterus schoepfii, Lagodon rhomboides, two members of the genus Opsanus, Sphoeroides spengleri, two members of the genus Trachinotus, and Stephanolepis hispidus. This group appears to be most like Atlantic spadefish and sheepshead, for which Level 3 assessments were made.

Similarly, there is another group that qualitatively appears to have life history and behavioral characteristics that are more similar to those found at the production end of the continuum, but also appear to be more restricted in their distribution than the reef-associated group that use many habitats (discussed in the previous paragraph). These more habitat-restricted species are reported to occur in coastal waters, and on shelf-edge banks, but are explicitly identified as not being found on coral reefs. This group includes two members of the genus Equetus, Gymnothorax nigromarginatus, two members of the genus Hypleurochilus, two members of the genus Hypsoblennius, Myrophis punctatus, Pseudupeneus maculatus, Saurita normani, two members of the genus Syacium, Syngnathus louisianae, three members of the genus Synodus, and the blue phase of Thalassoma bifasciatum. Furthermore, blennies are nest builders that depend upon hard substrate. Many members of this group also appear to be most like Atlantic spadefish and sheepshead, for which Level 3 assessments were made.

There are several small, cryptic species listed in ATable $\mathbf{1}$ as reef-associated that we believe to be more strongly associated with reefs than the many-habitat and restricted habitat reefassociated species (preceding two paragraphs), and whose life history and behavioral characteristics appear to place them solidly at the production end of Bohnsack's continuum. This group includes Callionymus bairdi, Coryphopterus punctipectophorus, Ophioblennius atlanticus, Prognathodes aya, Rypticus maculatus, the yellow phase of Thalassoma bifasciatum, and Trachinocephalus myops. Although information about the ecology and life history of this group on platforms is lacking, there are no analogues for these among the group for which Level 3 assessments were possible.

In addition, there are several species listed in ATable $\mathbf{1}$ as being reef-associated in FishBase, but whose life history and behavioral characteristics (at least qualitatively) do not strongly support placement near either endpoint of Bohnsack's continuum. This group has been reported to occur on a wide variety of natural hard-bottom habitats in the GOM, including platforms, but appear to have only moderate to low site fidelity. Many of these species support directed commercial fisheries, and all appear among the list of species harvested by recreational anglers. This group includes six members of the genus Lutjanus, including the red snapper L. camphechanus (site fidelity $<1 \%$ per year on standing platforms [31]), which is overfished but rebuilding, Rhomboplites aurorubens, Brotula barbata, three members of the genus Centropristis, Haemulon plumierii, and Paranthias furcifer. 
Of this group only the red snapper, and to some degree $R$. aurorubens, have been reasonably well studied, but almost all of the work on adults of these two species that has focused on recruits to platforms or has been done on small, low-relief, artificial reefs in the northeastern GOM. Similar to the results reported by Linberg and coworkers for gag grouper [29,30], studies of red snapper indicate that the value of artificial reefs as habitat is affected both by size and spatial arrangement of reef modules, and that the net effect on stock production of reefs is negative when fishing mortality is considered [32,33]. In addition, diet studies in the northeastern GOM indicate that adult red snapper rely very little on prey derived explicitly from reef habitats, whether collected on artificial [source 2 in Table 3] or natural reefs [34]. Despite these results, we caution against drawing inference about the role of platforms as habitat for red snapper given that much of the work has been done on relatively small, low-relief, reef modules. More recently, Simonsen and colleagues [15] compared diets of red snapper on standing platforms, toppled platforms, and on the natural reefs in the western GOM. They found that diets on both of the platform types were less diverse and provided less nutrition than diets on natural reefs. In addition, members of my laboratory and I [35] recently found that natural reefs offer a wider diversity of prey items, and reef-dependent prey species were found only in the diets at the natural reefs. Red Snapper at the natural reefs were on and above the reef, while feeding at the artificial reefs was predominantly on the surrounding seafloor and provided less caloric intake. Natural reefs found in the northwestern GOM appear to offer better habitat quality with regard to prey resources for red snapper compared to artificial reefs (standing and toppled platforms), a difference that should be taken into account as part of management decisions.

The other lutjanids in this group are much less abundant than red and vermilion snapper. Vermilion snapper, Rhomboplites aurorubens was overfished as recently as 2010, but the stock has recovered sufficiently to be considered rebuilt [36]. Of the remaining lutjanids reported in ATable 1, the dog snapper L. jocu is likely to be the most strongly reef associated, as is the creole fish, Paranthias furcifer. We believe the remainder of the species in this group to be reefassociated rather than dependent. This group as a whole is most similar to red snapper among the Level 3 species.

Level 3 Results: Sufficient life history information was available for five species to conduct a Level 3 analysis: red snapper, blue runner, sheepshead, Atlantic spadefish, and bluefish. Tables $\mathbf{1}$ and $\mathbf{2}$ provide data and their sources used in the calculations.

Calculated estimates of biomass production per year per platform using Rickers's method ranged from $306 \mathrm{~kg}$ platform ${ }^{-1}$ by sheepshead to $1627 \mathrm{~kg}$ platform ${ }^{-1}$ for blue runner (Table 3). Estimates using an empirical approach [3] were consistent in pattern, but averaged less than half of the values derived from Ricker's [4] method (Table 3). This difference was largely because we estimated specific growth rates $(G)$ for each species over a period that was shorter than their reported life span. For red snapper, blue runner, and sheepshead, the age classes we used were those in which high growth occurred during that period of their life cycle. Biomass production in the Ricker's method is sensitive to the ratio of G/Z i.e., specific growth rate and natural mortality rate, and the ratio is close to, or less than, one for all, but red snapper (Table 3). When the ratio is less than one, there is a net loss in population biomass. It is also important 
to note that the often highly productive pre-recruit period was not included in our calculations, which could have a large effect on the overall production estimates.

The results from the Powers [2] model showed that annual production for each species was dependent upon the index of reef exclusivity (Table 3). Species for which platforms provide only a small fraction of prey resources (e.g., red snapper, blue fish, and blue runner) are less dependent upon reefs compared to species such as Atlantic spadefish and sheepshead that depend heavily upon the fouling community on platform legs for food. Low annual production values for red snapper, bluefish, and blue runner also imply that platforms are more likely attracting individuals from surrounding natural habitats rather than producing new population biomass. These finding are consistent with recent diet studies of red snapper, and point out the sensitivity of production estimates to subtle changes in the $G / Z$ ratio that are not considered in the less complex methods $[2,3]$.

\section{Final Thoughts and Red Snapper}

The most controversial fishery in U.S. waters of the GOM is for northern red snapper Lutjanus campechanus, which collapsed in the late 1980s when stock biomass became too low to be fished commercially in almost half of the stock's former range (east of the Mississippi River). Red snapper management began in earnest in 1989, and the stock now is showing strong signs of recovery. More information about the history of red snapper management is available elsewhere [37-39] but the conflict among competing stakeholders has made stock recovery and sustainable fishing especially difficult to achieve.

Like the examples described by Hilborn [40], a 'faith-based fisheries' argument has been used to defer effective management of red snapper, and consequently has greatly strained the relationships among science, management, and stakeholders in the GOM. It has been argued that mass deployment of artificial reefs has substantially increased productivity of the red snapper stock. The premise is that artificial reefs have transformed less desirable fish biomass into red snapper biomass at locations on the shelf where the latter was not previously abundant [41]. The specifics of this argument were elucidated in a management perspective [42] which postulated that oil and gas platforms that began appearing in the western GOM in the late 1940s function secondarily as large artificial reefs, as well as a myriad of other artificial reef structures in the northcentral and eastern GOM since the 1970s, has enhanced biomass production of red snapper. True, results of the last benchmark stock assessment for red snapper [7] indicate that recruitment and stock productivity may have increased since the late 1980s. However, several other possible causes for this putative increase have been identified beyond artificial reef deployment [39]. The perspective [42] speaks to none of the other possible (more likely?) causes for change and further claims that red snapper were not present in the northwestern GOM until oil and gas platforms began being deployed offshore in the early 1940s. They disregard considerable information showing that a well-established red snapper fishery in the northwestern GOM began as early as 1892 [43]. 
The arrows in Figure 3 indicate when artificial reefs began to be deployed in large numbers relative to the estimated spawning stock biomass of red snapper. These deployments took the form of oil and gas platforms in the western GOM and all manner of materials in the east. In both cases, there is no obvious indication that artificial habitats have increased spawning stock biomass because overfishing was occurring until only recently, and changed in response to strong year classes. The artificial reef argument put forth in the perspective is simply not supported by the available information.

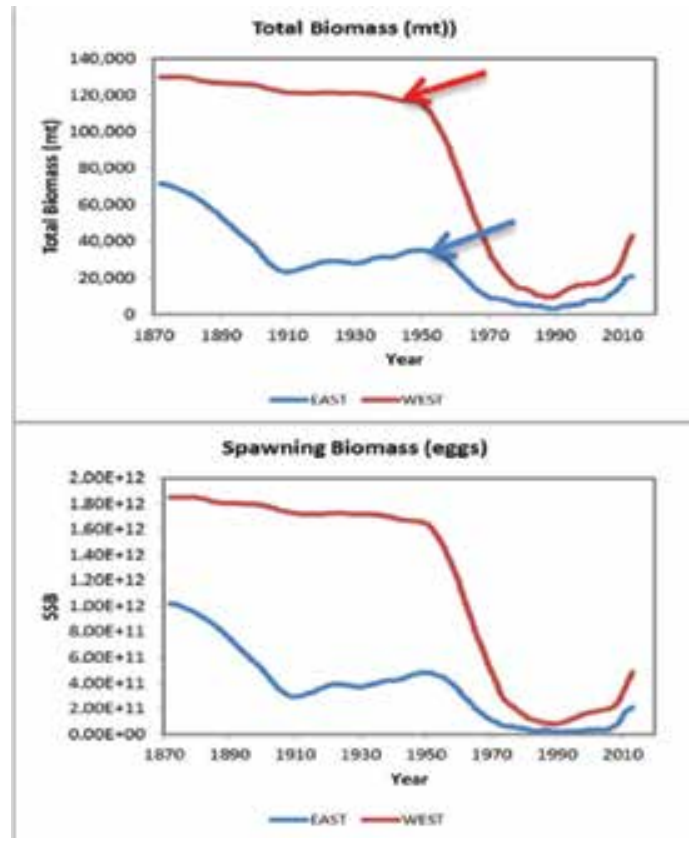

Figure 3. Model estimated spawning stock biomass in the eastern (blue line) and western (red line) US GOM of Mexico. Spawning stock biomass is the estimated weight of all mature females in each region of the GOM. The arrows indicate the year when oil and platforms (red arrow, 1942) and artificial reefs (blue arrow, 1950) began to be deployed in each area (The estimate is taken from the 2015 update of and is the most recent benchmark assessment for red snapper). The recent upturn in biomass is attributable to two relatively strong years classes produced in 2004 and 2006; this is the first time this has occurred over the $\sim 30$ year history of red snapper management.

We recognize that the stock assessment process for red snapper and other reef-associated species is controversial and sometimes difficult to understand, so in this chapter we have used simple models using a few parameters, to make our case. In Table 3 our results indicate that oil and gas platforms produce new red snapper biomass. However, even if only small increase in $\mathrm{Z}$ in the Ricker based method of estimation [4] is added (i.e., as fishing mortality $(Z=F+M)$ ), the production outcome for red snapper turns negative. We provided tables that include procedural details for readers that wish to see how we estimated production of red snapper on oil and gas platforms. It is entirely plausible that oil and gas platforms make some reefassociated species, including red snapper, more vulnerable to fishing. Our analysis does not address spatial variation in demographic rates due to the intrinsic habitat quality of essential 
fish habitat or artificial reefs at scales smaller than regional e.g., between Alabama, Louisiana, and Texas.

This is not a blanket recrimination of artificial reefs and artificial reef programs. There are clear examples in the literature where artificial reefs benefit fishes and ecosystems in which they have been employed. Good examples are where artificial reefs are used to mitigate for loss or injury to natural reefs, or used to reduce destructive diving and fishing pressure on natural reefs [44-47], to name a few.

Still, the debate about whether artificial habitats attract red snapper from nearby natural habitats or actually enhance production of new biomass (i.e., the attraction vs. production debate) has been called meaningless and unresolvable [40]. This subject often is debated in broad form for all reef-associated species and, as such, may be un-resolvable in the broader context-this issue has mostly been tried in the court of public opinion. However, a more quantitative approach is tractable for a well studies species like red snapper, although difficult due to the scale and complexity of needed studies [48].

Besides red snapper, many reef-associated species that are found on oil and gas platforms and highlighted in red in ATable 1 are overfished. The role that these structures play in the population dynamics of these species is unknown. Careful consideration and enumeration of potential positive and negative impacts of man-made habitats on dynamic coastal geographies on continental shelves should be made before such habitats are constructed.

\section{Appendices}

\begin{tabular}{|c|c|c|c|c|c|c|}
\hline Taxa & SF & DF & Diet & PC & Behavior & Dep. \\
\hline Abudefduf saxatilis & $\mathrm{H}$ & $\mathrm{N}$ & $\mathrm{R}$ & $\mathrm{R}$ ? & $\mathrm{R}, \mathrm{D}$ & Y \\
\hline Abudefduf taurus & $\mathrm{H}$ & $\mathrm{N}$ & $\mathrm{R}$ & $\mathrm{R}$ ? & $\mathrm{R}, \mathrm{D}$ & Y \\
\hline Acanthocybium solandri & $\mathrm{L}$ & Y & $\mathrm{P}$ & $\mathrm{R}$ & $\mathrm{P}, \mathrm{HM}$ & $\mathrm{N}$ \\
\hline Acanthurus chirurgus & $\mathrm{H}$ & $\mathrm{N}$ & $\mathrm{R}$ & $\mathrm{R}$ & $\mathrm{R}, \mathrm{D}$ & $\mathrm{Y}$ \\
\hline Acanthurus coeruleus & $\mathrm{H}$ & $\mathrm{N}$ & $\mathrm{R}$ & $\mathrm{R}$ ? & $\mathrm{R}, \mathrm{D}$ & Y \\
\hline Achirus lineatus & $\mathrm{L}$ & $\mathrm{N}$ & B & $\mathrm{R}$ & $\mathrm{D}$ & $\mathrm{N}$ \\
\hline Albula vulpes & L & $\mathrm{Y}$ & B & $\mathrm{R}$ & $\mathrm{D}$ & $\mathrm{N}$ \\
\hline Aluterus schoepfii & $\mathrm{H}$ & $\mathrm{N}$ & $\mathrm{R}, \mathrm{B}$ & $\mathrm{R}$ ? & $\mathrm{R}, \mathrm{D}$ & Y \\
\hline Aluterus scriptus & $\mathrm{H}$ & $\mathrm{N}$ & $\mathrm{R}, \mathrm{B}$ & $\mathrm{R}$ ? & $\mathrm{R}, \mathrm{D}$ & Y \\
\hline Amblycirrhitus pinos & $\mathrm{H}$ & $\mathrm{N}$ & $\mathrm{R}, \mathrm{B}$ & $\mathrm{R}$ ? & $\mathrm{R}, \mathrm{D}$ & $\mathrm{Y}$ \\
\hline Anchoa cubana & $\mathrm{L}$ & $\mathrm{N}$ & $\mathrm{P}$ & $\mathrm{R}$ & $\mathrm{P}$ & $\mathrm{N}$ \\
\hline Anchoa hepsetus & $\mathrm{L}$ & $\mathrm{N}$ & $\mathrm{P}$ & $\mathrm{R}$ & $\mathrm{P}$ & $\mathrm{N}$ \\
\hline Anchoa mitchilli & $\mathrm{L}$ & $\mathrm{N}$ & $\mathrm{P}$ & $\mathrm{R}$ & $\mathrm{P}$ & $\mathrm{N}$ \\
\hline
\end{tabular}




\begin{tabular}{|c|c|c|c|c|c|c|}
\hline Taxa & SF & DF & Diet & PC & Behavior & Dep. \\
\hline Anchoa nasuta & $\mathrm{L}$ & $\mathrm{N}$ & $\mathrm{P}$ & $\mathrm{R}$ & $\mathrm{P}$ & $\mathrm{N}$ \\
\hline Anchoviella perfasciata & $\mathrm{L}$ & $\mathrm{N}$ & $\mathrm{P}$ & $\mathrm{R}$ & $\mathrm{P}$ & $\mathrm{N}$ \\
\hline Ancylopsetta dilecta & $\mathrm{L}$ & $\mathrm{N}$ & B & $\mathrm{R}$ & $\mathrm{D}$ & $\mathrm{N}$ \\
\hline Ancylopsetta ommata & $\mathrm{L}$ & $\mathrm{Y}$ & $\mathrm{B}$ & $\mathrm{R}$ & $\mathrm{D}$ & $\mathrm{N}$ \\
\hline Antennarius ocellatus & $\mathrm{H}$ & $\mathrm{N}$ & $\mathrm{R}, \mathrm{B}$ & $\mathrm{H}$ & $\mathrm{R}, \mathrm{D}$ & $\mathrm{Y}$ \\
\hline Apogon maculatus & $\mathrm{H}$ & $\mathrm{N}$ & $\mathrm{R}, \mathrm{B}$ & $\mathrm{R} ?$ & $\mathrm{R}, \mathrm{D}$ & $\mathrm{Y}$ \\
\hline Apogon pseudomaculatus & $\mathrm{H}$ & $\mathrm{N}$ & $\mathrm{R}, \mathrm{B}$ & $\mathrm{R} ?$ & $\mathrm{R}$, & $\mathrm{Y}$ \\
\hline Archosargus probatocephalus & $\mathrm{M}$ & $\mathrm{Y}$ & $\mathrm{R}, \mathrm{B}$ & $\mathrm{R}$ & $\mathrm{R}, \mathrm{D}$ & RA \\
\hline Ariomma regulus & $\mathrm{L}$ & $\mathrm{N}$ & B & $\mathrm{R}$ & $\mathrm{P}$ & $\mathrm{S}$ \\
\hline Arius felis & $\mathrm{L}$ & $\mathrm{N}$ & B & $\mathrm{R}$ & $\mathrm{D}$ & $\mathrm{N}$ \\
\hline Bagre marinus & $\mathrm{L}$ & $\mathrm{Y}$ & $\mathrm{B}, \mathrm{P}$ & $\mathrm{R}$ & $\mathrm{D}$ & $\mathrm{N}$ \\
\hline Bairdiella chrysoura & $\mathrm{L}$ & $\mathrm{N}$ & $\mathrm{B}, \mathrm{P}$ & $\mathrm{R}$ & $\mathrm{D}$ & $\mathrm{N}$ \\
\hline Balistes capriscus & $\mathrm{H}$ & $\mathrm{Y}$ & $\mathrm{R}, \mathrm{B}$ & $\mathrm{H}$ & $\mathrm{R}, \mathrm{D}$ & $\mathrm{Y}$ \\
\hline Bodianus rufus & $\mathrm{H}$ & $\mathrm{Y}$ & $\mathrm{R}, \mathrm{P}$ & $\mathrm{R} ?$ & $\mathrm{R}, \mathrm{P}$ & $\mathrm{Y}$ \\
\hline Bollmannia communis & $\mathrm{L}$ & $\mathrm{N}$ & B & $\mathrm{R}$ & $\mathrm{D}$ & $\mathrm{N}$ \\
\hline Bregmaceros cantori & $\mathrm{L}$ & $\mathrm{N}$ & B & $\mathrm{R}$ & $\mathrm{D}$ & $\mathrm{N}$ \\
\hline Brevoortia patronus & $\mathrm{L}$ & $\mathrm{Y}$ & $P$ & $\mathrm{R}$ & $\mathrm{P}$ & $\mathrm{N}$ \\
\hline Brotula barbata & $\mathrm{L}$ & $\mathrm{N}$ & B & $\mathrm{R}$ & $\mathrm{D}$ & $\begin{array}{l}\text { RA } \\
\text { (juv) }\end{array}$ \\
\hline Callionymus bairdi & M? & $\mathrm{N}$ & $\mathrm{B} ?$ & $\mathrm{R} ?$ & $\mathrm{D}$ & RA, SG \\
\hline Cantherhines pullus & $\mathrm{H}$ & $\mathrm{N}$ & B & $\mathrm{H} ?$ & $\begin{array}{l}\text { R, D } \\
\text { (adults, juv=P) }\end{array}$ & $\begin{array}{l}\text { Y } \\
\text { (adults) }\end{array}$ \\
\hline Canthidermis sufflamen & $\mathrm{L}$ & $\mathrm{N}$ & $\mathrm{P}$ & $\mathrm{R}$ & $\mathrm{D}, \mathrm{P}$ & N, SG, RA \\
\hline Canthigaster rostrata & $\mathrm{H}$ ? & $\mathrm{N}$ & B & $\mathrm{H}$ ? & $\mathrm{R}, \mathrm{D}$ & Y?, RA \& SG \\
\hline Caranx bartholomaei & $\mathrm{L}$ & $\mathrm{N}$ & $\mathrm{P}$ & $\mathrm{R}$ & $\mathrm{HM}$ & RA \\
\hline Caranx crysos & $\mathrm{L}$ & $\mathrm{N}$ & $\mathrm{P}$ & $\mathrm{R}$ & $\mathrm{P}$ & RA \\
\hline Caranx hippos & $\mathrm{L}$ & $\mathrm{N}$ & $\mathrm{P}$ & $\mathrm{R}$ & $\mathrm{P}$ & RA \\
\hline Caranx latus & $\mathrm{L}$ & $\mathrm{N}$ & $\mathrm{P}$ & $\mathrm{R}$ & $\mathrm{P}$ & RA \\
\hline Caranx lugubris & $\mathrm{L}$ & $\mathrm{N}$ & $\mathrm{P}$ & $\mathrm{R}$ & $\mathrm{P}$ & RA \\
\hline Caranx ruber & $\mathrm{L}$ & $\mathrm{N}$ & $\mathrm{P}$ & $\mathrm{R}$ & $\mathrm{P}$ & RA \\
\hline Carcharhinus plumbeus & $\mathrm{L}$ & Y & $\mathrm{P}$ & $\mathrm{R}$ & $\mathrm{P}, \mathrm{HM}$ & $\mathrm{N}$ \\
\hline Caulolatilus intermedius & $\mathrm{L}$ & $\mathrm{Y}$ & $\mathrm{P}, \mathrm{B}$ & $\mathrm{R}$ & $\mathrm{D}$ & $\mathrm{N}$ \\
\hline Centropristis melana & M? & $\mathrm{Y}$ & $\mathrm{P}, \mathrm{B}$ & $\mathrm{R}$ & $\mathrm{D}$ & RA \\
\hline Centropristis ocyurus & M? & $\mathrm{N}$ & B & $\mathrm{R}$ & $\mathrm{R}, \mathrm{D}$ & $\mathrm{HB}$ \\
\hline
\end{tabular}




\begin{tabular}{|c|c|c|c|c|c|c|}
\hline Taxa & SF & DF & Diet & PC & Behavior & Dep. \\
\hline Centropristis philadelphica & M? & $\mathrm{N}$ & B & $\mathrm{R}$ & $\mathrm{P}, \mathrm{D}$ & $\mathrm{HB}$ \\
\hline Cephalopholis cruentatus & $\mathrm{H}$ & $\mathrm{N}$ & $\mathrm{P}$ & $\mathrm{H}$ ? & $\mathrm{R}, \mathrm{D}$ & Y \\
\hline Chaetodipterus faber & $\mathrm{H}$ & $\mathrm{N}$ & $\mathrm{B}, \mathrm{P}$ & $\mathrm{R}$ & $\mathrm{P}, \mathrm{P}$ & $\mathrm{Y} ?$ \\
\hline Chaetodon ocellatus & $\mathrm{H}$ & $\mathrm{N}$ & $\mathrm{R}$ & $\mathrm{H} ?$ & $\mathrm{R}, \mathrm{D}$ & $\mathrm{Y}$ \\
\hline Chaetodon sedentarius & $\mathrm{H}$ & $\mathrm{N}$ & $\mathrm{R}$ & $\mathrm{H} ?$ & $\mathrm{R}, \mathrm{D}$ & $\mathrm{Y}$ \\
\hline Cheilopogon cyanopterus & $\mathrm{L}$ & $\mathrm{N}$ & $\mathrm{P}$ & $\mathrm{R}$ & $\mathrm{P}$ & $\mathrm{N}$ \\
\hline Cheilopogon furcatus & $\mathrm{L}$ & $\mathrm{N}$ & $\mathrm{P}$ & $\mathrm{R}$ & $\mathrm{P}$ & $\mathrm{N}$ \\
\hline Chilomycterus schoepfii & M & $\mathrm{N}$ & B & $\mathrm{R}$ & $\mathrm{D}$ & RA, SG \\
\hline Chlorophthalmus agassizi & $\mathrm{L}$ & $\mathrm{N}$ & B & $\mathrm{R}$ & $\mathrm{D}$ & $\mathrm{N}$ \\
\hline Chloroscombrus chrysurus & $\mathrm{L}$ & $\mathrm{N}$ & $\mathrm{P}$ & $\mathrm{R}$ & $\mathrm{P}$ & $\mathrm{N}$ \\
\hline Chromis enchrysura & $\mathrm{H}$ & $\mathrm{N}$ & $\mathrm{P}$ & $\mathrm{H}$ & $\mathrm{D}$ & $\mathrm{Y}$ \\
\hline Chromis mutilineata & $\mathrm{H}$ & $\mathrm{N}$ & $\mathrm{R}$ & $\mathrm{H}$ & $\mathrm{D}$ & Y \\
\hline Chromis scotti & $\mathrm{H}$ & $\mathrm{N}$ & $\mathrm{R}$ & $\mathrm{H}$ & $\mathrm{D}$ & $\mathrm{Y}$ \\
\hline Citharichthys spilopterus & $\mathrm{L}$ & $\mathrm{Y}$ & B & $\mathrm{R}$ & $\mathrm{D}$ & $\mathrm{N}$ \\
\hline Clepticus parrae & $\mathrm{H}$ & $\mathrm{N}$ & $\mathrm{P}$ & $\mathrm{H}$ & $\mathrm{D}, \mathrm{P}$ & $\mathrm{Y}$ \\
\hline Coryphaena equiselis & $\mathrm{L}$ & $\mathrm{Y}$ & $\mathrm{P}$ & $\mathrm{R}$ & $\mathrm{P}, \mathrm{HM}$ & $\mathrm{N}$ \\
\hline Coryphaena hippurus & $\mathrm{L}$ & $\mathrm{Y}$ & $\mathrm{P}$ & $\mathrm{R}$ & $\mathrm{P}, \mathrm{HM}$ & $\mathrm{N}$ \\
\hline Coryphopterus punctipectophorus & M & $\mathrm{N}$ & $?$ & $\mathrm{R}$ & $\mathrm{D}$ & RA \\
\hline Cubiceps pauciradiatus & $\mathrm{L}$ & $\mathrm{N}$ & $\mathrm{P}$ & $\mathrm{R}$ & $\mathrm{P}$ & $\mathrm{N}$ \\
\hline Cyclopsetta chittendeni & $\mathrm{L}$ & $\mathrm{Y}$ & B & $\mathrm{R}$ & $\mathrm{D}$ & $\mathrm{N}$ \\
\hline Cyclopsetta fimbriata & $\mathrm{L}$ & $\mathrm{Y}$ & $?$ & $\mathrm{R}$ & $\mathrm{D}$ & $\mathrm{N}$ \\
\hline Cyclothone braueri & $\mathrm{L}$ & $\mathrm{N}$ & $\mathrm{P}$ & $\mathrm{R}$ & $\mathrm{P}$ & $\mathrm{N}$ \\
\hline Cynoscion arenarius & $\mathrm{L}$ & Y & $\mathrm{P}$ & $\mathrm{R}$ & $\mathrm{P}$ & $\mathrm{N}$ \\
\hline Cynoscion nebulosus & $\mathrm{L}$ & $\mathrm{Y}$ & $\mathrm{P}$ & $\mathrm{R}$ & $\mathrm{P}$ & $\mathrm{N}, \mathrm{RA}$ \\
\hline Cynoscion nothus & $\mathrm{L}$ & $\mathrm{Y}$ & $\mathrm{P}$ & $\mathrm{R}$ & $\mathrm{P}$ & $\mathrm{N}, \mathrm{RA}$ \\
\hline Decapterus punctatus & $\mathrm{L}$ & Y & $\mathrm{P}$ & $\mathrm{R}$ & $\mathrm{P}, \mathrm{D}$ & $\mathrm{N}$ \\
\hline Decodon puellaris & $\mathrm{H}$ ? & $\mathrm{N}$ & $\mathrm{R} ?$ & $\mathrm{H}$ & $\mathrm{D}$ & $\mathrm{Y}, \mathrm{HB}$ \\
\hline Dermatolepis inermis & $\mathrm{H}$ & $Y ?^{*}$ & $\mathrm{R}, \mathrm{P}$ & $\mathrm{H} ?$ & $\mathrm{D}$ & RA, HB \\
\hline Diplectrum bivittatum & $\mathrm{L}$ & $\mathrm{N}$ & B & $\mathrm{R}$ & $\mathrm{D}$ & $\mathrm{N}$ \\
\hline Diplectrum formosum & $\mathrm{L}$ & $\mathrm{N}$ & $\mathrm{P}$ & $\mathrm{R}$ & $\mathrm{D}$ & SG, HB \\
\hline Diplogrammus pauciradiatus & $\mathrm{H}$ & $\mathrm{N}$ & B & $\mathrm{R}$ & $\mathrm{D}$ & SG \\
\hline Diplophos taenia & $\mathrm{L}$ & $\mathrm{N}$ & $\mathrm{P}$ & $\mathrm{R}$ & $\mathrm{P}$ & $\mathrm{N}$ \\
\hline Diplodus holbrooki & $\mathrm{L}$ & $\mathrm{N}$ & B & $\mathrm{R}$ & $\mathrm{D}$ & N, SG \\
\hline Dormitator maculatus & $\mathrm{L}$ & $\mathrm{N}$ & $\mathrm{P}$ & $\mathrm{R}$ & $\mathrm{D}$ & $\mathrm{N}$ \\
\hline
\end{tabular}




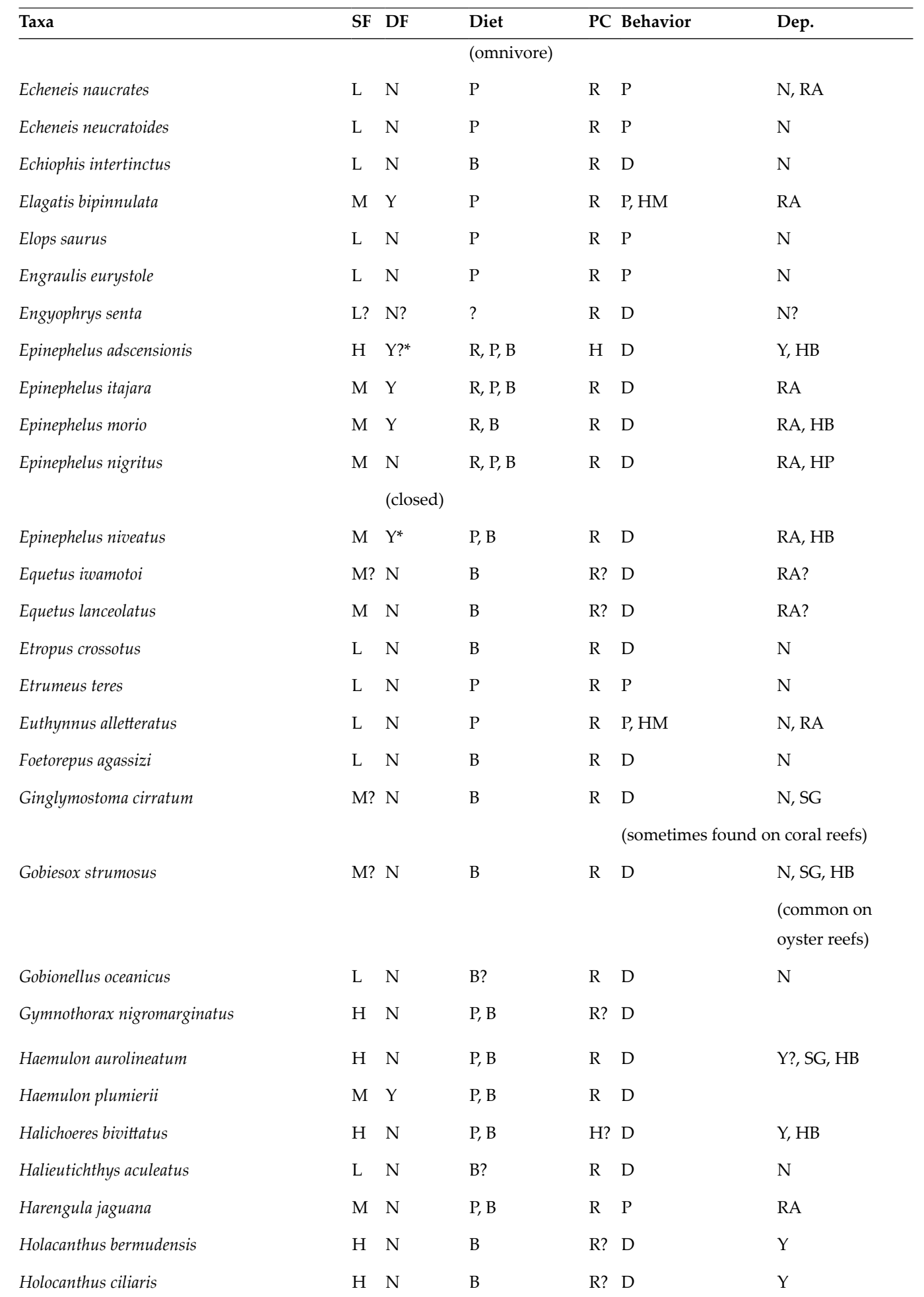




\begin{tabular}{|c|c|c|c|c|c|c|}
\hline Taxa & SF & DF & Diet & PC & Behavior & Dep. \\
\hline Holocanthus tricolor & $\mathrm{H}$ & $\mathrm{N}$ & B & $\mathrm{R} ?$ & $\mathrm{D}$ & Y, RA \\
\hline Holocentrus ascensionis & $\mathrm{H}$ & $\mathrm{N}$ & B & $\mathrm{R} ?$ & $\mathrm{D}$ & $\mathrm{Y}$ \\
\hline Hoplunnis macrura & $\mathrm{L} ?$ & $\mathrm{~N}$ & $\mathrm{~B} ?$ & $\mathrm{R} ?$ & $\mathrm{D}$ & N?, RA \\
\hline Hyperoglyphe perciformis & $\mathrm{L}$ & $\mathrm{N}$ & $\mathrm{P}$ & $\mathrm{R}$ & $\mathrm{P}$ & $\mathrm{N}$ \\
\hline Hypleurochilus geminatus & $\mathrm{H}$ & $\mathrm{N}$ & $\mathrm{B} ?$ & $\begin{array}{l}\mathrm{H} \\
\text { (nes } \\
\mathrm{t}- \\
\text { buil } \\
\text { der) }\end{array}$ & D & RA, HB \\
\hline Hypleurochilus multifilis & $\mathrm{H}$ & $\mathrm{N}$ & $\mathrm{B} ?$ & $\begin{array}{l}\mathrm{H} \\
\text { (nes } \\
\mathrm{t}- \\
\text { buil } \\
\text { der) }\end{array}$ & $\begin{array}{l}\mathrm{D} \\
\mathrm{s} \\
1\end{array}$ & RA, HB \\
\hline Hypsoblennius hentz & $\mathrm{H}$ & $\mathrm{N}$ & $\mathrm{B} ?$ & $\begin{array}{l}\mathrm{H} \\
\text { (nes } \\
\mathrm{t}- \\
\text { buil } \\
\text { der) }\end{array}$ & $\begin{array}{l}\text { D } \\
5 \\
1 \\
1 \\
0\end{array}$ & $\begin{array}{l}\text { RA, HB } \\
\text { (common on } \\
\text { oyster reefs) }\end{array}$ \\
\hline Hypsoblennius invemar & $\mathrm{H}$ & $\mathrm{N}$ & B & $\begin{array}{l}\mathrm{H} \\
\text { (nes } \\
\mathrm{t}- \\
\text { buil } \\
\text { der) }\end{array}$ & $\begin{array}{l}\text { D } \\
5 \\
1 \\
1 \\
1\end{array}$ & RA, HB \\
\hline Hypsoblennius ionthas & $\mathrm{H}$ & $\mathrm{N}$ & $\mathrm{B} ?$ & $\begin{array}{l}\mathrm{H} \\
\text { (nes } \\
\mathrm{t}- \\
\text { buil } \\
\text { der) }\end{array}$ & $\begin{array}{l}\mathrm{D} \\
\mathrm{s} \\
1 \\
1\end{array}$ & RA, HB \\
\hline Ioglossus calliurus & $\mathrm{L}$ & $\mathrm{N}$ & $\mathrm{P}$ & $\mathrm{R}$ & $\mathrm{D}$ & $\mathrm{N}$ \\
\hline Katsuwonus pelamis & $\mathrm{L}$ & Y & $\mathrm{P}$ & $\mathrm{R}$ & \multicolumn{2}{|c|}{$\begin{array}{l}\text { (associated with objects drifting at } \\
\text { surface) }\end{array}$} \\
\hline Kyphosus incisor & M? & $\begin{array}{l}\mathrm{N} \\
\text { (plar }\end{array}$ & $\begin{array}{l}\text { P? } \\
\text { cluding }\end{array}$ & $\begin{array}{l}\mathrm{R} \\
\mathrm{dm})\end{array}$ & $\mathrm{P}$ & Y?, HB. S \\
\hline Kyphosus sectatrix & M? & $\mathrm{N}$ & $\mathrm{P}, \mathrm{B}$ & $\mathrm{R}$ & $\mathrm{P}$ & $\mathrm{Y} ?, \mathrm{HB}, \mathrm{S}$ \\
\hline
\end{tabular}




\begin{tabular}{|c|c|c|c|c|c|c|}
\hline Taxa & SF & DF & Diet & \multicolumn{2}{|c|}{ PC Behavior } & Dep. \\
\hline & & \multicolumn{5}{|c|}{ (plants, including Sargassum, some benthic } \\
\hline & & \multicolumn{5}{|c|}{ crustaceans) } \\
\hline Lachnolaimus maximus & M? & $\mathrm{Y}$ & B & $\mathrm{R}$ & $\mathrm{D}$ & Y?, HB \\
\hline Lactophrys quadricornis & $\mathrm{L}$ & $\mathrm{N}$ & B & $\mathrm{R}$ & $\mathrm{D}$ & SG \\
\hline Lagodon rhomboides & M & $\mathrm{N}$ & $\mathrm{B}$ & $\mathrm{R}$ & $\mathrm{D}$ & RA, SG, HB \\
\hline Larimus fasciatus & $\mathrm{L}$ & $\mathrm{N}$ & $\mathrm{B}$ & $\mathrm{R}$ & $\mathrm{D}$ & $\mathrm{N}$ \\
\hline Leiostomus xanthurus & $\mathrm{L}$ & Y & B & $\mathrm{R}$ & $\mathrm{D}$ & $\mathrm{N}$ \\
\hline Lepophidium profundorum & $\mathrm{L}$ & $\mathrm{N}$ & B & $\mathrm{R}$ & $\mathrm{D}$ & $\mathrm{N}$ \\
\hline \multirow[t]{2}{*}{ Lepophidium staurophor } & $\mathrm{L}$ & $\mathrm{N}$ & $?$ & $\mathrm{R}$ & $\mathrm{D}$ & $\mathrm{N}$ \\
\hline & & & & & \multicolumn{2}{|c|}{ (deep water) } \\
\hline \multirow[t]{2}{*}{ Lestrolepis intermedia } & $\mathrm{L}$ & $\mathrm{N}$ & $?$ & $\mathrm{R}$ & $\mathrm{P}$ & $\mathrm{N}$ \\
\hline & & & & & \multicolumn{2}{|c|}{ (bathypelagic) } \\
\hline Lobotes surinamensis & M & $\mathrm{Y}$ & $\mathrm{P}, \mathrm{B}$ & $\mathrm{R}$ & $\mathrm{P}$ & RA \\
\hline & & & & & \multicolumn{2}{|c|}{ (often found associated with flotsam) } \\
\hline Lutjanus apodus & M & $\mathrm{Y}$ & $\mathrm{P}, \mathrm{B}$ & $\mathrm{R}$ & $\mathrm{D}$ & RA \\
\hline Lutjanus campechanus & M & $\mathrm{Y}$ & $\mathrm{P}, \mathrm{B}$ & $\mathrm{R}$ & $\mathrm{D}, \mathrm{P}$ & RA, HB \\
\hline Lutjanus griseus & M & $\mathrm{Y}$ & $\mathrm{P}$ & $\mathrm{R}$ & $\mathrm{P}$ & RA \\
\hline Lutjanus jocu & M & $\mathrm{Y}$ & $\mathrm{R}, \mathrm{P}, \mathrm{B}$ & $\mathrm{R}$ & $\mathrm{P}$ & RA, HB \\
\hline Lutjanus synagris & M & $\mathrm{Y}$ & $\mathrm{R}, \mathrm{P}, \mathrm{B}$ & $\mathrm{R}$ & $\mathrm{D}$ & $\mathrm{RA}, \mathrm{HB}$ \\
\hline \multirow[t]{2}{*}{ Lutjanus vivanus } & M & $\mathrm{Y}$ & $\mathrm{R}, \mathrm{P}, \mathrm{B}$ & $\mathrm{R}$ & $\mathrm{D}$ & RA, HB \\
\hline & & & & & \multicolumn{2}{|c|}{ (common on shelf-edge banks) } \\
\hline \multirow[t]{2}{*}{ Magnisudis atlantica } & $\mathrm{L}$ & $\mathrm{N}$ & $\mathrm{P}$ & $\mathrm{R}$ & $\mathrm{P}$ & $\mathrm{N}$ \\
\hline & & & & & \multicolumn{2}{|c|}{ (bathypelagic) } \\
\hline Makaira nigricans & $\mathrm{L}$ & $\mathrm{Y}$ & $\mathrm{P}$ & $\mathrm{R}$ & $\mathrm{P}, \mathrm{HM}$ & $\mathrm{N}$ \\
\hline Megalops atlanticus & $\mathrm{L}$ & $\mathrm{Y}$ & $\mathrm{P}$ & $\mathrm{R}$ & $\mathrm{P}$ & N, RA \\
\hline Membras martinica & $\mathrm{L}$ & $\mathrm{N}$ & $\mathrm{P}$ & $\mathrm{R}$ & $\mathrm{P}$ & $\mathrm{N}$ \\
\hline Microdesmus lanceolatus & $\mathrm{L}$ & $\mathrm{N}$ & $\mathrm{B} ?$ & $\mathrm{R}$ & $\mathrm{D}$ & $\mathrm{N} ?$ \\
\hline Microdesmus longipinnis & $\mathrm{L}$ & $\mathrm{N}$ & $\mathrm{B} ?$ & $\mathrm{R}$ & $\mathrm{D}$ & $\mathrm{N}$ \\
\hline Micropogonias undulatus & $\mathrm{L}$ & $\mathrm{Y}$ & B & $\mathrm{R}$ & $\mathrm{D}$ & $\mathrm{N}$ \\
\hline \multirow[t]{2}{*}{ Monolene sessilicauda } & $\mathrm{L}$ & $\mathrm{N}$ & B & $\mathrm{R}$ & $\mathrm{D}$ & $\mathrm{N}$ \\
\hline & & & & & \multicolumn{2}{|c|}{ (bathydemersal) } \\
\hline \multirow[t]{2}{*}{ Mugil cephalus } & $\mathrm{L}$ & Y & B & $\mathrm{R}$ & $\mathrm{P}$ & $\mathrm{N}$ \\
\hline & & & (plants) & & & \\
\hline Mugil curema & $\mathrm{L}$ & $\mathrm{Y}$ & B & $\mathrm{R}$ & $\mathrm{P}$ & $\mathrm{N}$ \\
\hline
\end{tabular}




\begin{tabular}{|c|c|c|c|c|c|c|}
\hline Taxa & SF & DF & Diet & PC & Behavior & Dep. \\
\hline Mullus auratus & $\mathrm{L}$ & $\mathrm{N}$ & B & $\mathrm{R}$ & $\mathrm{D}$ & $\mathrm{N}$ \\
\hline Mycteroperca microlepis & M & $\mathrm{Y}$ & $\mathrm{P}$ & $\mathrm{R}$ & \multicolumn{2}{|c|}{ adults offshore on rocky bottoms) } \\
\hline Mycteroperca phenax & M & $Y^{*}$ & $\mathrm{R}, \mathrm{P}$ & \multicolumn{3}{|c|}{$\begin{array}{l}\text { (high-relief rocky bottoms, often found on } \\
\text { Oculina reefs) }\end{array}$} \\
\hline Mycteroperca rubra & M & $\mathrm{Y}^{*}$ & $\mathrm{R}, \mathrm{P}, \mathrm{B}$ & $\mathrm{R}$ & $\mathrm{D}$ & $\begin{array}{l}\mathrm{RA}, \mathrm{HB} \\
\text { (rocky and sandy } \\
\text { bottoms) }\end{array}$ \\
\hline Mycteroperca venenosa & M & $Y^{*}$ & $\mathrm{R}, \mathrm{P}$ & $\mathrm{R}$ & \multicolumn{2}{|c|}{$\begin{array}{l}\text { (rocky and coral reefs, shelf-edge banks } \\
\text { in GOM) }\end{array}$} \\
\hline Myrophis punctatus & $\mathrm{L}$ & $\mathrm{N}$ & $\mathrm{B} ?$ & $\mathrm{R}$ & $\mathrm{D}$ & $\mathrm{RA}, \mathrm{SG}$ \\
\hline Neoconger mucronatus & M & $\mathrm{N}$ & B & $\mathrm{R}$ & $\mathrm{D}$ & $\begin{array}{l}\text { RA (offshore } \\
\text { banks) }\end{array}$ \\
\hline Ocyurus chrysurus & M & Y & $\mathrm{R}, \mathrm{P}, \mathrm{B}$ & $\mathrm{R}$ & $\mathrm{P}$ & $\begin{array}{l}\text { RA (mostly coral } \\
\text { reefs) }\end{array}$ \\
\hline Ogcocephalus declivirostris & $\mathrm{L}$ & $\mathrm{N}$ & $\mathrm{B} ?$ & $\mathrm{R}$ & $\mathrm{D}$ & $\mathrm{N}, \mathrm{HB}$ \\
\hline Ogcocephalus radiatus & $\mathrm{L}$ & $\mathrm{N}$ & $\mathrm{B} ?$ & $\mathrm{R}$ & $\mathrm{D}$ & $\mathrm{N}, \mathrm{HB}$ \\
\hline Oligoplites saurus & $\mathrm{L}$ & $\mathrm{N}$ & $\mathrm{P}, \mathrm{B}$ & $\mathrm{R}$ & $\mathrm{P}$ & RA \\
\hline Ophichthus gomesii & $\mathrm{L}$ & $\mathrm{N}$ & B & $\mathrm{R}$ & \multicolumn{2}{|c|}{ (common on shrimp grounds) } \\
\hline Ophidion nocomis & $\mathrm{L}$ & $\mathrm{N}$ & $\mathrm{B} ?$ & $\mathrm{R}$ & \multicolumn{2}{|c|}{ (uncommon, shallow sandy bays) } \\
\hline $\begin{array}{l}\text { Ophidion robinsi } \\
\text { (rare) }\end{array}$ & $\mathrm{L} ?$ & $\mathrm{~N}$ & $\mathrm{~B} ?$ & $\mathrm{R} ?$ & $\mathrm{D}$ & $\mathrm{N}$ \\
\hline $\begin{array}{l}\text { Ophidion selenops } \\
\text { (uncommon) }\end{array}$ & M? & $\mathrm{N}$ & $\mathrm{B} ?$ & $\mathrm{R} ?$ & $\mathrm{D}$ & RA \\
\hline Ophioblennius atlanticus & $\mathrm{H}$ & $\mathrm{N}$ & $\begin{array}{l}\text { B } \\
\text { (plants) }\end{array}$ & $\mathrm{H}$ & $\mathrm{D}$ & $\begin{array}{l}\text { RA } \\
\text { (rocky reefs and } \\
\text { corals) }\end{array}$ \\
\hline Opisthognathus aurifrons & $\mathrm{H}$ & $\mathrm{N}$ & $\mathrm{R}, \mathrm{P}$ & $\mathrm{R} ?$ & $\mathrm{D}$ & $\mathrm{Y} ?$ \\
\hline Opisthognathus lonchurus & $\mathrm{H}$ & $\mathrm{N}$ & $\mathrm{R}$ ? & $\mathrm{R} ?$ & $\mathrm{D}$ & $\mathrm{Y} ?$ \\
\hline Opsanus beta & $\mathrm{M}$ & $\mathrm{N}$ & $\mathrm{B}$ & $\mathrm{H} ?$ & $\mathrm{D}$ & RA, SG \\
\hline
\end{tabular}




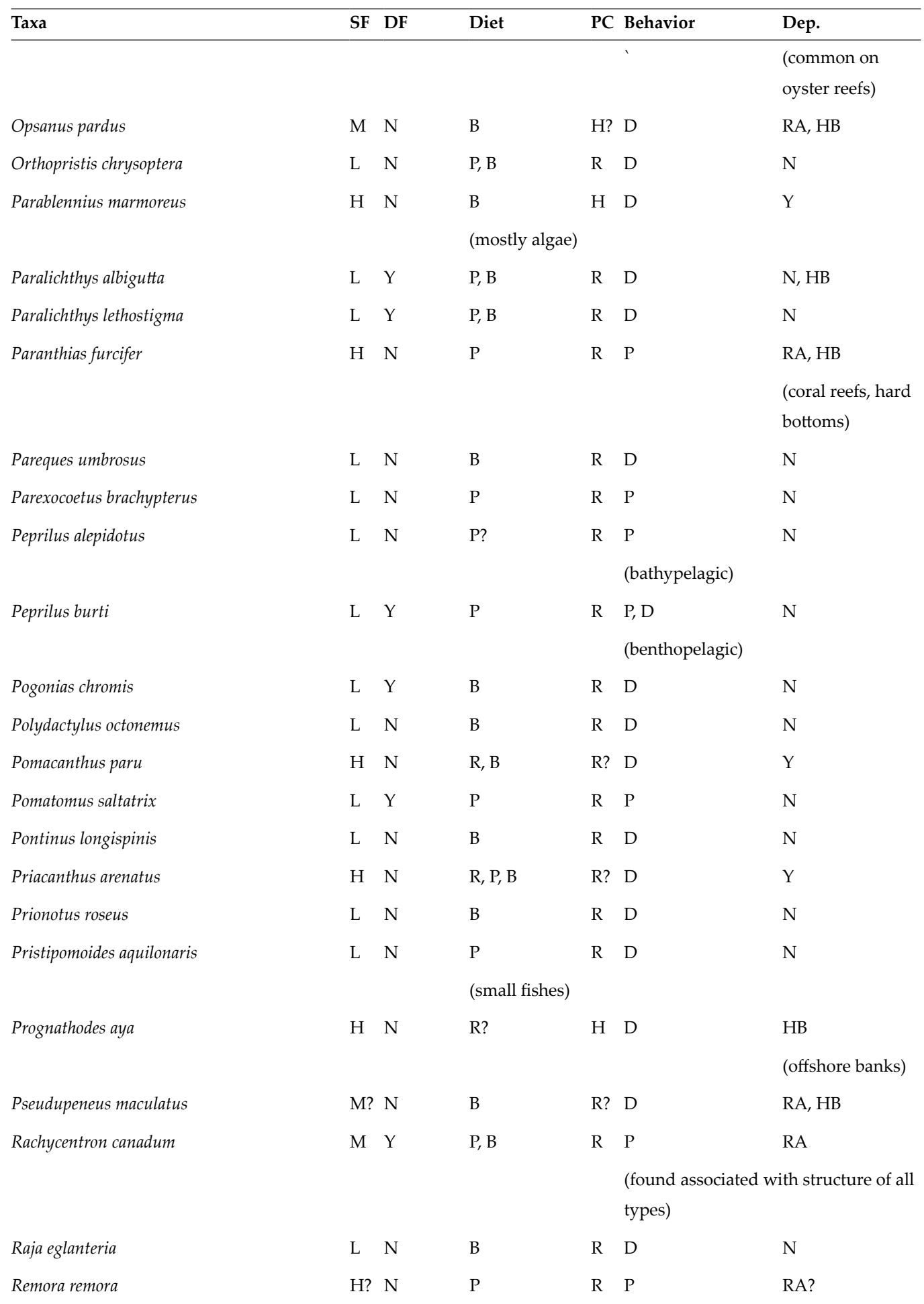




\begin{tabular}{|c|c|c|c|c|c|c|}
\hline Taxa & SF & DF & Diet & PC & Behavior & Dep. \\
\hline Rhomboplites aurorubens & M & Y & $\mathrm{P}, \mathrm{B}$ & $\mathrm{R}$ & $\mathrm{P}$ & $\begin{array}{l}\text { (usually attached } \\
\text { to sharks, turtles) } \\
\text { RA, HB } \\
\text { (HB on shelf- } \\
\text { edge) }\end{array}$ \\
\hline Robia legula & $\mathrm{L}$ & $\mathrm{N}$ & $\mathrm{P}$ & $\mathrm{R}$ & $\begin{array}{l}\mathrm{P} \\
\text { (bathypelagic) }\end{array}$ & $\mathrm{N}$ \\
\hline Ruvettus pretiosus & $\mathrm{L}$ & $\mathrm{N}$ & $\mathrm{P}, \mathrm{B}$ & $\mathrm{R}$ & $\begin{array}{l}\mathrm{P} \\
\text { (bathypelagic) }\end{array}$ & $\mathrm{N}$ \\
\hline Rypticus maculatus & M? & $\mathrm{N}$ & B & $\mathrm{R}$ & $\mathrm{D}$ & RA? \\
\hline Sardinella aurita & $\mathrm{L}$ & Y & $\mathrm{P}$ & $\mathrm{R}$ & $\mathrm{P}$ & RA \\
\hline Saurida brasiliensis & $\mathrm{L}$ & $\mathrm{N}$ & $\begin{array}{l}\mathrm{P} \\
\text { (nekton) }\end{array}$ & $\mathrm{R}$ & $\mathrm{D}$ & $\mathrm{N}$ \\
\hline Saurida normani & M & $\mathrm{N}$ & $\mathrm{P}$ & $\mathrm{R}$ & $\mathrm{D}$ & RA \\
\hline Saurida suspicio & & $\mathrm{L}$ & & $\mathrm{N}$ & $\mathrm{P}$ & $\mathrm{R}$ \\
\hline Scartella cristata & $\mathrm{H}$ & $\mathrm{N}$ & $\mathrm{R}, \mathrm{B}$ & $\mathrm{H}$ & $\mathrm{D}$ & Y \\
\hline $\begin{array}{l}\text { Schedophilus medusophagus } \\
\text { (GOM record is doubtful) }\end{array}$ & $\mathrm{L}$ & $\mathrm{N}$ & $\mathrm{P}$ & $\mathrm{R}$ & $\mathrm{P}$ & $\mathrm{N}$ \\
\hline Sciaenops ocellatus & $\mathrm{L}$ & Y & $\mathrm{P}, \mathrm{B}$ & $\mathrm{R}$ & $\mathrm{D}, \mathrm{P}$ & $\mathrm{N}$ \\
\hline Scomber japonicus & $\mathrm{L}$ & Y & $\mathrm{P}$ & $\mathrm{R}$ & P, HM & $\mathrm{N}$ \\
\hline Scomberomorus cavalla & $\mathrm{L}$ & Y & $\mathrm{P}$ & $\mathrm{R}$ & P, HM & RA \\
\hline Scomberomorus maculatusL & $\mathrm{Y}$ & $\mathrm{P}$ & $\mathrm{R}$ & $\begin{array}{l}\mathrm{P}, \\
\mathrm{HM}\end{array}$ & & RA \\
\hline Scorpaena brasiliensis & $\mathrm{L}$ & $\mathrm{N}$ & B & $\mathrm{R}$ & $\mathrm{D}$ & $\mathrm{HB}$ \\
\hline Selar crumenophthalmus & $\mathrm{L}$ & $\mathrm{N}$ & $\mathrm{P}$ & $\mathrm{R}$ & $\mathrm{P}$ & RA \\
\hline Selene setapinnis & $\mathrm{L}$ & $\mathrm{N}$ & $\mathrm{P}, \mathrm{B}$ & $\mathrm{R}$ & $\begin{array}{l}\text { P } \\
\text { (benthopelagic) }\end{array}$ & $\mathrm{N}$ \\
\hline Selene vomer & $\mathrm{L}$ & $\mathrm{N}$ & $\mathrm{P}, \mathrm{B}$ & $\mathrm{R}$ & $\mathrm{P}$ & $\mathrm{N}$ \\
\hline Seriola dumerilii & M & $\mathrm{Y}$ & $\mathrm{P}$ & $\mathrm{R}$ & P, HM & RA \\
\hline Seriola fasciata & M & Y & $\mathrm{P}$ & $\mathrm{R}$ & $\mathrm{P}, \mathrm{HM}$ & RA \\
\hline Seriola rivoliana & M & $\mathrm{Y}$ & $\mathrm{P}$ & $\mathrm{R}$ & $\mathrm{P}, \mathrm{HM}$ & RA \\
\hline Seriola zonata & M & Y & $\mathrm{P}$ & $\mathrm{R}$ & $\mathrm{P}, \mathrm{HM}$ & $\mathrm{N}$ \\
\hline Serranus subligarius & $\mathrm{L}$ & $\mathrm{N}$ & B & $\mathrm{R}$ & $\mathrm{D}$ & $\mathrm{N}$ \\
\hline Sphoeroides parvus & $\mathrm{L}$ & $\mathrm{N}$ & B & $\mathrm{R}$ & $\mathrm{D}$ & $\mathrm{N}$ \\
\hline
\end{tabular}




\begin{tabular}{|c|c|c|c|c|c|c|}
\hline Taxa & SF & DF & Diet & PC & Behavior & Dep. \\
\hline Sphoeroides spengleri & $\mathrm{L}$ & $\mathrm{N}$ & B & $\mathrm{R}$ & $\mathrm{D}$ & $\begin{array}{l}\text { RA } \\
\text { (SG, reef flats) }\end{array}$ \\
\hline Sphyraena barracuda & M & Y & $\mathrm{P}$ & $\mathrm{R}$ & $\mathrm{P}$ & RA, SG \\
\hline Sphyraena borealis & M & $\mathrm{N}$ & $\mathrm{P}$ & $\mathrm{R}$ & $\mathrm{P}$ & RA \\
\hline Sphyraena guachancho & $\mathrm{L}$ & $\mathrm{N}$ & $\mathrm{P}$ & $\mathrm{R}$ & $\mathrm{P}$ & $\mathrm{N}$ \\
\hline Stegastes partitus & $\mathrm{H}$ & $\mathrm{N}$ & $\mathrm{R}, \mathrm{B}$ & $\mathrm{R}$ ? & $\mathrm{D}$ & $\mathrm{Y}$ \\
\hline Stegastes variabilis & $\mathrm{H}$ & $\mathrm{N}$ & $\mathrm{R}, \mathrm{B}$ & $\mathrm{R} ?$ & $\mathrm{D}$ & $\mathrm{Y}$ \\
\hline Stellifer lanceolatus & $\mathrm{L}$ & $\mathrm{N}$ & $\mathrm{B}$ & $\mathrm{R}$ & $\mathrm{D}$ & $\mathrm{N}$ \\
\hline Stenotomus caprinus & $\mathrm{L}$ & $\mathrm{N}$ & B & $\mathrm{R}$ & $\mathrm{D}$ & $\mathrm{N}$ \\
\hline Stephanolepis hispidus & $\mathrm{H}$ ? & $\mathrm{N}$ & B & $\mathrm{R} ?$ & $\mathrm{P}, \mathrm{D}$ & RA \\
\hline Syacium gunteri & M & $\mathrm{N}$ & $\mathrm{B}, \mathrm{P}$ & $\mathrm{R}$ & $\mathrm{D}$ & RA \\
\hline Syacium papillosum & M & $\mathrm{N}$ & B & $\mathrm{R}$ & $\mathrm{D}$ & RA \\
\hline Symphurus civitatium & $\mathrm{L}$ & $\mathrm{N}$ & $\mathrm{B} ?$ & $\mathrm{R}$ & $\mathrm{D}$ & $\mathrm{N}$ \\
\hline Syngnathus louisianae & $\mathrm{H}$ & $\mathrm{N}$ & $\mathrm{P}$ & $\mathrm{R}$ & $\mathrm{D}$ & RA \\
\hline Synodus foetens & $\mathrm{L}$ & $\mathrm{N}$ & B & $\mathrm{R}$ & $\mathrm{D}$ & $\mathrm{HB}$ \\
\hline Synodus poeyi & $\mathrm{L}$ & $\mathrm{N}$ & B & $\mathrm{R}$ & $\mathrm{D}$ & RA, HB \\
\hline Synodus synodus & M & $\mathrm{N}$ & $\begin{array}{l}\mathrm{P} \\
\text { (nekton) }\end{array}$ & $\mathrm{R}$ & $\mathrm{D}$ & $\mathrm{RA}, \mathrm{HB}$ \\
\hline Tetragonurus atlanticus & $\mathrm{L}$ & $\mathrm{N}$ & $\begin{array}{l}\mathrm{P} \\
\text { (jellyfish) }\end{array}$ & $\mathrm{R}$ & $\mathrm{P}$ & $\mathrm{N}$ \\
\hline Thalassoma bifasciatum & $\mathrm{H}$ & $\mathrm{N}$ & $\mathrm{R}, \mathrm{B}$ & $\mathrm{R}$ & $\mathrm{D}$ & RA, SG \\
\hline Thunnus albacares & $\mathrm{L}$ & Y & $\mathrm{P}$ & $\mathrm{R}$ & $\mathrm{P}, \mathrm{HM}$ & $\mathrm{N}, \mathrm{RA}$ \\
\hline Thunnus atlanticus & $\mathrm{L}$ & Y & $\mathrm{P}$ & $\mathrm{R}$ & $\mathrm{P}, \mathrm{HM}$ & $\mathrm{N}, \mathrm{RA}$ \\
\hline Thunnus thynnus & $\mathrm{L}$ & Y & $\mathrm{P}$ & $\mathrm{R}$ & $\mathrm{P}, \mathrm{HM}$ & $\mathrm{N}$ \\
\hline Trachinocephalus myops & M & $\mathrm{N}$ & $\mathrm{B}, \mathrm{P}$ & $\mathrm{R}$ & $\mathrm{D}$ & RA, HB \\
\hline Trachinotus carolinus & $\mathrm{L}$ & Y & $\mathrm{B}, \mathrm{P}$ & $\mathrm{R}$ & $\begin{array}{l}\text { D } \\
\text { (benthopelagic) }\end{array}$ & $\mathrm{N}$ \\
\hline Trachinotus falcatus & M & Y & $\mathrm{B}$ & $\mathrm{R}$ & $\mathrm{D}$ & RA \\
\hline Trachinotus goodei & M & Y & $\mathrm{B}, \mathrm{P}$ & $\mathrm{R}$ & $\begin{array}{l}\mathrm{P} \\
\text { (benthopelagic) }\end{array}$ & RA \\
\hline Trachurus lathami & M & Y & $\mathrm{P}$ & $\mathrm{R}$ & $\begin{array}{l}\mathrm{P} \\
\text { (minor, bait) }\end{array}$ & RA \\
\hline Trichiurus lepturus & $\mathrm{L}$ & Y & $\mathrm{P}, \mathrm{B}$ & $\mathrm{R}$ & $\mathrm{P}, \mathrm{D}$ & $\mathrm{N}$ \\
\hline Trichopsetta ventralis & $\mathrm{L}$ & $\mathrm{Y}$ & B & $\mathrm{R}$ & $\mathrm{D}$ & $\mathrm{N}$ \\
\hline
\end{tabular}




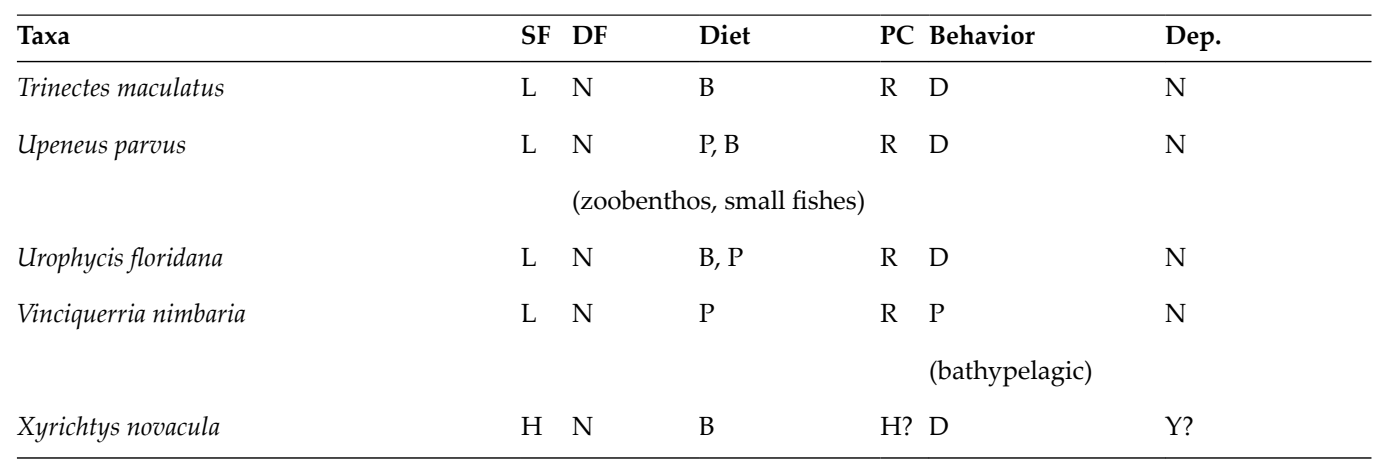

Appendix Table 1. Fish taxa reported to occur on Gulf of Mexico oil and gas platforms: SF=Site Fidelity (High, Moderate, Low); DF = Directed Fishery (Yes or No, includes recreational fishing); Diet (Reef, Benthic, Pelagic); PC = Population Control (Habitat limited, Recruitment limited; Behavior (Reef, Demersal, Pelagic, Highly Migratory); Dep = Reef or Habitat Dependent (Yes, No, Reef Associated, Sargassum, Sea Grass, Hard Bottom). Red highlight = overfished; Yellow highlight $=$ Caribbean expatriate

\section{Author details}

James H. Cowan, Jr.* and Kenneth A. Rose

*Address all correspondence to: jhcowan@lsu.edu

Department of Oceanography and Coastal Sciences, Louisiana State University, Baton Rouge, USA

\section{References}

[1] Bohnsack, J.A. (1989) Are high densities of fishes at artificial reefs the result of habitat limitation or behavioral preference? Bull. Mar. Sci. 44:631-645.

[2] Powers, S.P., Grabowski, J.H., Peterson, C.H., Lindberg, W.J. (2003) Estimating enhancement of fish production by offshore artificial reefs: uncertainty exhibited by divergent scenarios. Mar. Ecol. Prog. Ser. 264: 265-277.

[3] Edgar, G.J., Shaw, C. (1995) The production and trophic ecology of shallow-water fish assemblages in southern Australia III. General relationships between sediments, seagrasses, invertebrates and fishes. J. Exp. Mar. Biol. Ecol. 194: 107-131.

[4] Ricker, W.E. (1975) Computation and interpretation of biological statistics of fish populations. Bull. Fish. Res. Bd. Can. 191: 1-382.

[5] Wilson, C.A., Nieland, D.A. (2001) Age and growth of red snapper, Lutjanus campechanus, from the northern Gulf of Mexico off Louisiana. Fish. Bull. U.S. 99: 653-664. 
[6] Fischer, A., Baker, M.S., Jr., Wilson, C.A. (2004) Red snapper (Lutjanus campechanus) demographic structure in the northern Gulf of Mexico based on spatial patterns in growth rates and morphometrics. Fish. Bull., US 102: 593-603.

[7] SEDAR 31 (2012) Gulf of Mexico Red Snapper Stock Benchmark Assessment Report, Southeast Data and Assessment Review. North Charleston SC., p. 1103 Available online at:http//www.sefsc.noaa.gov/sedar/Sedar_Workshops.jsp?WorkshopNum=31

[8] Goodwin, J.M. IV, Johnson, A.G. (1986) Age, growth, and mortality of blue runner, Caranx crysos from the northern Gulf of Mexico. Northeast Gulf Sci, 8: 107-114.

[9] Beckman, D.W., Stanley, A.L., Render, J.H., Wilson, C.A. (1991) Age and growth-rate estimation of sheepshead Archosargus probatocephalus in Louisiana waters using otoliths. Fish. Bull., US 89: 1-8.

[10] Hayse, J.W. (1990). Feeding habits, age, growth, and reproduction of Atlantic spadefish Chaetodipterus faber (Pisces: Ephippidae) in South Carolina. Fish. Bull. US 88:67-83.

[11] Barger, L.E. (1990). Age and growth of bluefish Pomatomus saltatrix from the northern Gulf of Mexico and the U.S. South Atlantic Coast. Fish. Bull. US 88: 805-809.

[12] McCawley, J.R., Cowan, J.H. Jr., Shipp, R.L., (2006) Diel feeding periodicity and prey habitat preference of red snapper, Lutjanis campechanus, on Alabama artificial reefs. Gulf. Mex. Sci. 24: 14-27

[13] McCawley, J.R., Cowan, J.R. Jr. (2007). Seasonal and size specific diet and prey demand of red snapper on Alabama artificial reefs: Implications for management. pp. 77-104 In Patterson, W.F., Cowan, J.H. Jr., Fitzhugh, G.R., Nieland, D.L. (eds.) Red Snapper Ecology and Fisheries in the US Gulf of Mexico. Am. Fish. Soc., Symposium 60, Bethesda, Maryland.

[14] Randall, J.E., (1967). Food habits of reef fishes of the West Indies. Stud. Trop. Oceanogr. Miami 5: 665-847.

[15] Simonsen, K.A., Cowan, J.H. Jr., Boswell, K.M., (2015). Habitat differences in the feeding ecology of red snapper (Lutjanus campechanus, Poey 1860): a comparison between artificial and natural reefs in the northern Gulf of Mexico. Environ. Biol. Fish. 98: 811824.

[16] Scharf, F.S., Manderson, J.P., Fabrizio, M.C., Pessutti, J.P., Rosendale, J.E., Chant R.J., Bejda, A.J., (2004). Seasonal and interannual patterns of distribution and diet of bluefish within a middle Atlantic bight estuary in relation to abiotic and biotic factors. Estuaries 27: 426-436.

[17] Hanisko, D.S., Lyczkowski Shultz, J., (2003). Occurrence and pelagic habitat of reef fish larvae in the Gulf of Mexico. pp. 205-224, In Stanley, D., Scarborough-Bull, A., (eds). Fisheries, Reefs, and Offshore Development, Am. Fish. Soc. Symposium 36, Bethesda, Maryland. 
[18] Robins, C.R., Ray, G.C., (1986). A Field Guide to Atlantic Coast Fishes, North America. Houghton Mifflin, New York, USA. p. 354

[19] Richards, W., (ed) (2006) Early stages of Atlantic fishes. An identification guide for the western central north Atlantic, Volumes I and II Taylor and Francis, Boca Raton, USA.

[20] Böhlke J.E., Chaplin, C.C.G., (1968). Fishes of the Bahamas and adjacent waters Livingston Publication Co Wynnewood, Pennsylvania, USA. p. 771

[21] Hoese, H.D., Moore, R., (1977). Fishes of the Gulf of Mexico, Texas, Louisiana, and adjacent waters. Texas A\&M Press. p. 377

[22] Randall, J.E., (1996). Caribbean Reef Fishes. $3^{\text {rd }}$ edition, TFH Publications Inc., Neptune City, New Jersey, USA. p. 368

[23] Carpenter, K.E., (2002). The Living Marine Resources of the Western Central Atlantic, Vol 1 to 3, FAO Species Identification Guide for Fishery Purposes, and American Society of Icthyologists and Herpetologists Special Publication Number 5. Food and Agriculture Organization of the United Nations. Rome, Italy.

[24] Kells V, Carpenter K., (2011). A Field Guide to Coastal Fishes from Maine to Texas. The Johns Hopkins University Press, Baltimore, Maryland, USA. p. 448

[25] SEDAR 4 (2004) Stock Assessment of the Deepwater Snapper-Grouper Complex in the South Atlantic. Southeast Data and Assessment Review SEDAR4-SAR1, Charleston, SC, p. 594

[26] Kingsley, M.C.S. (ed.). 2004. The goliath grouper in southern Florida: assessment review and advisory report. Report prepared for the South Atlantic Fishery Management Council, the Gulf of Mexico Fishery Management Council, and the National Marine Fisheries Service. Data and Assessment Review. Vii + p. 17 (See http://www.gulfcouncil.org/downloads/goliathfinalSEDAR2004.pdf).

[27] SEDAR 33, (2014). Gulf of Mexico Gag Stock Assessment Report. Southeast Data and Assessment Review, North Charlston, SC p. 609. Available online at: http:// www.sefsc.noaa.gov/sedar/Sedar_Workshops.jsp?WorkshopNum=33

[28] Porch, C.E., Eklund, A.M., Scott, G.P., (2006). A catch-free stock assessment model with application to goliath grouper (Epinephelus itajara) off southern Florida. Fish. Bull., US 104: 89-101.

[29] Lindberg, W.J., Frazer, T.K., Portier, K.M., Vose, F., Loftin, J., Murie, D.J., Mason, DM, Nagy, B., Hart, M.K., (2006). Density-dependent habitat selection and performance by a large mobile reef fish. Ecol. Appl. 16: 731-746

[30] Lindberg, W.J., Loftin, J., (1998). Effects of Artificial Reef Characteristics and Fishing Mortality on Gag (Mycteroperca microlepis) Productivity and Reef Fish Community Structure. Gainesville, FL, Florida Dept. of Environmental Protection. p. 47

[31] Westmeyer, M.P., Wilson, C.A., Nieland, D.L., (2007). Fidelity of red snapper to petroleum platforms in the northern Gulf of Mexico. pp. 105-122 In Patterson, W.F., 
Cowan, J.H. Jr., Fitzhugh, G.R., Nieland, D.L. (eds.) Red Snapper Ecology and Fisheries in the US Gulf of Mexico. Am. Fish. Soc., Symposium 60, Bethesda, Maryland.

[32] Strelcheck, A.J., Cowan, J.H. Jr., Shah. A., (2005). Influence of Reef Location on ArtificalReef Fish Assemblages in the Northcentral Gulf of Mexico. Bull. Mar. Sci 77: 425-440.

[33] Strelcheck, A.J., Cowan, J.H. Jr., Patterson, W.F. III. (2007) Site fidelity, movement, and growth of red snapper; implications for artificial reef management. pp. 147-162 In Patterson, W.F., Cowan, J.H. Jr., Fitzhugh, G.R., Nieland, D.L. (eds.) Red Snapper Ecology and Fisheries in the US Gulf of Mexico. Am. Fish. Soc., Symposium 60, Bethesda, Maryland.

[34] Wells R.J.D., Cowan, J.H. Jr., Fry, B., (2008). Feeding ecology of red snapper, Lutjanus campechanus, in the northern Gulf of Mexico. Mar. Ecol. Prog. Ser. 361: 213-225

[35] Schwartzkopf, B.D., Cowan, J.H. Jr., (in review). Nutritional condition of red snapper Lutjanus campechanus on natural and artificial reefs in the northwestern Gulf of Mexico. J Fish Biol.

[36] National Oceanographic and Atmospheric Administration, National Marine Fisheries Service (2013). Framework action to set the annual catch limit and bag limit for vermillion snapper and yellow snapper, and modify the venting tool requirement. Gulf of Mexico Fishery Management Council Pursuant to National Oceanic and Atmospheric Administration Award No. NA10NMF4410011. p. 183

[37] Hood P.B., Strelcheck, A.J., Steele, P., (2007). A history or red snapper management in the Gulf of Mexico. pp. 267-284 In Patterson, W.F., Cowan, J.H. Jr., Fitzhugh, G.R., Nieland, D.L. (eds.) Red Snapper Ecology and Fisheries in the US Gulf of Mexico. Am. Fish. Soc., Symposium 60, Bethesda, Maryland.

[38] Goodyear, CP., (1995). Red snapper in U.S. waters of the Gulf of Mexico. National Marine Fisheries Service, Southeast Fisheries Science Center, Miami Laboratory, Miami MIA-95/96-05. p. 103

[39] Porch, C.E., Turner, S.C., Schirripa, M.J., (2007). Reconstructing the commercial landings of red snapper in the Gulf of Mexico from 1872-1963. pp. 337-354 In Patterson, W.F., Cowan, J.H. Jr., Fitzhugh, G.R., Nieland, D.L. (eds.) Red Snapper Ecology and Fisheries in the US Gulf of Mexico. Am. Fish. Soc., Symposium 60, Bethesda, Maryland.

[40] Hilborn, R., (2006). Faith-based fisheries. Fisheries 32(11): 554-555.

[41] Shipp, R.L., (1999). The artificial reef debate: Are we asking the wrong questions? Gulf Mex. Sci. 17: 51-55.

[42] Shipp, R.L., Bortone, S.A., (2009). A Prospective of the importance of artificial habitat on the management of red snapper in the Gulf of Mexico. Rev. Fish. Sci. 17: 41-47. 
[43] Carpenter, J.S., (1965). A review of the Gulf of Mexico Red Snapper Fishery. US Dept. Interior., US Fish. Wildl. Serv., Bur. Comm. Fish. Circular 208. p. 41

[44] Bortone, S.A., (1998). Resolving the attraction-production dilemma in artificial reef research: some yeas and nays. Fisheries 23 (3): 6-10.

[45] Claudet, J., Pelletier, D., (2004). Marine protected areas and artificial reefs: A review of the interactions between management and scientific studies. Aquat. Living Resour. 17: 129-138.

[46] Page, H.M., Dugan, J.E., Schroeder, D.M., Nishimoto, M.M., Love, M.S., Hoesterey, J.C., (2007). Trophic links and condition of a temperate reef fish: comparisons among offshore oil platform and natural reef habitats. Mar. Ecol. Prog. Ser. 344:245-256

[47] Pitcher, T.J., Seaman, W., (2000). Petrarch's Principle: how protected human-made reefs can help the reconstruction of fisheries and marine ecosystems. Fish and Fisheries 1:73-81.

[48] Cowan, J.H. Jr., Grimes, C.B., Patterson, W.P. III, Walters, C.J., Jones, A.C., Lindberg, W.L., Sheehy, D., Pine, W.E. III, Powers, J.D., Campbell, M.D., Lindeman, K.C., Diamond, S.L., Hilborn, R., Gibson, H.T., Rose, K.A., (2011). Red snapper management in the Gulf of Mexico: science- or faith-based? Rev. Fish. Biol. Fisheries 21: 187-204. 


\title{
Chapter 6
}

\section{The Brown Seaweeds Fishery in Chile}

\author{
Julio A. Vásquez \\ Additional information is available at the end of the chapter
}

http://dx.doi.org/10.5772/62876

\begin{abstract}
Chilean fishery of brown algae includes species belonging to the genus Lessonia, Durvillaea, and Macrocystis, which can be found along the coast, ranging latitudes from $18^{\circ}$ to $55^{\circ} \mathrm{S}$. The exploitation of these seaweeds is done mainly in the Northern coast because the environmental conditions of this region decrease initial production costs. Brown algae are exploited from natural populations and exported to international markets as row material, source of alginates, widely utilized in diverse manufacturing processes and industries. International demand for Chilean kelps has produced sustained increase in harvest during the last decade, reaching more than 390,000 dry tons/year. This chapter approaches the most relevant aspects of the brown seaweed fishery in Chile which covers a wide range of the Southeast Pacific coast, considering the number of commercial species, its abundance and distribution, knowledge achieved on their ecology and biology regarding management, and conservation of these resources, and finally, provides tools for stakeholders and policy makers directed to sustainable management of natural kelp beds occurring in the cold temperate seas.
\end{abstract}

Keywords: Brown algae, kelp, fishery, coastal environment, management

\section{Introduction}

Chile, a narrow and long country with over $4500 \mathrm{~km}$ of continental coastline, has an ancient tradition in the use of sea resources. Numerous algae, shellfish, and fish species have been incorporated in the diet and every day habits of his inhabitants, since prehistoric times. The astonishing evidence found at the archaeological site Monte Verde, dated 12,500 years BP and located near Puerto Montt ( $\left.41^{\circ} \mathrm{S}\right)$, provides evidence of Pre-Clovis human settlement in South America, and exhibits ancient use of macroalgae, probably as food and for medicinal purposes $[1,2]$. The diet of coastal human communities incorporated brown and red algae as significant 
components along the last 500 years, especially in those coastal populations situated South beyond $30^{\circ} \mathrm{S}[3]$.

As sources for alginates production, brown algae in Chile are exploited from natural populations and exported to world markets as row and dried commodity for alginates extraction [4, 5]. The local national gel industry, as well as invertebrate aquaculture production, utilizes only a minor fraction of the annual harvest [6]. During the last decade, a sustained increase of harvesting has been taking place, because of the international demand for Chilean kelp; production has reached more than 390,000 dry tons associated with an economic return of more than US\$ 90 million [5, 7]. Chilean brown algae of economic importance belong to genus Lessonia, Durvillaea, and Macrocystis, and they occur throughout the coast from $18^{\circ}$ to $55^{\circ} \mathrm{S}$ [8]. Even this wide distribution range, the exploitation of these resources is done mainly in the Northern region of the country between $18^{\circ}$ and $32^{\circ} \mathrm{S}$, because environmental conditions, such as remarkable air high temperature and dryness of the coastal desert, which decrease production costs of drying process close to zero and, consequently, the total processing cost before their commercialization [6].

In Chile, the harvest of brown algae is also matter of social relevancy since more than 15,000 people depend more or less directly on the exploitation and collection of this marine resource [9]. As established by local law, only authorized and registered artisanal fisherman are allowed to harvest such kelp [6]; however, enforcement measures and control are difficult to put into effect because of the topography of coastal territory where these natural populations of kelp occur, but also due to their extension and accessibility [10]. From the point of view of their ecological role, kelps have been defined as engineer species in the coastal marine ecosystems; they are key species which participate maintaining and preserving foci of high biological and genetic diversity $[11,12]$. Also, these species are sensitive to disturbances from both natural and/or anthropogenic origin [13, 12].

\section{Species in the fishery}

Geographic distribution and occurrence of commercial brown seaweed are associated with high-energy environments in the Southeast Pacific (Figure 1). Lessonia species can be intertidal and subtidal as well; they form belts along exposed rocky coasts (Figure 1A, B, D); Macrocystis forms shallow kelp beds ranging from intertidal zone to $c a .15 \mathrm{~m}$ depth in Northern latitudes (Figure 1C, G); it is gradually replaced toward Southern areas by Durvillaea (Figure 1F), which dominates the intertidal zone in wave-exposed areas [8]. In South direction and beyond $42^{\circ} \mathrm{S}$, Macrocystis is the most abundant and dominant kelp species [15]; Lessonia species have almost continuous distribution along the whole Chilean continental coast; instead, the distribution of Macrocystis is fragmented into populations that form patches in Northern Chile [11, 16, 13], contrasting with its continuous coastal belts distribution from $42^{\circ} \mathrm{S}$ toward Cape Horn $\left(55^{\circ}\right.$ $58^{\circ}$ S); Macrocystis distribution includes the Chilean Southern fjord zone, surrounding Cape Horn, and ascending in North direction by the Argentinian exposed coast until Chubut area in the Atlantic $\left(41^{\circ} \mathrm{S}\right)$. Several elements are combined to determine the observed kelp distri- 
bution patterns; they result from multifactorial interaction of complex life-history strategies of the involved species with environmental factors, such as spatial and temporal variations in water movement, nutrient availability, light, and temperature [17, 16, 12].

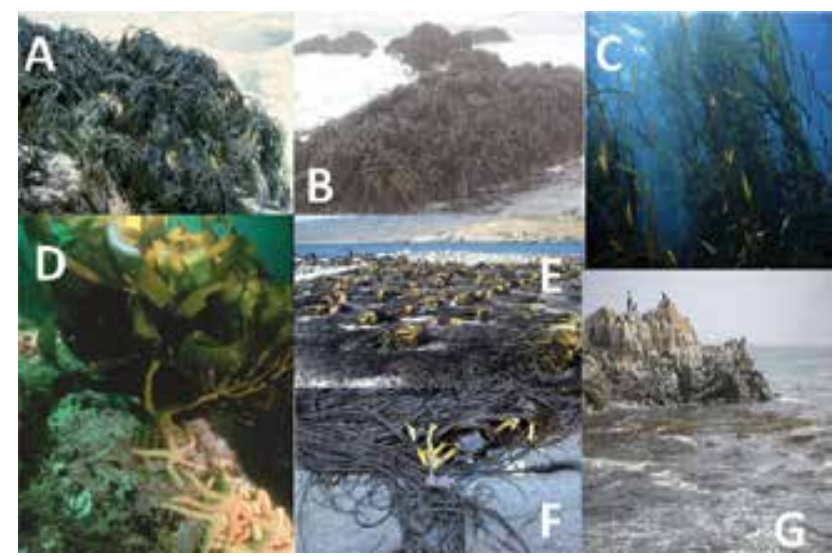

Figure 1. Intertidal beds of Lessonia nigrescens (A, B), subtidal beds of Macrocystis pyrifera (C), subtidal Lessonia trabeculata (D), Harvest on the beach of Lessonia nigrescens (E), Durvillaea antarctica, intertidal beds of Macrocystis pyrifera (G).

Chilean kelp species commercially exploited are as follows: Lessonia trabeculata, Lessonia berteroana, Lessonia spicata (members of Lessonia nigrescens complex, for details see [18-20]); these are all species having two morphotypes during their natural life cycle, which represent very different ecological roles and requirements, in both environmental and physiological aspects. Large and conspicuous (so, harvestable) sporophytes alternate with microscopic few cell and benthic organisms which are the gametophytes.

\section{Biological and ecological aspects}

Studies on the distribution and abundance of Chilean commercial brown seaweed were scarce and locally restricted until the end of 2000 [21-29, 30, 31]. Other than this, the use of noncomparable methodologies in the few studies carried out, which approached biomass stocks information, did not allow extrapolation and inter-annual comparisons of the available total biomass. Similar situation occurred in relation to distribution studies of the involved species, both in temporal and spatial gradients [4]. Harmonization of methods or collection of information, as well as systematization of them, is essential aspects of the population ecology of commercial species, in order to propose adequate regulations and policies that guarantee a sustainable management of these resources.

One of the few extensive and intensive evaluations of biomass distribution of Lessonia trabeculata, Lessonia nigrescens, and Macrocystis pyrifera was done during 2004-2005, for the geographic extension ranging between $26^{\circ}$ and $32^{\circ} \mathrm{S}$; its main goal was to determine the 
distribution and abundance of the mentioned species in more than $700 \mathrm{~km}$ of coast. During the study, 140 sampling stations were established separated by 4.5 linear $\mathrm{km}$, excluding a priori sandy beaches and soft bottom subtidal areas because they represent inadequate substrates for kelp's spores settlement $[6,5]$. L. trabeculata was found in rocky subtidal habitats between 0 and $30 \mathrm{~m}$ depth in the whole study area. Depending on the extension of the rocky platform into the subtidal zone, local biomass up to 50,000 wet tons was recorded. Estimation of abundance indicated a standing stock of approximately 800,000 wet tons of L. trabeculata in the study area. L. nigrescens was distributed in a continuous pattern along the rocky intertidal zone of the whole study area, with local biomass (sampling station) registered between 50 and 4000 wet tons. Using GIS abundance polygons were constructed which revealed a standing stock of more than 100,000 wet tons of L. nigrescens in the study area [6]. In contrast, Macrocytsis evidenced fragmented distribution within the study area. Local populations were small and estimated biomass fluctuated between 2 and 12 wet tons. The sum of local biomass allowed estimation of a standing stock that did not exceed 200 wet tons for the entire study area at the time $[6,5]$.

In contrast to the lack of ecological information used to determine fishery regulations, several studies arise since the middle 1980s approaching different aspects of kelp knowledge, such as biology and population ecology [12, 13, 17, 32, 33], genetics and taxonomy [18-20, 34], enhancement and cultivation [35-38], new and novel uses for their natural by products, for medical nanotechnology, for example (see [39-41]).

Because of Lessonia nigrescens represents more than 70\% of total landings of brown Chilean seaweed fishery, several studies have been focused on this species. Studies on genetics, molecular biology, and population ecology show that L. nigrescens is a species complex composed by two cryptic species: Lessonia berteroana and Lessonia spicata [18, 42, 43]; L. berteroana is distributed from the South of Perú $\left(c a .15^{\circ} \mathrm{S}\right)$ to approximately $30^{\circ} \mathrm{S}$, and L. spicata occurs form $30^{\circ} \mathrm{S}$ toward South [20]. In the last decade, the kelp harvest in Chile has been sustained principally by the Lessonia nigrescens complex, especially in the area known as latitudinal break for biodiversity distribution which location is considered approximately at $30^{\circ} \mathrm{S}$ [19].

Exploited and unexploited species belonging to Lessonia nigrescens complex form Northern Chile were compared using morphological and demographic parameters such as density, biomass, recruitment, and population structure [5]. These are traits which allow estimation of the effect of harvesting in other natural populations of brown algae [44-47], and the assessment of the impact of natural disturbances $[48,16,13]$ and other anthropogenic activities on such species [37]. In this context, the morphological and demographic parameters used for evaluate L. nigrescens could be useful as ecological indicators for: (1) to evaluate the consequences of good harvesting practices agreed upon by fisherman, (2) to compare the effect of harvesting in areas with different administration policies, (3) to monitor the sustainability of exploited kelps, and (4) to propose to competent authorities the precautionary and/or recovery adequate measures for sustainable managing of dynamics population of commercially important brown algae. 


\section{Collection, harvest, and landings}

Largely and until year 2000, the whole brown algae fishery in Chile was based on the collection of natural mortality kelp from coastal populations. A sudden and significant increase of its demand, other than as raw material for alginate source, also as food source for cultivated abalones introduced in Chile in the last 16 years, triggered the harvest of kelp species. Since then, the Chilean brown seaweed fishery becomes an extractive fishery in which converge four main factors: (1) still the international market request for alginic acid source; (2) use for feeding the emergent local farming of several kelp-consuming organisms under controlled conditions; (3) the switch of fishers toward the harvest of commercial brown seaweeds as consequence of the collapse of other benthic fisheries, and (4) the strong impact on local economy produced by the international fluctuation of the price of copper. This metal constitutes the Chilean main resource, representing more than $60 \%$ of the internal gross product (PIB, as its acronym in Spanish); it provides direct and/or indirect jobs for thousands of people in the country, being Chile the first copper producer around the world. Local economy is extremely sensitive to fluctuations of international cooper price, and the fall (currently crush) of it provokes significant unemployment, particularly of non-specialized workforce; as one of its primary consequences, unemployed people are forced to migrate to coastal areas where they can develop subsistence economy based on precarious jobs represented by the collection and harvesting of brown seaweeds $[9,6]$.

During the last 35 years in Chile brown algae, landings have fluctuated between 40,000 and 390,000 tons/year, showing sustained increase since 2000 (Figure 2); L. nigrescens and L. trabeculata comprise more than $90 \%$ of the total production of them, whereas Macrocystis and local consumption of Durvillaea antarctica, contribute only marginally to total landings [61].

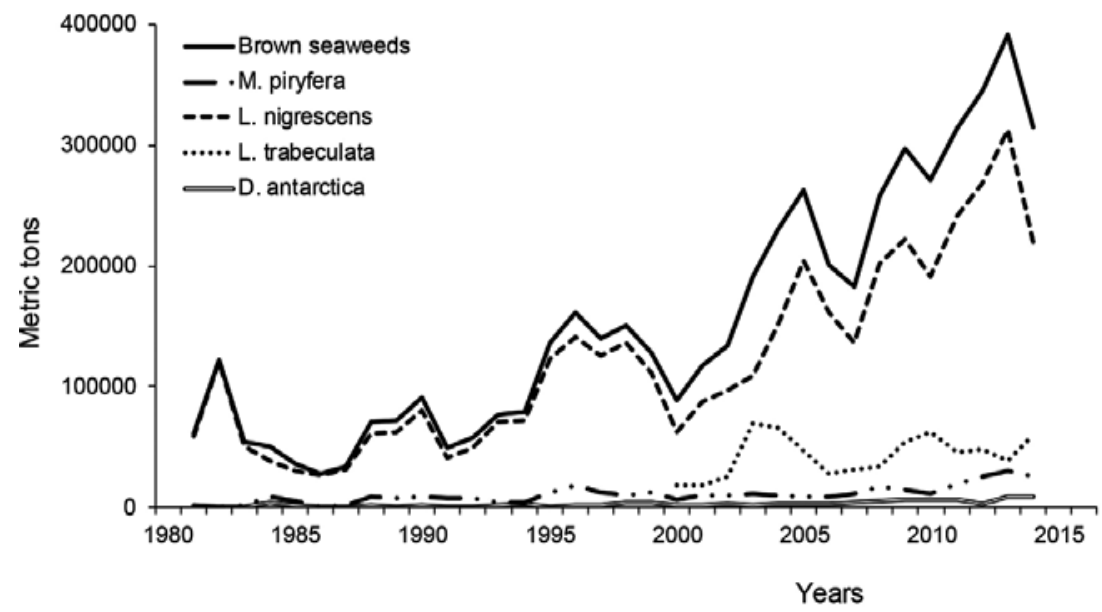

Figure 2. Temporal landing (1980-2014) of brown seaweeds of economic importance in Chile. Source: National Fishery Service (Chile) [61]. 
The significant rise of kelp demand, as commodity source of alginic acid around the world during the last years, explains the increase of kelp extraction. A smaller fraction of this increment is consequence of the yield reduction of kelp used for milling, because of higher humidity contents of lately processed plants if compared with those from previous years [7, 50]. From a different perspective, during 1997-1998 when a severe ENSO event occurred, Chilean exports of brown algae showed a considerable peak, probably related to significant mortalities generated by this large scale oceanographic event. The warming of the ocean surface, simultaneously to decreasing of nutrients concentrations, both associated with "El Niño," has strong impact over kelp populations and thousands of dead plants are cast ashore by waves which end collected by fishermen [16, 23, 60].

Since 2005, the abalone cultivation industry exhibits a remarkable and sustained growth, especially in Northern Chile; this commercial activity consumes close to 4800 tons of fresh alga/ year, mainly Macrocystis; neither the utilization nor the economic yield of this activity is comparable, until date, to demand of Chilean kelp as source for alginate extraction.

\section{Management}

Chilean authorities have implemented a management and conservation strategy program for economically important brown algae, considering its economic, social, and ecological importance, and also the significant increase of kelp harvest. The expectative of this program is focused on surveillance of available and harvestable biomass, evaluation of strength of harvesting (Capture per Union Effort-CPUE), and characterization of the productive chain based on these primary producers. As a result of this strategy, carried on since 2010, plus several years of kelp knowledge achieved, recommendations have been established for the management of kelp sustainability. The premise is "how to harvest is more important than how much you harvest" [5]. This program has been implemented in three Chilean conservation tools performed at the country level and which represent three different conservation strategies: (1) marine protected areas (marine park, marine reserve), (2) open-access areas for artisanal fishermen (OAA), where they collect and harvest marine resources, and (3) management areas for exploitation of benthic resources (MAEBR), where organized fisherman have some territorially rights assigned over a sector of the coast. The conservation strategy involved in MAERB is based on co-management (see [50-55]).

The main practical recommendations of the program for the sustainability of brown seaweeds are focused on selective harvesting of adult sporophytes and maintenance of a permanent stock of individuals able to reproduce, recruitment facilitation, decrease of grazing by benthic invertebrates, and permitting the sustainability of kelps and the conservation of its associated biodiversity $[6,5,56,62]$. Considering all aspects mentioned, the following bio-ecological recommendations must be applied to kelp beds subjected to significant, frequent, and intense harvesting: (1) to harvest the whole plant, including the holdfast. (2) To harvest plants with a basal diameter larger than $20 \mathrm{~cm}$. (3) To harvest one out of every three plants, with preference for the biggest specimens, thereby thinning the population. (4) For the particular case of Macrocystis, to cut the canopy to one meter below the surface. 
According to administration regime (Conservation Strategy) assigned by competent authority to natural populations, the density of both adult plants and juvenile recruitment of Lessonia nigrescens is subjected to temporal variation (Figure 3). In marine protected areas like marine parks or marine reserves (MPA), the annual renewal of kelp populations exhibits a seasonal cycle wherein the natural mortality of adults is compensated by intense juvenile recruitment (Figure 3A). In MAEBR, the density of adult plants decreases during the maximum harvest period, which is preferably carried on during spring and summer; in these conditions, the annual cycle of kelp renewal is maintained by recruitment of juvenile plants post-harvest (Figure 3B). In OAA, where the kelp harvest occurs all along the year, adult plants density decreased significantly (Figure 3C). Thus, constant releasing of substrate by permanent harvesting facilitates sustained juvenile recruitment, which significantly increases the density of recruits throughout the year; this last population renewal process takes places independ-

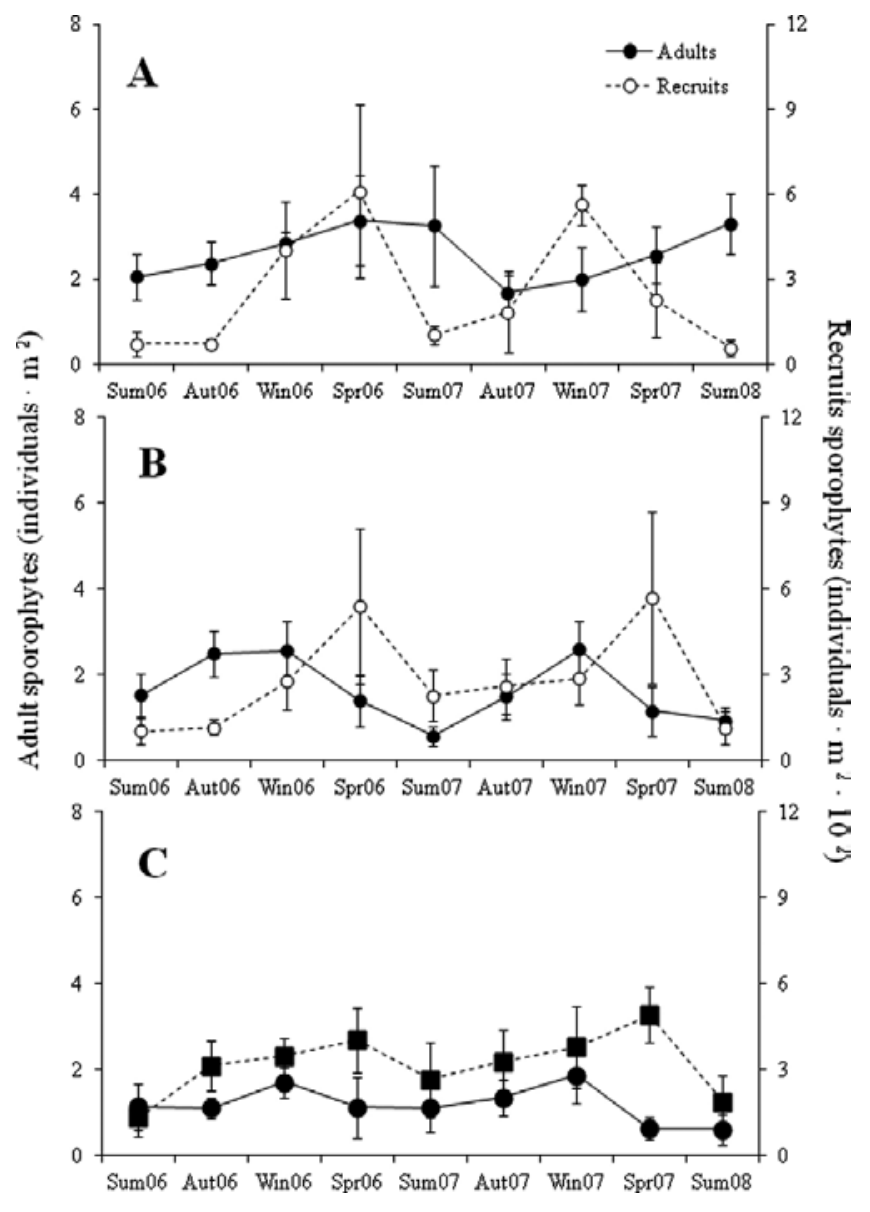

Figure 3. Temporal variation in the density of Lessonia nigrescens complex adult plants and recruits in kelp beds located in marine protected areas MPC (A), management areas for exploitation of benthic resources (MAEBR), and open-access area (OAA). Mean + 2SE [49]. 
ently of seasonal variation in opposition to what was observed in Lessonia populations belonging to Conservation Strategies of MAEBR and MPA (Figure 3).

The density of adult plants is greatest in populations inside MPA in contrast to those inside OAA (Figure 3). As previously exposed in MAEBR, the seasonal harvest of Lessonia decreases the density of adults; however, this impact of harvesting is significantly lower than which is observed in OAA (Figure 3). In these open-access areas, the density of adult plants is less because of high harvesting pressure produces contraction of the stock of reproductive plants, and thus negatively affects the kelp renewal. There exists an exception to this pattern observed in OAA constituted by those populations where the difficulty of access to the coastline generates a barrier to permanent harvest. In this case, topography constraints to access generate effects that mimic a sort of natural co-management; in this way, the pattern of size distribution of Lessonia plants in OAA is quite similar to the pattern observed in MAERB [49].
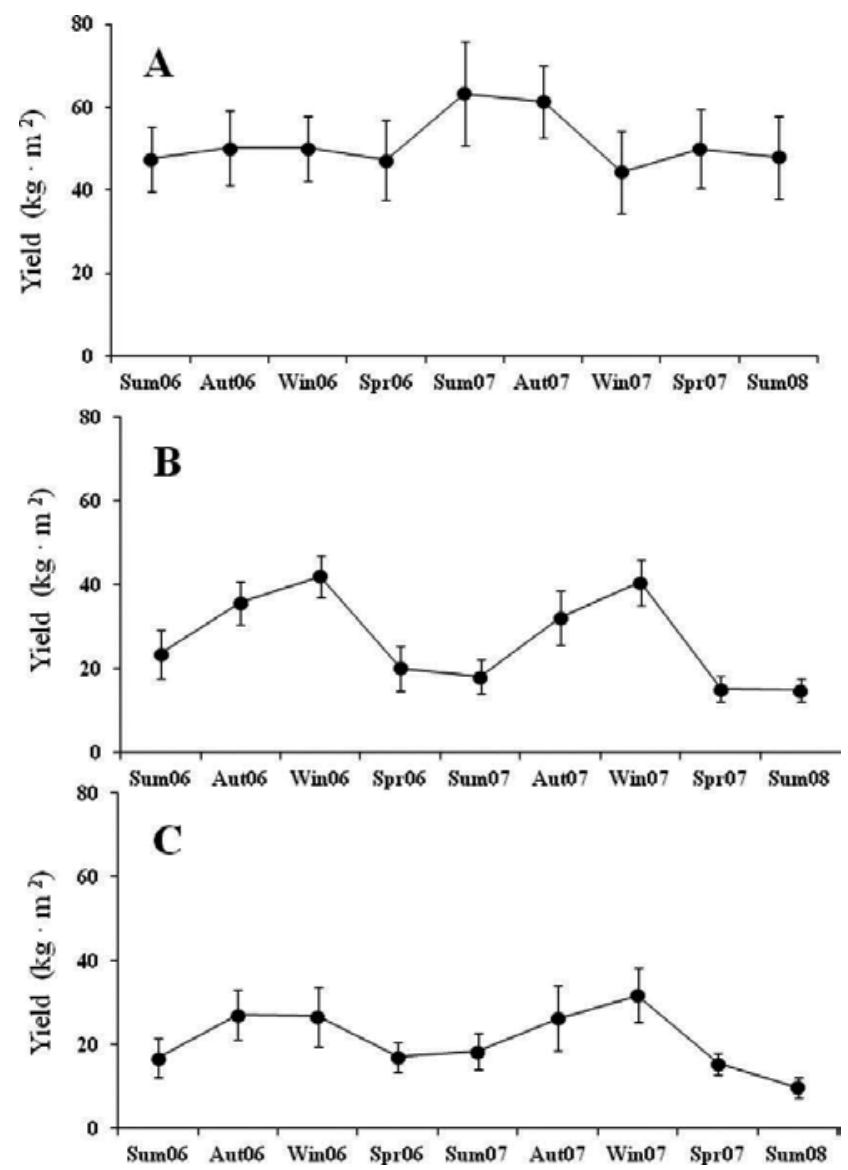

Figure 4. Temporal variation of Lessonia nigrescens yield (biomass $\mathrm{kg} \mathrm{m}^{2}$ ) in kelp beds located in marine protected areas MPC (A), management areas for exploitation of benthic resources (MAEBR), and open-access area (OAA). Mean + 2SE [49]. 
In MPA, Lessonia yield ( $\mathrm{kg}$ of biomass $/ \mathrm{m}^{2}$ ) is constant throughout an annual cycle and close to $50 \mathrm{~kg} / \mathrm{m}^{2}$ (Figure 4A). By contrast, the available biomass in MAEBR evidences marked seasonality with an annual cycle of renewal of the kelp post-harvest during spring and summer (Figure 4B). A similar tendency is observed in OAA, even if with significantly less available biomass which does not surpass $25 \mathrm{~kg} / \mathrm{m}^{2}$ (Figure 4C). Available biomass is biggest in MPA populations and lowest in OAA populations. In MAEBR and OAA, the available biomass is 50 and 65\% lower, respectively, than stocks in MPA [50]. The available biomass in MAEBR represents the permissible limit for sustainable exploitation of the kelp forests and is evidence of the adequate application of the management plan. On the other hand, the level of available biomass in OAA is an indicator of highly exploited populations, and its management program would help to establish sustainability parameters dealing with a strong harvest pressure [49].

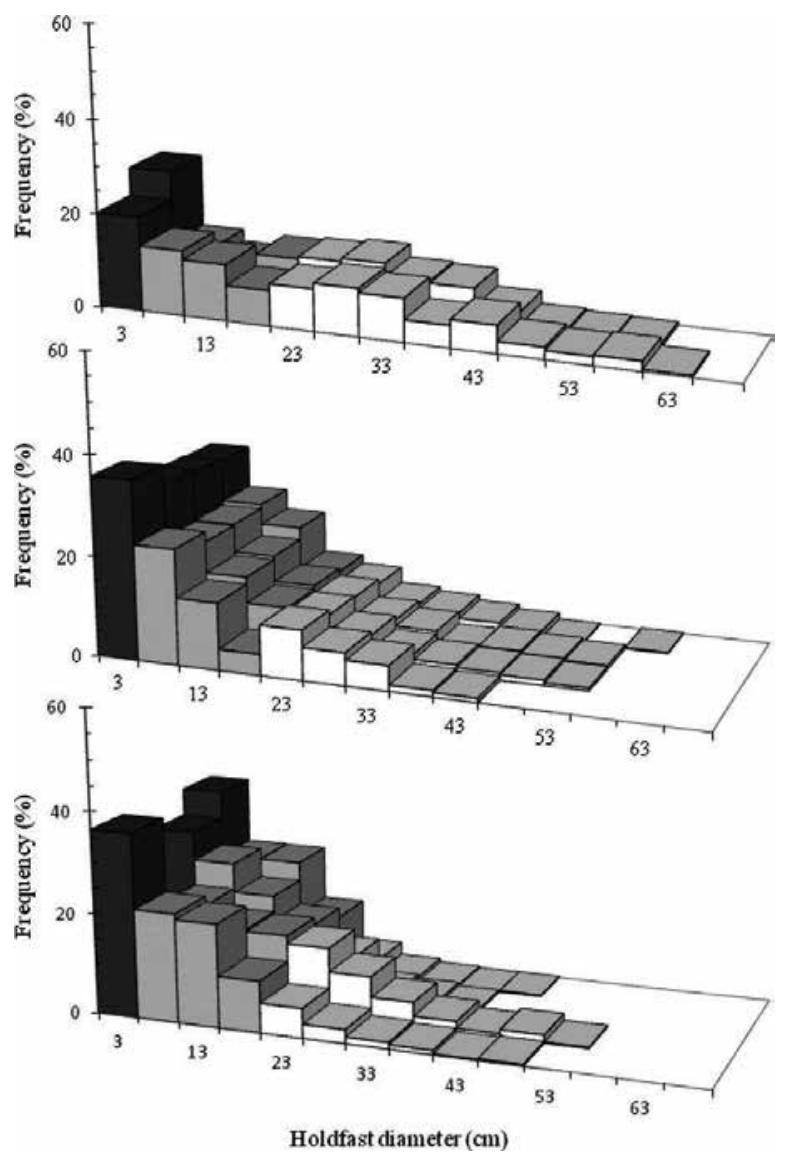

Figure 5. Population structure of Lessonia nigrescens in kelp beds located in marine protected areas MPC (A), management areas for exploitation of benthic resources (MAEBR), and open-access area (OAA). The black bars indicate recruits $(<5 \mathrm{~cm}$ long), the gray bars indicate juvenile plants (without reproductive structures, $<20 \mathrm{~cm}$ holdfast diameter), and white bars indicate adult plants (with reproductive structures, $>20 \mathrm{~cm}$ in holdfast diameter) [49]. 
The size structure of Lessonia nigrescens populations, according with the morphological variables suggested [6], varies according to the management and conservation measures applied (Figure 5). In MPA, 20\% of the populations are recruits and 35\% are juveniles, and the rest of the population is adults with large-sized plants (Figure 4A). In MAEBR and OAA, recruits represent $35 \%$ of the whole population, while juvenile plants represent 45 and $55 \%$, respectively (Figure 5B, C). In MAEBR, the fraction of adult plants is renewed by the growth of juvenile plants during the annual cycle, while in OAA, strong harvesting pressure facilitates recruitment and colonization of free primary substrate. In MPA, the portion of adult plants available for harvesting is in general, $45 \%$ of the population. In MAEBR, the harvestable portion corresponds to $25 \%$ of the total available biomass. By contrast, in OAA, the available biomass for commercial harvesting did not exceed $10 \%$ of the total plants in the whole Lessonia population studied in Northern Chile [5, 49].

After 25 years of observation and assessment of Lessonia populations, after thousands of hours of field monitoring and abundant literature produced, and based on bio-ecological knowledge accomplished, the main concept associated with recommendation for sustainable management of Lessonia nigrescens complex is "how to harvest is more important than how much you harvest" [6]. This resource management practice has been spread among fisherman during the last 15 years and adopted voluntarily as an alternative to the traditional precautionary method, in which the fishing authority imposes a capture quota, arises from the total available biomass $[5,49]$. However, fulfilling the premise previously mentioned requires good practices on the part of artisanal fishermen, who are the only authorized users to harvest brown algae in Chile. The correct application of the management recommendations of MAEBR seems to be strongly related to the social capital that co-management generates [54], a concept that does not make sense in OAA where harvesting activity is individual and difficult to enforce (see [52-54]). The wide latitudinal extension of the littoral zone and several restrictions to it access increase the cost of enforcement and decrease the efficacy of control of the fishing authority [10]. Therefore, as in many other cases if not all of them, the construction of participative awareness is a key factor in the conservation of natural populations of Chilean kelps and the sustainability of this resource $[5,49]$.

As last recommendations, it will be necessary to make significant progress in areas such as: (a) perfection of the capacities of commercial management by using social capital, (b) optimization of control mechanisms and enforcement considering the idiosyncrasy of Chilean artisanal fishermen, (c) improvement of information flow between and among the different actors in the productive chain and the authorities, and (d) establishment of controlled extraction of brown algae by using management plans from territorial perspective.

A participative, adaptive, and multidisciplinary management plan requires ecological indicators that permanently monitor administrative measures agreed upon by the direct users of Lessonia resource. Considering that these ecological indicators need to be validated [55], they can be selected from administrative measures regarding brown algae such as volume harvested, capture per amount of effort, and minimum legal size of capture [50]. Landing of harvested volume is an easy indicator to track and verify but requires an efficient, participative recording system, in real time, allowing the reaching and use of information at the right 
moment (Table 1). Capture per amount of effort and minimum legal size are indicators that are comparatively more complex to monitor and enforce, because they depend on the participation of scientific observers and also on the interest of fishermen to generate such records (Table 1). These indicators are useful tools to assign harvest quotas, establish rotation areas, or to establish extractive or biological bans [49].

\begin{tabular}{|c|c|c|c|c|c|c|}
\hline $\begin{array}{l}\text { Resource } \\
\text { variable }\end{array}$ & Description & $\begin{array}{l}\text { Time } \\
\text { regime }\end{array}$ & $\begin{array}{l}\text { Decision } \\
\text { policy }\end{array}$ & $\begin{array}{l}\text { Verification } \\
\text { source }\end{array}$ & $\begin{array}{l}\text { Additional } \\
\text { requirements }\end{array}$ & $\begin{array}{l}\text { Investment } \\
\text { items }\end{array}$ \\
\hline $\begin{array}{l}\text { Landing } \\
(\mathrm{kg})\end{array}$ & $\begin{array}{l}\text { Fishing/ } \\
\text { harvesting } \\
\text { area }\end{array}$ & $\begin{array}{l}\text { Permanent } \\
\text { (daily) }\end{array}$ & $\begin{array}{l}\text { Once } \\
\text { fishing } \\
\text { quota is } \\
\text { reached, } \\
\text { stop } \\
\text { the } \\
\text { harvest }\end{array}$ & $\begin{array}{l}\text { Artisanal } \\
\text { fishing }\end{array}$ & $\begin{array}{l}\text { Implemen } \\
\text { tation } \\
\text { of an } \\
\text { electronic } \\
\text { registration } \\
\text { system for } \\
\text { harvest/ } \\
\text { landing }\end{array}$ & $\begin{array}{l}\text { Implemen } \\
\text { tation, } \\
\text { maintenance } \\
\text { of } \\
\text { electronic } \\
\text { equipment. } \\
\text { Training }\end{array}$ \\
\hline $\begin{array}{l}\text { Capture } \\
\text { per } \\
\text { unit } \\
\text { effort } \\
\text { (CPUE) }\end{array}$ & $\begin{array}{l}\text { Capture } \\
\text { per } \\
\text { unit } \\
\text { effort }(\mathrm{kg} / \mathrm{h} / \\
\text { fisherman) } \\
\text { per bed } \\
\text { or area. } \\
\text { Fishing gear: } \\
\text { "barreta" }\end{array}$ & $\begin{array}{l}\text { Permanent } \\
\text { (Monthly) }\end{array}$ & $\begin{array}{l}\text { Once } \\
\text { CPUE } \\
>150 \\
\mathrm{~kg} / \text { fisherman/h } \\
\text { (Fishing ban, } \\
\text { extraction } \\
\text { area rotation, } \\
\text { change } \\
\text { fishing } \\
\text { gear) }\end{array}$ & $\begin{array}{l}\text { Scientific } \\
\text { survey, } \\
\text { Landing } \\
\text { register, } \\
\text { Fishermen } \\
\text { statistics }\end{array}$ & $\begin{array}{l}\text { Implemen } \\
\text { tation } \\
\text { of CPUE } \\
\text { registration } \\
\text { system by area }\end{array}$ & $\begin{array}{l}\text { Monitors } \\
\text { for } \\
\text { recording } \\
\text { landing } \\
\text { information. } \\
\text { Training }\end{array}$ \\
\hline $\begin{array}{l}\text { Minimum } \\
\text { legal size } \\
\text { of capture (MLS) }\end{array}$ & $\begin{array}{l}\text { Morpholo } \\
\text { gical } \\
\text { variable: } \\
\text { holdfast } \\
\text { diameter. MLS } \\
20 \mathrm{~cm}\end{array}$ & $\begin{array}{l}\text { Permanent } \\
\text { (seasonal) }\end{array}$ & $\begin{array}{l}\text { Once } \\
\text { MLS of } \\
\text { holdfast } \\
\text { diameter } \\
\leq 20 \mathrm{~cm} . \\
\text { (Change } \\
\text { harvesting } \\
\text { area, } \\
\text { fishing } \\
\text { ban) }\end{array}$ & $\begin{array}{l}\text { Scientific } \\
\text { survey, } \\
\text { landing } \\
\text { register, } \\
\text { fishermen } \\
\text { statistics }\end{array}$ & $\begin{array}{l}\text { Implemen } \\
\text { tation } \\
\text { of a } \\
\text { registration } \\
\text { system of } \\
\text { MLS by } \\
\text { area }\end{array}$ & $\begin{array}{l}\text { Monitors } \\
\text { for } \\
\text { recording } \\
\text { landing } \\
\text { information. } \\
\text { Training }\end{array}$ \\
\hline
\end{tabular}

Table 1. Resource variables proposed to monitor the harvest of Lessonia nigrescens complex.

The effect of harvesting in OAA has been explained by the absence of precautionary management measures in a scenario of high demand for biomass [9, 14, 44, 46]. Thus, management based on the ecosystem approach requires ecological indicators sensitive to harvesting 
pressure, which allow establishment of decision criteria that are easy to observe, communicate, and measure by both scientific observers and artisanal fishermen [49]. Demographic attributes, such as density of adult plants, biomass per unit of area, recruitment, and size structure all constitute indicators that satisfy these characteristics, are easy to obtain and can be evaluated along spatial and temporal gradients (Table 2) [49].

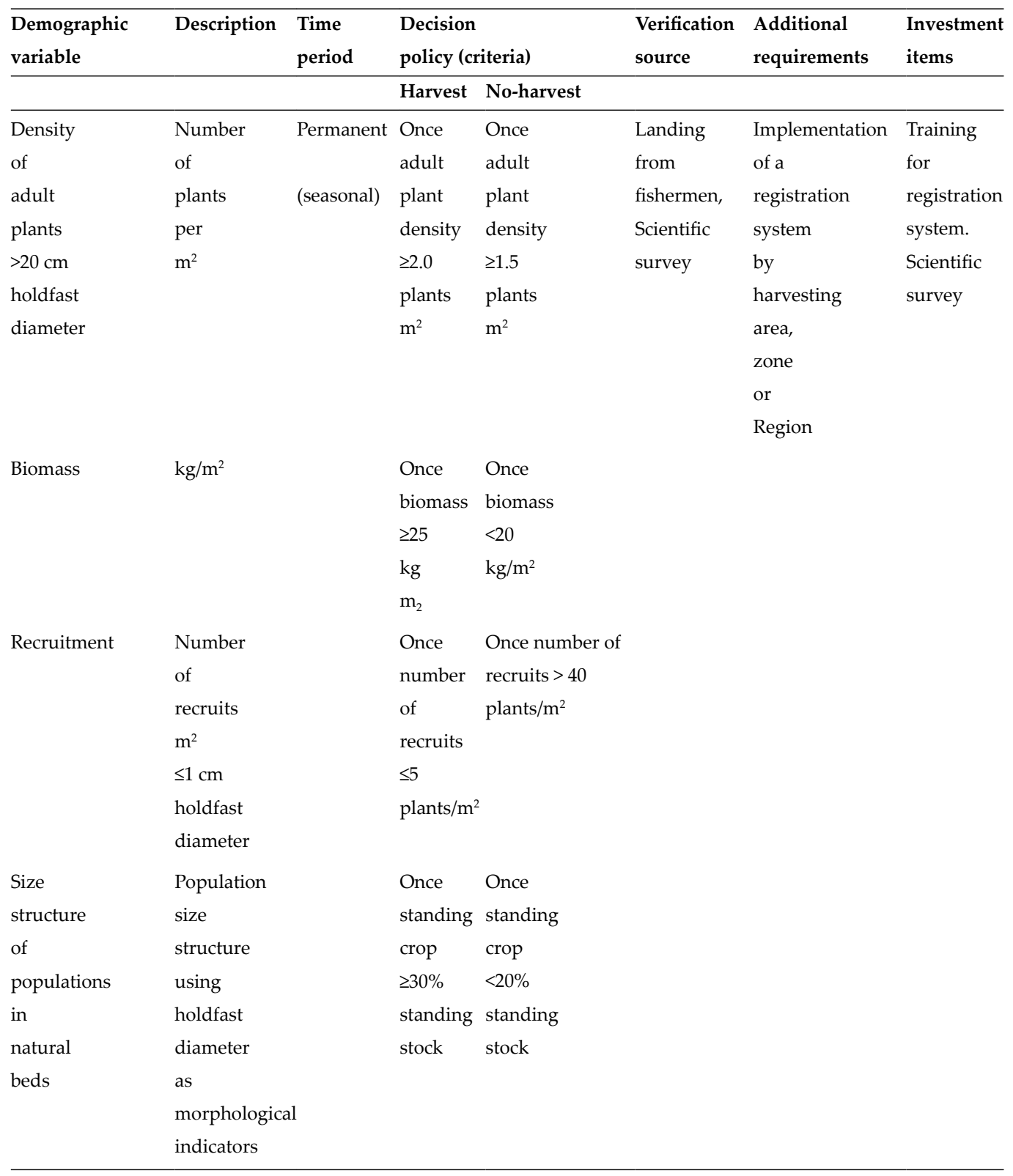

Table 2. Demographic variables proposed to monitor the harvest of Lessonia nigrescens complex. 
Based on demographic indicators, the rule establishes that the harvest in OAA should begin when the abundance and biomass of a population per unit of area is close to biomass or demographic levels detected in an un-intervened population (e.g., MPA): There is a minimal density of recruits, the portion of adult plants must be above $40 \%$ of the total population, and the percentage of remaining adult plants in the area should be enough to generate post-harvest recruitment (Table 2). Afterward, once the population reaches levels of abundance and biomass per unit of area similar to those found in the population under intense harvesting pressure (e.g., OAA), its sustainability will depend on following elements: (1) stability of recruitment frequency, (2) maintenance of a stock of reproductive individuals, and (3) stability of harvesting frequency. Once these indicators exceed the harvesting period should end and should be followed by a recess period (ban or quotas), until adequate pre-harvest values would be reached (Table 2). Thus, the installation of a permanent monitoring program of the populations of Lessonia nigrescens complex in OAA and in MAEBR, using demographic indicators, will allow as follows: (a) validation of the application of management plans, (b) detection of the deleterious effects on population dynamics produced by exogenous disturbances in the harvest, (c) respect the necessary period to renew the forest to optimal harvesting levels, and if necessary, (d) determination of extraction quotas by sector, and (e) establishment of extraction bans in a justifiable, participative, and localized way.

\section{Concluding remarks}

The landings of brown seaweeds in Chile [61] reach 390,000 wet tons/year being the world's largest landings from natural populations. This fishery is managed under the concept of "good practices," based on biological and ecological knowledge of the species $[6,12,14,23,25,32,48$, 57-59]. Most of the brown macroalgae are known as foundational species of marine ecosystems [12]; they constitute the basis of coastal food webs [14, 26, 60, 62], contribute significantly to the total biomass of the ecosystem [23,32], and are highly connected with all trophic levels [61]; they provide shelter, food, nursery, and breeding areas [23, 32, 6]. Indiscriminate harvest of a foundational species as L. nigrescens can generate a significant negative impact on the ecosystem with unknown effects. In this context, ecological indicators proposed [49] are tools for stakeholders and policy makers, enabling greater sustainability of exposed rocky shores in cold temperate seas of the world where these kelp of economic importance are key dominant organisms in cover, biomass, and ecological role.

\section{Acknowledgements}

This synthesis is the result of numerous research projects financed by public and private institutions and with the participation of many co-workers, students, and technicians. I deeply appreciate the support of CONICYT-Chile, FONDECYT, FONDEF-Huam AQ12I0001, and COPRAM-Chile. 


\section{Author details}

Julio A. Vásquez

Address all correspondence to: jvasquez@ucn.cl

Department of Marine Biology, Faculty of Marine Science, Center for Advanced Studies in Arid Zones (CEAZA), Universidad Católica del Norte, Coquimbo, Chile

\section{References}

[1] Dillehay T (1989) Monte Verde. Late Pleistocene Settlement in Chile. Volume 1. Paleoenvironment and site context. Smithsonian Institution Press, Washington \& London.

[2] Dillehay T (1997) Monte Verde. Late Pleistocene Settlement in Chile. Volume 2. The archaeological context and interpretation. Smithsonian Institution Press, Washington \& London.

[3] Vásquez JA \& Vásquez LA (2016) Algas Marinas Chilenas: aspectos etnográficos y socioculturales. Anales del VI Congreso Internacional de Etnobotánica, Córdoba (Spain), November 17-21, 2014.

[4] Vásquez JA \& Fonck E (1994) Algas productoras de ácido algínico en Sudamérica: diagnóstico y proyecciones. In: Documento de Campo $\mathrm{N}^{\circ} 13$ Situación actual de la industria de macroalgas productoras de ficocoloides en América Latina y el Caribe. FAO-Italia. Programa Cooperativo Gubernamental: 17-26.

[5] Vásquez JA, Piaget N \& Vega JMA (2012) Chilean Lessonia nigrescens fishery in northern Chile: how do you harvest is more important than how much do you harvest. Journal of Applied Phycology 24:417-426.

[6] Vásquez JA (2008) Production, use and fate of Chilean brown seaweeds: re-sources for a sustainable fishery. Journal of Applied Phycology 20 (5):457-467.

[7] Vásquez JA, Zuñiga S, Tala F, Piaget N, Rodriguez DC \& Vega JMA (2014) Economic evaluation of kelp forest in northern Chile: values of good and service of the ecosystem. Journal of Applied Phycology 26:1081-1088.

[8] Hoffmann AJ \& Santelices B (1997) Flora Marina de Chile Central. Ediciones Universidad Católica de Chile, Santiago. Chile 356 pp.

[9] Vásquez JA \& Westermeier R (1993) Limiting factors in optimizing seaweed yield in Chile. Hydrobiologia 260/261:313-320. 
[10] Frangoudes K (2011) Seaweeds Fisheries Management in France, Japan, Chile and Norway. Cahiers Biologie Marine 52:517-525.

[11] Vásquez JA (1992) Lessonia trabeculata, a subtidal bottom kelp in northern Chile: a case of study for a structural and geographical comparison. In: U. Seeliger (Ed.), Coastal Plant Communities of Latin America. Academic Press Inc., San Diego: 77-89.

[12] Graham MH, Vásquez JA \& Buschmann AH (2007) Global ecology of the giant kelp Macrocystis: from ecotypes to ecosystems. Oceanography and Marine Biology: An Annual Review 45:39-88.

[13] Vásquez JA, Vega JMA \& Buschmann AH (2006) Long term variability in the structure of kelp communities in northern Chile and the 1997-98 ENSO. Journal of Applied Phycology 18:505-519.

[14] Thiel M, Macaya EC, Acuña E, Arntz WE, Bastias H, Brokordt K, Camus PA, Castilla JC, Castro LR, Cortés M, Dumont CP, Escribano R, Fernandez M, Gajardo JA, Gaymer CF, Gomez I, González AE, González HE, Haye PA, Illanes JE, Iriarte JL, Lancellotti DA, Luna-jorquera G, Luxoro C, Manriquez PA, Marín V, Muñoz P, Navarrete SA, Perez E, Poulin E, Sellanes J, Sepúlveda HH, Stotz W, Tala F, Thomas A, Vargas CA, Vásquez JA \& Vega A (2007) The Humboldt Current System of northern-central Chile: oceanographic processes, ecological interactions and socioeconomic feedback. Oceanography and Marine Biology: An Annual Review 45:195-344.

[15] Buschmann AH, Moreno C, Vásquez JA \& Hernandez-Carmona MC (2006) Reproduction strategies of Macrocystis pyrifera (Phaeophyta) in southern Chile: the importance of population dynamics. Journal of Applied Phycology 18:575-582.

[16] Vega JA, Vásquez JA \& Buschmann AH (2005) Population biology of the subtidal kelps Macrocystis integrifolia and Lessonia trabeculata (Laminariales, Phaeophyceae) in an upwelling ecosystem of northern Chile: interannual variability and El Niño 1997-1998. Revista Chile Historia Natural 78:33-50.

[17] Muñoz V, Hernández-González MC, Buschmann AH, Graham MH \& Vásquez JA (2004) Variability in per capita oogonia and sporophyte production from giant kelp gametophyte (Macrocystis pyrifera, Phaeophyceae). Revista Chile Historia Natural 77:639-647.

[18] Tellier F, Tapia J, Faugeron S, Destombe C \& Valero M (2011) The Lessonia nigrescens species complex (Laminariales, Phaeophyceae) Shows strict parapatry and complete reproductive isolation in a secondary contact zone. Journal of Phycology 47:894-903.

[19] Tellier F, Vega JMA, Broitman B, Vásquez JA, Valero M \& Faugeron S (2011) The importance of having two species instead of one in kelp management: the Lessonia nigrescens species complex. Cahiers Biologie Marine 52:455-465. 
[20] González A, Beltrán J, Hiriart-Bertrand L, Flores V, de Reviers B, Correa JA \& Santelices, B (2012) Identification of cryptic species in the Lessonia nigrescens complex (Phaeophyceae, Laminariales). Journal of Phycology 48:1153-1165.

[21] Alveal K, Romo H \& Avila M (1982) Estudios del ciclo de vida de Macrocystis pyrifera de Isla Navarino, Chile. Gayana Botanica 39:1-12.

[22] Borazo de Zaixo AL, Piriz ML \& Romanello EE (1983) Posibilidades de desarrollo de la industria alguera de la Provincia de Santa Cruz (República Argentina). Informe preparado para el proyecto "Cinco Provincias Argentinas OEA" 187 pp.

[23] Santelices B, Castilla JC, Cancino J \& Schmiede P (1980) Comparative ecology of Lessonia nigrescens and Durvillaea antartica (Phaeophyta) in central Chile. Marine Biology 59:119-32.

[24] Santelices B \& Lopehandía J (1981) Chilean seaweeds resources: a quantitative review of potential and present utilization. In: 10th Proc Int Seaweed Symp: 725-730.

[25] Santelices B (1982) Bases Biológicas para el manejo de Lessonia nigrescens (Phaeophyta, Laminariales) en Chile Central. Monografías Biológicas 2:135-150.

[26] Santelices B (1989) Algas marinas de Chile: Distribución, Ecología, Utilización, Diversidad. Ediciones Universidad Católica de Chile, Santiago de Chile, 399 pp.

[27] Werlinger C \& Alveal K (1988) Evaluación de algas en ambientes restringidos del Golfo de Arauco (Chile): Punta Fuerte Viejo a Río Tubul. Gayana Botánica 45:461-474.

[28] Vásquez JA (1991) Variables morfométricas y relaciones morfológicas de Lessonia trabeculata Villouta \& Santelices, 1986 en poblaciones submareales del Norte de Chile. Revista Chile Historia Natural 64:271-279.

[29] Vásquez JA (1993) Natural mortality of giant kelp Macrocystis pyrifera affecting the fauna associated with its holdfasts. Pacific Science 47:180-184.

[30] Vásquez JA (2015) Evaluación de poblaciones de Lessonia nigrescens ("huiro negro”) en cuatro localidades del norte de Chile (II y III Región). Informe de Circulación restringida para Exportaciones M2. 76 pp.

[31] Westermeier R, Murúa P, Patiño DJ, Muñoz L, Atero C \& Müller DG (2014) Repopulation techniques for Macrocystis integrifolia (Phaeophyceae: Laminariales) in Atacama, Chile. Journal of Applied Phycology. 26:511-518.

[32] Santelices B \& Ojeda FP (1984) Effects of canopy removal on the understory algal community structure of coastal forests of Macrocystis pyrifera from southern South America. Marine Ecology Progress Series 14:165-173.

[33] Vásquez JA \& Buschmann AH (1997) Herbivory-kelp interactions in subtidal Chilean communities: a review. Revista Chile Historia Natural 70:41-52. 
[34] Macaya EC \& Zuccarello GC (2010) Genetic structure of the giant kelp Macrocystis pyrifera along the southeastern Pacific. Marine Ecology Progress Series 420:103-102.

[35] Vásquez, JA \& Tala F (1995) Experimental repopulation of Lessonia nigrescens (Phaeophyta, Laminariales) in intertidal areas of northern Chile. Journal of Applied Phycology 7:347-349.

[36] Gutiérrez A, Correa T, Muñoz V, Santibáñez A, Marcos R, Cáceres C \& Buschmann AH (2006) Farming of the giant kelp Macrocystis pyrifera in southern Chile for development of novel food products. Journal of Applied Phycology 18:259-267.

[37] Correa JA, Lagos N, Medina M, Castilla JC, Cerda M, Ramírez M, Martínez E, Faugeron S, Andrade S, Pinto R \& Contreras L (2006) Experimental transplants of the large kelp Lessonia nigrescens (Phaeophyceae) in high-energy wave exposed rocky intertidal habitats of northern Chile: experimental, restoration and management applications. Journal of Experimental Marine Biology and Ecology 335:13-18.

[38] Westermeier R, Patiño DJ \& Müller DG (2007) Sexual compatibility and hybrid formation between the giant kelp species Macrocystis pyrifera and Macrocystis integrifolia (Phaeophyceae: Laminariales) in Chile. Journal of Applied Phycology 19:215-221.

[39] Wolff R, Zimmermann D, Weber M, Feilen P, Ehrhart F, Salinas-jungjohann RM, Katsen A, Behringer M, Geßner P, Plieb L, Steinbach A, Spitz J, Vásquez JA, Schneider S, Bamberg E, Weber MM, Zimmermann U \& Zimmermann H (2005) Real-time 3-D darkfield microscopy for the validation of the cross-linking process of alginate microcapsules. Biomaterials 26:6386-6393.

[40] Zimmermann H, Zimmermann D, Reuss R, Feilen PJ, Manz B, Katsen A, Weber M, Ihmig FR, Ehrhart F, Geßner P, BehringerM, SteinbachA, Wegner LH, Sukhorukov VL, Vásquez JA, SchneiderS, Weber MM, Volke F, Wolff R \& Zimmermann U (2005) Towards a medically approved technology for alginate-based microcapsules allowing long-term immunoisolated transplantation. Journal of Material Science: Materials in Medicine 16:491-501.

[41] Zimmermann H, Wahlisch F, Baier C, Westhoff M, Reuss R, Zimmermann D, Behringer M, Ehrhart F, Katsen-Globa A, Giese C, Marx U, Sukhorukov VL, Vásquez JA, Jakob P, Shirley SG \& U Zimmermann (2007) Physical and biological properties of barium crosslinked alginate membranes. Biomaterials 28:1327-1345.

[42] Oppliger LV, Correa JA, Faugeron S, Beltrán J, Tellier F, Valero M \& Destombe C (2011) Sex ration variation in the Lessonia nigrescens complex (Laminariales, Phaeophyceae): effect of latitude, temperature and marginality. Journal of Phycology 47:5-12.

[43] Oppliger LV, Correa JA, Engelen AH, Tellier F, Vieira V, Faugeron S \& Destombe C (2012) Temperature effects on gametophyte life-history traits and geographic distribution of two cryptic kelp species. Plos one 7 (6):e39289. 
[44] Thompson SA, Knoll H, Blanchette CA \& Nielsen KJ (2010) Population consequences of biomass loss due to commercial collection of the wild seaweed Postelsia palmaeformis. Marine Ecology Progress Series 413:17-31.

[45] Omoregie E, Tjipute M \& Murangi J (2010) Effects of harvesting of the Namibian kelp (Laminaria pallida) on the re-growth rate and recruitment. African Journal of Food, Agriculture, Nutrition and Development 10:2542-2555.

[46] Ugarte R (2011) An evaluation of the mortality of the brown seaweed Ascophyllum nodosum (L.) Le Jol. produced by cutter rake harvests in southern New Brunswick, Canada. Journal of Applied Phycology 23:401-407.

[47] Ugarte R \& Sharp G (2012) Management and production of the brown algae Ascophyllum nodosum in the Canadian maritimes. Journal of Applied Phycology 24:409-416.

[48] Martínez EA, Cárdenas L \& Pinto R (2003) Recovery and genetic diversity of the intertidal kelp Lessonia nigrescens (Phaeophyceae) 20 years after El Niño 1982/83. Journal of Phycology 39:504-508.

[49] Vega JMA, Broitman B \& Vásquez JA (2014) Monitoring the sustainability of Lessonia nigrescens complex (Laminariales, Phaeophyta) in northern Chile under strong harvest pressure. Journal of Applied Phycology 26:791-801.

[50] Gelcich S, Edwards-Jones G, Kaiser MJ \& Watson E (2005a) Using discourses for policy evaluation: the case of marine common property rights in Chile. Society and Natural Resources 18:377-391.

[51] Gelcich S, Edwards-Jones G \& Kaiser MJ (2005b) Importance of attitudinal differences among artisanal fishers towards co-management and conservation of marine resources. Conservation Biology 19:865-875.

[52] Gelcich S, Godoy N \& Castilla JC (2009). Artisanal fishers' perceptions regarding coastal co-management policies in Chile and their potentials to scale-up marine biodiversity conservation. Ocean Coastal Management 52:424-432.

[53] Marín A, Gelcich S, Castilla JC \& Berkes F (2012) Exploring social capital in Chile's coastal benthic co-management system using a network approach. Ecology and Society $17: 13$

[54] Garcia SM \& Cochrane KL (2005) Ecosystem approach to fisheries: a review of implementation guidelines. ICES Journal of Marine Science 62:311-318.

[55] Vásquez JA (2013) Implementación de un sistema piloto de auto-atención electrónica, para la acreditación de origen de recursos pesqueros. Informe Final Proyecto 11BPC 10060. INNOVA-CORFO Chile. 125 pp.

[56] Vásquez JA \& Santelices B (1990) Ecological effects of harvesting Lessonia (Laminarials, Phaeophyta) in central Chile. Hydrobiologia 204/205:41-47.

[57] Camus P, Vásquez E, González E \& Galaz L (1994) Fenología espacial de la diversidad intermareal en el norte de Chile: patrones comunitarios de variación geográfica e 
impacto de los procesos de extinción-recolonización post El Niño 82-83. Medio Ambiente 12 (1):57-68.

[58] Vásquez JA (1995) Ecological effects of brown seaweed harvesting. Botanica Marina 38:251-257.

[59] Seeley RH \& Schlesinger WH (2012) Sustainable seaweed cutting? The rockweed (Ascophyllum nodosum) industry of Maine and the Martitime Provinces. Annals New York Academy of Science 1249:84-103.

[60] Vásquez JA \& Vega JMA (2004) El Niño 1997-1998 en el norte de Chile: efectos en la estructura y en la organización de comunidades submareales dominadas por algas pardas. In: Avaria S, Carrasco J, Rutland J and Yañez E (Eds.). El Niño-La Niña 19972000 sus efectos en Chile. CONA. Valparaíso. Chile. 119-135.

[61] Anuario Estadística de Pesca. Subsecretaría de Pesca y Acuicultura, Ministerio de Economía Fomento y Reconstrucción. Gobierno de Chile. www.sernapesca.cl.

[62] Vásquez JA \& Santelices B (1984) Comunidades de macroinvertebrados en discos de adhesión de Lessonia nigrescens en Chile central. Revista Chile Historia Natural 57:131-154. 

Chapter 7

\title{
Setting Up Traceability Tools for the Indonesian Blue Swimming Crab Fishery: A Case Study in Southeast Sulawesi
}

\author{
Hawis Madduppa , Zairion, Siti Nuraini , \\ Kuncoro Nugroho and Bambang Arif Nugraha
}

Additional information is available at the end of the chapter

http://dx.doi.org/10.5772/64252

\begin{abstract}
The Indonesian blue swimming crab fishery developed rapidly during the 1990s to become an important source of income for coastal communities. The blue swimming crab (BSC) in 2015 is the third highest export commodity in Indonesia, primarily to USA markets. Southeast (SE) Sulawesi is a relatively minor area for blue swimming crab production (approximately 1200-2000 mt per annum), in which only a subset of Asosiasi Pengelolaan Rajungan Indonesia (APRI) members are active, and it may be a conducive region in which to conduct a pilot activity to form a fisheries management structure that demonstrates the benefits that can be achieved via collaboration. The control document (CD) is a traceability and documentation process to be implemented by all of the segments of the supply chain (collectors/cooking stations, miniplants, and processors) in order to promote compliance to new Ministry and Marine Affair (MMAF) regulations and generate the records and documents of the supply chain application and verification of the new regulations. The self-recorded logbook by the fishermen and miniplant, as the point in the supply chain, could help with a meaningful and long-term solution to the fishery management in Southeast Sulawesi. This is the first trial of CD in Indonesia and could be a good model for BSC fishery in other region in Indonesia.
\end{abstract}

Keywords: Rajungan, control document, traceability, seafood, Indonesia 


\section{Introduction}

The coastal waters of Indonesia are a biodiversity repository of global importance. Coastal waters, and the ecosystems they contain, are also essential to the health and subsistence of coastal Indonesian communities. Indonesia's fisheries are open access, and in combination with increasing populations, increased demand, and increased access to international seafood markets, this has resulted in overfishing of coastal and offshore fisheries. Since the 1980s, overfishing in Indonesia has led to serial depletion of coastal resources, and some fishing communities have started using fishing techniques that damage habitats. Overfishing started in the west of the Indonesian archipelago, moved to the east, and from shallow coastal to deeper offshore waters. Usually, overfishing first affects the larger species, which means that coastal waters are now nearly depleted of large piscivorous fish [1, 2]. Overfishing in coastal waters is now considered one of the main threats to marine biodiversity in Indonesia. Because fish stocks have been depleted, fishing families are now struggling to survive as they experience a decline in their food security and income level. As each local resource declines, fishing communities are forced to find yet another resource, either by traveling further afield in the hope of finding less depleted resources or by adopting more effective, but generally more expensive and often destructive fishing techniques.

USAID-Indonesia Marine and Climate Support (IMACS) Project is assisting Ministry and Marine Affair (MMAF) and local fishery agencies (DKP) to strengthen fisheries management and to abate overfishing [Asosiasi Pengelolaan Rajungan Indonesia (APRI) 2015]. A means to do this is to put in place systems that enable local management on a fishery-by-fishery basis, as opposed to centralized management of a large area that comprises various fisheries. At a local level, stakeholder groups need to be formed to take a role in fishery management. Such groups must include fishers, traders, plant owners, and regulators (government officials), and the group must have the support of stock assessment experts. Furthermore, a monitoring system must be put in place to provide data for a basic stock assessment and to inform harvest control rules.

Through support of the National Fisheries Institute (NFI) Crab Council of US importers, the Indonesian Blue Swimming Crab Association or Asosiasi Pengelolaan Rajungan Indonesia (APRI) has been driving the blue swimming crab (BSC) sustainability initiative in Indonesia since 2007. APRI is an industry trade association comprised of blue swimming crab (Portunidae: Portunus pelagicus) processors and exporters. The fishery directly employs more than 65,000 fishermen and 130,000 women working in miniplants and factories. The BSC fisheries indirectly impact thousands of others from miniplant owners, gear manufacturers, middlemen, ice vendors, and fisher communities. APRI members campaign sustainable crab harvest to the supply chain through protecting immature stocks and allowing crab to grow to mature size, collaborating with Universities, fishery scientists, and eNGOs, supporting the MMAF to develop a National Fishery Management Framework, and working closely with fishers' community to establish community-based fishery management (CBFM).

The Indonesian BSC fishery can be categorized as coastal and small scale, which developed rapidly during the 1990s to become an important source of income for coastal communities. 
Over the last decade, approximately 20,000 mt per annum of BSC has been exported, primarily to USA markets, which are now demanding that the product's sustainability be certified. However, since 2008, government and industry production figures show that landings, and the average size of BSCs being caught, have been declining. This trend is following trends in region where BSC fisheries developed earlier and where catches have now declined to very low levels due to overfishing and might be also overfished. The trends in the Indonesian BSC fishery are already threatening the profitability and sustainability of the fishery, which is effectively controlled by a small, well-organized group of processing companies that have effectively structured themselves into an industry association (APRI), and who are growing increasingly interested and active in regard to making their fishery sustainable.

The BSC species of Indonesia as well as in South-East Asia region is P. pelagicus (Portunidae) and one among of this species complex known previously are: P. armatus of Australia, $P$. reticulatus at western Andaman Sea and P. segnis at western Indian Ocean [3]. This species is likely those and some of portunid species, which has high productivity, rapid growth rates (i.e., [4-8]), and low intrinsic vulnerability to fishing by using fuzzy logic expert system criteria [9]. International experience shows that due to their high productivity, rapid growth rates, and low intrinsic vulnerability to fishing, depleted BSC stocks can recover quickly by maintaining and restoring both immature size crabs and breeding population in the stock. The biological characteristics of BSC, the coherent organized nature of the industry, and its reliance on sustainability conscious export markets make the BSC fishery strategic for beginning the process of developing models for the collaborative management of coastal fisheries.

Southeast (SE) Sulawesi is an important pilot area for the IMACS project in that approximately 1200-2000 mt per annum of blue swimming crab are caught. Meetings between APRI and IMACS suggest that because SE Sulawesi is a relatively minor area for BSC production, in which only a subset of APRI members are active, it may be a conducive region in which to conduct a pilot activity to form a fisheries management structure that demonstrates the benefits that can be achieved via collaboration. The province is in the center of the Coral Triangle, and successful activities undertaken in the province can be replicated to other provinces and districts.

The livelihoods of coastal fishers and the integrity of the coastal ecosystems go hand in hand. In principle, Indonesia's coastal fisheries are open access. This means that visiting fishers can nullify any successes in stock recovery that resident fishers may have achieved through improved management [10]. In the situation of the blue swimming crab fishery, however, a large part of the sector is organized in a producer's organization (APRI). At least $80 \%$ of Indonesia's BSC grow through APRI processors before product go to market. Through this organization, it is possible to control a large part of the fishery, and this means that control can be exerted on fishing behavior and on participation in the fishery. For this reason, a stakeholder group comprising the BSC sector of SE Sulawesi is in a good position to implement effective management in partnership with local government.

The objective of the study was to describing the BSC fishery and the fishery improvement project (FIP) in Southeast Sulawesi, obtaining biological data from landing information at fishermen and miniplants, and was to expand to incorporate catch and effort data derived from 
fishing vessels. The key point of this project is on the fishermen and the miniplant, where the first chain of the supply, which could be a critical point to control and to trace the BSC. This study was initially focused on self-reporting of catch by fishery stakeholders, establishing a foundation for auditable control documentation and a robust traceability system.

\section{Materials and methods}

\subsection{Study site}

Geographical area of main BSC fisheries in SE Sulawesi is Tiworo strait and vicinity. This area is located at western Laut Banda (Banda Sea), part of Fisheries Management Area (FMA) of Indonesia (WPP-RI 714) and FAO Fishing Area 71, western and central Pacific (Figure 1).

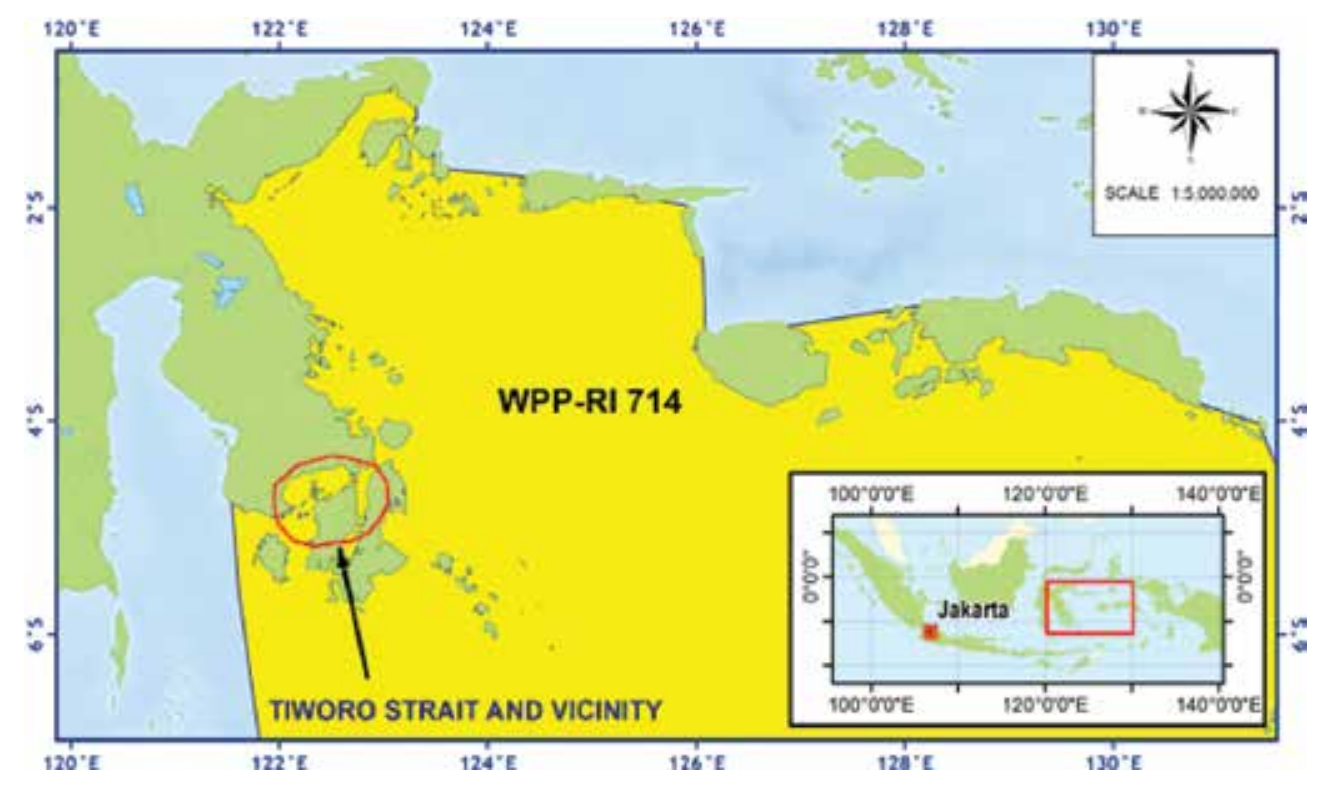

Figure 1. Boundary area of BSC fisheries management in Tiworo strait and vicinity of Southeast Sulawesi (red line), Fisheries Management Area (FMA 714) of Indonesia (yellow area).

\subsection{BSC fishery in Southeast Sulawesi and registration system}

The BSC fishery was studied based on references and field observations at the local government and direct information from fishermen. The information includes fishermen, miniplants, fishing gear, number of fishing gear, fishing ground, boat (size and length). APRI initiated logbook data collection for both fishers and miniplants. The registered vessel using a unique vessel identifier (UVI) number that tagged onto the boat, for example, APRI-IMACS-001. The registration system is initially following the Kartu Nelayan (Fishermen Card) implemented by the Ministry of Marine Affair and Fisheries. However, most fishermen do not have their KTP 
(Indonesian ID). So, we registered the fishermen based on their miniplants. The owners of the miniplant list their fishermen, and then, fishermen were asked their availability for their participation during data trial collection. This process was conducted before, during and after training for logbook. Each fisherman was asking about their profile including where they sell their catch, boat type and size, number of fishing gear.

\subsection{Logbook system}

The fishermen filled the logbook independently or assisted by enumerator at each site. Depending on the area, fishermen usually sell their catch to supplier or directly to miniplants. At each miniplant, we also give a logbook. We have identified from the beginning the fishermen with their supplier or miniplant. Fishery logbooks detailed including vessel UVI, gear type, gear volume, soak time, landing port, target specie volume, primary and secondary species, liters of gas used, and fishing effort cost. Miniplant logbooks detailed include Fisher UVI, gear type, volume of raw material received, crabs with egg-bearing females, and crabs at minimum legal size (MLS). The data from each fishermen and miniplant were collected by enumerators and those data were sent to APRI enumerator managers.

\subsection{Fishermen perception}

Pre- and post-tests were conducted before and after training, as a basis for evaluation. The question includes the following: catch record and fishing gears in 3-5 years, the basic knowledge of blue swimming crab biology, the awareness of ministerial decree, the catch composition (number of berried female), and the needs of management for BSC.

\subsection{Consequence analysis of the BSC stock}

Implementation of UVI numbers for vessels, fisher logbooks, and miniplant logbooks are the building blocks by which blue swimming crab fisheries can have a transparent and auditable control document (CD) system. Data collection program by incorporating catch and effort data derived from fishing vessels. Lastly information derived from fisher logbooks will contribute to assessing fishery impacts to retained, by-catch, and ETP species, as well as ecosystems and habitats using Marine Stewardship Council (MSCs) risk-based framework (RBF) methodology [16]. Consequence analysis (CA) was used to score data-deficiency for stock status outcome. Consequence of the fishing activity on the most vulnerable subcomponent was determined by the stakeholder input during the workshop, using quantitative and qualitative biological indicator data.

\section{Results and discussion}

\subsection{BSC fishery in Southeast Sulawesi}

Crab harvesters in Southeast Sulawesi using boats of $12 \mathrm{~m}$ length, $0.7 \mathrm{~m}$ of width and $0.3-0.5 \mathrm{~m}$ of height. Some fishermen do not own a boat and a boat can be used by two different fishermen. 
Meanwhile, the exact number of fishermen is uncertain, but is approximately 3500 . The number of boats involved in the SE Sulawesi BSC fisheries in 2013 was 2311 among which 1239 nonpowered $<1$ GT boats, 964 small boats with outboard engine, and 108 powered $<5$ GT boats (Data Management Commission 2014 in APRI and USAID-IMACS 2014) [13-15].

The BSC is mostly caught with trap and bottom gillnet. The fishing gear used is depending of fishing ground characteristics, but according to stakeholders met during the site visit, trap is the fishing gear the most used for both shallow and deep water $(<10 \mathrm{~m}$ and $>10 \mathrm{~m}$ depth, respectively). Meanwhile, gillnet is commonly used for crab fishing at deep water. The BSC is also a retained species in other fisheries such as those using trawl, trammel nets, and seine nets (APRI and USAID-IMACS 2014). The traps used are mostly collapsible or folding traps, round or square form and depending of the locality, with a size of $30-40 \mathrm{~cm} \times 30 \mathrm{~cm} \times 20 \mathrm{~cm}$ and mesh size nets of $1 \mathrm{inch}$. The trap limit is the capacity of the boat. One fisher carries about 100 200 traps connected to a main line, with an average of 150 traps/boat/harvester (IMACS 2013 in APRI and USAID-IMACS 2014). Traps are baited with fish pieces and are usually soaked overnight. Bottom gillnets used are monofilament of $100 \mathrm{~m}$ length and $80 \mathrm{~cm}$ height per-set, with mesh size of 3.5-4.5 inches. There is no limit of the number of gillnets used, but a fisherman usually soaks $5-20$ sets of nets. Soaking time is typically $11-13 \mathrm{~h}$.

\begin{tabular}{lllll}
\hline No. Subfishing area & Fishing base & Subdistrict & District/city \\
\hline 1 & Eastern Kendari Bay & Bungkutoko village & East Kendari & Kendari City \\
2 & Kolono Bay & Puupi & Kolono & Konawe Selatan \\
3 & Northeast (NE) Tiworo strait & & & \\
& a. Lahia Bay & Pamandati and Polewali village & Lainea & Konawe Selatan \\
& b. Renda island and Tampo waters & Renda island and Tampo & Napabalano & Muna \\
4 & Southern Tiworo strait & & & \\
& a. Maginti, Gala and Pajala waters & Pajala and Gala island & Maginti & Muna Barat \\
& b. Bangko waters & Bangko island & Tiworo Selatan & Muna Barat \\
5 & Northern Buton strait & Raha & Raha & Raha \\
6 & Western Tiworo strait & Kasipute & - & Bombana \\
\hline
\end{tabular}

Table 1. Subfishing area, fishing base, subdistrict and district jurisdiction in Southeast Sulawesi.

The fishing areas are located in coastal waters of the Tiworo strait and vicinity. Based on the fisher base and landing based of caught crabs, there is several subfishing fishing areas at Tiworo strait and vicinity (Table 1 and Figure 2).

Management arrangement of Southeast BSC fisheries is under regulation of Ministry and Marine Affair (MMAF) of Indonesia. The regulation, such as minimum legal size (MLS) of $\mathrm{crab}$, is $100 \mathrm{~mm}(10 \mathrm{~cm})$ carapace width and prohibit to catch berried female (Minister Decree No. 1, year 2015), which is effectively applied in January 2016. During January-December 2015, it is prohibit catching individual BSC below $55 \mathrm{~g}$ (Minister Circular Letter No. 18, year 2015). 
The BSC is also prohibiting to catching Under Minister Decree No. 2, year 2015, also restricted to catch by trawl.

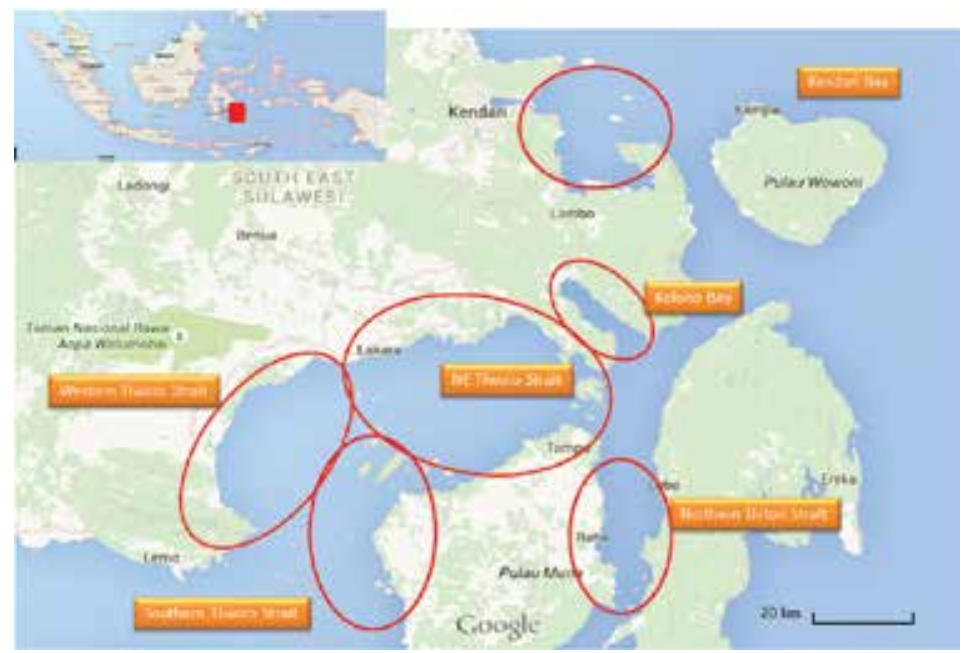

Figure 2. Subunit of fishing area at Tiworo strait and vicinity of Southeast Sulawesi.

\subsection{Logbooks and unique vessel identifier (UVI), and training}

APRI initiated logbook data collection for both fishers and miniplants, as well as compile a vessel registry of 208 participants using a unique vessel identifier (UVI) number that tagged onto the boat. APRI, with the assistance of Survival Fisheries Partnership (SFP), Haluoleo University (UHO), and DKP Kendari conducted a training program for miniplant logbooks, fisher logbooks, and UVI numbers. A total of 208 vessels were registered with UVI numbers, the correlating fishers working on those vessels were trained to fill-in logbooks. A total of 12 miniplants were trained to fill-in miniplant logbooks at their receiving centers (Table 2). Fishers and miniplants were trained during the same event. In all, there were five training sessions across the province.

\begin{tabular}{lll}
\hline Location & Fishers \# & Miniplant \# \\
\hline Pajala and Pulau Gala, Muna & 34 & 3 \\
Raha/Tampo, Muna & 41 & 2 \\
Pulau Bangko, Muna & 26 & 2 \\
Pamandati, Konawe Selatan & 38 & 1 \\
Bungkutoko, Kendari & 27 & 2 \\
Kasipute, Bombana & 41 & 2 \\
\hline
\end{tabular}

Table 2. Training on control document conducted at each location in SE Sulawesi in a period of May-July 2015. 

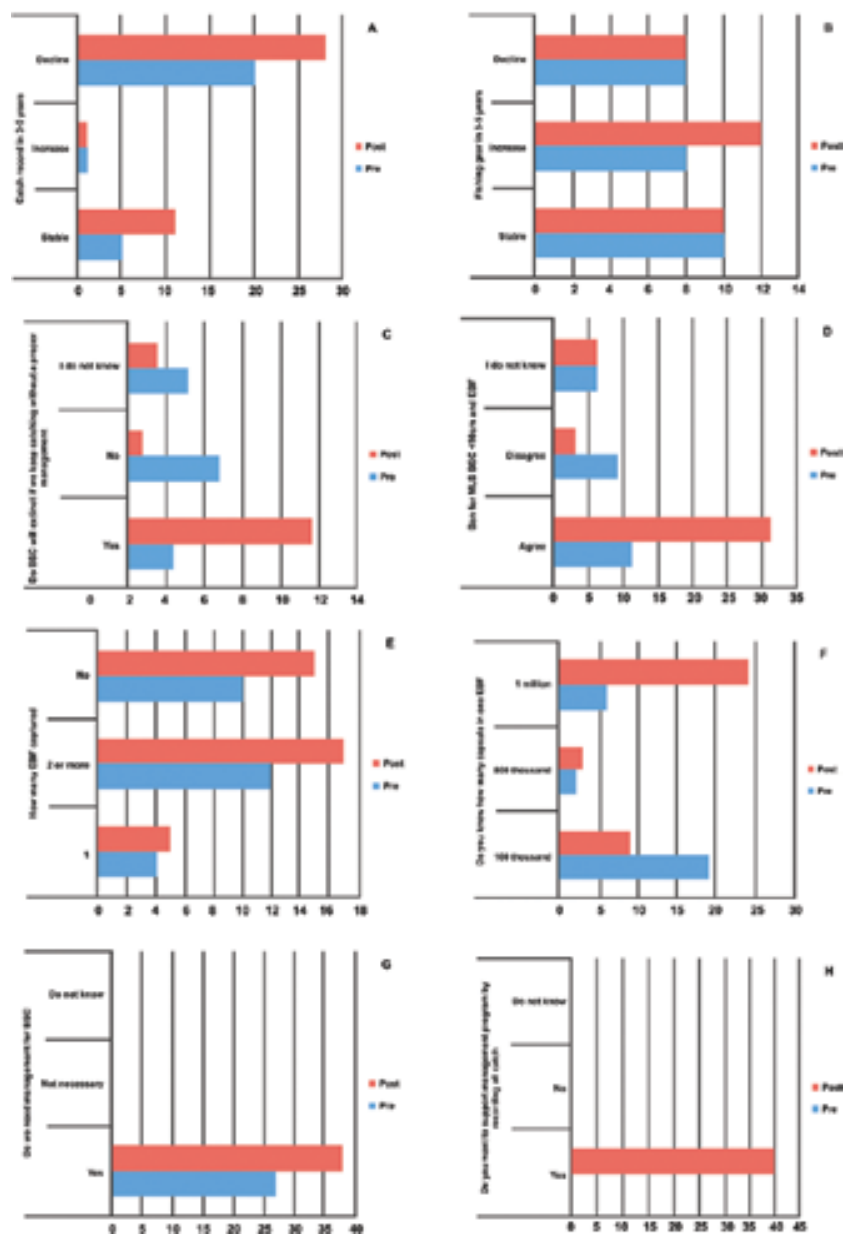

Figure 3. Pre- and post-evaluation with questions: (a) the condition of catch record in 3-5 years, (b) the number of fishing gear in 3-5 years, (c) do blue swimming crab will extinct if we keep catching without a proper management, (d) knowledge on ban for MLS BSC under $10 \mathrm{~cm}$ and EBF, (e) how many egg-berried-female captured, (f) how many capsule or eggs from one egg-berried-female, $(\mathrm{g})$ do we need management for blue swimming crab in SE Sulawesi, and (h) their support of IFISH program in SE Sulawesi.

The training objectives were to (1) record raw material going through the supply chain as a basis for the control document, (2) investigate catch composition with regard to ecosystem impacts, and (3) train fishermen and miniplant on how to fill in the logbook itself. The training was organized to achieve the training objectives. The training includes theory on the importance of blue swimming crab management trough data collection to see the impact to the ecosystem and also to see catch composition, and the dynamics of BSC as well. Fishermen and miniplants owner were giving the materials by experts, in order to give the understanding why we need management on the BSC. They were asking their support to participate on the IFISH program, and they were taught on how to fill the logbook. From data that will be collected, that is time departed to and back from fishing area, type and number of gear that 
used and gasoline consumption per trip per day. From the data, we can analyze how the business status. It will formulated and find solution whether need conservation area to protect BSC from distinction.

Pre- and post-tests were conducted before and after training, as a basis for evaluation (Figure 3). Based on the test, most fishermen said their catch within 3-5 years was declining; even some of them have increased their fishing gear number. They have changing their mind after the training about the extinction of BSC with over exploitation. Most fishermen agree with the current regulation on minimum landing size and egg berried female. The test also shows their lack of knowledge on the impact of catching of eggberried female, and how many potential crab will be lost if they are caught.

The fishermen and miniplants owner are ready and support the management of blue swimming crab in SE Sulawesi and are willing to participate in the IFISH program. Over all, the training seems change the perception of the fishermen.

\subsection{Consequence analysis of the BSC stock}

As a result of data documentation by fishermen and miniplants, the consequence analysis (CA) was used to score data deficiency for stock status outcome. Consequence of the fishing activity on the most vulnerable subcomponent was determined by the stakeholder input during the workshop, using quantitative and qualitative biological indicator data (Table 3) [17].

\begin{tabular}{llll}
\hline Principle 1: stock status outcome & Scoring element & Consequence subcomponent & Consequence score \\
\hline Tiworo strait and vicinity blue swimming crab Portunus pelagicus & Population size & 60 \\
fisheries & &
\end{tabular}

Reproductive capacity

Geographic range

$\begin{array}{ll}\begin{array}{l}\text { Principle 1: stock } \\ \text { status outcome }\end{array} & \begin{array}{l}\text { Scoring element } \\ \text { Rationale for most } \\ \text { vulnerable } \\ \text { subcomponent }\end{array} \\ \begin{array}{l}\text { Rationale for } \\ \text { consequence score }\end{array} & \begin{array}{l}\text { Population size as well as reproductive capacity and age/size structure was considered almost } \\ \text { equal vulnerable subcomponent based on the impact of exploitation pattern and biomass } \\ \text { fully exploited. According to USAID-IMACS (2015), the BSC catch per-unit of effort (CPUE) } \\ \text { in Tiworo strait tends to decrease and its stock status was "overfished." However, trend in } \\ \text { exploitation rate, biomass, and recruitment indicates that fishing is not adversely damaged } \\ \text { recruitment in long time. As the fishery is defined as fully developed and fully capacity, it } \\ \text { cannot conclude that its impact on stock size is minimal as well as it is not having an impact } \\ \text { on life history and population dynamic parameter }\end{array}\end{array}$




\section{Principle 1: stock Scoring element

- The BSC stock is intensively fished (ca. $80 \%$ of the estimated biomass). Available evidence suggests that there may be a detectable change in reproductive capacity as the BSC are caught in their first year of growth. The minimum landing size (MLS) of $10 \mathrm{~cm} \mathrm{CW}$ that will be implemented for this fishery also allow for catching individuals in their first year of growth and the BSC at this size is still $<10 \%$ SPR in Tiworo strait. A retained BSC is defined as one that is retained by traps having an escape vent approximately $3.5 \times 5.0 \mathrm{~cm}$ at each side or entangled by gillnet having mesh size $>4$ inch. Even though the BSC of this size are in their first year of growth and will became a reproductive period and spawned at least once before being caught. Moreover, caught berried female shall be reduced. The harvest strategy ensures that long-term recruitment dynamics is not adversely damaged by fishing

- Size frequency distribution of the species is available, showing that recruitment is not being adversely damaged. However, level of catch and fleet structure do not enable a qualitative assessment to determine that the impact of population dynamics is minimal

Indicators used are as follows:

- There are two main fleet structures in all fishing area: traps and gillnet, while another fleet is minitrawl that operate at western Tiworo strait. The trap fleets have an access to most shallow waters ( $<7 \mathrm{~m}$ depth) and few fleets used traps at deeper, contrastingly to gillnet fleets. In addition, fishing area where the minitrawl operates, there were almost no above two fleets operates in these areas. Thus, all of fleets have full access to the stock at almost the entire BSC habitat

- The stock biomass remaining only 0.2 biomass MSY and implementation of minimum landing size of $10 \mathrm{~cm}$ CW for existing stock remaining SPR <10\% (USAID-IMACS 2015)

- Prohibited to catch crabs at size $<10 \mathrm{~cm} \mathrm{CW}$ was $>10 \%$ as well as berried female were still neglected by the fisher

Exploitation rate:

- Management aims to stock rebuilding proposed by USAID-IMACS team, such as (a) reducing fishing effort gradually; (b) reducing fishing effort dramatically about $50 \%$ of f-msy; (c) moratorium for at least 1 year, (4) implementing minimum landing size (MLS), and etc

- Identification of nursery habitat for implemented another management measure in sufficient season or wide (close season during peak recruitment or nursery habitat protection)

- Fishing by minitrawl must be stopped to reduce fishing effort and damaged to habitat, which is guided by the Minister of Marine Affair and Fishery Decree No. 2, year 2015

- Data collection of the BSC catch per-unit of effort (CPUE) and stock assessment need to be made durable in order to monitor changes in the stock status over time and improved fisher mindful against unreported fishing

Fishing area and seasonality: 


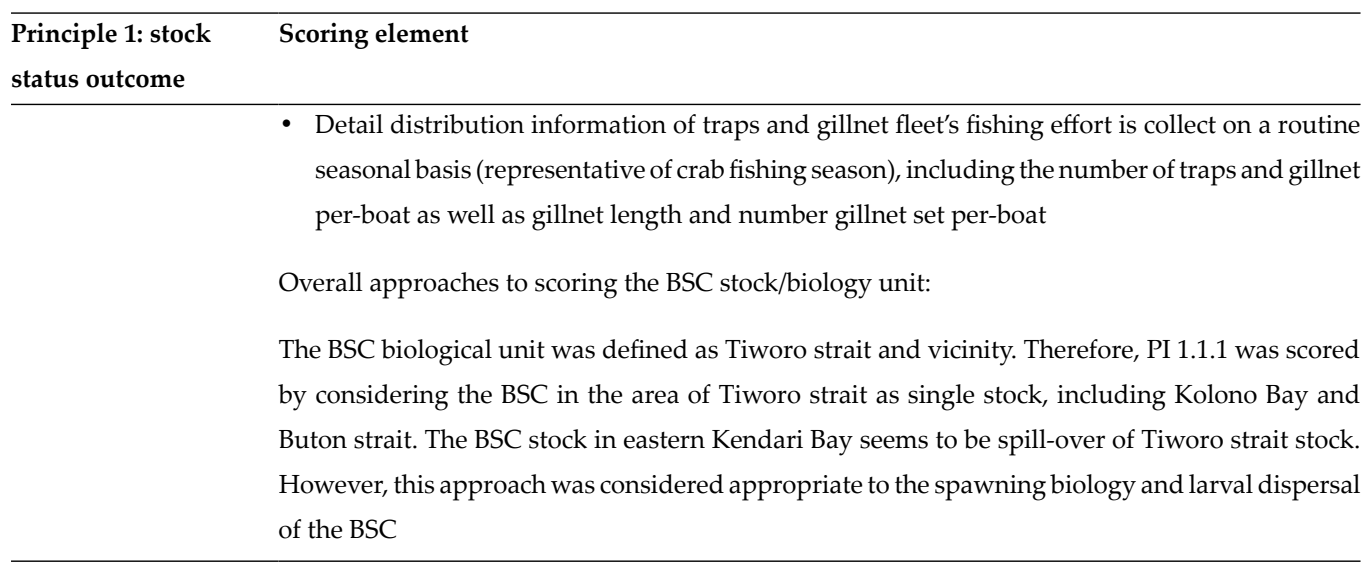

Table 3. Consequence analysis score and justification.

Based on available data and information collected from the field and the RBF workshop, the fully RBF assessment could not be conducted and not feasible yet, this report act as preassessment RBF. High productivity and low intrinsic vulnerability to fishing of the BSC seem to be not guaranteeing on stock rebuilding and might relate to overcapacity, offspring survival, and recruitment succeeds, as well as the BSC habitat quality. The current study recommends continuing: (1) recording of the BSC CPUE data and incorporating to non-targeted species for both number of individual and weight, where non-targeted catches are recorded at species level and family level in some cases; (2) recording daily, monthly, and annually catches BSC for each fishery; (3) mapping spatial-temporal fishing ground and spatial-temporal community structure at the BSC fishing area; (4) mapping vulnerable habitat, the high potential BSC nursery habitat, and its environmental quality status; and (5) stock rebuilding could be by integrated management, that is, reducing fishing effort and ban minitrawl fishery, increasing the BSC reproduction capacity, protect the high potential and sufficient wide area of the BSC nursery habitat.

\subsection{APRI's role on control document and audit system}

Asosiasi Pengelolaan Rajungan Indonesia (APRI) is an industry trade association comprised of blue swimming crab processors and exporters. The fishery directly employs more than 65,000 fishermen and 130,000 women working in miniplants and factories. Blue swimming crab fisheries indirectly impact thousands of others from miniplant owners, gear manufacturers, middlemen, ice vendors, and fisher communities. Through support of the NFI Crab Council (US importers), APRI has been driving the sustainability initiative for blue swimming crab fisheries in Indonesia since 2007. The overarching goal of APRI's sustainability efforts is to operate their fisheries on par with the MSC standard. Through initiating a fishery improvement project (FIP), APRI has supported cross-sectorial roundtable to address fishery management, fishery research, and stock assessment data collection. APRI advocates fishery policies based on good science so that crab resources remain productive and the fishery viable in the future. APRI collaborates with NGO's, Universities, fishery scientists, and the Ministry of 
Marine Affairs and Fisheries (MMAF). Key to their strategy has been to develop a national fishery management framework and then working closely with fisher community stakeholders to establish. APRI's members cover more than $80 \%$ of the export volume and could be a beneficial for controlling the fishery.

The BSC fishery industry is happening in Southeast Sulawesi for a long time; however, lack of knowledge observed in the fishermen, in terms of the biology of the crabs. From the training, we observe that they do not know about the importance on why we need to manage the crabs. The trends in the Indonesian blue swimming crab fishery are already threatening the profitability and sustainability of the fishery, which is effectively controlled by a small, well-organized group of processing companies that have effectively structured themselves into an industry association (APRI), and who are growing increasingly interested and active in regard to making their fishery sustainable.

Since early 2015, APRI together with NFI Crab Council and SFP have been crafting and trialing a control document (CD) system. In order to strengthen compliance among producers and facilitate the supply chain's accountability, traceability, and verification, the CD gives buyers new tools to use with their suppliers to verify that the products being traded are from legitimate producers operating in legal fisheries and that the gear employed and the captures landed are compliant with local and international regulations. The control document specifies that not only does a particular shipment/product bought need to be legal within national regulations, it further requires that the entire product the supplier handles, for all customers, is legal also. The CD comprises three components that ensure its successful application: (a) a letter of warranty or private contract that requires legal trading of fish products along the entire commercial chain; (b) a list of control points that conform to the full regulatory and legal framework relevant to the fish products marketed; and (c) a guide to a third-party audit mechanism, which lists the main control check points, from producer to retailer, and identifies recognized and reputable independent auditing bodies. CDs are adopted on a voluntary basis by those producers, traders, and/or suppliers that wish to ensure a sustainable supply of marine products to responsible consumers all over the world, while combating IUU effectively and supporting livelihoods in producer countries. The supply chain participating in the process needs to agree on the penalties framework, including full and potentially permanent exclusion from the supply chain for violators of the CD stipulations (e.g., suppliers can be delisted due to failure or refusal of an audit and denied contracts until compliance is verified at their cost). The CD is a traceability and documentation process to be implemented by all of the segments of the supply chain (collectors/cooking stations, miniplants, and processors) in order to promote compliance to new MMAF regulations and generate the records and documents of the supply chain application and verification of the new regulations [11, 12].

\section{Conclusion}

The BSC fishery industry is happening in Southeast Sulawesi for a long time; however, lack of knowledge observed in the fishermen, in terms of the biology of the crabs. From the training, 
we observed that they have lack of information about the importance on why we need to manage the crabs. The key point of this industry is on the fishermen and the miniplant, where the first chain of the supply, which could be a critical point to control and to trace the BSC. This study was the first effort in Indonesia that initially focuses on self-reporting of catch by fishery stakeholders, establishing a foundation for auditable control documentation and a robust traceability system. The self-recorded logbook by the fishermen and miniplant, as the point in the supply chain, could help with a meaningful and long-term solution to the fishery management in Southeast Sulawesi. The control document can support the implementation of Ministerial Decree on minimum landing size and ban of specific fishing gear. The study in SE Sulawesi could be a good model for BSC fishery in other region in Indonesia.

\section{Acknowledgements}

The study was supported by IMACS USAID (Subcontract No. IMACS-APRI-01), The Government of Southeast Sulawesi, and The Data Management Committee (DMC) Kendari. We are grateful to Jeremy Crawford for his assistance on this project (2015).

\section{Author details}

Hawis Madduppa ${ }^{1,2^{*}}$, Zairion ${ }^{3}$, Siti Nuraini ${ }^{2}$, Kuncoro Nugroho ${ }^{2}$ and Bambang Arif Nugraha ${ }^{2}$

*Address all correspondence to: hawis@ipb.ac.id

1 Department of Marine Science and Technology, Faculty of Fisheries and Marine Science, Bogor Agricultural University, Bogor, Indonesia

2 Indonesian Blue Swimming Crab Association (APRI), Gresik, Jawa Timur, Indonesia

3 Department of Aquatic Resources Management, Faculty of Fisheries and Marine Science, Bogor Agricultural University, Bogor, Indonesia

\section{References}

[1] Madduppa HH, von Juterzenka K, Syakir M, Kochzius M. 2014. Socio-economy of marine ornamental fishery and its impact on the population structure of the clown anemonefish Amphiprion ocellaris and its host anemones in Spermonde Archipelago, Indonesia. Ocean \& Coastal Management, 100: 41-50. doi:10.1016/j.ocecoaman. 2014.07.013 
[2] Madduppa H, Subhan B, Suparyani E, Siregar AM, Arafat D, Tarigan SA, Alimuddin DK, Rahmawati F, Bramandito A. 2013. Dynamics of fish diversity across an environmental gradient in the Seribu Islands reefs off Jakarta. Biodiversitas, 14(1): 17-24. doi: 10.13057/biodiv/d140103

[3] Lai JCY, Ng PKL, Davie PJF. 2010. A revision of the Portunus pelagicus (Linnaeus, 1758) species complex (Crustacea: Brachyura: Portunidae), with the recognition of four species. The Raffles Bulletin of Zoology 58(2): 199-237.

[4] de Lestang S, Hall NG, Potter IC. 2003. Reproductive biology of the blue swimming crab (Portunus pelagicus, Decapoda: Portunidae) in five bodies of water on the west coast of Australia. Fishery Bulletin 101(4): 745-757.

[5] Ernawati T. 2013. Dinamika populasi dan pengkajian stok sumberdaya rajungan (Portunus pelagicus Linnaeus) di perairan Kabupaten Pati dan sekitarnya [Population dynamic and stock assessment of the blue swimming crab (Portunus pelagicus Linnaeus) in coastal waters of Pati and adjacent area]. Magister thesis. Bogor (ID): Graduate School of Bogor Agricultural University (IPB). 79p.

[6] Kangas MI. 2000. Synopsis of the biology and exploitation of the blue swimmer crab, Portunus pelagicus Linnaeus, in Western Australia. Fisheries Western Australia, Perth, Western Australia. Fisheries Research Report No. 121.

[7] Kunsook C. 2011. Stock assessment and movement pattern for sustainable management of blue swimming crab, Portunus pelagicus (Linnaeus, 1758): Case study in Kung Krabaen Bay, Chanthaburi Province, Thailand [Dissertation]. Bangkok (TH): Faculty of Science, Chulalongkorn University. 166p.

[8] Zairion. 2015. Pengelolaan berkelanjutan perikanan rajungan (Portunus pelagicus) di Lampung Timur [Sustainable management of the blue swimming crab (Portunus pelagicus) fisheries in East Lampung]. PhD Dissertation. Graduate School of Bogor Agricultural University (IPB). 236p.

[9] Cheung WL. 2007. Vulnerability of marine fishes to fishing: from global overview to the northern South China Sea. PhD Dissertation. The Faculty of Graduate Studies, The University of British Colombia. 354p.

[10] Hamid A. 2015. Habitat, biologi reproduksi dan dinamika populasi rajungan (Portunus pelagicus Linnaeus, 1758) sebagai dasar pengelolaan di Teluk Lasongko, Sulawesi Tenggara [Habitat, reproductive biology and population dynamic of the blue swimming crab (Portunus pelagicus Linnaeus 1758) as a basic of its management at Lasongko Bay, Southeast Sulawesi]. PhD Dissertation. Graduate School of Bogor Agricultural University (IPB). 160p.

[11] MMAF [Ministry of Marine Affairs and Fisheries]. 2015. Ministerial Decree of Marine Affairs and Fisheries Republic Indonesia No.1 Minimum Landing Size for Blue Swimming Crab, Mud Crab, and Lobster year 2015. 
[12] MMAF [Ministry of Marine Affairs and Fisheries]. 2015. Ministerial Decree of Marine Affairs and Fisheries Republic Indonesia No. 2 ban operation for specific fishing gear year 2015.

[13] APRI and USAID-IMACS. 2013. Marine Stewardship Council Pre-Assessment Report for the Asosiasi Pengelolaan Rajungan Indonesia (APRI) Tiworo Strait, Southeast Sulawesi Blue Swimming Crab Trap and Gillnet Fisheries.

[14] MSC [Marine Stewardship Council]. 2014. MSC Fisheries Certification Requirements and Guidance, Version 2.0, 1st October, 2014.

[15] MSC [Marine Stewardship Council]. 2014. MSC Fisheries Standard and Guidance v2.0 (Extracted from Annexes SA, SB, SC and SD of the Fisheries Certification Requirements v2.0), Version 2.0, 1st October, 2014.

[16] MSC [Marine Stewardship Council]. 2010. Fisheries Assessment Methodology and Guidance to Certification Bodies, Including Default Assessment Tree and Risk-Based Framework, Version 2.1, 1st May, 2010.

[17] Patrick W.S., P, Spencer, O. Ormseth, J. Cope, J. Field, D. Kobayashi, T, Gedamke, E. Cortés, K. Bigelow, W. Overholtz, J. Link, and P. Lawson. 2009. Use of productivity and susceptibility indices to determine stock vulnerability, with example applications to six U.S. Fisheries. U.S. Dep. Commer., NOAA Tech. Memo. NMFS-F/SPO-101, 90p. 

Chapter 8

\title{
Direction of Fisheries (SUISAN) Education from a Historical Perspective in Japan
}

\author{
Tsuyoshi Sasaki
}

Additional information is available at the end of the chapter

http://dx.doi.org/10.5772/62733

\begin{abstract}
Fishing, aquaculture, and food processing is collectively referred to as "SUISAN", and the term was translated to "fisheries" in the Meiji period. Fisheries education in Japan was at its dawn. Fisheries education was necessary for improvement of local fisheries subsistence. Fisheries education was performed, centering on nurturing of mid-career engineers for deep-sea fishing after 1950s. However, when the Heisei period in the 1990 s started, "participatory = citizen involvement type fisheries education" was promoted extensively. Future establishment of a Japanese version of Sea Grants is desired to promote citizen involvement in fisheries education with systematized involvement of universities, research institutions, aquaria, and local people.
\end{abstract}

Keywords: Matsubara Shinnosuke, fisheries (SUISAN) education, participatory fisheries education, sea grant college program, Japan

\section{Introduction}

Japan, surrounded by the sea, has been blessed with coastal bounties from ancient times. For Japanese, familiarization with fishing and ocean matters with enhanced understanding about oceans and their utilization is important for the construction of a sustainable society. At present however, opportunities to learn about fisheries and oceans are not sufficient. In 2001, the Fisheries Basic Act was enacted. Article 23 of the act stipulates that, "Measures to enrich understanding and concern of the public about fisheries industry should be taken" [1]. Furthermore in 2007, the Basic Act on Ocean Policy was enacted. Article 28 of the act mandates "promotion of education relating to ocean" [2]. Under such circumstances, the Japanese Society of Fisheries Science opened the "Children's Fisheries College" on its homepage as one 
activity to promote understanding of fisheries and oceans. The society has been performing activities, such as "presentation of research outcome by high school students" at spring, and autumn general social assemblies [3], publication of explanatory tests of the "Verseau Books" series, which explains special areas of fisheries in an easy-to-understand format, and the enhancement of education targeted at the general public, elementary school, middle school, and high school pupils and students. This report describes "fisheries education" related to the ocean, which has been conducted continuously from the Meiji period to the present day, with a review of the history of fisheries education, and exploration of the direction of future fisheries education and its historical transition.

\section{Dawn of fisheries (SUISAN) education in the Meiji period}

In 1880, Prof. S. Matsubara (first director of Imperial Fisheries Institute) who built up the foundations of fisheries education that have stood the test of time through the present day, visited Germany as the administrative official attending the Berlin International Exhibition. After graduating from Tokyo Medical School (present Faculty of Medicine, The University of Tokyo), Prof. Matsubara was teaching biology to medical school students and also working as the General Affairs official of the Agriculture Department. He completed a list of Japanese fishes in German, "Special-Katalog für die Japanische Abtheilung der Internationalen Fischerei-Ausstelung zu Berlin", and introduced it with scientific names in 1880 [4]. It is said that Europeans were astonished to find that as many as 600 kinds of Japanese fishes are listed, although fish species known in Germany were only 50 [5]. While staying in Europe, Prof. Matsubara probably realized that Japan is a seafaring nation surrounded by ocean and is blessed with resources of a bountiful sea. After returning, he wrote his “Observation of German Agriculture" [6] covering protection of fishery, fishery law, farming, fishery association, fishery academic surveys, and others that he experienced while staying in Germany. These observations resulted in the foundation of the Japanese Society of Fisheries, the first organization supporting the Japanese fisheries industry in 1882. At a convention held by the society in 1884, he presented his "Present and future of Japanese fisheries industry" [7], and forecasted that fishery resources, now abundant, will decrease due to fishing. He appealed for greater attention to the necessity of restrictions on fishery, improvement of aquaculture technology, and food processing technology. Prof. Matsubara wrote in his diary in 1908 that fishery, aquaculture, and food processing collectively referred to as "SUISAN", and the term was translated to "fisheries" in 1880s. Subsequently, he wrote the "Charter for Foundation of Fisheries Training Schools" [8], fisheries training schools were established aiming to improve local fisheries industry in November 1888 at Shiba, Minato-ward, Tokyo (believed to be Tokyo Joshi Gakuen at present) [9]. At the fisheries training school, K. Okamura, K. Uchimura, C. Sasaki, and S. Matsubara, as well as M. Sekisawa (the school Headmaster), delivered lectures [4]. Thus, full-scale fisheries education started in Japan. Furthermore, in "Personal opinion on fisheries expansion policy" issued in 1890 [5], he stated that "Topographical features of Japan are suited for fishery according to the statistics of 1887 , the number of fishery workers were $860,000(1,650,000$ according to the survey in 1881), whereas those of U.S. were 100,000 (1880), 
the U.K. were 160,000, and France were 150,000. It should be said that Japan has the greatest number of fishery workers in the world. Germany deems fish as a new resource, even though their coastal waters are narrow, and the U.S. is struggling to expand fishery activities as if they had already used their other resources completely, even though they still have the greatest land resources in the world. Japan is in a good position to promote fisheries businesses using natural geographical features, but its slow progress is regrettable." In 1893, rules for occupational training school [10] were enacted. After 1895, fisheries training schools were established throughout the nation for "teaching of businessmen through training schools" (fisheries expansion opinion). The first fisheries training school, founded at a higher elementary school in Miyako-cho, was run by the Kuwagasaki-ryocho Union [11]. In 1897, the fisheries training school was succeeded by the National Fisheries Training School to fulfill fisheries education. In 1899, fisheries schools were founded throughout the nation as a secondary educational institution by the Occupational School Ordinance. From 1896, fisheries training schools adopted fisheries teacher development courses to produce fisheries teachers to work actively in the nation [8].

As explained above, the Meiji period was the dawn of fisheries education. The framework of fisheries education constructed during this period continues to this day. Fisheries education aimed at "acquisition of fishing, aquaculture and food processing for the improvement of local fisheries industry" was instituted in every region of the nation. Foundations of fisheries education were established.

\section{Fisheries education after the war}

According to the educational system reform announced after the war, fisheries education for those before entering high school was performed in "vocational courses" taught in middle school. However, "vocational courses" were replaced by "technology and homemaking" in 1958, and fisheries education in middle school disappeared gradually [8]. Professional education for developing human resources to support local fisheries industries was conducted in fisheries high schools. Fisheries education for students was possible at fisheries high schools only. The government course curriculum guidelines issued in 1953 defined the objective of fisheries education as follows: "Occupational education in the high school is quite professional in all respects, each field requires special knowledge and technology particular to fisheries industries, and one should acquire wide knowledge about fisheries industries overall. Therefore, the general aim of occupational education should be met, and students are requested to understand each subject of the fisheries industry, operating fishing boats, carrying out fishery, aquaculture, food processing. (...) In short, the target is to nurture human resources who can participate in businesses immediately after entering the workforce, serve as a driving force for fisheries industry development and eventually reach mid-career success after obtaining technology and knowledge corresponding to demands of the real world." It seems apparent that, even after the war, objectives of fisheries education succeeded in fisheries education performed in the Meiji period, and that teaching of fisheries engineers was an important national objective. 
Differences between Meiji period education and postwar education were such that prewar secondary fisheries education placed importance on "mainly teaching of mid-career engineers contributing to development of local fisheries industry", whereas postwar education targeted "teaching of mid-career engineers for deep-sea fishing" as well as development of local fisheries industry and "fulfillment of construction of training ships and facilities and equipment" [12].

The background of placing emphasis on the teaching of mid-career engineer is such that the financial base of facilities and equipment such as training ships of fisheries high schools was strengthened after the Act on Promotion of Vocational Education was enacted in 1951. The first training ship constructed by governmental subsidies of said act was "Toyama Maru (222 GT)" of Toyama Prefecture. Because its haul was excellent, Toyama Maru was assigned as a model ship of deep-sea fishery training by the Ministry of Education, Culture, Sports, Science and Technology and many fisheries high schools participated in deep sea tuna longline fishing [13].

In 1952, the MacArthur line was abolished upon conclusion of the San Francisco Peace Treaty, and subsequent construction of fishing boats over 300 GT to be used for deep-sea fishing was promoted. The fishery course of fisheries high school immediately after the war aimed at acquisition of class B first officer qualification as one target. However, a class B first officer qualification cannot be used by captains of ships over 300 GT. Therefore, establishment of a specialist course to obtain class A second officer qualification, authorizing a person to serve as the captain of a ship over $300 \mathrm{GT}$, and upscaling of training ships were promoted nationwide. In 1952, specialist courses were established at fisheries high schools in Awa, Yaizu, and Hamada for the first time. Most students who finished this course played active roles in large fishing boats and the shipping industry. Their achievements resulted in successive establishment of specialist courses in fisheries high schools nationwide [12].

The fishing industry has been blessed greatly with innovation of science and technology and fish catches have increased accordingly. The White Paper on Science and Technology in 1962 reported that "Fish catches has been increasing by about 300,000 tons yearly thanks to progress of science and technology relating to the increased capability of fishing boats, progress of fishing technology, improvement of equipment and materials for fishing, cultivation of new fishing places, etc." [14].

However, because of oil shocks in 1972 and the 200-nautical-mile issue for fishing, the size of the deep-sea fishing system started to decrease. Fish catches reached their respective peaks in the 1980s and subsequently showed a downward trend. Under such circumstances, although large-sized training ship education was maintained, the number of deep-sea fishing boats decreased. In some cases, students were unable to find a job in fishing boats even after obtaining a ship officer diploma. Consequently, students who wished to enter fisheries high schools decreased and retention of fisheries high schools was regarded pessimistically. The Kumamoto Prefectural Fisheries High School stated in their journal commemorating their 45th anniversary that the "Postwar fishing industry continued to expand, greatly influenced by education provided at this school. The number of students continued to increase year by year. In 1973, no course of the school met its admission quota, probably because of influences of the first oil 
crisis. This eventuality was remarkable in fishing courses, and even at present, admissions have not yet recovered" [15]. The school has stated that severe circumstances related to the fishing industry are coupled directly with student recruitment.

\section{New fisheries education in the Heisei period}

The mainstream of fisheries education in fisheries high schools after the war was teaching of mid-career engineers using large training ships. However, because of social situations, changes in industrial structure, decreased employment offers for deep-sea fishing, etc., prospective students who wish to enter fisheries high schools decreased, and the continued existence of fisheries high schools became doubtful. During and after 1989, every school undertook improvement and review of fisheries education to cope with the demands of the new era. For example, Kyoto Prefectural Fisheries High School was quick to change their name to Ocean High School, and taught marine sports such as diving, boardsailing, yachting, etc. Iwate Prefectural Miyako Fisheries High School started investigation research activities in "research subjects" in which students themselves took the initiative in solving problems related to familiar themes such as aquatic marine environmental surveys and effective utilization of fisheries products. Miyazaki Prefectural Ocean High School regarded their training ship as a vessel of prefecture residents, and performed teacher training aggressively, planning experiential voyages for elementary school and middle school pupils and students to deepen their understanding about fisheries activities by residents. Ibaraki Prefectural Ocean High School constructed a large diving pool at the school geared to diving education such that they held training sessions for scuba-diving instructors. They targeted fisheries high school teachers and offered its use as the main site of an all-Japan fisheries and ocean high school diving championship. Shizuoka Prefectural Yaizu SUISAN High School streamlined learning environments, so that students can tackle fishing practical training voluntarily, such as pole-and-line fishing of tuna. During the Heisei period, fisheries high schools in the country actively promoted "research on given projects" to enhance students' independence and inquiry capability together with conventional, professional, and technical education, with originality and ingenuity of "integrated training" and regional contribution activities using their expertise to deepen citizens' understanding about fisheries. If conventional fisheries education for teaching of fisheries engineer is called "technology acquisition type fisheries education", then that education centering on enhancement of interest and concern of the learners, increased independence, and understanding of fisheries should be widely regarded as "participatory fisheries education" [16].

In parallel with such a flow of new fisheries education, according to the Life-long Learning Promotion Act enacted in 1992, career-long education [17], assigning importance to motivation and rewarding life of individuals, was regarded as the pillar instead of results-based education pursuing economic development. Furthermore, in 1998, the Act to Promote Specified Nonprofit Activities (nonprofit organization law) [18] was passed, the goal of supporting general citizens' activities to contribute to society was declared. At present, approximately 40,000 groups are established, of which 750 groups are engaged in education relating to the ocean [19]. 
It is noteworthy that many civic activities engaged in ocean-related education share a relation with fishing experiences or fish-eating experiences [20]. Such learning activities are of independent activities rooted in traditional cuisine, culture, and climate of every region. It might be said to be "participatory fisheries education" for the enhancement of understanding about fisheries industries.

In addition, government curriculum guidelines issued in 1998 included "time for integrated study" [21] and aimed at teaching of pupils' capabilities to solve a theme independently, in addition to improving physical and intellectual ability. Odaiba-gakuen Koyo Elementary School in Minato-ward, Tokyo is practicing observation of living things on tidal wetlands, nurturing Zostera beds, laver (Pyropia yezoensis) culture, etc. as school-wide environmental education of the sea. Mats-saki middle school in Ofunato City is pursuing enrichment of the understanding of major fisheries industries in the region through experiencing farming of wakame (Undaria pinnatifida) seaweed from seeding to harvest with the cooperation of the local fisheries workers' union. As described above, elementary schools and middle schools throughout the nation are promoting "participatory fisheries education" actively in cooperation with local activists and fisheries operators in "time for integrated study" [20]. Furthermore, Article 23 of the Fisheries Basic Act enacted in 2001 specifies, "Measures should be taken to deepen public understanding and concern about fisheries industries" [1]. Article 28 of the Basic Act on Ocean Policy enacted in 2007 specifies "promotion of public understanding of ocean", [2] thereby supporting such "participatory fisheries education".

The Japanese Society of Fisheries Science opened the "Children's Fisheries University" on its homepage. In 2000, started publication of the familiarization and enlightenment book "Verseau Books" jointly with Seizando Publishing Co., Ltd. which explains fisheries industries in a comprehensive and comprehensible way for the general public and for high school students. In addition, from 2007, the society has been helping with "presentation of research by high school students" [3]. From 2009, the fisheries education field has been newly added as a research field for academic papers presented at the spring and autumn general assembly of the Japanese Society of Fisheries Science.

\section{Direction of future fisheries education}

Since the dawn of fisheries education in Japan during the Meiji period, the mainstream of fisheries education in the country has been teaching professionals and fisheries engineers. Fisheries education starting from the Heisei period used, in addition to the above, "participatory fisheries education", which enhances independence of learners and deepens understanding of fisheries, rooted in the tradition of the region and food culture. "Participatory fisheries education" is a new activity that blossomed during the Heisei period. Throughout the nation, these activities have been enhancing the understanding of fisheries industries and the ocean. Certainly, "participatory fisheries education" emphasizes processes until an outcome is obtained, and does not result directly in technological development and increased income. Nevertheless, with this type of education, all local residents consider and discuss fisheries 
industries and the ocean, understand fisheries industries comprehensively, and make decisions and take action from a broad perspective. Thereby, independence and human power are strengthened, the region is activated, and a new field is created [22].

Such "participatory fisheries education" is a new trend that has been adopted long after the Heisei period. However, although every activity of this education is excellent as a subjective activity of individuals (points), organizational activities forming linear and planar relations have not been forthcoming. For further promotion of such approaches, development of concrete legal systems should be conducted such that, instead of mere technological development education, the upwelling of "participatory fisheries education" can be ranked definitely as a national project. Moreover, an organizational framework should be established to convert individual activities to a more solid linear and planar arrangement. Some ideas include institutionalization of fisheries, ocean-related universities, high schools, institutions, and social education facilities such as aquaria throughout the nation.

Here, the author would like to introduce a national project in the U.S. that has been promoting participatory ocean education among citizens. The U.S. has a Sea Grant College program (SGCP) [23] proposed by Dr. Spilhaus at the American Fisheries Society in the 1960s. SGCP, assisted primarily by the Sea Grant Office (SGO) of the federal government, assigned the Sea Grant College Office (SGCO) in universities in 33 states (coastal area across the U.S. and around Great Lakes including universities in Puerto Rico) and a Sea Grant College Extension (SGE) in each county to realize organized system at the federal government level, state government level, and local level. Furthermore, SGE is working together with citizens' groups such as NPO, aquaria, museums, schools, and research institutions in every region.

At present, 400 SGE staff members are actively working as agents, communicators, educators, and the like throughout the U.S. The SGE staff members are promoting participatory ocean education to enhance ocean literacy using research outcomes from universities, networks linking universities, and regional networks using workshops, research meetings, videos, webpage design, radio shows, etc.

For instance, at the Florida Sea Grant College, a management office (SGCO) has been established within University of Florida. The SGE office is provided in 29 of 36 counties as a subordinate institution, and professional staffs are stationed in each SGE office. In Escambia county, located in western Florida, Mr. Andrew Diller is stationed as the SGE program specialist providing workshops on oceanic environmental education, coastal organisms, and marine turtle education for adults and children. Such quiet dedication in every region brings remarkable fruit to regional development [22]. The author would like to propose establishment of a "Japanese version Sea Grant" to promote "participatory fisheries education" actively in every region.

In areas stricken by the Great East Japan Earthquake on March 11, 2011 disaster, such momentum is being fostered that understanding of our bountiful ocean should be enhanced through experiential activities instead of emphasizing the horrors of the sea and distancing children from oceans [24]. To support reconstruction of the Sanriku coastal region, Iwate University, working together with Kitasato University, and fisheries universities such as the 
Tokyo University of Marine Science and Technology, established the Kamaishi satellite, the headquarters of Sanriku reconstruction promotion, and extension centers in each coastal city [25]. It is expected that such Kamaishi satellite and extension centers in each coastal area will become a precursor of a "Japanese version Sea Grant", contributing to the development of "participatory fisheries education" and acting as the nucleus of Sanriku reconstruction supported primarily by local residents.

\section{Acknowledgements}

The author would like to express his appreciation to Ms. H. Iwamatsu, Library of Tokyo University of Marine Science and Technology who contributed greatly to the collection and sorting of data related to SUISAN education.

\section{Author details}

Tsuyoshi Sasaki

Address all correspondence to: t-sasaki@kaiyodai.ac.jp

Department of Marine Science and Technology, Tokyo University of Marine Science and Technology, Tokyo, Japan

\section{References}

[1] Fisheries Agency: “Fisheries Basic Act." http://www.jfa.maff.go.jp/j/policy/ kihon_keikaku/aramasi/kihonhou.html (Accessed 2011-01-03).

[2] Headquarters for Ocean Policy: “Basic Act on Ocean Policy.” http://www.kantei.go.jp/ jp/singi/kaiyou/konkyo7.pdf (Accessed 2011-01-03).

[3] T. Sasaki (2007) Research paper presentation by high school students at The Japanese Society of Fisheries Science, "Journal of The Japanese Society of Fisheries Science" 73:1214-1216.

[4] H. Iwamatsu (2010) Bust before center lecture hall, No.1, S. Matsubara, Director of Suisan Training School, "Rakusui" 831:23-26.

[5] S. Matsubara (1891) Personal opinion on Suisan industry expansion policy. Japan Fisheries Association. p. 50.

[6] S. Matsubara (1881) Observation of agriculture in Germany, Agriculture Bureau. Ministry of Agriculture. p. 53. 
[7] S. Matsubara (1884) Present and future of Japanese Suisan industry. Newsletter of Japan Fisheries Association. p. 32.

[8] F. Katayama (1937) History of Japanese Suisan. Agriculture and Suisan Company. pp. 593-724.

[9] T. Arimoto (2012) Long history of Tokyo Bay - 123 years of Ocean Science Department, "Conference of Thinking of SUISAN II."

[10] H. Yamagishi (1984) Industrialization and occupational education in Japan. University of Tokyo Press. p. 380.

[11] S. Kawabata (2007) Reconsidering school history - The oldest school in Japan, Commemoration of 100th Anniversary of Iwate Prefectural Miyako Suisan High School. pp. 58-59.

[12] M. Nakatani (2004) History of ocean education. Seizando-Shoten Publishing. p. 182.

[13] Toyama Prefectural Suisan High School (2007) "100 years of Tomisui": 56.

[14] Ministry of Education, Culture, Sports, Science and Technology: "White Paper on Science and Technology in 1962." http://www.mext.go.jp/b_menu/hakusho/html/ hpaa196201/hpaa196201_2_114.html (Accessed 2012-4-3).

[15] Kumamoto Prefectural Suisan High School (1986) Journal Commemorating 45th Anniversary of Suisan education. pp. 262-266.

[16] T. Sasaki (2011) Approach for regional contribution activity by Suisan and ocean related high schools, "Journal of The Japanese Society of Fisheries Science" 77: 419-420.

[17] Ministry of Education, Culture, Sports, Science and Technology: "Law concerning lifelong learning promotion measures execution system." http://law.e-gov.go.jp/htmldata/ H02/H02HO071.html (Accessed 2011-01-03).

[18] Ministry of Education, Culture, Sports, Science and Technology: "Act to Promote Specified Nonprofit Activities." http://law.e-gov.go.jp/htmldata/H10/H10HO007.html (Accessed 2011-01-03).

[19] Y. Suenaga: "Basic Act on Ocean Policy and ocean education in Japan," International Ocean Education Review Session. http://140.111.34.34/docdb/files/ dma7d90c0e0b303a0ca.pdf (Accessed 2010-12-10).

[20] K. Teramoto, T. Sasaki, M. Tsunoda (2010) Sato-Umi Tanteidan (Ocean-human relationship Explorer). Nobunkyo. p. 165.

[21] Ministry of Education, Culture, Sports, Science and Technology: "Notification No. 175 by the ministry." http://www.mext.go.jp/b_menu/shuppan/sonota/990301b.htm (Accessed 2011-01-03).

[22] T. Sasaki (2011) Theory and practice of hydrosphere environmental education. Seizando-Shoten Publishing. p. 214. 
[23] Sea Grant College Office (2010) Fundamentals of Sea grant. Extension Program. Sea Grant College. p. 59.

[24] T. Sasaki (2011) Learning from great earthquake, "Lecture meeting by Kanto branch office of The Japanese Society of Fisheries Science in fiscal."

[25] T. Sato (2012) Encounter with Great Eastern Japan Earthquake and approach to reconstruction, "Monthly Report of The Japan Economic Research Institute" 405:48-55. 
Chapter 9

\title{
Fishery Status and Taxonomy of the Carangids (Pisces) in the Northern Arabian Sea Coast of Pakistan
}

\author{
Nazia Qamar, Sher Khan Panhwar and \\ Ghazala Siddiqui \\ Additional information is available at the end of the chapter
}

http://dx.doi.org/10.5772/62627

\begin{abstract}
The objectives of this study were i) to evaluate number of existing members of the family Carangidae in the area ii) to establish a distinguishable and lucid key based on the taxonomic characteristics, meristic count and otolith description. In this study, thirtysix species were collected from the main fish landing facilities between 2012 2015. Fish body colour, taxonomic characteristics, fin rays and otolith shape description were used to identify each species. Otolith description comprises of shape of ostium, sulcus and margins of anterior and posterior surface along with distinct definite shape possess by each species make it easier for identification.

This species catalogue would treasure and latest information on the existing species of the family Carangidae in the area, and provide an ease to identification especially for closely resembling species. In addition, this list includes seven unreported species from the area.
\end{abstract}

Keywords: Carangidae, taxonomy, otolith, Fishery, Northern Arabian Sea Coast, Pakistan

\section{Background information}

Family Carangidae comprises 140 species and is widely distributed throughout the Western Indian Ocean and Western Pacific, from Japan to Australia and eastward to Fiji [1-3] (Table 1). The carangids inhabit coastal, estuarine, and marine waters of tropical, subtropical, and temperate regions. This family has attracted many researchers around the world due to its recognition for sport fishing, recreational, and substantial marketable 
value particularly species of Scomberoides, Megalaspis, Parastromateus, and Caranx. Genus Scomberoides comprises of four species: S. commersonnianus, S. lysan, S. tala, and S. tol found in the Indian Ocean. In terms of biomass, many species of this family are well known for instance [4] recorded $27.2 \mathrm{~kg}$ Caranx hippos, this fish species is considered as a recreational and commercial throughout its wide distribution. Popularity of jacks in game fishing highlighted [5,6] and added that because of huge demand and human consumption indicated that stocks of such fishes have been gradually depleting throughout the world. The carangids has specific role in food web and ecosystem such as these are large predatory species exclusively feeds on clupeid, engraulid, trichurid, cuttlefish [7]. They are active swimmer fishes, pelagic, and gregarious, live in turbid water by forming school (small to large) or solitary, in clear water [8]. Most of the species rather common in the inshore reef, coastal or in shore waters within the depth range of 20-100 m. Some species such as Carangoides ferdau and C. hedlandensis are benthic confined to 100-200 m depth [8]. Recently, Panhwar et al. and Qamar et al. $[9,10]$ documented the population dynamics of Megalaspis cordyla, Scomberoides commersonnianus, and S. tol in Pakistan. Skeletal anomalies found in $M$. cordyla collected from Karachi fish harbor and Ormara based on x-ray photograph was also reported [11].

\begin{tabular}{|c|c|c|c|c|}
\hline Author & Year & Location & Genera & Species \\
\hline Present study & 2015 & Northern Arabian Sea Coast of Pakistan & 19 & 36 \\
\hline Abdussamad et al. [14] & 2013 & Tuticorin, India. & 20 & 60 \\
\hline Matsunuma et al. [15] & 2011 & East coast of Malay peninsula, Malaysia & 15 & 27 \\
\hline Quigley [16] & 2007 & North-Eastern Atlantic \& Mediterranean & 14 & 25 \\
\hline Kuiter [17] & 2000 & South-eastern Australia & 13 & 23 \\
\hline Gunn [18] & 1990 & Australia & 18 & 63 \\
\hline Huda [19] & 1988 & Pakistan & 16 & 34 \\
\hline Farooq and Niazi [20] & 1988 & Pakistan & 4 & 9 \\
\hline Bianchi (FAO) [1] & 1985 & Pakistan & 20 & 42 \\
\hline Laroche et al. [21] & 1984 & World wide & 30 & 140 \\
\hline Nelson [22] & 1984 & World wide & 32 & 140 \\
\hline Fischer \& Bianchi [8] & 1983 & Indian ocean & 22 & 65 \\
\hline Jalil \& Khaliluddin [23] & 1972 & Pakistan & N/A & 24 \\
\hline
\end{tabular}

*Courtesy by Ahmed M, Marine Fisheries of Pakistan, 1985.

Table 1. List of genera and species of the family Carangidae reported around world.

Torpedo trevally, Megalaspis cordyla is monotypic schooling species and comprises approximately $25 \%$ in terms of biomass to the family Carangidae in Pakistan. Marine fisheries statistics indicated highest landing (9722 mt) in 2001 and the lowest (3559 mt) in 2008 [11]. However, no separate data for queenfishes are recorded by MFD, though the 
members of Scomberoides genus have largely contributing in the capture fishery of the country, but recent trends indicated that the landing of genus Scomberoides has been reduced from 17,779 MT in 1999 to 9073 MT in 2009 [12]. The major portion of the catch belongs to S. commersonnianus whereas torpedo trevally, Megalaspis cordyla is also landed in sufficient quantity recorded at the major fish landing sites. The FAO, 2012 has figured out landing records of S. commersonnianus in the Western Indian Ocean, which have increased from 4994 in 2001 to 11,374 in 2010 [13]. In the local market, talang queen fish is mainly sold at approximately US\$ $2-3 / \mathrm{kg}$, whereas needle scaled queenfish, and torpedo trevally at approximately US\$ 1-2 and 0.5 and $1.5 \mathrm{~kg}$, respectively, depends upon the premium to the lowest quality. Carangids mainly caught with gill nets, seines on hook and line and trawl nets. The seasonal variations in the landings of $S$. commersonnianus showed higher quantities in between the period of August to October (Katti) and smaller quantities in April to May (Cheeta) following in June to July (Unaro) due to the excessive monsoon currents and closed fishing season in the area [1].

This family encompasses a diverse group of fishes known variously by common names such as jacks, scads, pompanos, queen fishes, king fishes, and trevallies, among others, which are characterized by variable body shapes elongated, fusiform to extremely ovate and strongly compressed [22, 24, 25]. The characteristics features of carangids are the presence of elongated Pterygiophores and one or two anal spines often embedded in adults [26], deeply forked caudal fin with equal lobes, slender caudal peduncle [27], and a distinctive swimming mode known as "carangiform" responsible for the name of this family [28]. A detailed description, comparison, ecological distribution, and key characters of the carangids documented from the Australian waters [18]. Abdussamad et al. [14] have reported occurrence of 60 species belonging to 20 genera of the family Carangidae based on macrotaxonomic characters from Indian waters. Further, they added a new morphological feature based on the first dorsal fin for the differentiation of carangids: group I, first dorsal fin is absent such as genus Parastromateus and Alectis; group II, described as modification of first dorsal fins into spines such as Genus Scomberoides, Trachinotus, and Naucrates; group III, well-developed first dorsal fin with spiny rays such as genus Megalaspis, Elagatis, Decapterus, Seriolina, Seriola, Atropus, Ulua, Uraspis, Gnathanodon, Carangoides, Alepes, Caranx, Selaroides, Atule, and Selar.

In Pakistani waters, the number of species is not clearly known, since Bianchi [1] identified 42 and Huda [19] 34 species. Nevertheless, the family Carangidae is a dominant finfish group in these waters contributing a major contribution of the commercial fisheries resources. According to Bianchi [1], species representing four subfamilies (tribes) of carangids in Pakistani waters: Alectis ciliaris A. indicus, Alepes djedaba, A. melanoptera, A. vari, Atropus atropos, Atule mate, Carangoides caeruleopinnatus, C. chrysophrys, C. ferdau, C. fulvoguttatus, C. gymnostethus, C. malabaricus, C. bajad, C. hedlandensis, C. oblongus, C. plagiotaenia, C. praeustus, C. talamparoides, Caranx ignobilis, C. melampygus, C. sexfasciatus, C. para, Decapterus macrosoma, D. russelli, Elagatis bipinnulata, Gnathanodon speciosus, Megalaspis cordyla, Naucrates ductor, Parastromateus niger, Scomberoides commersonniansus, S. lysan, S. tol, Selar crumenophthalmus, Selaroides leptolepis, Seriolina nigrofasciata, Trachinotus africanus, T. baillonii, T. blochii, T. mookalee, Trachurus indicus, Uraspis secunda. 
In the present study, various surveys of major fish landing sites were made along the Sindh and Baluchistan coast during 2012-2015 to evaluate number of existing species of the family Carangidae in Pakistani waters. In these surveys, thirty-six species were identified with seven new from the area, namely Alepes kleinii, Carangoides armatus, Caranx sem, Scomberoides tala, Seriola dumerili, Trachinotus russelii, Uraspis uraspis. The morphometric and meristic count was taken for each specimen following the protocols of Smith-Vaniz [27]: Standard length(S L), head length (HL), curve and straight lateral line length (CLL, SLL), number of gill rakers (upper and lower), number of spines and fin rays, number of lateral line scales and scutes, number of anal spine, pattern of breast squamition, type of adipose eyelid, and all possible body measures. The parameters of each sagittal otolith such as length, height, weight, and shapes of cauda, ostium, excisura, and sulcus acusticus were recorded. Finally, the sex identification was established from macroscopic observation based on color pattern and size of the gonad [29].

The study was aimed to prepare a species catalogue with otolith descriptions for the available species of the family Carangidae to provide an ease in taxonomic identification of closely resembling species on the basis of characteristics derived from [18, 27] (Table 2), (Figure 1).

\begin{tabular}{|c|c|c|c|c|c|c|c|}
\hline \multicolumn{2}{|c|}{ Serial Species (N) } & \multirow{2}{*}{$\begin{array}{l}\text { Author name } \\
\text { Bloch, } 1788\end{array}$} & \multicolumn{2}{|c|}{ TL FL GIRTH BW } & \multicolumn{3}{|c|}{ OL/TL OH/OL OW } \\
\hline 1 & Alectis ciliaris (2) & & $43 \quad 39.526 .2$ & 895 & 50 & 2.2 & $0.0037 \mathrm{M}$ \\
\hline 2 & Alectis indicus (4) & Rüppell, 1830 & 23.520 .524 & 108.4 & 50 & 2.1 & $0.0048 \mathrm{~F}$ \\
\hline 3 & Alepes djedaba (18) & Forsskål, 1775 & $24 \quad 21.819 .5$ & 270 & 27 & 2.6 & $0.0048 \mathrm{M}$ \\
\hline 4 & Alepes kleinii (16) & Bloch, 1793 & 17.614 .812 .8 & 50 & 50 & 2.4 & $0.0034 \mathrm{M}$ \\
\hline 5 & Alepes melanoptera (5) & Swainson, 1839 & $17.515 \quad 11.5$ & 52 & 44 & 2.1 & $0.0029 \mathrm{M}$ \\
\hline 6 & Alepes vari (9) & Cuvier, 1833 & $22.119 \quad 14.2$ & 101.75 & 524 & 2.3 & $0.0047 \mathrm{~F}$ \\
\hline 7 & Atropus atropos (25) & Schneider, 1801 & 15.813 .516 & 60 & 57 & 2.1 & $0.0009 \mathrm{M}$ \\
\hline 8 & Atule mate (15) & Cuvier, 1833 & $27 \quad 23.416$ & 61.08 & 45 & 2.1 & $0.0054 \mathrm{M}$ \\
\hline 9 & Carangoides armatus (4) & Rüppell, 1830 & $\begin{array}{lll}37 & 32 & 29\end{array}$ & 85 & 43 & 2.5 & $0.011 \mathrm{~F}$ \\
\hline 10 & Carangoides chrysophrys (7) & Cuvier, 1833 & 21.418 .518 .5 & 136.47 & 744 & 2.4 & $0.0022 \mathrm{M}$ \\
\hline 11 & Carangoides hedlandensis (12) & Whitley, 1933 & $18.116 \quad 15$ & 51 & 40 & 2.9 & $0.010 \mathrm{M}$ \\
\hline 12 & Carangides malabaricus (20) & Bloch \& Schneider & 2319.817 & 113 & 56 & 2.5 & $0.0042 \mathrm{~F}$ \\
\hline 13 & Carangoides praeustus(18) & Bennett, 1830 & 20.818 .214 & 94 & 44 & 2 & $0.0039 \mathrm{~F}$ \\
\hline 14 & Caranx ignobilis(3) & Forsskål, 1775 & 28.524 .521 & 265.4 & 36 & 1.9 & $0.0054 \mathrm{M}$ \\
\hline 15 & Caranx para (2) & Cuvier, 1833 & $16.515 \quad 13$ & 53.5 & 44 & 2.7 & $0.0039 \mathrm{M}$ \\
\hline 16 & Caranx sem (2) & Cuvier, 1833 & $76 \quad 69.549$ & 4000 & 36 & 0.7 & $0.0055 \mathrm{M}$ \\
\hline 17 & Caranx sexfasciatus (17) & Quoy \& Gaimard, 1824 & $19 \quad 16.313$ & 83 & 38 & 2.5 & $0.0069 \mathrm{M}$ \\
\hline 18 & Decapterus russelli (22) & Rüppell, 1830 & 19.518.59.5 & 60.8 & 58 & 3.6 & $0.0041 \mathrm{~F}$ \\
\hline 19 & Elagatis bipinnulata (03) & Quoy \& Gaimard, 1824 & $35 \quad 28.516$ & 271 & 40 & 1 & $0.0024 \mathrm{M}$ \\
\hline
\end{tabular}




\begin{tabular}{|c|c|c|c|c|c|c|c|}
\hline \multicolumn{2}{|c|}{ Serial Species (N) } & \multirow{2}{*}{$\begin{array}{l}\text { Author name } \\
\text { Forsskäl, } 1775\end{array}$} & \multicolumn{2}{|c|}{ TL FL GIRTH BW } & \multicolumn{3}{|c|}{ OL/TL OH/OL OW } \\
\hline 20 & Gnathanodon speciosus (02) & & 20.818 .514 & 94 & 56 & 1.8 & $0.0027 \mathrm{~F}$ \\
\hline 21 & Megalaspis cordyla (298) & Linnaeus, 1758 & 42.738 .722 & 710 & 50 & 2.5 & $0.0015 \mathrm{M}$ \\
\hline 22 & Parastromateus niger (56) & Bloch, 1975 & 25.627 .224 & 320 & 56 & 1.8 & $0.0027 \mathrm{~F}$ \\
\hline 23 & Scomberoides commersonnianus (1044) & Lacepêde, 1802 & 64.356 .134 .5 & 1900 & 33 & 2 & $0.0016 \mathrm{~F}$ \\
\hline 24 & Scomberoides lysan (18) & Forsskäl, 1775 & $\begin{array}{lll}73 & 63 & 32.5\end{array}$ & 2200 & 38 & 1.1 & $0.0078 \mathrm{M}$ \\
\hline 25 & Scomberoides tala (9) & Cuvier, 1832 & $51 \quad 43.528$ & 213.9 & 38 & 1.6 & $0.0083 \mathrm{~F}$ \\
\hline 26 & Scomberoides tol (255) & Cuvier, 1832 & $\begin{array}{lll}68 & 59 & 24.5\end{array}$ & 1700 & 38 & 1.4 & $0.0079 \mathrm{M}$ \\
\hline 27 & Selar crumenophthalmus (23) & Bloch, 1793 & $21 \quad 19.512$ & 93.2 & 60 & 2.4 & $0.0081 \mathrm{M}$ \\
\hline 28 & Selaroides leptolepis (8) & Cuvier, 1833 & $17 \quad 15 \quad 12$ & 62.18 & 63 & 2.6 & $0.0046 \mathrm{~F}$ \\
\hline 29 & Seriola dumerili (10) & Risso,1810 & 21.31912 .5 & 95 & 40 & 1.7 & $0.003 \mathrm{M}$ \\
\hline 30 & Seriolina nigrofasciata (14) & Rüppell, 1829 & 35.131 .619 .6 & 405.5 & 56 & 1.3 & $0.003 \mathrm{~F}$ \\
\hline 31 & Trachinotus baillonii (4) & Lacepêde, 1801 & $15.814 \quad 15$ & 55.8 & 44 & 23 & $0.0021 \mathrm{M}$ \\
\hline 32 & Trachinotus blochii (6) & Lacepêde, 1801 & $26 \quad 22 \quad 23$ & 226 & 49 & 2.5 & $0.0017 \mathrm{M}$ \\
\hline 33 & Trachinotus mookalee (6) & Cuvier, 1832) & 27.822 .822 & 238 & 50 & 1.5 & $0.0029 \mathrm{M}$ \\
\hline 34 & Trachinotus russelii (4) & Cuvier, 1832 & $54 \quad 40 \quad 32$ & 1200 & 27 & 23 & $0.0058 \mathrm{M}$ \\
\hline 35 & Trachurus indicus (3) & Nekrasov, 1966 & $27.624 \quad 14$ & 168 & 50 & 2.9 & $0.0229 \mathrm{~F}$ \\
\hline 36 & Uraspis uraspis (8) & Günther, 1860 & 25.622 .521 .4 & 257.5 & 27 & 2.3 & $0.0015 \mathrm{~F}$ \\
\hline
\end{tabular}

Table 2. Summary of the length and otolith data of the 36 species and sex.
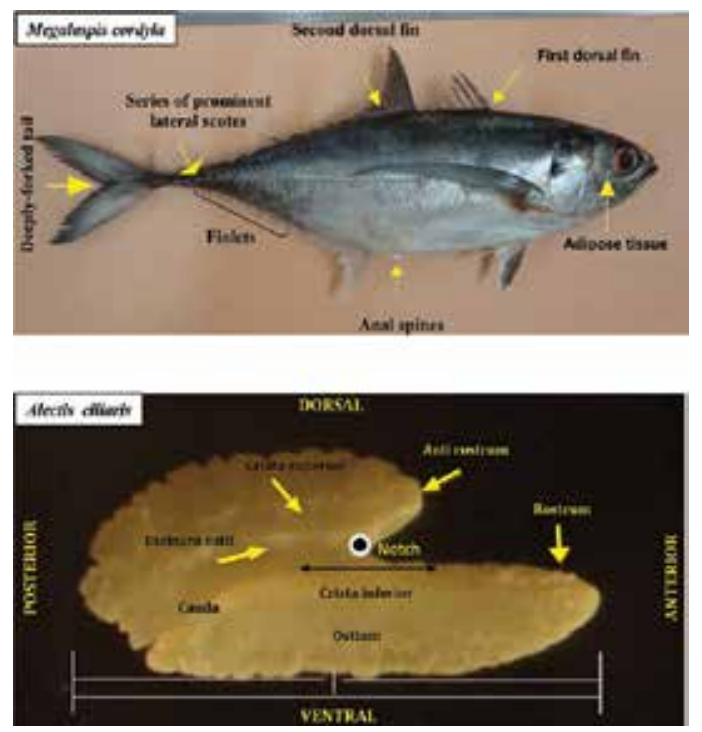

Figure 1. General Description of Fish and Otolith. 


\section{Morphological and otolith descriptions 36 species}

\subsection{African pompano, Alectis ciliaris}

Body has ovate (to pentagonal) shape, strongly compressed, tapering evenly from midpoint posteriorly and elongated with growth. Dorsal and ventral profile is equally convex. Eye is large and greater than snout length. Mouth is low with protractile jaws. Villiform tooth are arranged in bands in lower jaw, villiform teeth also present in tongue, palatines, and vomer. Maxilla extends two-thirds behind of eye. Head large comprised 30\% of FL and nape is rounded. Gill rakers 5 upper and 13 on the lower limb of first gill arch. Dorsal fin with 7 shortfree embedded spines. Second soft dorsal fin with 1 spine followed by 19 rays. First 7-8 rays of soft dorsal and anal fin are elongated and filamentous in juveniles. Pectoral fin long, falcate, extended beyond the straight lateral line and greater than pelvic fin. In juveniles, pelvic fin is elongated. Anal fin with 1 spine followed by 19 rays, and caudal fin is deeply forked. Lateral line is strongly concave above pectoral fin, deeply arched and junction of curved and straight lateral line is below 12-14 dorsal soft rays. Curve lateral line is greater than straight lateral line, straight lateral line with 22 scutes. Scales are minute and deeply embedded in the skin, in juveniles, 5-7 crosses extensive bands throughout the body present (Figure A1).

Otolith shape: lanceolated. Margins: dorsoventrally crenate. Sulcus acusticus: heterosulcoid, ostiocaudal, median in position. Ostium: funnel-like shorter than cauda. Cauda: tubular and elliptic in shape, slightly curved ending closed to the postero ventral region. Anterior region: lanceolated; rostrum narrow, elongated, and pointed; antirostrum short, broad, pointed; excisura wide " $v$ " shaped with a deep notch. Posterior region: oblique - round (Figure A2).

\subsection{Indian threadfish, Alectis indicus}

Body has ovate to pentagonal shape, strongly compressed, tapering evenly with midpoint posteriorly and strongly compressed laterally. Dorsal and ventral profile is evenly convex. Eyes are small and about half the length of snout. Mouth is low with protractile jaws, villiform teeth are arranged in bands in lower jaw and also present on tongue, palatines, and vomer. Teeth are absent in adults. Maxilla extends slightly before the anterior margin of eye. Head is angledshaped, large and comprises 33\% of FL. Gill rakers: 8 upper and 21 in the lower limbs of first gill arch. Dorsal fin with 7 short-free embedded spines. Second soft dorsal fin with 1 spine followed by 20 rays. First five rays of soft dorsal and anal fin are elongated and filamentous in young. Pectoral fin is long, falcate, reaching the straight lateral line, and equal than HL. In juveniles, pelvic fin is elongated. Anal fin with 1 spine followed by 16 rays. Caudal fin is deeply forked and $28 \%$ of FL. Lateral line is strongly concave above pectoral fin and deeply arch and junction of curved and straight lateral line is below sixth dorsal soft rays. Curve lateral line is greater than straight lateral line. Straight lateral line with 4 scales and 14 weak scutes. Scales are minute and deeply embedded in the skin (Figure B1).

Otolith shape: oblong. Margins: dorsal sinuate, ventral crenate. Sulcus acusticus: heterosulcoid, ostial, median in position. Ostium: funnel-like. Cauda: elliptic, straight ending close to the 
ventral margin. Anterior region: peaked; rostrum broad, long, rounded; antirostrum absent; excisura wide without notch. Posterior region: oblique (Figure B2).

\subsection{Shrimp scad, Alepes djedaba}

Body has fusiform shape, strongly compressed. Dorsal and ventral profile is evenly convex. Eye is covered with adipose eyelid posteriorly. Snout is pointed and equal to eye diameter about $25 \%$ of HL. Superior maxilla is large, slightly concave posteriorly. A single row of minute comb-like teeth present in row on both jaws. Minute teeth also present in tongue, vomer, and palatines. Shoulder girdle margin is smooth and without papilla. Head length is about $25 \%$ of FL. Gill rakers 10 upper and 29 lower, in first gill arch.

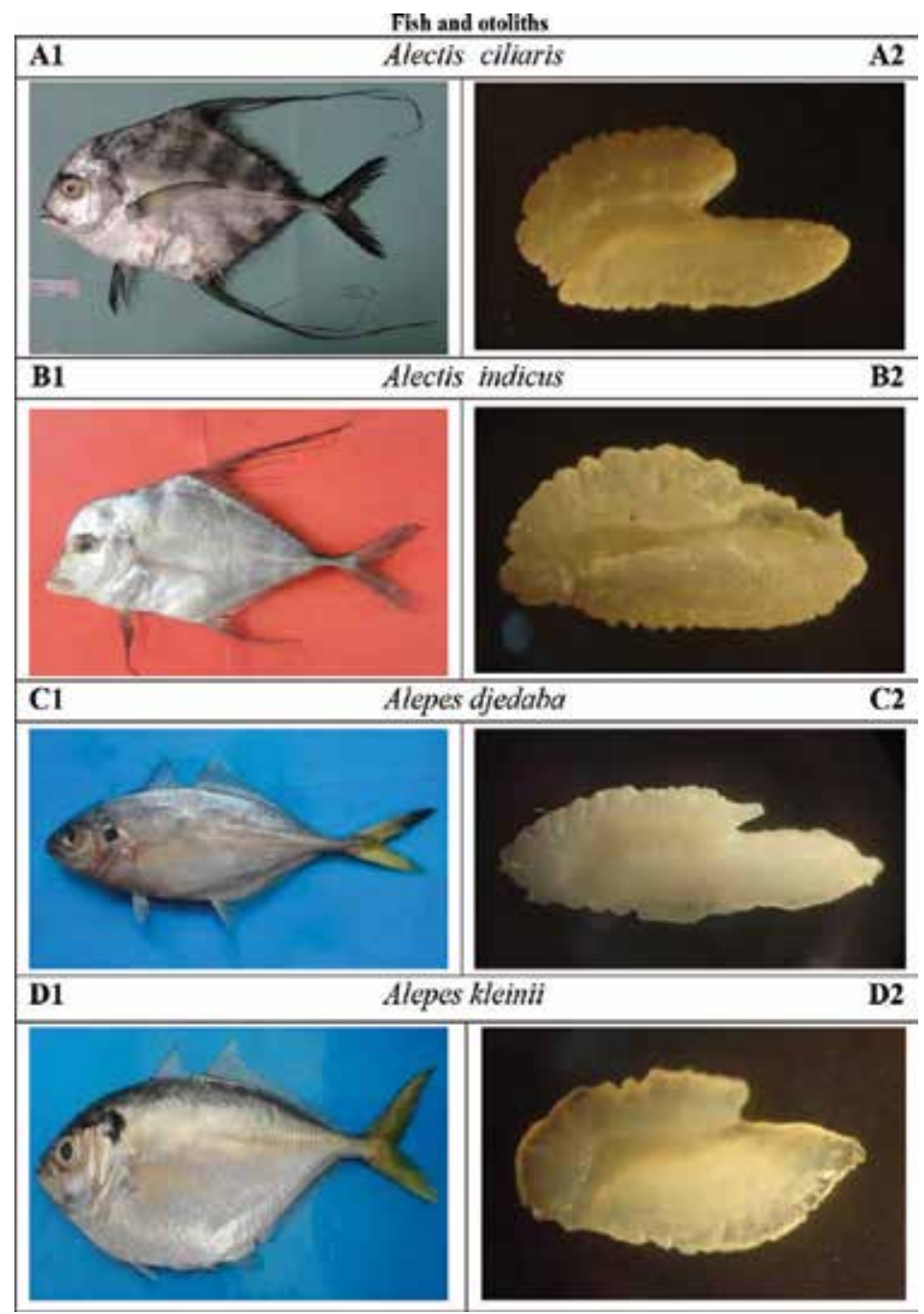


First dorsal fin is membranous, with 8 spines (third spine is moderately high), second dorsal fin with 1 spine followed by 25 rays. Two detached anal spines are present. Anal fin with 1 spine and 19 soft rays. Pectoral fin is long and falcate about 33\% of FL. Dorsal fin is low, anal fin slightly falcate. Caudal fin is deeply forked about $26 \%$ FL. The distance from snout to anal fin origin is $51 \%$ FL. Curved lateral line is shorter than straight line and junction is below second soft dorsal fin rays. Curve lateral line with 33 scales and straight lateral line with 2 scales and 46 scutes (Figure $\mathbf{C} \mathbf{1}$ ).

Otolith shape: lanceolated. Margins: dorsal margine crenate, ventral margin irregular. Sulcus acusticus: heterosulcoid, ostial, median. Ostium: funnel-like. Cauda: tubular, strongly curved ending close to the ventral margin. Anterior region: peaked; rostrum broad, long, pointed; antirostrum short, narrow, pointed; excisura wide a shallow notch. Posterior region: oblique (Figure C2).

\subsection{Razorbelly scad, Alepes kleinii (new record)}

Body has oblong shape, laterally compressed. Ventral profile is more convex than dorsal profile. Eye diameter is equal to snout length. Posterior half of the eye is covered with adipose eyelid. Maxilla is slightly concave posteriorly. Tiny comb-like teeth arranged in band is present in upper jaw. Opercular spot is very distinct. Head length comprises of $24 \%$ FL. Gill rakers 10 in upper limb and 24-28 in lower limb.

Two separate dorsal fin. First dorsal fin is membranous with 7-8 spines. Second dorsal fin with 1 spine followed by 20-23 soft rays. Pectoral fin is long and falcate. Pelvic fin is short and hyaline. Anal fin with 2 detached anal spines and 1 spine followed by 18-20 soft rays. Caudal fin is deeply forked about $33 \%$ of the FL. Vertical 9-10 brownish band equal in width are present above the lateral line. Curve lateral line is shorter than straight lateral line. Scales on curve lateral line are $28-31$, and scutes on straight lateral line are 32-40. Junction of CLL and SLL is below the seventh-eighth ray of second dorsal fin (Figure D1).

Otolith shape: lanceolated. Margins: dorsal margin irregular, ventral margin crenate. Sulcus acusticus: heterosulcoid, ostial, median. Ostium: funnel-like. Cauda: tubular, strongly curved ending close to the posterior margin. Anterior region: peaked; rostrum broad, medium, pointed; antirostrum short, broad, round; excisura wide with a shallow notch. Posterior region: round (Figure D2).

\subsection{Blackfin scad, Alepes melanoptera}

Body has oblong shape, moderately compressed. Dorsal and ventral profile evenly convex. Eye covered with adipose eyelid posteriorly. Snout is pointed and equal to eye. A single row of minute uniserate, comb-like teeth present in row on both jaws. Biserate dentition on premaxilla. Maxilla ends at the center of eye. Head length about $24 \%$ forked length. Gill rakers 9 upper and 23 lower, in first gill arch. Smooth Shoulder girdle margin without papillae.

First dorsal fin is membranous, with 8 spines, second dorsal fin with 1 spine followed by 24 rays. Two detached anal spines are present. Anal fin with 1 spine and 18 soft rays. Pectoral fin 
long and falcate about 30\% forked length. Longest spine of first dorsal fin about equals to second dorsal fin. Soft dorsal fin low, anal fin slightly falcate. Caudal fin deeply forked about $28 \%$ forked length. The distance from Snout to anal fin origin is $57 \%$ forked length. Curved lateral line shorter than straight line and junction below second soft dorsal fin rays. Chord of curved line 2.2 times shorter than straight lateral line. Curve lateral line with 30 scales and straight lateral line with 4 scales and 50 scutes (Figure E1).

Otolith shape: lanceolated. Margins: crenate. Sulcus acusticus: heterosulcoid, ostial, median. Ostium: funnel-like. Cauda: tubular, slightly curved at the end, ending far from the ventral margin. Anterior region: peaked; rostrum narrow, long, pointed; antirostrum absent or few developed; excisura wide without notch. Posterior region: oblique (Figure E2).

\subsection{Herring scad, Alepes vari}

Body has fusiform shape, moderately compressed. Dorsal and ventral profile evenly convex. Eye is covered with adipose eyelid posteriorly. Snout is pointed and greater than eye. A single row of minute uniserrate, comb-like teeth present in row on both jaws. Bi-serrate dentition in premaxilla. Maxilla extends to one-third of eye. Head length is about $24 \%$ of FL. Gill rakers 10-12 upper and 26-29 lower, in first gill arch. Smooth shoulder girdle margin without papillae.

First dorsal fin is membranous, with 8 spines, second dorsal fin with 1 spine followed by 20 25 rays. Two detached anal spines are present. Anal fin with1 spine and 19 soft rays. Pectoral fin is long and falcate about $27 \%$ of FL. Longest spine of first dorsal fin is shorter than second dorsal fin. Soft dorsal fin is low, anal fin slightly falcate. Caudal fin is deeply forked about $26 \%$ of FL. The distance from snout to anal fin origin is $50 \%$ of FL. Curved lateral line is shorter than straight line, and junction is below third soft dorsal fin rays. Chord of curved line is $2.1-2.5$ times to straight lateral line. Curve lateral line with $38-42$ scales and straight lateral line with 2 scales and 50-55 scutes (Figure F1).

Otolith shape: fusiform. Margins: dorsal margin sinuate, ventral margin crenate. Sulcus acusticus: heterosulcoid, ostial, median in position. Ostium: funnel-like longer than cauda. Cauda: tubular, markedly flexed posteriorly from the ventral margin. Anterior region: peaked; rostrum broad, elongated, pointed; antirostrum short, peaked; excisura wide with a small shallow notch. Posterior region: oblique (Figure F2).

\subsection{Cleftbelly trevally, Atropus atropos}

Body is ovate, strongly compressed. Nape profile is convex. Eye is equal or slightly larger to snout length. Narrow band of teeth is present on upper jaw. Lower jaw with a single series of teeth. Head is about $26 \%$ of FL. Gill rakers upper 9, lower 18 in first gill arch. Ventral side of breast is naked, and diagonally extends to the base of pectoral fin. Prominent opercular spot is present.

First dorsal fin with 8 spines, soft dorsal fin with 21 soft rays. Pectoral fin is falcate and greater than pelvic fin. Pelvic fin is large and blackish. Lobe of second dorsal fin length is $15 \%$ of FL. 
Anal fin with 1 spine followed by 20 soft rays. Adult shows sexual dimorphism between the second and twelfth ray of soft dorsal fin, filamentous in male. Belly has a deep median groove covering pelvic fin and anal spine. Two detached anal spines are present. Tip of pelvic fin extends to the origin of anal fin. Caudal fin is deeply forked and constituting 27\% of FL. Lateral line is concave above pectoral fin and junction is below 4-6 rays of soft dorsal fin. Straight lateral line is greater than curved lateral line, having 3 scales and 38 strong scutes (Figure G1).
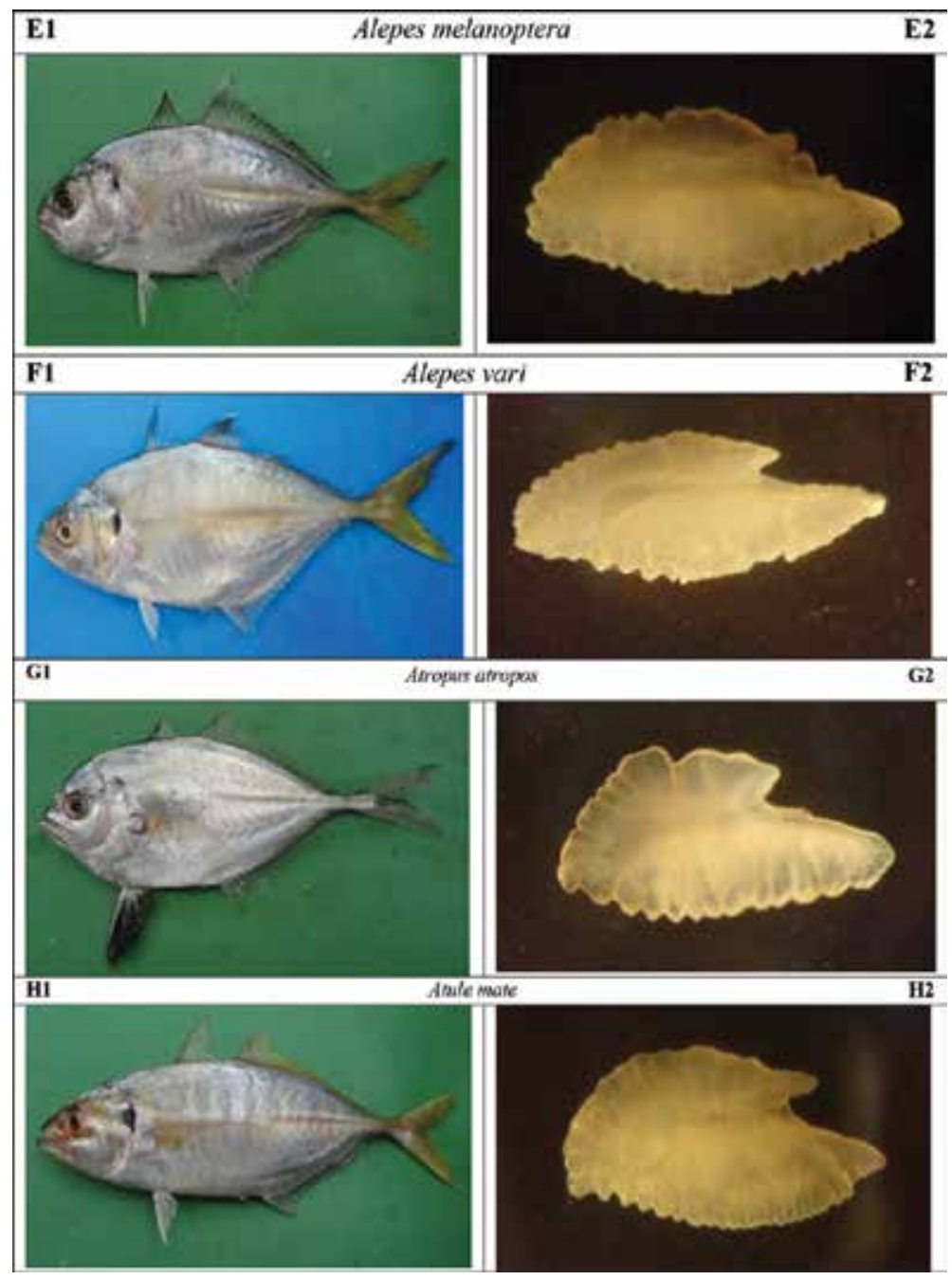

Otolith shape: elliptic-lanceloted. Margins: dorsal irregular, ventral serrate. Sulcus acusticus: heterosulcoid, ostial, median in position. Ostium: funnel-like shorter than cauda. Cauda: tubular, strongly flexed ending close to the ventral margin. Anterior region: peaked; rostrum broad, long, pointed; antirostrum short, narrow, pointed; excisura wide with an acute v-shaped medium notch. Posterior region: oblique (Figure G2). 


\subsection{Yellowtail scad, Atule mate}

Body has fusiform shape, moderately compressed. Dorsal and ventral profile is evenly convex. Eye is covered with adipose eyelid except for vertical slit centered on pupil. Snout is pointed and greater than eye. A single row of minute uniserate, comb-like teeth present on both jaws. Biserate dentition in premaxilla. Maxilla extends to one-third of eye anteriorly. Head length is about $26 \%$ of FL. Gill rakers 10-12 upper and 24-26 lower in first gill arch. Smooth shoulder girdle margin without papillae.

First dorsal fin is membranous, with 8 spines, second dorsal fin with 1 spine followed by 2024 rays. Two detached anal spines are present: anal fin with 1 spine and 19 soft rays. Pectoral fin is long and falcate about $31 \%$ of FL. Soft dorsal fin is low, anal fin slightly falcate. Caudal fin is deeply forked about $33 \%$ of FL. The distance from snout to anal fin origin is $50 \%$ of FL. Curved lateral line is shorter than straight line, and junction is below sixth soft dorsal fin rays. Chord of curved line is 2.1 times to straight lateral line. Curve lateral line with 40 scales and straight lateral line with 2 scales and 52 scutes. Last soft dorsal and anal fin finlet are joined by inter radial membrane and about twice the length of previous ray (Figure H1).

Otolith shape: fusiform. Margins: dorso-ventral posterior margin dentate. Sulcus acusticus: heterosulcoid, ostial, median. Ostium: funnel-like. Cauda: tubular, strongly curved ending close to the posterior margin. Anterior region: lanceolated; rostrum broad, medium, pointed; antirostrum short, narrow, pointed; excisura wide with a shallow notch. Posterior region: oblique (Figure H2).

\subsection{Longfin trevally, Carangoides armatus (new record)}

Body has ovate (to hexagonal) shape, deep, and compressed; eye diameter is less than snout length. Head is steep and straight from snout to nape without any break in contour (bump). Villiforms teeth are arranged in bands in both jaws, which expended anteriorly. Vomerine tooth is wedge patch shaped. Breast is ventrally naked to behind the origin of pelvic fin up to naked base of pectoral fin. Head length comprises of 30\% of FL. Gill rakers are 10 lower and 23 upper in first gill arch.

First dorsal fin is modified into 8 free spines, and soft dorsal fin consists of 1 spine followed by 22 soft rays. Dorsal and anal fin 3-12 middle rays elongate and filamentous, longer than head length in male. Pectoral fin is long and falcate. Pelvic fin is long in juveniles. Anal fin with two detached anal spines with 1 spines followed by 20 rays. Caudal fin is deeply forked and $27 \%$ of FL. Lateral line is strongly arched, and junction is below 12-14 soft dorsal rays. Curved lateral line is longer than straight line. Straight lateral line consist of 20 scales and 23 scutes (Figure I1).

Otolith shape: lanceolated. Margins: dorsal margin sinuate, ventral margin crenate. Sulcus acusticus: heterosulcoid, ostial, median in position. Ostium: funnel-like longer than cauda. Cauda: tubular, strongly flexed posteriorly. Anterior region: peaked; rostrum broad, elongated, pointed; antirostrum short, roundly peaked; excisura wide with a shallow notch. Posterior region: oblique (Figure I2). 


\subsection{Longnose trevally, Carangoides chrysophrys}

Body has oval shape, strongly compressed. Dorsal profile is more convex. Snout is greater than eye diameter. Dorsal outline of snout to nape is straight and then convex to the origin of dorsal fin. Small villiform teeth are arranged in bands anteriorly widened. Head length comprises of 30\% FL. Gill rakers: 5 in upper limb and 15 in lower limb. Two separate dorsal fin. First dorsal fin is membranous with 7-8 spines, second dorsal fin with 1 spine followed by 21 soft rays. Pectoral fin is long and falcate. Pelvic fin is short and hyaline. Anal fin with 2 detached anal spines and 1 spine followed by 16 soft rays. Caudal fin is deeply forked about $27 \%$ of FL. Curve lateral line is shorter than straight lateral line. Scales on curve lateral line is $28-31$ and scutes on straight lateral line are 32-40. Junction of CLL and SLL is below seventh-eighth ray of second dorsal fin (Figure J1).

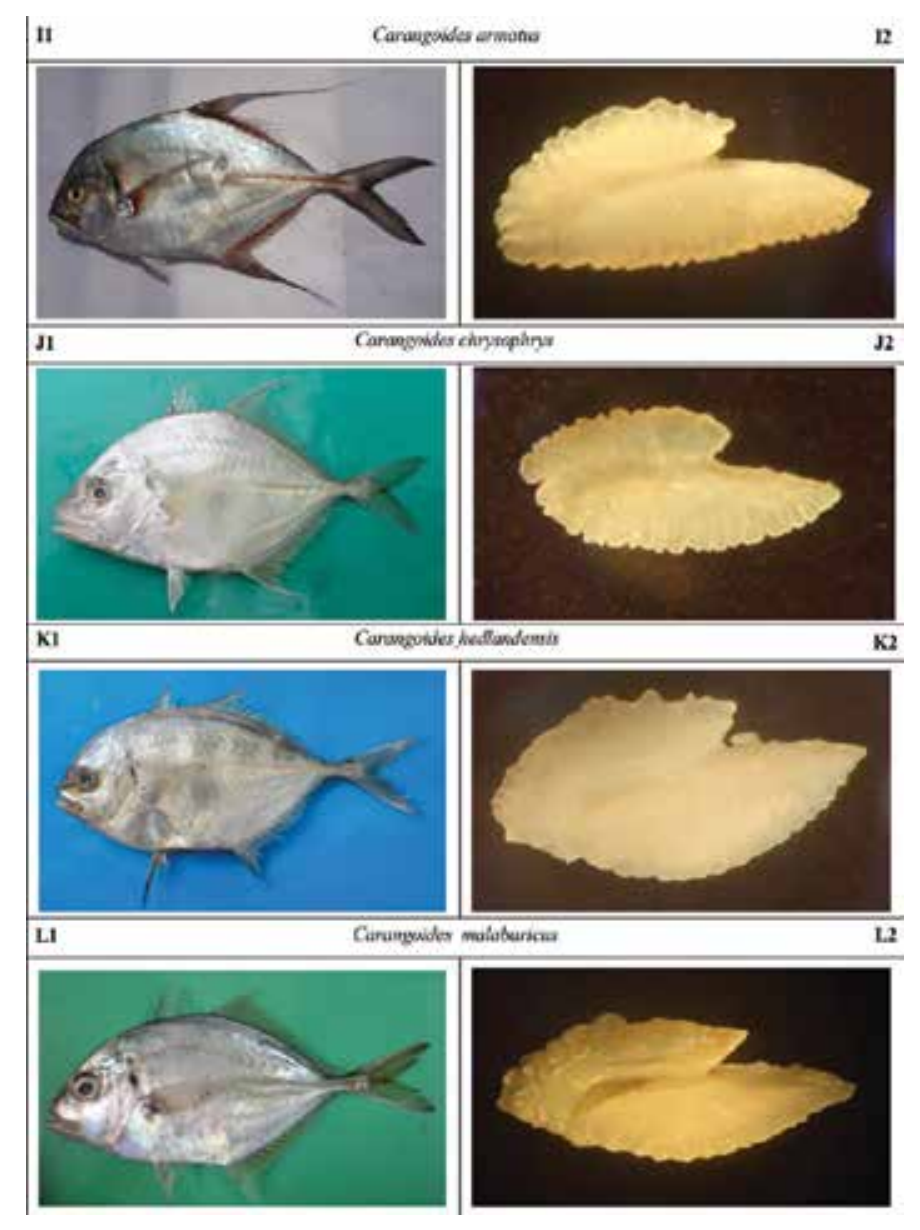

Otolith shape: lanceolated. Margins: dorso-ventrally crenate. Sulcus acusticus: heterosulcoid, ostial, median in position. Ostium: funnel-like. Cauda: tubular, strongly flexed posteriorly. 
Anterior region: lanceolated; rostrum narrow, elongated, peaked; antirostrum short, broad, round; excisura wide with a shallow notch. Posterior region: oblique-irregular (Figure J2).

\subsection{Bumpnose trevally, Carangoides hedlandensis}

Body has ovate shape and deep, laterally compressed. Ventral profile is more convex than dorsal side. Snout length is equal to eye diameter. Head profile is steep, dorsal contour of forehead convex, with "bump" on interorbital space. Villiform teeth are arranged in bands in both jaws which widens anteriorly. Patchy wedge-shaped vomerine teeth. Breast is naked and confined below pectoral fin. Head constituted 27\% of FL. Gill rakers 8 upper and 25 lower limbs of first gill arch.

First dorsal fin membraneous with 8 spines and second dorsal fin with 1 spine followed by 21 rays (3-8) producing filamentous and elongate, longer than head length in male. Pectoral fin is long and falcate. Pelvic fin short. Anal fin with two detached spines with 1 spine followed by 18 soft rays. Caudal fin is deeply forked and $26 \%$ of FL. Lateral line is strongly arched, and junction is below 12-14 soft dorsal rays. Curved lateral line is longer than the straight line. Straight laterally consists of 12 scales and 28 scutes (Figure K1).

Otolith shape: lanceolated. Margins: crenate. Sulcus acusticus: heterosulcoid, ostial, median. Ostium: funnel-like. Cauda: tubular, strongly curved ending close to the ventral margin. Anterior region: peaked; rostrum narrow, long, pointed; antirostrum short, broad, round; excisura wide with a shallow notch. Posterior region: oblique (Figure K2).

\subsection{Malabar trevally, Carangides malabaricus}

Body has oval shape, deep, and compressed; dorsal profile more convex is prominent to nape. Eye diameter is less than snout length. Head is steep and straight from snout to nape without any break in contour (bump). Villiform teeth are arranged in bands in both jaws, which expended anteriorly. A conical outer tooth is present. Vomerine tooth is roughly triangular. Breast is ventrally naked and behind the origin of pelvic fin upto origin of second dorsal fin. Head length comprises of $24-28 \%$ of FL. Gill rakers are 12 lower and 25 upper in first gill arch.

First dorsal fin is modified into 8 free spines and second dorsal fin consists of 1 spine followed by 23 soft rays. Pectoral fin is long and falcate. Pelvic fin is short. Anal fin with two detached anal spines with 1 spines followed by 18-19 rays. Caudal fin is deeply forked and 27\% of FL. Lateral line is strongly arched, and junction is below 12-14 soft dorsal rays. Curved lateral line is longer than straight line. Straight lateral line consists of 19 scales and 38 scutes (Figure L1).

Otolith shape: fusiform. Margins: dorsal, lobed, ventral, sinuate. Sulcus acusticus: heterosulcoid, ostial, median. Ostium: funnel-like. Cauda: tubular, strongly curved posteriorly ending close to the ventral margin. Anterior region: peaked; rostrum broad, short, pointed; antirostrum short, broad, pointed; excisura wide with a shallow v-shaped notch. Posterior region: peaked (Figure L2). 


\subsection{Brownback trevally, Carangoides praeustus}

Body is elliptic, elongated, and laterally compressed. Dorsal and ventral profile is identical. Snout is greater than eye. Straight head profile dorsally. Mouth is pointed and terminal. Teeth are conical, arrange in small irregular row in both jaws. Narrow bands of anterior tooth are arranged in upper jaw. Head length is $26 \%$ of FL. Breast ventrally naked, small patch of prepatch scale, remained separated from naked base of pectoral. Gill rakers upper 12 and 30 in lower limb of first gill arch.

First dorsal fin is membranous with 8 spines, and second dorsal fin consists of 1 spine followed by 23 soft rays. Height of third longest spinous dorsal fin is equal to soft dorsal fin lobe. Pectoral fin is long and falcate. Pelvic fin is short. Anal fin with two detached anal spines with 1 spines followed by 18-19 rays. Caudal fin is deeply forked and $28 \%$ of FL. Lateral line is strongly arched, and junction is below 11-12 soft dorsal rays. Curved lateral line is longer than straight line. Straight lateral line consists of 10 scales and 30 scutes (Figure M1).

Otolith shape: Trapezoidal-lanceolated. Margins: dorsal margin sinuate, ventral margin crenate. Sulcus acusticus: heterosulcoid, ostial, median. Ostium: funnel-like. Cauda: tubular, strongly curved ending close to the posterior margin. Anterior region: peaked; rostrum broad, medium, pointed; antirostrum short, narrow, pointed; excisura wide with an acute medium notch. Posterior region: oblique (Figure M2).

\subsection{Giant trevally, Caranx ignobilis}

Body has oblong shape, laterally compressed. Profile of dorsal body is more convex from snout to soft dorsal fin. Snout is pointed and greater than eye. Adipose eyelid covered the eye, extending beyond the posterior border of the eye. Maxilla slightly extends to posterior margin of eye. Strong canines in outer row tooth of both jaws. Small villiform tooth is present in inner bands of upper jaw. In upper jaw, canines are widely spaced in adult. Ventral profile of breast is completely naked with a patch of prepelvic scale. Head length comprises $29 \%$ of FL. Gill rakers 4 upper and 14 lower in first gill arch.

First dorsal fin is membranous, with 8 spines and second dorsal fin with 1 spine followed by 18 rays. Two detached anal spines are present, anal fin with 1 spine followed by 16 soft rays. Pectoral fin is long and falcate about 37\% of FL and longer than HL. Pelvic fin is short. Soft dorsal fin and anal fin lobe is slightly falcate. Caudal fin is deeply forked about $23 \%$ of FL. The distance from snout to anal fin origin is $62 \%$ of FL. Curved lateral line is longer than straight line, and junction is below fourth-fifth soft dorsal fin rays. Curved lateral line with 46 scales and straight lateral line with 4 scales and 29 scutes. Scale in body is cycloid and small, entirely covered the body except small portion behind pectoral fin (Figure N1).

Otolith shape: fusiform. Margins: crenate. Sulcus acusticus: heterosulcoid, ostial, median. Ostium: funnel-like. Cauda: tubular, strongly curved ending close to the ventral margin. Anterior region: slightly curved at tip, peaked; rostrum broad, long, pointed; antirostrum absent; excisura wide without notch. Posterior region: oblique (Figure N2). 


\subsection{Green jack, Caranx para}

Body oval, laterally compressed and ventral profile more convex. Eye equal to snout length and covered with adipose eyelid which extends posterior half of eye. Maxilla broad and concave posteriorly. Teeth of lower jaw are arrange in irregular rows. Lower jaw with a single row of conical teeth. Head profile steep from snout to origin of second dorsal fin and ovate

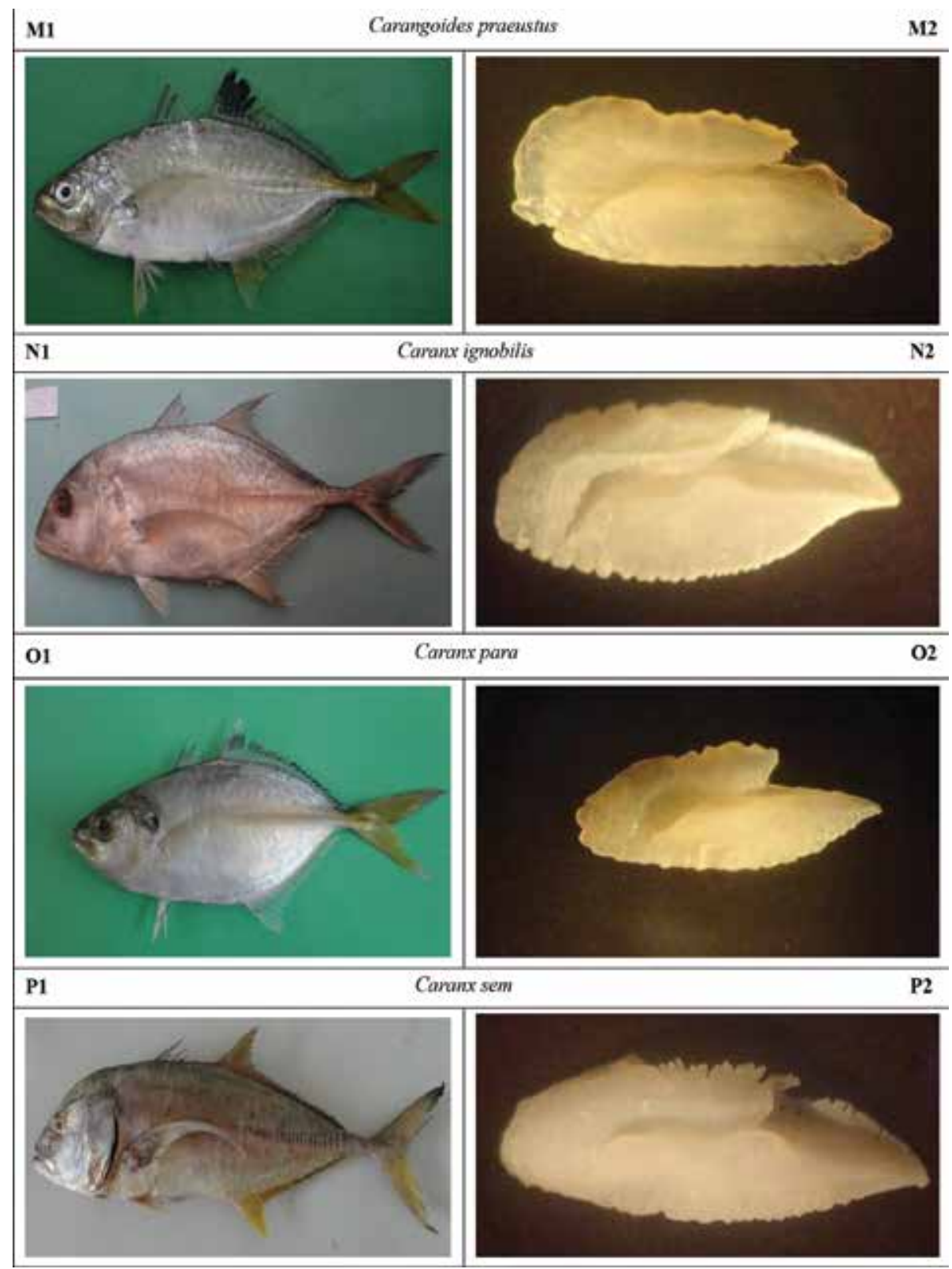


posteriorly. Head length is $28 \%$ of forked length. Shoulder girdle margin smooth and without papillae. Gill rakers upper 12 and 26 lower limbs of the first gill arch.

First dorsal fin membranous with 8 spines, soft dorsal fin with 1 spine followed by 25 soft rays and 1.75 times shorter than head length. Dorsal and anal fin lobe falcate. Pectoral fin long $34 \%$ of forked length, falcate, tip end reaches beyond the junction of CLL and SLL. Anal fin with two detached anal spines with 1 spines followed by 20 rays. Anal fin behind the origin of soft dorsal fin. Caudal fin deeply forked, dorsal lobe longer, and $31 \%$ of forked length. Lateral line strongly arched and junction below fourth-sixth soft dorsal rays. Straight lateral line is longer than curved lateral line. Straight lateral line consists of 45 scutes and scales small and cycloid (Figure 01).

Otolith shape: lanceolated. Margins: dorso-ventral posteriorly sinuate. Sulcus acustics, heterosulcoid, ostial, median. Ostium: funnel-like equal to the length of cauda. Cauda: tubular, markedtly curved posteriorly from the middle region. Anterior region: peaked; rostrum elongated, pointed; antirostrum short, broad, peaked; excisura wide with a V-shaped notch. Posterior region: round-oblique (Figure O2).

\subsection{Blacktip trevally, Caranx sem (new record)}

Body has oblong and elongated shape, laterally compressed. Profile of dorsal body is more convex from snout to soft dorsal fin. Ventral profile is slightly convex. Snout is pointed and greater than eye. Eye is moderate and covered anteriorly with small adipose eyelid and posteriorly extends to the pupil. Maxilla extends to the posterior margin of the eye. Strong canines present in outer row teeth of both jaws. Small villiform teeth are present in inner bands of upper jaw. Head length comprises 30\% of FL. Gill rakers: 4 upper and 15 lower in first gill arch.

First dorsal fin is membranous, with 8 spines, second dorsal fin with 1 spine followed by 20 rays. Two detached anal spines are present. Anal fin with 1 spine followed by16 soft rays. Pectoral fin is long and falcate longer than HL. Pelvic fin is short. Soft dorsal and anal fin is slightly falcate. Caudal fin is deeply forked about $30 \%$ of FL. Curved lateral line is longer than straight line, and junction is below fourth-fifth soft dorsal fin rays. Straight part of lateral line is 2.4 times of forked length with 4 scales and 30 scutes. Scale in body is cycloid and small, entirely covered the body and in breast, small-to-large patch of prepelvic scale. All fins are brightly yellow to olive yellow in color, and distal half of upper lobe of caudal fin is dark black (Figure P1).

Otolith shape: fusiform. Margins: dorsal dentate, ventral crenate. Sulcus acusticus: heterosulcoid, ostial, median. Ostium: funnel-like. Cauda: tubular, strongly curved ending close to the ventral margin. Anterior region: slightly curved at tip, peaked; rostrum broad, long, pointed; antirostrum absent; excisura wide without notch. Posterior region: oblique-round (Figure P2).

\subsection{Bigeye trevally, Caranx sexfasciatis}

Body has fusiform shape, laterally compressed. Profile of dorsal body is more convex from snout to soft dorsal fin. Snout is pointed and greater than eye. Adipose eyelid completely 
covered the eye, which extends moderate anteriorly and posteriorly to the margin of pupil. Maxilla extends to posterior margin of eye. Strong canines in outer row tooth of both jaws. Small villiforms teeth are present in inner bands of upper jaw. Breast is completely covered with scales. Head length comprises $27-30 \%$ of forked length. Gill rakers 6 upper and 16-18 lower in first gill arch. First dorsal fin is membranous, with 8 spines, second dorsal fin with 1 spine followed by 20-21 rays. Two detached anal spines are present. Anal fin with 1 spine followed by16-19 soft rays. Pectoral fin is long and falcate about $31 \%$ of FL and longer than HL. Pelvic fin is short. Soft dorsal fin is low, anal fin slightly falcate. Caudal fin is deeply forked about $30 \%$ of FL. The distance from snout to anal fin origin is $58 \%$ of FL. Curved lateral line is longer than straight line, and junction is below fourth-fifth soft dorsal fin rays. Curve lateral line with 46 scales and straight lateral line with 6 scales and 32-37 scutes. Scale in body is cycloid and small, which is entirely covered the body except small portion behind pectoral fin (Figure Q1).

Otolith shape: fusiform. Margins: dorsal crenate, ventral serrate. Sulcus acusticus: heterosulcoid, ostial, median in position. Ostium: funnel-like equal to ostial length with perforated colliculum. Cauda: tubular, strongly curved posteriorly ending close to the ventral margin. Anterior region: slightly curved at tip, peaked; rostrum broad, elongated, pointed; antirostrum absent; excisura wide without notch. Posterior region: oblique (Figure Q2).

\subsection{Indian scad, Decapterus russelli}

The body has fusiform shape and elongated, quite slender, and considerably compressed. Prominent moderate eye covered entirely with adipose except vertical slit centered on the pupil. Eye diameter is smaller than snout length. Eye is moderate and covered by adipose eyelid in a vertical slit. The upper jaw is slightly concave, ending straight above with a narrow band of minute teeth. Lower jaw has an irregular series of minute teeth. Body is bright yellow with transparent fins. Head length comprises of $28 \%$ of FL length. Gill rakers: upper 10, lower 33-34 on first gill arch. Shoulder girdle margin with two papillae: The lower papilla is larger.

First dorsal fin is separate and membranous with 7 spines and second dorsal fin with 1 spine followed by $26-28$ rays. Terminal dorsal and anal fin with distinct single-detached finlet. Pectoral fin is long, and end tip reaches to the second ray of second dorsal fin. Anal fin with 2 detached spines and 1 spine followed by 24 soft rays. Caudal fin is deeply forked with $18 \%$ of FL. Anal fin origin is slightly beyond the vertical line of second dorsal fin. Curve lateral line shorter than straight lateral line, junction of curve and straight lateral line below eleventhtwelfth ray of second dorsal fin. The scale in CLL is 38 and 2 in SLL followed by 35-39 scutes (Figure R1).

Otolith shape: elliptical. Margins: dorsal sinuate, ventral crenate. Sulcus acusticus: heterosulcoid, ostial, median. Ostium: funnel-like. Cauda: tubular, strongly curved ending close to the ventral margin. Anterior region: peaked; rostrum broadly pointes, medium; antirostrum short, broadly pointed; excisura wide with a medium notch. Posterior region: peaked (Figure R2). 


\subsection{Rainbow runner, Elagatis bipinnulata}

Body has elongated shape, subcylindrical, and fusiform. Snout diameter is greater than eyes. Mouth is small, and head is pointed. Eye is small, moderately developed adipose. Maxilla does not extend to the anterior margin of the eye. Villiform teeth are arranged in both jaws, vomer, and palatines in bands, tongue centrally arranged in bands. Head length comprised of $24 \%$ FL. Gill rakers: upper 11 and 23, lower on first gill arch.

First dorsal fin is modified into 7 spines. Second dorsal fin with 1 spine followed by 26 rays excluding finlet. Terminal detached dorsal and anal fin with distinct double rayed finlet. Pectoral fin length is equal to pelvic fin length and double in head length. Anal fin without detached spines with 1 spine attached followed by 19 soft rays. Caudal fin is deeply forked with $31 \%$ FL. Anal fin origin is beyond the soft dorsal fin. Anal fin base is shorter than about 1.5 times lower than soft dorsal fin base. Lateral line is slightly arch without scutes. (Figure S1).

Otolith shape: lanceolated, clearly curved. Margins: dorsal irregular, ventral serrate-dentate. Sulcus acusticus: heterosulcoid, ostial, median. Ostium: funnel-like. Cauda: tubular slightly curved ending posteriorly very close to the ventral margin. Anterior region: lanceolatedcurved; rostrum narrow, long, pointed; antirostrum short, broad, pointed; excisura wide with a U-shallow notch. Posterior region: oblique-irregular (Figure S2)

\subsection{Golden trevally, Gnathanodon speciosus}

Body has oblong shape, laterally compressed. Snout length is greater than eye. Maxilla is protractile and extends to below posterior one-third of an eye. Lips are papillose. Upper jaw without teeth and lower jaw with small teeth (absent in adult). Head is $26 \%$ of FL. Gill rakers: 6 upper, 20 lower in first gill arch.

First dorsal fin is membranous with 7 spines and second dorsal fin with 1 spine followed by 22 soft rays. Soft dorsal is low. Anal fin is falcate. Pectoral fin is long, falcate and 35\% of FL. Anal fin with 2 detached spines. Anal fin with 1 spine and 18 soft rays. Anal fin is slightly behind the second dorsal fin. Snout to anal fin distance is $49 \%$ of FL. Caudal fin deeply forked $30 \%$ of FL. Body color is golden with $7-11$ alternating broad black bands. Lateral line is moderately arching anteriorly, junction of curved and straight lateral line below twelfth ray of second dorsal fin. Curve lateral line is longer than straight lateral line contained 0.85 times in a straight line. Straight part of lateral line containing 10 scale followed by 24 scutes. Breast is completely covered with scale (Figure T1).

Otolith shape: elliptic-fusiform. Margins: crenate. Sulcus acusticus: heterosulcoid, ostial, median. Ostium: funnel-like shorter than cauda. Cauda: tubular, strongly flexed posteriorly from the middle margin. Anterior region: peaked; rostrum broad, medium, pointed; antirostrum short, narrow, pointed; excisura wide with an acute medium notch. Posterior region: oblique (Figure T2). 


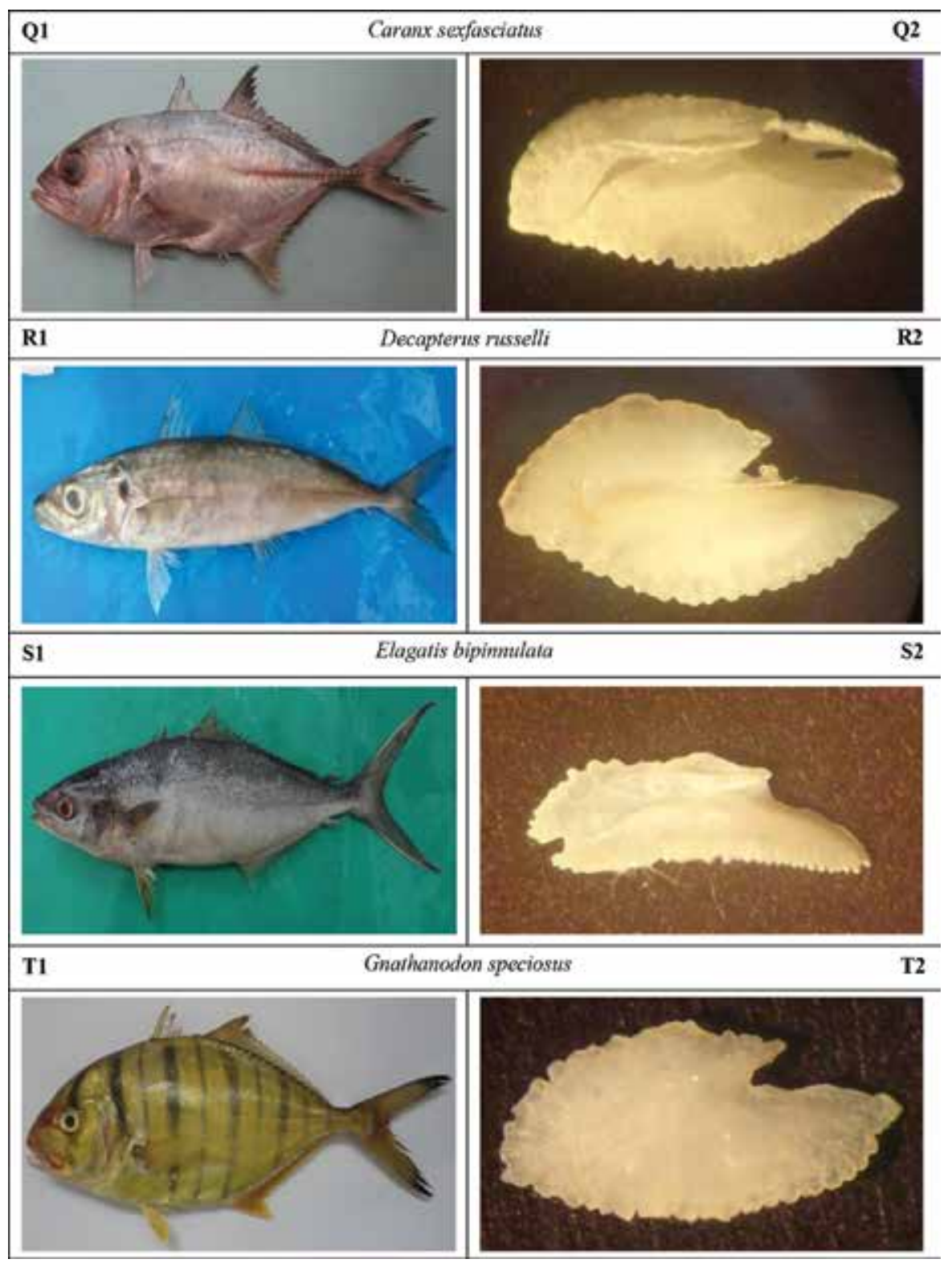

\subsection{Torpedo scad, Megalaspis cordyla}

Body has fusiform and elongate shape, posteriorly compressed and subcylindrical. Eye is large and greater than snout length with well-developed adipose eyelid covered entirely except vertical slit, snout is blunt, and maxilla extends posteriorly to the center of eye. Small villiform teeth is in upper jaw, anteriorly narrow bands and single row of teeth in lower jaw. Head length comprises of $28 \%$ of FL. Gill rakers are 10-12 lower and 24-30 upper in first gill arch. 
First dorsal fin is membranous with 8 spines, and second dorsal fin consists of 1 spine followed by 17 soft rays posteriorly $8-10$ consisting of detached finlets. Second dorsal fin and anal fin lobe is falcate. Pectoral fin is long falcate and tip end reaches to the straight lateral line. Anal fin with two detached anal spines with 1 spines followed by 18 soft rays, posteriorly 8-10 consisting of detached finlets. Anal fin is behind the origin of soft dorsal fin. Caudal peduncle with a marked median keel. Caudal fin is deeply forked and $28 \%$ of FL. Curved lateral line is shorter than straight line. Straight lateral line consists of 8 scales and 22 scutes. Scales are small and cycloid (Figure U1).

Otolith shape: lanceolated. Margins: dorsally sinuate, ventrally dentate. Sulcus acusticus: heterosulcoid, ostial, median in position. Ostium: funnel-like. Cauda: tubular, markedly flexed posteriorly from the middle region ending close to the ventral margin. Anterior region: lanceolated with dentate protuberances; rostrum narrow, elongated, pointed; antirostrum absent; excisura wide with a square-shaped medium notch. Posterior region: oblique (Figure U2).

\subsection{Black pomfrets, Parastromateus niger}

Body has deep and ovate shape, laterally compressed, dorsal and ventral profile is convex. Mouth is terminated with enlarged teeth that bridge the epibranchial 4-ceratobranchial 4 joints. Form of teeth on the pharyngeal teeth plates is elongate and filamentous. Color is dark brown in juvenile and silvery gray to bluish brown in adult. Gill rakers: upper 8-10 and lower 15-24 on first gill arch. The first dorsal fin is superficially absent. The first dorsal fin with small, short 4-5 embedded spines followed by one spine and 38-44 soft rays. Pectoral fin is long and falcate. Pelvic fin absent in adult. Dorsal and anal fin entirely rounded, broad lobes, and identical. Anal fin with 2 anal spines followed by 1 spine and 33-42 soft rays. The lateral line is visible with slight curved entirely become straight at 29-31 soft dorsal fin rays. Straight part of lateral line with 15- to 17-week scutes forming straight keel on caudal peduncle (Figure V1).

Otolith shape: elliptical-lanceolated. Margins: dorsal irregular, ventral crenate-dentate. Sulcus acusticus: heterosulcoid, ostial, median in position. Ostium: funnel-like equal to caudal length. Cauda: tubular, slightly curved ending far to the ventral margin. Anterior region: peaked; rostrum broad, elongated, pointed; antirostrum short, broad, round; excisura wide with an acute shallow notch. Posterior region: oblique (Figure V2).

\subsection{Talang queenfish, Scomberoides commersonnianus}

The body has fusiform shaped and elongated, laterally compresses. Dorsal and ventral profiles are identical. Adipose eyelid is developed. Snout length is greater than eye diameter. Snout blunt, head, and nape are slightly concave. Maxilla extends beyond the posterior margin of the eye. Lower jaw has two rows of teeth. Large conical tooth presents in outer row. Small villiform tooth is present in inner row. Head length comprises 19\% of FL. Gill rakers are large and slender, 2-5 upper, and 11-14 lower.

First dorsal fin with 1 embedded spine and 6-7 free short spines, and second dorsal fin with 1 spine followed by 18-20 soft rays. Pectoral fin is short and greater than pelvic fin. Pelvic fin is 
short, depressible into shallow groove. Soft dorsal and anal fin is falcate, equal in length. Posteriorly consisting of semi-detached finlet. Two detached anal spine are present. Anal fin with 1 spine followed by 17-20 soft rays. Distal half of dorsal and anal fin is dusky. Caudal fin is deeply forked and comprises $25 \%$ of FL. Dorsal and anal fin is originated in a line. Scales are lanceolate below the lateral line and deeply embedded. Lateral line is little angulated just above the pectoral fin, slightly irregular and without scutes. A series of plumbaeous blotches (6-8) round to oval is present just above or touching the lateral line. Caudal peduncle groove is absent (Figure W1).

Otolith shape: lanceolated-triangular. Margins: dorsal sinuate, ventral crenate. Sulcus acusticus: heterosulcoid, ostial, median. Ostium: funnel-like. Cauda: tubular slightly curved posteriorly ending very close to the ventral margin. Anterior region: lanceolated; rostrum narrow, elongated, pointed; antirostrum short, broad, pointed; excisura wide with a shallow notch. Posterior region: round-irregular (Figure W2).

\subsection{Doublespotted queenfish, Scomberoides lysan}

Body has fusiform and elongated shape, laterally compressed. Dorsal and ventral profile is identical. Adipose eyelid is developed. Snout length is greater than eye diameter. Snout blunt, head, and nape are slightly concave. Maxilla extends beyond the posterior margin of the eye. Lower jaw has two rows of teeth. Large conical tooth presents in outer row. Small villiform teeth is present in inner row. Dentary is subequal in length. Head length comprises 19\% of FL. Gill rakers are large and slender, 4-9 upper, and 14-21 lower.

First dorsal fin with 1 embedded spine and 6-7 free short spines, and second dorsal fin with 1 spine followed by 18-21 soft rays. Pectoral fin is not falcate and equal in length of pelvic fin. Pelvic fin is short, depressible into shallow groove. Soft dorsal and anal fin is falcate, equal in length, posteriorly consisting of semidetached finlet. Two detached anal spine are present, anal fin with 1 spine followed by 18-20 soft rays. Soft dorsal and anal fin comprises 11-12\% of FL, and distal half of soft dorsal fin is pigmented black. Caudal fin is deeply forked and comprises $26 \%$ of FL. Anal fin is originated slightly just behind the second dorsal fin. Scales are lanceolate below the lateral line and mid-body, deeply embedded. Lateral line is little angulated just above the pectoral fin, slightly irregular and straight posteriorly without scutes. Two series of (6-8) blotches rounded to vertically oblong is present just above and below the lateral line. Caudal peduncle groove is absent (Figure $\mathbf{X} \mathbf{1}$ ).

Otolith shape: approximately triangular. Margins: dorsal sinuate, ventral crenate. Sulcus acusticus: heterosulcoid, ostial, median. Ostium: funnel-like. Cauda: tubular, strongly curved posteriorly from the middle region ending far from the ventral margin. Anterior region: lanceolated with dentate protuberances; rostrum narrow, elongated, pointed; antirostrum very short, broad, pointed upward; excisura wide with a shallow notch. Posterior region: oblique (Figure X2). 


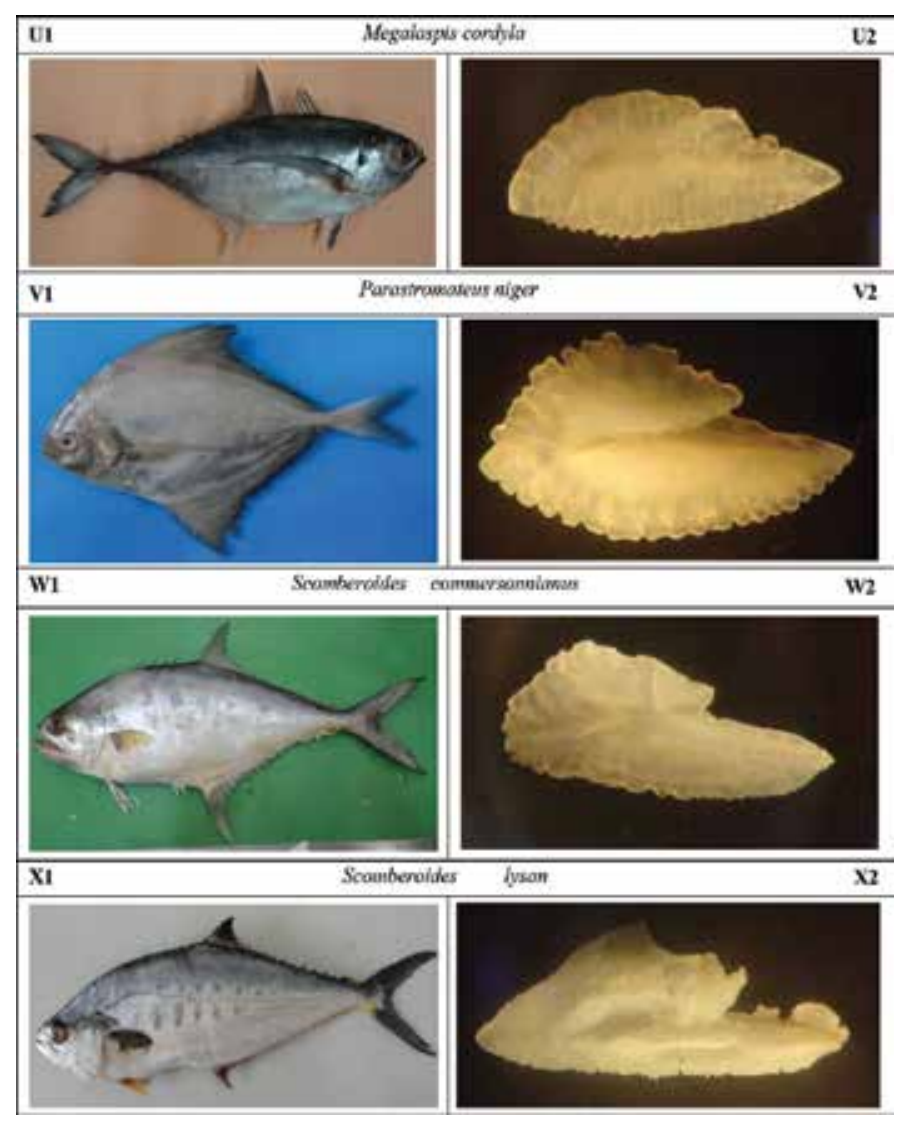

\subsection{Barred queenfish, Scomberoides tala (new record)}

Body shaped is elongated, dorsal, and ventral profile strongly compressed. Adipose eyelid is well developed. Snout length is greater than eye diameter. Snout blunt with midline joint to the upper lip by a frenum. Maxilla extends beyond the posterior margin of the eye. Lower jaw has two rows of teeth, large conical teeth present in inner row. Small villiform teeth are present in outer row. Head length comprises $19 \%$ of the forked length. Gill rakers are large and slender, 2-3 upper, and 8-10 lower.

First dorsal fin with 1 embedded spine and 6-7 free short spines. Second dorsal fin with 1 spine followed by 18-20 soft rays. Pectoral fin is slightly falcate and shorter in pelvic fin length. Pelvic fin is short, depressible into shallow groove. Soft dorsal and anal fin is falcate, equal in length, posteriorly consisting of semidetached finlet. Two detached anal spine are present, anal fin with 1 spine followed by 17-19 soft rays. Soft dorsal and anal fin comprises $14-15 \%$ of the forked length in a specimen greater than $40 \mathrm{~cm}$ FL. Caudal fin is deeply forked and comprises $27 \%$ of the forked length, anal fin origin in a line with second dorsal fin. Scales are lanceolate below the lateral line on mid-body, deeply embedded in skin. Lateral line is little angulated just above the pectoral fin, slightly irregular and straight posteriorly without scutes. A single 
series of (4-8) blotches rounded to vertically oblong is present, and first 6-7 blotches intersecting the lateral line. Caudal peduncle groove is absent (Figure Y1).

Otolith shape: lanceolated-triangular. Margins: dorsal sinuate, ventral serrate. Sulcus acusticus: heterosulcoid, ostial, median. Ostium: funnel-like. Cauda: tubular slightly curved posteriorly from the middle region ending very close to the ventral margin. Anterior region: lanceolated; rostrum narrow, long, pointed; antirostrum short, broad, pointed; excisura wide with a medium notch. Posterior region: oblique-irregular (Figure Y2).

\subsection{Needlescaled queenfish, Scomberoides tol}

The body has fusiform and elongated shape, laterally compressed. Dorsal and ventral profile are identical. Adipose eyelid is developed. Snout length is greater than the eye diameter. Snout blunt, head, and nape are slightly concave. Maxilla extends beyond the posterior border of the pupil. Lower jaw has two rows of teeth. Large conical teeth present in outer row. Small villiform teeth are present in inner row. Dentary in both jaw are sub equal in length. Head length comprises $18 \%$ of FL. Gill rakers are large and slender, 5-8 upper, and 16-20 lower.

First dorsal fin with 1 embedded spine and 6-7 free short spines, and second dorsal fin with 1 spine followed by 17-20 soft rays. Pectoral fin is not falcate and equal in length of pelvic fin. Pelvic fin is short in shallow groove. Soft dorsal and anal fin is falcate, equal in length, posteriorly consisting of semidetached finlet. Two detached anal spine are present. Anal fin with 1 spine followed by 18-21 soft rays. Soft dorsal and anal fin comprises 10\% of FL and the distal half of soft dorsal fin are pigmented black. Caudal fin is deeply forked and comprises $23 \%$ of FL, anal fin origin in a line with second dorsal fin. Scales are needle like, below the lateral line and mid-body, deeply embedded in skin. Lateral line is little angulated just above the pectoral fin, slightly irregular, and straight posteriorly without scutes. A single series of (5-8) blotches rounded to vertically oblong is present, first $4-5$ blotches intersecting the lateral line. Caudal peduncle groove is absent (Figure Z1).

Otolith shape: lanceolated, slightly curved. Margins: dorsal sinuate, ventral crenate. Sulcus acusticus: heterosulcoid, ostial, median. Ostium: funnel-like. Cauda: tubular slightly curved ending very close to the ventral margin. Anterior region: lanceolated; rostrum narrow, long, pointed; antirostrum short, broad, peaked; excisura wide with a shallow notch. Posterior region: oblique (Figure $\mathbf{Z} 2$ ).

\subsection{Bigeye scad, Selar crumenophthalmus}

Body has fusiform and elongated shape, moderately compressed. Ventral profile of body is more convex than dorsal. Eye is large and greater than snout length and covered with adipose eyelid except for vertical slit centered on pupil. Snout is pointed. Lower jaw with a single row of minute is uniserrate tooth. Villiform tooth is also arranged in vomer, palatines, and on central band on tongue. Maxilla extends to below anterior two-third of eye. Head length is about $30 \%$ of FL. Gill rakers: 10-11 upper and 30-34 lower in first gill arch. Smooth shoulder girdle margin with deep furrow having 2 papillae, large papilla above, and lower papilla near lower edge. First dorsal fin is membranous, with 8 spines, and second dorsal fin with 1 spine followed by 
20-21 rays. Two detached anal spines are present, anal fin with 1 spine and 19-22 soft rays. Pectoral fin is long and falcate about $24-27 \%$ of FL and shorter than HL. Pelvic fin is short. Soft dorsal fin is low, anal fin slightly falcate. Dorsal and anal fins without detached terminal finlet. Caudal fin is deeply forked about $24 \%$ of FL. The distance from snout to anal fin origin is $57 \%$ of FL. Curved lateral line is longer than straight line, and junction is below twelfth-fourteenth soft dorsal fin rays. Curve lateral line with 48 scales and straight lateral line with 11 scales and 30-37 scutes. Scales in body are cycloids and small, entirely covered the body except small portion behind pectoral fin (Figure AA1).

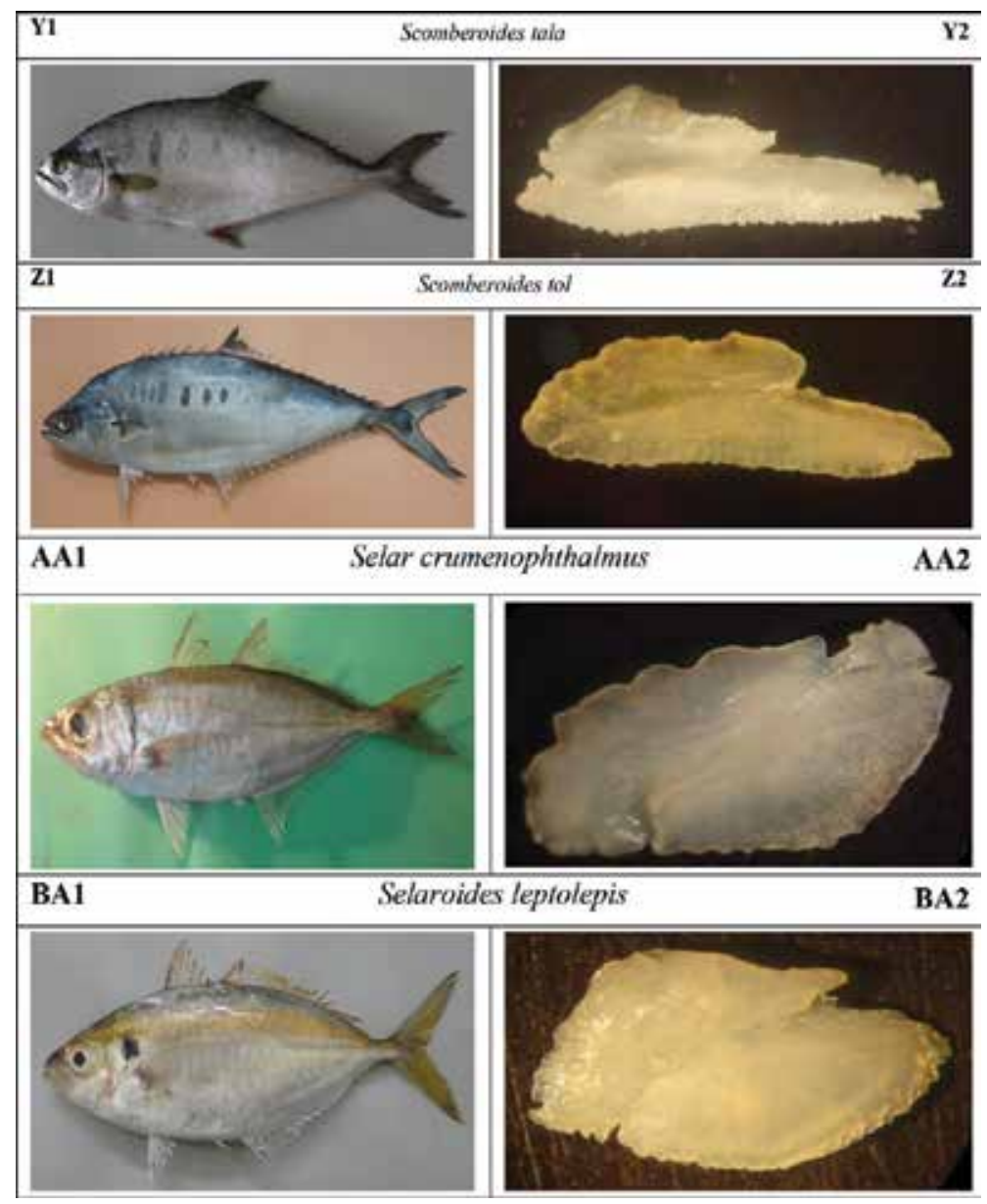

Otolith shape: elliptic. Margins: dorsal, entire, ventrally, sinuate. Sulcus acusticus: heterosulcoid, ostial, median. Ostium: oval. Cauda: tubular, markedly curved posteriorly ending close to the ventral margin. Anterior region: peaked, broad with one big protuberance; rostrum broad, small, pointed; antirostrum very short; excisura tiny notch. Posterior region: round (Figure AA2). 


\subsection{Yellowstripe scad, Selaroides leptolepis}

Body has elliptic and oblong shape, laterally compressed. Dorsal and ventral profile is identically and equally convex. Yellow stripes on broad eyes equally or slightly greater than snout length. Eye is covered with adipose eyelid posteriorly. Maxilla is protractible and concave above. No tooth in upper jaw and lower jaw with minute tooth. Head is small and comprised of $24-27 \%$ of FL. Gill rakers: 10-12 upper, 21-24 in lower limb of first gill arch. Breast is completely covered with First dorsal fin is membranous with 8 spines and second dorsal fin with 1 spine followed by 26 soft rays. Dorsal and anal fin rays are low, not falcate. No ventral grooves are present. Third spine of first dorsal fin is about double than second dorsal fin. Anal fin with two detached spines. Anal fin with 1 spines followed by 19-22 soft anal rays is present. Caudal fin is deeply forked about $28 \%$ of FL. Lateral line is deeply concave above pectoral fin, straight part is greater than curved part, and their junction is below the twelfth ray of soft ray (Figure BA1).

Otolith shape: elliptic. Margins: dorsal, entirely smooth, ventral, crenate. Sulcus acusticus: heterosulcoid, ostial, median. Ostium: funnel-like. Cauda: tubular, strongly curved posteriorly ending close to the ventral margin. Anterior region: pointed; rostrum elongated, broadly pointed; antirostrum narrow, short, blunt; excisura wide with a shallow notch. Posterior region: oblique (Figure BA2).

\subsection{Greater amberjack, Seriola dumerilli (new record)}

Body has fusiform shape, moderately compressed and shallow. Eye is moderate, lower than snout length. Ventral profile is more convex. Maxilla is broad at end extending posterior margin of eye. Super maxilla is broad. Teeth are arranged in a broad band in both jaws. Head length is $25-28 \%$ of FL. Gill rakers: upper 6-8, lower 14-16 in first gill arch.

First dorsal spinous fin is short and membranous with 7-8 spines, and second dorsal fin consists of 1 spine followed by 28-34 soft rays. Anterior ray of second dorsal fin is slightly elevated and $13-14 \%$ of FL. Pectoral fin is shorter than pelvic fin. Anal fin with 2 detached spines (embedded in larger specimen) followed by 1 spine and 19-21 soft rays. Caudal fin is deeply forked and about $23-26 \%$ of FL. The distance from snout to origin of anal fin is $60-64 \%$ of FL. Lateral line without scutes, moderately curved above pectoral fin and smoothly straight posteriorly. A cutaneous keel on each side of caudal peduncle is present. Body color is olive dorsally and laterally and silvery belly, snout to the origin of second dorsal fin (Figure CA1).

Otolith shape: lanceolated. Margins: dorsal lobed, ventral serrate-dentate. Sulcus acusticus: heterosulcoid, ostial, median. Ostium: funnel-like. Cauda: tubular, strongly curved ending posteriorly far from the posterior margin. Anterior region: lanceolated; rostrum narrow, long, pointed; antirostrum short, narrow, pointed; excisura wide with an acute shallow notch. Posterior region: rounded-irregular (Figure CA2).

\subsection{Blackbanded trevally, Seriolina nigrofasciata}

Body shape is oblong and elongated, moderately shallow and compressed. Snout is rounded and greater than the eye. Super maxilla is slender and rounded. Maxilla rounded at the end 
extending beyond the posterior border of the pupil. Head consists of $25-29 \%$ of FL. Head profile is steeply raising to interorbital region and point a curve moderately to spinous dorsal fin. Minute villiform teeth arranged in series in both jaws and in central band on tongue. Gill rakers of first gill arch comprised of 2-5 upper, 7-9 lower such as a knob-like masses, including rudiments.

First dorsal spinous fin is short and membranous with 7- to 8-week spines, of which some are embedded in skin, and second dorsal fin consists of 1 spine followed by 33-37 rays. A ray of dorsal and anal fin is slightly elevated but not falcate. Pectoral fin is short, not falcate. Pelvic fin is greater than pectoral fin in length $18 \%$ of FL. Anal fin 1 embedded spine followed by 18 20 soft rays. The distance from snout to anal fin origin is $60 \%$ of FL. Caudal fin consists of $23-$ $28 \%$ of FL. A cutaneous keel on each side of caudal peduncle is developed in adult. Curve lateral line is arched moderately below 24 soft ray of second dorsal fin. In juveniles, $6-7$ dark oblong band and blotches is present which disappear with age (Figure DA1).

Otolith shape: lanceolated. Margins: dorsal lobed, ventral crenate. Sulcus acusticus: heterosulcoid, ostial, median in position. Ostium: funnel-like. Cauda: tubular, strongly curved posteriorly ending close to the ventral margin. Anterior region: lanceolated; rostrum narrow, long, pointed; antirostrum short, narrow, pointed; excisura wide with a shallow notch. Posterior region: angled (Figure DA2).

\subsection{Small spotted dart, Trachinotus baillonii}

Body has elliptical and oblong shape, laterally compressed. Dorsal and ventral profile is identical. Eye is equal to snout length. Snout is pointed. Maxillae extend beyond the anterior border of eye. Palatine and villiform teeth are arranged in bands in jaws and vomer in a triangular patch. Tongue without teeth. Head is small and comprises $25-27 \%$ of FL. Gill rakers on upper 6-7, lower 14-18 on first gill arch.

First dorsal fin modified into 6-7 short free spines, and second dorsal fin with 1 spine followed by $22-24$ soft rays. Dorsal fin is long, falcate, and comprises of $35 \%$ of Fl. Pectoral fin greater than pelvic fin, but relatively shorter than dorsal and anal fin. Two detached anal spine are present. Anal fin consists of 1 spine followed by 18-21 soft rays. Anal fin originated just behind the dorsal fin. Lateral line is slightly irregular, weekly convex above pectoral fin, containing 2-5 black spot (less than eye diameter) along the line. No scutes and caudal pedunclee groove are present. Caudal fin deeply forked about $40 \%$ of FL (Figure EA1).

Otolith shape: elliptic-fusiform. Margins: Dorso-ventrally crenate-serrate. Sulcus acusticus: heterosulcoid, ostial, median. Ostium: funnel-like shorter than cauda. Cauda: tubular, slightly curved posteriorly ending close to the ventral margin. Anterior region: peaked with a small protuberance; rostrum long, broad, peaked; antirostrum short, broad, round; excisura wide without notch. Posterior region: round (Figure EA2).

\subsection{Snubnose pompano, Trachinotus blochi}

Body shape is elliptical and oblong, laterally compressed. Dorsal and ventral profile is identical. Eye is smaller than snout length. Snout is rounded. Maxillae extend beyond the 
anterior border of eye. Small villiform teeth are arranged in band in both jaws. No teeth on tongue. Head is small and comprises $22-28 \%$ of FL. Gill rakers on upper 6, lower 8-12 on first gill arch.

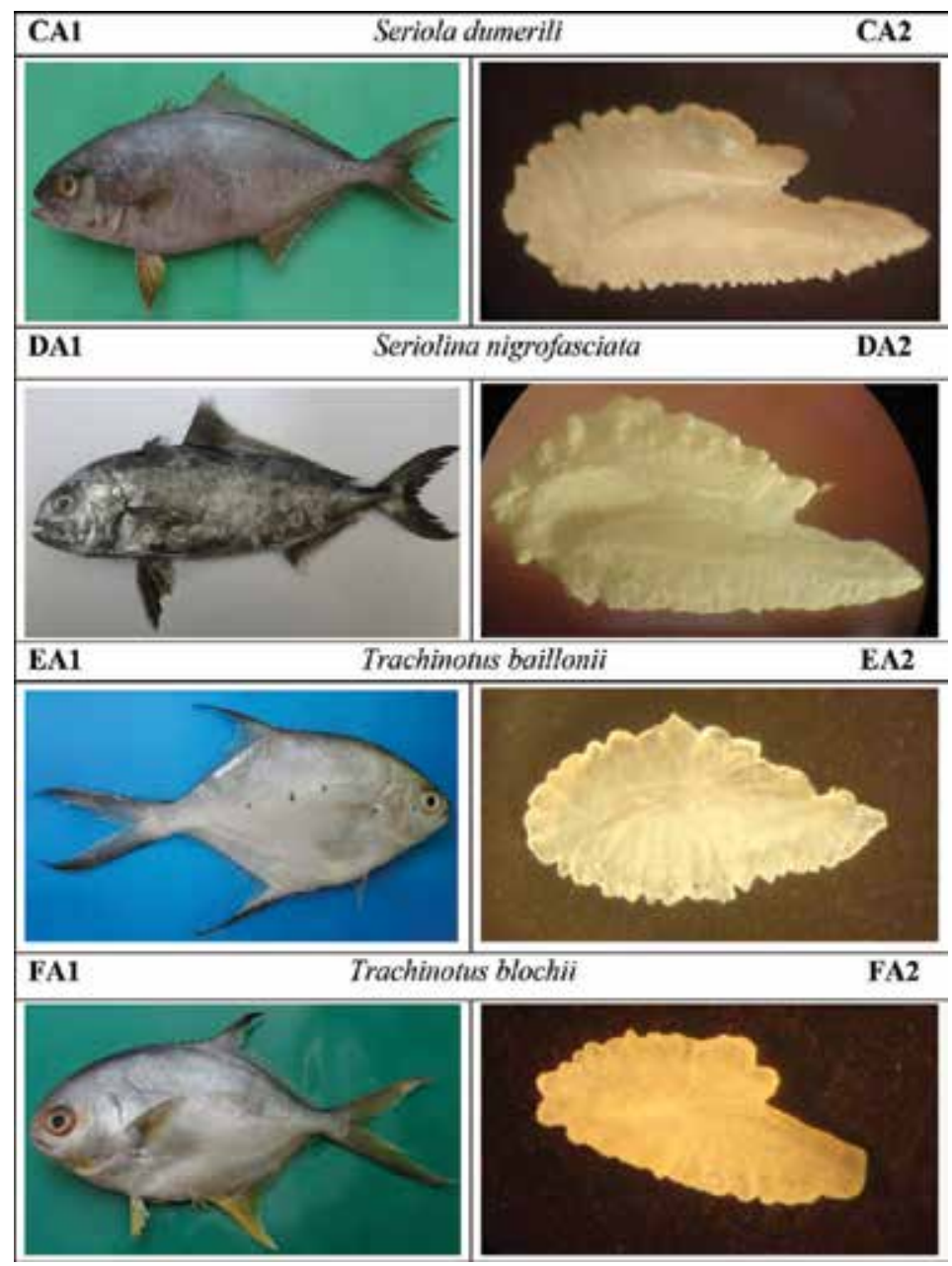

First dorsal fin modified into 6-7 short free spines, often embedded in adult, and second dorsal fin with 1 spine followed by 22-23 soft rays. Pectoral fin is greater than pelvic fin, but relatively shorter than dorsal and anal fin. Two detached anal spine present. Anal fin consists of 1 spine followed by 17-18 soft rays. Anal fin originated just behind the dorsal fin. Snout to anal fin distance is $56-62 \%$ of FL. Height of second dorsal fin lobe is $28 \%$ of FL. Lateral line is slightly irregular, weekly convex above pectoral fin and straight posteriorly. First predorsal bone inverted teardrop-shaped, and supra-occipital bone is thin and blade like in young. No scutes and caudal peduncle groove are present. Caudal fin deeply forked about 26-34\% of FL (Figure FA1). 
Otolith shape: fusiform. Margins: crenate-lobed. Sulcus acusticus: heterosulcoid, ostial, median. Ostium: funnel-like. Cauda: tubular, slightly curved ending posteriorly close to the ventral margin. Anterior region: peaked; rostrum long, broad, pointed; antirostrum short, broad, blunt; excisura wide with a shallow notch. Posterior region: oblique-irregular (Figure FA2).

\subsection{Indian pompano, Trachinotus mookalee}

Body has ovate shape, laterally compressed. Dorsal and ventral profile is identical. Eye is smaller than snout length. Snout is rounded. Maxillae extend beyond the anterior border of eye. Small villiform teeth are arranged in band in both jaws. Narrow patches of teeth are present in a tongue. Head is small and comprises $25-26 \%$ of FL. Gill rakers on upper 6-8, lower 10-15 on first gill arch.

First dorsal fin modified into 6-7 short free spines, and second dorsal fin with 1 spine followed by $20-22$ soft rays. Pectoral fin is greater than pelvic fin, but relatively shorter than dorsal and anal fin. Two detached anal spine are present. Anal fin consists of 1 spine followed by 17-18 soft rays. Anal fin is originated just behind the dorsal fin. Snout to anal fin distance is $55 \%$ of FL. Height of second dorsal fin lobe is $28 \%$ of FL. Lateral line is slightly irregular, weekly convex above pectoral fin. First predorsal bone shaped as an inverted-L with the anteriorly projecting arm. No scutes and caudal peduncle groove are present. Caudal fin deeply forked about 37\% of FL (Figure GA1).

Otolith shape: elliptic-fusiform. Margins: Dorso-ventrally crenate. Sulcus acusticus: heterosulcoid, ostial, median. Ostium: funnel-like. Cauda: tubular, slightly curved posteriorly ending close to the ventral margin. Anterior region: irregular with a prominent protuberance joining to antirostrum; rostrum long, wide pointed upward; antirostrum very short, broad, peaked; excisura wide without notch. Posterior region: oblique (Figure GA2).

\subsection{Large spotted dart, Trachinotus botla (russelii) (new record)}

Body has elliptical shape, laterally compressed. Dorsal and ventral profile is identically convex. Snout rounded. Teeth villiform are arranged in bands in both Jaws and absent in adult. Gill rakers: 7-9 on upper limb and 11-15 lower limb of first gill arch.

First dorsal fin with 6 short free spines, second soft dorsal fin with 1 spine followed by 23 soft rays. Pectoral fin is short and shorter than pelvic fin. Anal fin with 1 spine followed by 19 rays. Dorsal fin lobe is greater than anal fin lobe. Anal fin with 1 spine and 22 soft rays. Caudal fin is deeply forked. Lateral line is strongly concave above pectoral fin and deeply arch. Scales are minute and deeply embedded in the skin. A series of 5 plumbeous spots present, first three large spots intersecting the lateral line and other small two spots touching the lateral line. Scutes are absent in lateral line (Figure HA1).

Otolith shape: fusiform. Margins: irregular to dentate. Sulcus acusticus: heterosulcoid, ostial, median. Ostium: funnel-like. Cauda: tubular, slightly curved posteriorly ending close to the ventral margin. Anterior region: peaked; rostrum moderately long, broad, rounded; antirostrum short, broad, irregular upward; excisura wide with an acute and deep notch. Posterior region: round-irregular (Figure HA2). 


\subsection{Arabian scad, Trachurus indicus}

Body shape is elongate, laterally compressed; dorsal and ventral profile is identical. Eye is moderate, slightly smaller than snout. Adipose eyelid is covered the entire eye except the vertical slit of the eye. Maxilla extends to the middle of pupil. Small villiform teeth are arranged single row in both jaws. Opercular dark crescent shape bloch is present. Head length comprises of 29\% FL. Gill rakers: 12-15 in upper limb, 35-40 in lower limb of first gill arch.

Two separate dorsal fin. First dorsal fin is membranous with 7-8 spines. Soft dorsal fin with 1 spine followed by 32 soft rays. Pectoral fin is long and falcate and greater than HL. Pelvic fin is moderate and hyaline. Anal fin with two detached anal spines and 1 spine followed by 28 soft rays. Finlet absent. Caudal fin is deeply forked about 28\% FL. Curve lateral line is longer than straight lateral line. Scutes on curve lateral line are 38, and scutes on straight lateral line are 37-40. Junction of CLL and SLL is below the ninth-tenth ray of second dorsal fin. Dorsal accessory lateral line is terminating at the base of caudal peduncle (Figure IA1).

Otolith shape: lanceolated. Margins: sinuate. Sulcus acusticus: heterosulcoid, ostial, median. Ostium: funnel-like. Cauda: tubular, slightly curved ending close to the ventral margin. Anterior region: peaked; rostrum long, broad, peaked; antirostrum short, broad, blunt; excisura wide without notch. Posterior region: oblique (Figure IA2).

\subsection{Whitemouth jack, Uraspis uraspis (new record)}

Body shape is oval; compressed, ventral profile is slightly convex to isthmus than straight to the origin of second dorsal fin. Maxilla is extended to the anterior margin of the eye. Small pointed teeth are arranged in bands on both jaws. Tongue and floor of mouth is white with dark blue to black border. Naked area of breast extends to half of the pectoral fin base. Head length is $30.6 \%$ of FL. Gill rackers upper 3-5 and 13-15, lower limbs of the first gill arch.

Two detached dorsal fin with 3-4 posteriorly embedded spines before first dorsal fin. First dorsal fin section is small, membranous and consists of 7-8 spine and second dorsal fin with 1 spine followed by 27-32 spines. Pectoral fin is long, falcate and reaches to the junction of curved and straight lateral line. Pectoral fin length is $31.8 \%$ of FL. Pelvic fin length decreases with age. Anal fin with two detached and embedded spines followed by 19-23 soft rays. Caudal fin is deeply forked $33.6 \%$ of FL. Straight lateral is 1.02-1.05\% shorter than straight lateral line. Scutes on straight lateral line are strong to moderate consist of 35-38 antrose (projecting anteriorly) (Figure JA1).

Otolith shape: elliptic-lanceolated. Margins: dorsal irregular, ventral sinuate. Sulcus acusticus: heterosulcoid, ostial, median. Ostium: funnel-like. Cauda: tubular, strongly curved posteriorly ending close to the ventral margin. Anterior region: peaked; rostrum long, narrow, peaked. Anti-rostrum short, broad, pointed; excisura wide with an acute and deep notch. Posterior region: oblique-flattened (Figure JA2). 


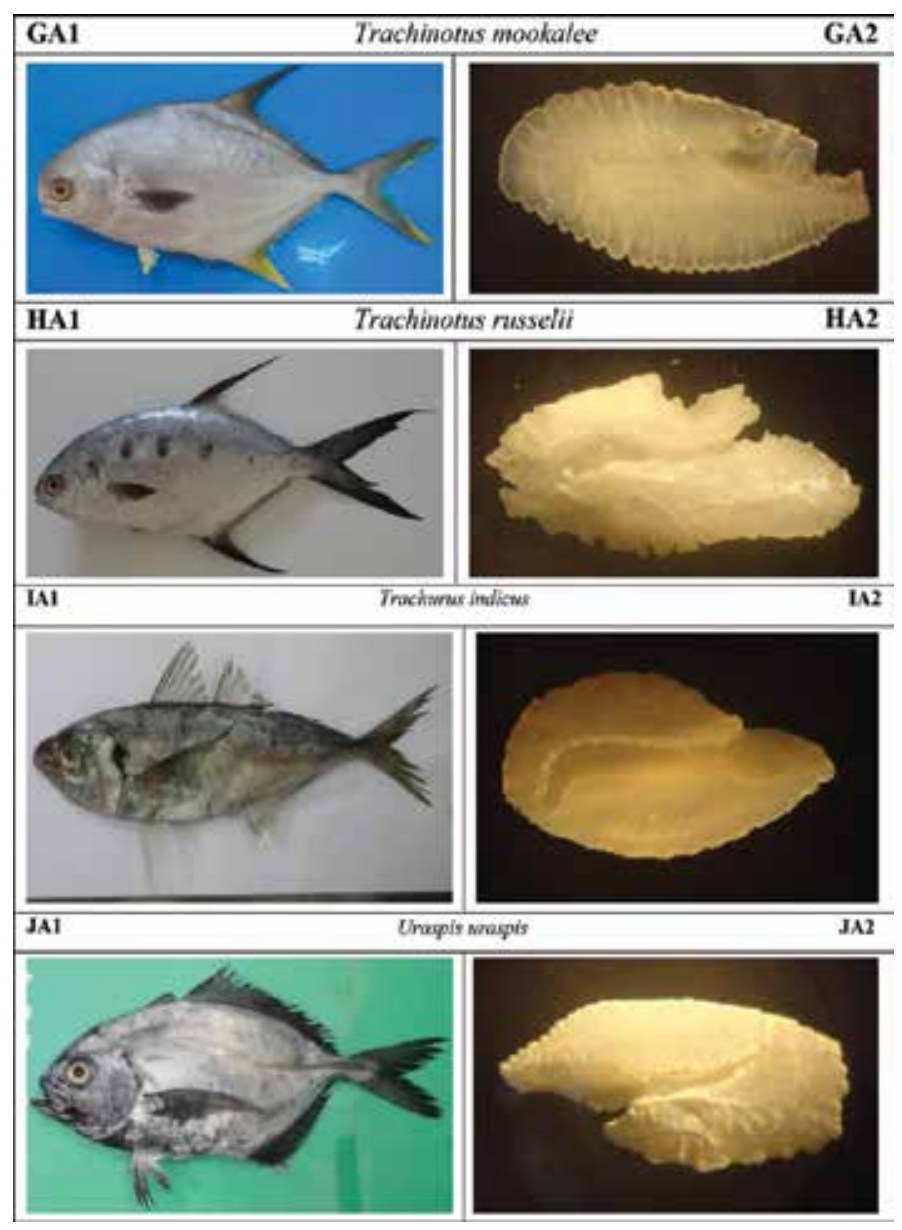

\section{Acknowledgements}

This chapter is the part of Ph.D dissertation of Dr. Nazia Qamar. We thank Victor Tusset, Spanish Research Council for candid comments and suggestions. The Director, CEMB, University of Karachi is greatly acknowledged for the facilities provided during the study.

\section{Author details}

Nazia Qamar, Sher Khan Panhwar* and Ghazala Siddiqui

*Address all correspondence to: sk.panhwar@uok.edu.pk

Center of Excellence in Marine Biology, University of Karachi, Sindh, Pakistan 


\section{References}

[1] Bianchi G.. FAO species identification sheets for fishery purposes-Field guide to the commercial marine and brackish-water species of Pakistan, prepared with the support of PAK/77/033/ and FAO (FIRM) Regular Programme. FAO, Rome. 1985: 200.

[2] Nelson, J.S.. Fishes of the world. John Wiley \& Sons, New York. 2006.

[3] Riede K.. Global register of migratory species - from global to regional scales. Final Report of the R\&D Project 80805 081, Federal Agency for Nature Conservation, Bonn, Germany. 2004; 329.

[4] Smith-Vaniz W.F. and Carpenter K.E.. Review of the crevalle jacks, Caranx hippos complex (Teleostei: Carangidae), with a description of a new species from West Africa. Fisheries Bulletin. 2007; 105(2): 207-233.

[5] Sudekum A. E., Parrish J.D., Radtke R. L. Ralston S.. Life history of large jacks in undistributed, shallow, oceanic communities. Fisheries Bulletin, 1991; 89(3): 493-513.

[6] Thompson R. Munro J. L.. The biology, ecology, and bionomics of the jacks, Carangidae. In: Munro JL (ed) Caribbean coral reef fishery resources. Int. Cent. Living Aquat. Res. Manage, Manila, Philippines. 1983; 82-93.

[7] Qamar N., Panhwar S. K., Jahangir S.. Seasonal variation in diet composition of Torpedo Trevally, Megalaspis cordyla (Linneaus, 1758) depending upon its size and sex. Pakistan Journal of Zoology. 2015; 47(4): 1171-1179.

[8] Fischer W. Bianchi G.. FAO species identification sheets for fishery purposes In: Field guide to the commercial marine and brackish-water species of Pakistan prepared with the support of PAK/77/033/ and FAO (FIRM) Regular Program. FAO, Rome. 1983; 200.

[9] Panhwar S. K., Qamar N., Jahanghir, S.. Fishery and stock estimates of Talang queenfish, Scomberoides commersonnianus (Fam: Carangidae) from the Arabian sea coast, Pakistan, Pakistan journal of agricultural sciences. 2014; 51(4): 1111-1116

[10] Qamar N., Panhwar S. K. Brower S.. Population characteristics and biological reference point estimates for two carangid fishes Megalaspis cordyla and Scomberoides tol in the Northern Arabian Sea, coast of Pakistan. Pakistan Journal of Zoology. 2016;48(3): 869-874.

[11] Qamar N., Jahangir S., Waryani B., Panhwar S. K., Bhutto A. H.. Anomalous torpedo trevally, Megalaspis cordyla 1. (Pisces: Carangidae) found in Pakistan. International journal of biology and biotechnology. 2015;12 (2): 193-196.

[12] Hand book of the fisheries statistics of Pakistan, Marine Fisheries Department. 2012; 20: $1-217$.

[13] FAO.. Fishery and aquaculture country profile, FAO"e Fisheries Department, Rome, 2012; 1-18. 
[14] Abdussamad E. M., Prathibha Rohit K. P., Said Koya O. M. M. J., Habeeb M. Jeyabalan, K.. Carangids (Family Carangidae) in the seas around Indian subcontinent with description of macro-taxonomic characters for the field identification of genera and species. Indian Journal of Fisheries. 2013; 60 (2): 21-3.

[15] Matsunuma M., Motomura H, Matsuura K., Shazili N. and Ambak M.. Fishes of Terengganu East coast of Malay Peninsula, Malaysia, National Museum of Nature and Science, Tokyo, University Malaysia Terengganu, Terengganu, and Kagoshima University Museum, Kagoshima. 2011; 25.

[16] Quigley D. T., Flannery G. K., Shea J. O.. Fish note: trigger fish Balistes capriscus Gmelin. Irish Naturalists Journal. 1993; 24: 223-228.

[17] Kuiter R. H.. The complete divers and fishermans guide to coastal fishes of southeastern Australia. Gary Allen, Sydney. 2000; 437.

[18] Gunn J. S.. A revision of selected genera of the family Carangidae (Pisces) from Australian waters. Record of Australian museum, Supplement. .1990; 12: 1-77.

[19] Hoda S. M. S.. Fishes from the coast of Pakistan. Biologia (Lahore). 1988; 34: 1-38

[20] Ahmad M. F., Niazi, M. S.. Important edible fishes of Pakistan. Zoological Survey Department, Government of Pakistan.1988: 1-31.

[21] Laroche W. A. Smith- Vaniz W.F. Richardson, S. L.. Carangidae: Development. In: Moser H. G., Richards W. J., Cohen D. M., Fahay M. P., Kendall. A. W., Richardson S. L. (EDS.), Ontogeny and systematic of fishes. Special publication 1, American Society of Ichthyologists and Herpetologists. 1984; 510-522.

[22] Nelson J.S.. Fishes of the world. John Wiley \& Sons, New York. 1984.

[23] Jalil S. A. Khaliluddin M. A.. checklist of marine fishes of Pakistan. Government of Pakistan. 1972: 1-16.

[24] Bannikov, A. F.. On the taxonomy, composition and origin of the family Carangidae. Journal of applied ichthyology.1987; 24: 4156-158. (Originally published in Russian in Voprosy Ikhtiologii,(6): 833-839.

[25] Eschmeyer W. N.. Catalog of the genera of recent fishes. California Academy of Science, San Francisco. 1990: 697.

[26] Smith-Vaniz, W.F. Opistognathidae. Jaw fishes. p. 2588-2589. In K.E. Carpenter and V.H. Niem (eds.) FAO species identification guide for fishery purposes. The living marine resources of the Western Central Pacific. Volume 4. Bony fishes part 2 (Mugilidae to Carangidae). FAO, Rome. 1999.

[27] Smith-Vaniz, W. F. Carangidae. In: Fischer W. and Bianchi,G. (Eds.).. FAO species identification sheets for fishery purpose, Western Indian Ocean (Fishery area 51), Vol. 1,FAO, Rome. 1984. 
[28] Webb P. W.. Hydrodynamics and energetics of fish propulsion. Bulletin of the fisheries research board of Canada. 1975;190:1-156.

[29] Brown-Peterson N. J., Wyanski D. M., Saborido-Rey F., Macewicz B. J. Lowerre-Barbieri S. K.. A standardized terminology for describing reproductive development in fishes. Marine and Coastal Fisheries: Dynamics, Management, and Ecosystem Science [online serial] 2011; 3: 52-70. 


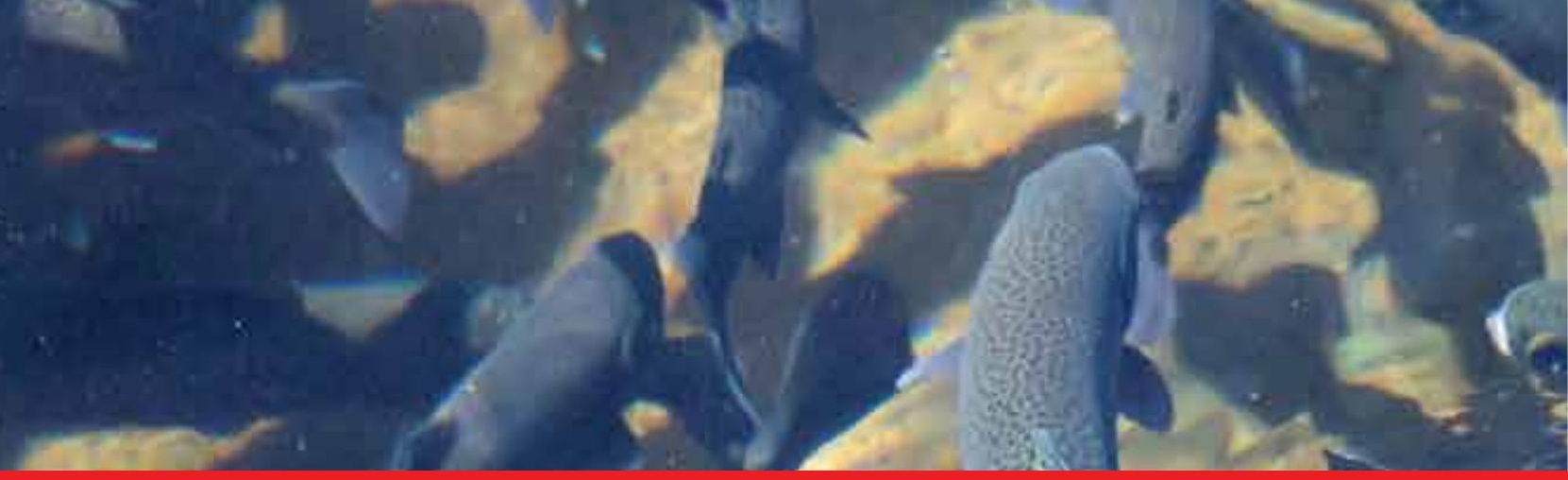

\section{Edited by Heimo Mikkola}

This book has nine chapters on Aquaculture Wetland Ecosystem Services Approach and Climate Change Adaptation, which explain how different aquaculture systems could maximize the benefits that society receives from both aquaculture production and the ecosystem services provided by wetland ecosystems. Sustainable development of aquaculture must take into account the societal value of ecosystem services for an efficient and environmentally sound production of food.

Although some issues regarding the potential benefits and implementation of sustainable aquaculture remain, the consideration of food security and minimizing ecosystem impacts suggest that the time has come to take action. If we can efficiently farm the land, why can't we farm more the sea and inland waters?

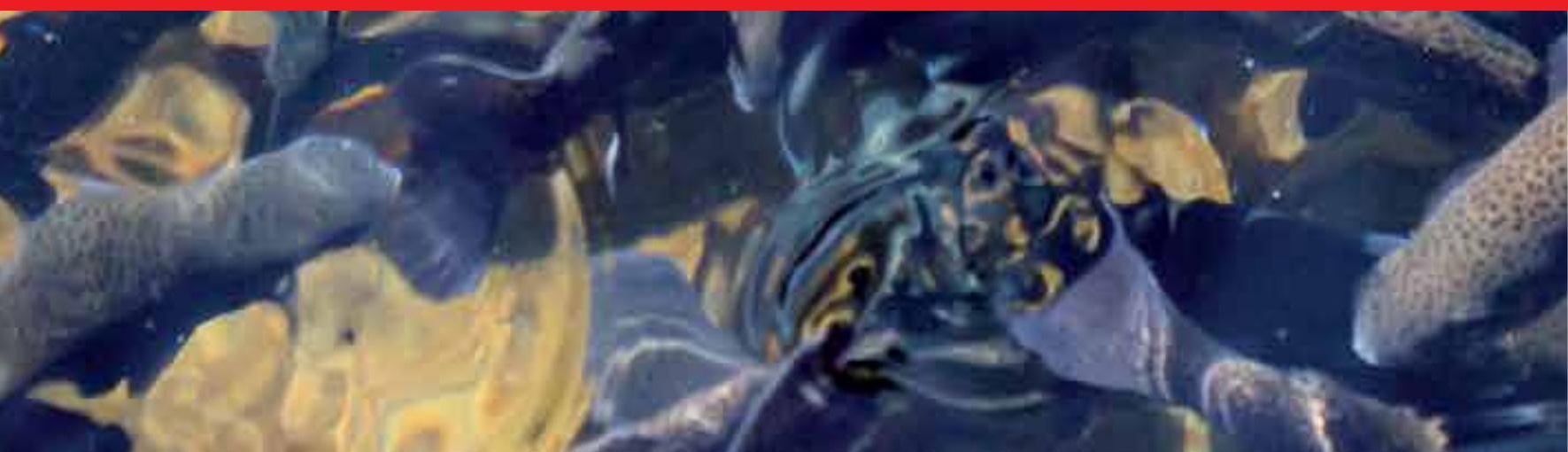

